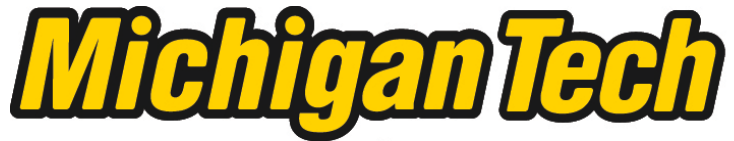 \\ Michigan Technological University Create the Future Digital Commons @ Michigan Tech
}

Dissertations, Master's Theses and Master's Reports - Open

Dissertations, Master's Theses and Master's

Reports

2014

\section{Assessment of Flood Risk Under Future Climate Conditions}

Kaye M. LaFond

Michigan Technological University

Follow this and additional works at: https://digitalcommons.mtu.edu/etds

Part of the Environmental Engineering Commons, and the Water Resource Management Commons Copyright 2014 Kaye M. LaFond

\section{Recommended Citation}

LaFond, Kaye M., "Assessment of Flood Risk Under Future Climate Conditions", Master's Thesis, Michigan Technological University, 2014.

https://doi.org/10.37099/mtu.dc.etds/754

Follow this and additional works at: https://digitalcommons.mtu.edu/etds

Part of the Environmental Engineering Commons, and the Water Resource Management Commons 


\title{
ASSESSMENT OF FLOOD RISK UNDER FUTURE CLIMATE CONDITIONS
}

By

Kaye M. LaFond

\begin{abstract}
A THESIS
Submitted in partial fulfillment of the requirements for the degree of MASTER OF SCIENCE

In Environmental Engineering
\end{abstract}

MICHIGAN TECHNOLOGICAL UNIVERSITY

2014

(C) 2014 Kaye M. LaFond 
This thesis has been approved in partial fulfillment of the requirements for the Degree of MASTER OF SCIENCE in Environmental Engineering.

Department of Civil and Environmental Engineering

Thesis Advisor: $\quad$ Dr. Veronica W. Griffis

Committee Member: $\quad$ Michael D. Hyslop

Committee Member: $\quad$ Dr. David W. Watkins Jr.

Department Chair: $\quad$ Dr. David W. Hand 
To my cats Rosalie, Ruger, and Mr. Tomwith love from your ever-adoring mother. 


\section{Table of contents}

List of figures................................................................................................................. vii

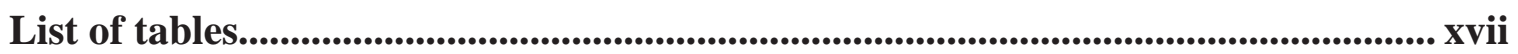

Acknowledgements ...................................................................................................................... xxiii

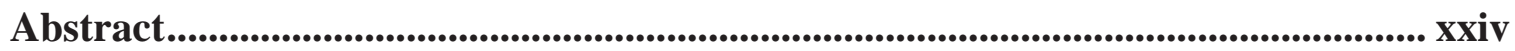

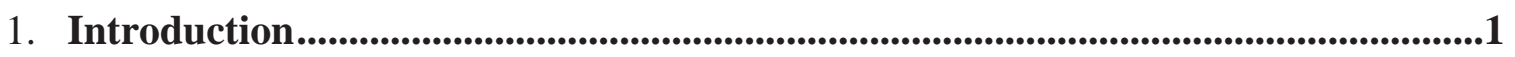

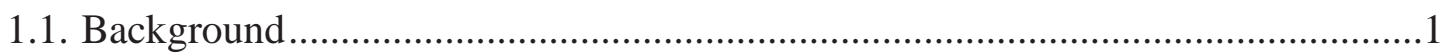

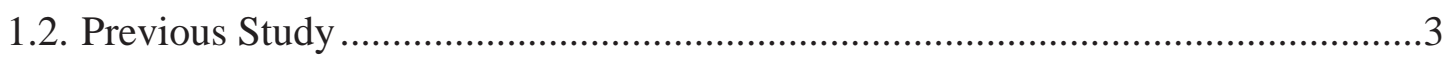

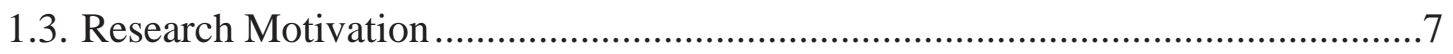

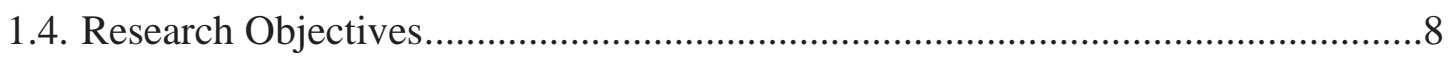

2. Watershed Selection and Characteristics ..............................................................11

2.1. Watershed Selection Process ..............................................................................11

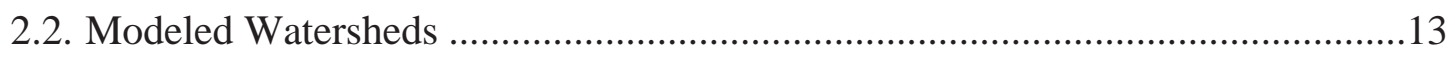

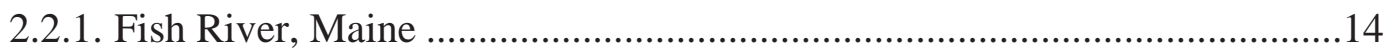

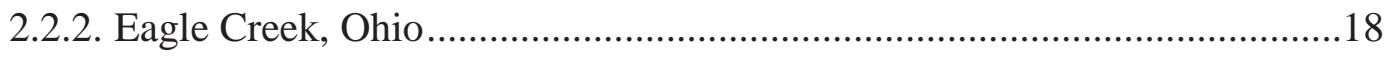

2.2.3. Wakatomika Creek, Ohio ………………………...............................22

2.2.4. Pond Creek, Kentucky ............................................................................25 
3. GCMs/Gridded Weather Data.......................................................................................30

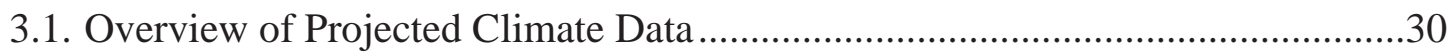

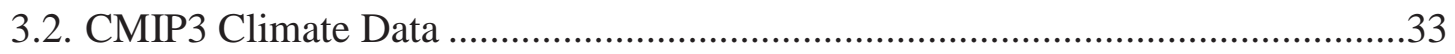

3.3. Selection of Representative Climate Projections............................................. 34

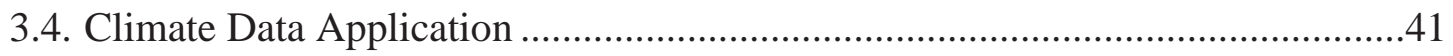

4. Hydrologic Modeling With ArcSWAT ...............................................................60

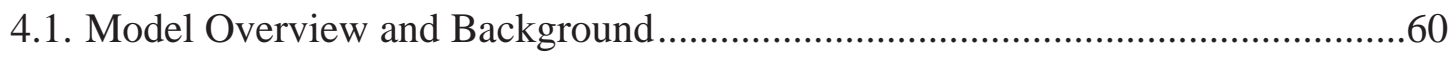

4.2. Acquisition and Manipulation of Spatial Data ..............................................62

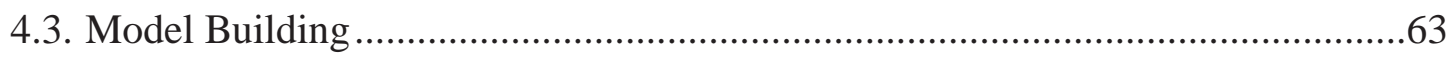

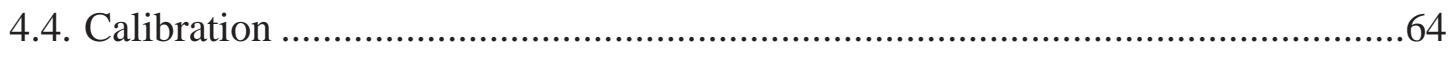

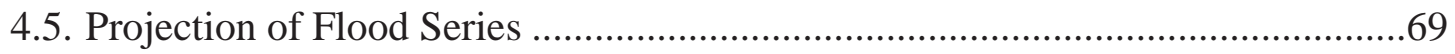

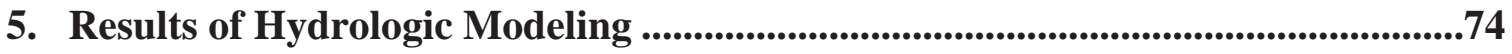

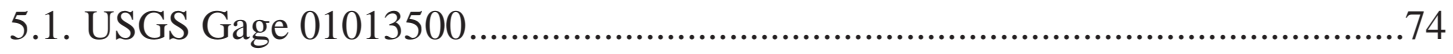

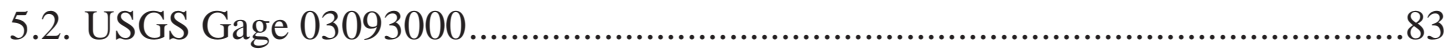

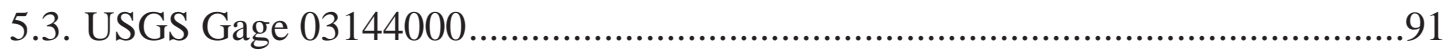

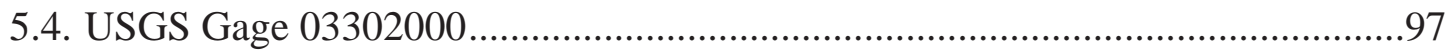




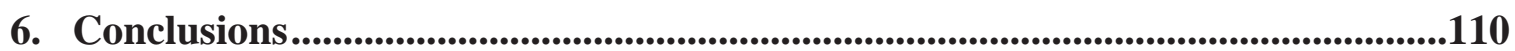

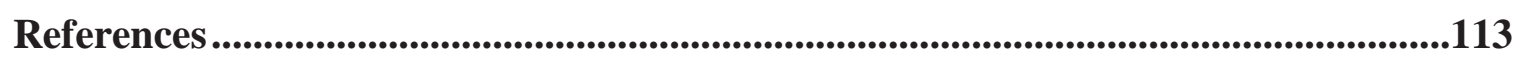

Appendix A - Monthly Averaged Climate Model Output .........................................119

Appendix B - Spatial Data: DEMs and Soil Layers .....................................................136

Appendix C - Calibrated Parameters........................................................................................146 


\section{List of Figures}

Figure 1.1 Location and designation (degree of impairment) of previously analyzed sites within the northeastern quadrant of the United States.

Figure 2.1 Map showing location and land cover distribution of the Fish River watershed upstream of USGS Gage Station 01013500................................................15

Figure 2.2 Sample hydrograph of daily flows at USGS Gage Station 01013500 from $1 / 1 / 1990$ to $12 / 31 / 1992$

Figure 2.3 Annual maximum flows measured at USGS Gage Station 01013500 from 1930 to 2012

Figure 2.4 Map showing location and land cover distribution of the Eagle Creek watershed upstream of USGS Gage Station 03093000 .19

Figure 2.5 Sample hydrograph of daily flows at USGS Gage Station 03093000 from

$1 / 1 / 1990$ to $12 / 31 / 1992$

Figure 2.6 Annual maximum flows measured at USGS Gage Station 03093000 from 1938 to 2012

Figure 2.7 Map showing location and land cover distribution of the Wakatomika Creek watershed upstream of USGS Gage Station 03144000

Figure 2.8 Sample hydrograph of daily flows at USGS Gage Station 03144000 from $1 / 1 / 1990$ to $12 / 31 / 1992$

Figure 2.9 Annual maximum flows measured at USGS Gage Station 03144000 from 1937 to 2012 
Figure 2.10 Map showing location and land cover distribution of the Pond Creek Watershed upstream of USGS Gage Station 03302000 .26

Figure 2.11 Sample hydrograph of daily flows at USGS Gage Station 03302000 from $1 / 1 / 1997$ to $12 / 31 / 1999$

Figure 2.12 Annual maximum flows measured at USGS Gage Station 03302000 from 1945 to 2011 .28

Figure 3.1 Absolute change in temperature and percent change in precipitation of 53 climate projections (bias corrected) for the Fish River watershed upstream of USGS Gage Station 01013500; pink squares denote the 9 representative scenarios

Figure 3.2 Absolute change in temperature and percent change in precipitation of 53 climate projections (bias corrected) for the Eagle Creek watershed upstream of USGS Gage Station 03093000; pink squares denote the 9 representative scenarios

Figure 3.3 Absolute change in temperature and percent change in precipitation of 53 climate projections (bias corrected) for the Wakatomika Creek watershed upstream of USGS Gage Station 03144000; pink squares denote the 9 representative scenarios .39

Figure 3.4 Absolute change in temperature and percent change in precipitation of 53 climate projections (bias corrected) for the Pond Creek watershed upstream of USGS Gage Station 03302000; pink squares denote the 9 representative scenarios 
Figure 3.5 Visual representation of bias correction for climate data application 41

Figure 3.6 Visual representation of delta change method for climate data application.....44

Figure 3.7 Monthly averaged observed, hindcasted, forecasted and bias corrected forecast precipitation (mm/day) in the Fish River watershed (USGS Gage Station 01013500) corresponding to climate model cccma_cgcm3, emissions scenario alb, and model run 3 .

Figure 3.8 Monthly averaged hindcasted, forecasted, observed and delta changed precipitation (mm/day) in the Fish River watershed (USGS Gage Station 01013500) corresponding to climate model cccma_cgcm3, emissions scenario $\mathrm{a} 1 \mathrm{~b}$, and model run 3

Figure 3.9 Overall changes in temperature projected by each data application method, relative to the baseline period of 1961-1999, for the nine representative climate scenarios for the Fish River watershed (USGS Gage Station 01013500)

Figure 3.10 Overall changes in precipitation projected by each data application method, relative to the baseline period of 1961-1999, for the nine representative climate scenarios for the Fish River watershed (USGS Gage Station 01013500)

Figure 3.11 Overall changes in temperature projected by each data application method, relative to the baseline period of 1961-1999, for the nine representative climate scenarios for the Eagle Creek watershed (USGS Gage Station 03093000)...........53

Figure 3.12 Overall changes in precipitation projected by each data application method, relative to the baseline period of 1961-1999, for the nine representative climate scenarios for the Eagle Creek watershed (USGS Gage Station 03093000) 
Figure 3.13 Overall changes in temperature projected by each data application method, relative to the baseline period of 1961-1999, for all selected GCM/emissions scenario/run combinations, for the Wakatomika Creek watershed (USGS Gage Station 03144000).

Figure 3.14 Overall changes in precipitation projected by each data application method, relative to the baseline period of 1961-1999, for all selected GCM/emissions scenario/run combinations, for the Wakatomika Creek watershed (USGS Gage Station 03144000)

Figure 3.15 Overall changes in temperature projected by each data application method, relative to the baseline period of 1961-1999, for all selected GCM/emissions scenario/run combinations, for the Pond Creek watershed (USGS Gage Station 03302000)

Figure 3.16 Overall changes in precipitation projected by each data application method, relative to the baseline period of 1961-1999, for all selected GCM/emissions scenario/run combinations, for the Pond Creek watershed (USGS Gage Station 03302000)

Figure 3.17 Absolute change in temperature and percent change in precipitation for both bias corrected and delta changed data of 9 representative climate projections for the Fish River watershed upstream of USGS Gage Station 01013500......

Figure 3.18 Absolute change in temperature and percent change in precipitation for both bias corrected and delta changed data of 9 representative climate projections for the Eagle Creek watershed upstream of USGS Gage Station 03093000 
Figure 3.19 Absolute change in temperature and percent change in precipitation for both bias corrected and delta changed data of 9 representative climate projections for the Wakatomika Creek watershed upstream of USGS Gage Station 03144000 ...57

Figure 3.20 Absolute change in temperature and percent change in precipitation for both bias corrected and delta changed data of 9 representative climate projections for the Pond Creek watershed upstream of USGS Gage Station 03302000. .57

Figure 4.1 Observed and modeled daily flows over the validation period 1/1/1996 12/31/1999 for the Fish River watershed (USGS Gage Station 01013500)

Figure 4.2 Observed and modeled daily flows over the validation period 1/1/1996 12/31/1999 for the Eagle Creek watershed (USGS Gage Station 03093000) .......68

Figure 4.3 Observed and modeled daily flows over the validation period 1/1/1996 12/31/1999 for the Wakatomika Creek watershed (USGS Gage Station 03144000). .68

Figure 4.4 Observed and modeled daily flows over the validation period 10/1/1990 9/30/1992 for the Pond Creek watershed (USGS Gage Station 03302000)

Figure 4.5 LP3 distributions (P3 in log space) fit to observed and modeled AMF series over the period of 1980-1999 for the Fish River watershed (USGS Gage Station $01013500)$

Figure 4.6 LP3 distributions (P3 in log space) fit to observed and modeled AMF series over the period of 1980-1999 for the Eagle Creek watershed (USGS Gage Station 03093000) .72 
Figure 4.7 LP3 distributions (P3 in log space) fit to observed and modeled AMF series over the period of 1980-1999 for the Wakatomika Creek watershed (USGS Gage

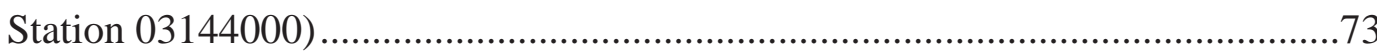

Figure 4.8 LP3 distributions (P3 in log space) fit to observed and modeled AMF series over the period of 1980-1999 for the Pond Creek watershed (USGS Gage Station 03302000) .73

Figure 5.1 LP3 distributions (log space) produced using projected bias corrected climate data overlaid with the LP3 distribution fit to observed AMF for the Fish River watershed (USGS Gage Station 01013500)

Figure 5.2 LP3 distributions (log space) produced using delta changed climate data overlaid with the LP3 distribution fit to observed AMF for the Fish River watershed (USGS Gage Station 01013500) .77

Figure 5.3 LP3 distributions (log space) of observed (1980-1999) and modeled (20462065) AMF series using two different climate data methods and the median future climate scenario (gfdl_cm2.1.a2) for the Fish River Watershed (USGS Gage Station 01013500)

Figure 5.4 LP3 distributions (log space) of observed (1980-1999) and modeled (20462065) AMF series using the two different climate data methods and the driest future climate scenario (ipsl_cm4.1.a2) for the Fish River Watershed (USGS Gage Station 01013500) 
Figure 5.5 LP3 distributions (log space) of observed (1980-1999) and modeled (20462065) AMF series using two different climate data methods and the wettest future climate scenario (cccma_cgcm3_1.3.a1b) for the Fish River Watershed (USGS Gage Station 01013500)

Figure 5.6 LP3 distributions (log space) produced using projected bias corrected climate data overlaid with the distribution fit to the observed AMF series for the Eagle Creek watershed (USGS Gage Station 03093000)

Figure 5.7 LP3 distributions (log space) produced using delta changed climate data overlaid with the distribution fit to the observed AMF series for the Eagle Creek watershed (USGS Gage Station 03093000)

Figure 5.8 LP3 distributions (log space) of observed (1980-1999) and modeled (20462065) AMF series using two different climate data methods and the median future climate scenario (gfdl_cm2.1.a2) for the Eagle Creek Watershed (USGS Gage Station 03093000)

Figure 5.9 LP3 distributions (log space) of observed (1980-1999) and modeled (20462065) AMF series using two different climate data methods and the driest future climate scenario (miroc3_2_medres.1.a1b) for the Eagle Creek Watershed (USGS Gage Station 03093000) .89

Figure 5.10 LP3 distributions (log space) of observed (1980-1999) and modeled (20462065) AMF series using two different climate data methods and the wettest future climate scenario (cnrm_cm3.1.a1b) for the Eagle Creek Watershed (USGS Gage Station 03093000) .90 
Figure 5.11 LP3 distributions (log space) produced using projected bias corrected climate data overlaid with the distribution fit to the observed AMF series for the Wakatomika Creek watershed (USGS Gage Station 03144000) .95

Figure 5.12 LP3 distributions (log space) produced using delta changed climate data overlaid with the distribution fit to the observed AMF series for the Wakatomika Creek watershed (USGS Gage Station 03144000) .95

Figure 5.13 LP3 distributions (log space) of observed (1980-1999) and modeled (20462065) AMF series using two different climate data methods and the median future climate scenario (mri_cgcm2_3_2a.2.a2) for the Wakatomika Creek Watershed (USGS Gage Station 03144000)

Figure 5.14 LP3 distributions (log space) of observed (1980-1999) and modeled (20462065) AMF series using two different climate data methods and the driest future climate scenario (miroc3_2_medres.2.a1b) for the Wakatomika Creek Watershed (USGS Gage Station 03144000) 96

Figure 5.15 LP3 distributions (log space) of observed (1980-1999) and modeled (20462065) AMF series using two different climate data methods and the wettest future climate scenario (cnrm_cm3.1.a1b) for the Wakatomika Creek Watershed (USGS Gage Station 03144000) .97

Figure 5.16 LP3 distributions (log space) produced using projected bias corrected climate data overlaid with the distribution fit to the observed AMF series for the Pond Creek watershed (USGS Gage Station 03302000) .101 
Figure 5.17 LP3 distributions (log space) produced using delta changed climate data overlaid with the distribution fit to the observed AMF series for the Eagle Creek watershed (USGS Gage Station 03302000)................................................102

Figure 5.18 LP3 distributions (log space) of observed (1980-1999) and modeled (20462065) AMF series using two different climate data methods and the median future climate scenario (cnrm_cm3.1.a1b) for the Pond Creek Watershed (USGS Gage Station 03302000) 103

Figure 5.19 LP3 distributions (log space) of observed (1980-1999) and modeled (20462065) AMF series using two different climate data methods and the driest future climate scenario (miroc3_2_medres.1.a1b) for the Pond Creek Watershed (USGS Gage Station 03302000) .104

Figure 5.20 LP3 distributions (log space) of observed (1980-1999) and modeled (20462065) AMF series using two different climate data methods and the wettest future climate scenario (mri_cgcm2_3_2a.1.a2) for the Pond Creek Watershed (USGS Gage Station 03302000) .104

Figure B.1 DEM of Fish River watershed (USGS Gage Station 01013500) .................137

Figure B.2 DEM of Eagle Creek watershed (USGS Gage Station 03093000)...............138

Figure B.3 DEM of Wakatomika Creek watershed (USGS Gage Station 03144000) ....139

Figure B.4 DEM of Pond Creek watershed (USGS Gage Station 03302000)................140

Figure B.5 SSURGO soils layer of Fish River watershed (USGS Gage Station 01013500) .141 
Figure B.6 SSURGO soils layer of Eagle Creek watershed (USGS Gage Station

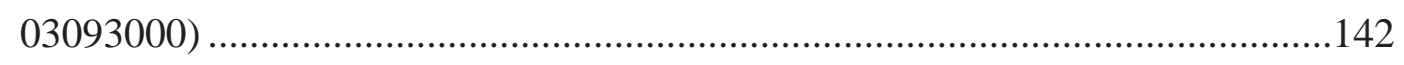

Figure B.7 SSURGO soils layer of Wakatomika Creek watershed (USGS Gage Station

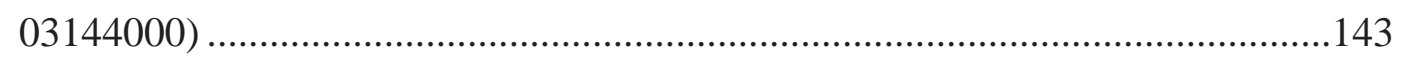

Figure B.8 SSURGO soils layer of Pond Creek watershed (USGS Gage Station

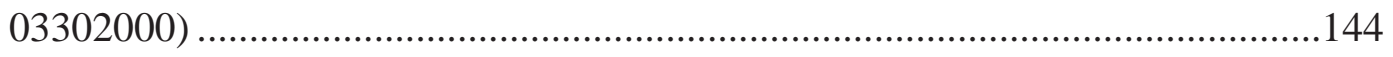




\section{List of Tables}

Table 1.1 Incidence of significant correlation (at 10\% level) between the 10-year moving average of AMF series and climatic indices with various lead times; proportions out of 256 unimpaired and 143 moderately impaired study sites 6

Table 2.1 Physical characteristics of case study watersheds .......................................12

Table 2.2 Climatic and human factors associated with case study watersheds ................13

Table 2.3 Summary statistics of annual maximum flows from 1930 to 2012, associated LP3 distribution parameters, and relevant flow percentiles at USGS Gage Station 01013500

Table 2.4 Summary statistics of annual maximum flows from 1938 to 2012, associated LP3 distribution parameters, and relevant flow percentiles at USGS Gage Station 03093000

Table 2.5 Summary statistics of annual maximum flows from 1937 to 2012, associated LP3 distribution parameters, and relevant flow percentiles at USGS Gage Station 03144000 .

Table 2.6 Summary statistics of annual maximum flows from 1945 to 2011, associated LP3 distribution parameters, and relevant flow percentiles at USGS Gage Station 03302000

Table 3.1 Summary of selected GCM/emissions scenario/run combinations, and associated overall changes in temperature and precipitation projected by each climate data application method, relative to the baseline period of 1961-1999, for the Fish River watershed (USGS Gage Station 01013500) 
Table 3.2 Summary of selected GCM/emissions scenario/run combinations, and associated overall changes in temperature and precipitation projected by each climate data application method, relative to the baseline period of 1961-1999, for the Eagle Creek watershed (USGS Gage Station 03093000) 49

Table 3.3 Summary of selected GCM/emissions scenario/run combinations, and associated overall changes in temperature and precipitation projected by each climate data application method, relative to the baseline period of 1961-1999, for the Wakatomika Creek watershed (USGS Gage Station 03144000)..... .50

Table 3.4 Summary of selected GCM/emissions scenario/run combinations, and associated overall changes in temperature and precipitation projected by each climate data application method, relative to the baseline period of 1961-1999, for the Pond Creek watershed (USGS Gage Station 03302000) .51

Table 3.5 Means of observed daily temperature $\left({ }^{\circ} \mathrm{C}\right)$ and precipitation $(\mathrm{mm})$ calculated for each month and each watershed over the periods of 1961-1999 and 19801999

Table 3.6 Standard deviations of observed daily temperature $\left({ }^{\circ} \mathrm{C}\right)$ and precipitation $(\mathrm{mm})$ calculated for each month/watershed over the periods of 1961-1999 and 19801999 .59

Table 4.1 Goodness-of-fit measures for the calibration of four modeled watersheds

Table 5.1 Summary statistics of observed and modeled AMF series for the Fish River watershed (USGS Gage Station 01013500) and associated changes in temperature and precipitation projected under nine representative future scenarios .75 
Table 5.2 Flow percentiles (cms) of LP3 distributions fit to observed AMF series for the Fish River watershed (USGS Gage Station 01013500) and modeled AMF series for the nine representative future climate scenarios each applied using two methods .76

Table 5.3 Summary statistics of observed and modeled AMF series for the Eagle Creek watershed (USGS Gage Station 03093000) and associated changes in temperature and precipitation projected under nine representative future scenarios

Table 5.4 Flow percentiles (cms) of LP3 distributions fit to observed AMF series for the Eagle Creek watershed (USGS Gage Station 03093000) and modeled AMF series for nine representative future climate scenarios each applied using two methods. .86

Table 5.5 Summary statistics of observed and modeled AMF series for the Wakatomika Creek watershed (USGS Gage Station 03144000) and associated changes in temperature and precipitation projected under nine representative future scenarios

Table 5.6 Flow percentiles (cms) of LP3 distributions fit to observed AMF series for the Wakatomika Creek watershed (USGS Gage Station 03144000) and modeled AMF series for nine representative future climate scenarios each applied using two methods

Table 5.7 Summary statistics of observed and modeled AMF series for the Pond Creek watershed (USGS Gage Station 03302000) and associated changes in temperature and precipitation projected under nine representative future scenarios .98 
Table 5.8 Flow percentiles of LP3 distributions fit to observed AMF series for the Pond Creek watershed (USGS Gage Station 03302000) and modeled AMF series for nine representative future climate scenarios each applied using two methods....100

Table 5.9 Land cover distribution, scaled observed mean peak flow values, and scaled modeled mean peak flow values for the four case study watersheds

Table A.1 Monthly averages of hindcasted gridded precipitation ( $\mathrm{mm} /$ day) for the Fish River watershed (USGS Gage Station 01013500) calculated over the periods of 1961-1999 and 1980-1999

Table A.2 Monthly averages of hindcasted gridded temperature $\left({ }^{\circ} \mathrm{C}\right)$ for the Fish River watershed (USGS Gage Station 01013500) calculated over the periods of 19611999 and 1980-1999 121

Table A.3 Monthly averages of forecasted gridded precipitation ( $\mathrm{mm} / \mathrm{day})$ for the Fish River watershed (USGS Gage Station 01013500) calculated over the period of 2046-2065.

Table A.4 Monthly averages of forecasted gridded temperature $\left({ }^{\circ} \mathrm{C}\right)$ for the Fish River watershed (USGS Gage Station 01013500) calculated over the period of 20462065

Table A.5 Monthly averages of hindcasted gridded precipitation (mm/day) for the Eagle Creek watershed (USGS Gage Station 03093000) calculated over the periods of 1961-1999 and 1980-1999 .124 
Table A.6 Monthly averages of hindcasted gridded temperature $\left({ }^{\circ} \mathrm{C}\right)$ for the Eagle Creek watershed (USGS Gage Station 03093000) calculated over the periods of 19611999 and 1980-1999 125

Table A.7 Monthly averages of forecasted gridded precipitation ( $\mathrm{mm} /$ day) for the Eagle Creek watershed (USGS Gage Station 03093000) calculated over the period of 2046-2065 126

Table A.8 Monthly averages of forecasted gridded temperature $\left({ }^{\circ} \mathrm{C}\right)$ for the Eagle Creek watershed (USGS Gage Station 03093000) calculated over the period of 20462065

Table A.9 Monthly averages of hindcasted gridded precipitation ( $\mathrm{mm} /$ day) for the Wakatomika Creek watershed (USGS Gage Station 03144000) calculated over the periods of 1961-1999 and 1980-1999

Table A.10 Monthly averages of hindcasted gridded temperature $\left({ }^{\circ} \mathrm{C}\right)$ for the Wakatomika Creek watershed (USGS Gage Station 03144000) calculated over the periods of 1961-1999 and 1980-1999 .129

Table A.11 Monthly averages of forecasted gridded precipitation ( $\mathrm{mm} /$ day) for the Wakatomika Creek watershed (USGS Gage Station 03144000) calculated over the period of 2046-2065. 130

Table A.12 Monthly averages of forecasted gridded temperature $\left({ }^{\circ} \mathrm{C}\right)$ for the Wakatomika Creek watershed (USGS Gage Station 03144000) calculated over the period of 2046-2065 
Table A.13 Monthly averages of hindcasted gridded precipitation (mm/day) for the Pond Creek watershed (USGS Gage Station 03302000) calculated over the periods of 1961-1999 and 1980-1999 132

Table A.14 Monthly averages of hindcasted gridded temperature $\left({ }^{\circ} \mathrm{C}\right)$ for the Pond Creek watershed (USGS Gage Station 03302000) calculated over the periods of 19611999 and 1980-1999 .133

Table A.15 Monthly averages of forecasted gridded precipitation ( $\mathrm{mm} /$ day) for the Pond Creek watershed (USGS Gage Station 03302000) calculated over the period of 2046-2065 .134

Table A.16 Monthly averages of forecasted gridded precipitation ( $\mathrm{mm} /$ day) for the Pond Creek watershed (USGS Gage Station 03302000) calculated over the period of 2046-2065 135

Table B.1 Component soil series for all watersheds and SSURGO map units..... 145

Table C.1 Calibrated parameters for the Eagle Creek watershed upstream of USGS Gage Station 01013500 .147

Table C.2 Calibrated parameters for the Eagle Creek watershed upstream of USGS Gage Station 03093000 148

Table C.3 Calibrated parameters for the Wakatomika Creek watershed upstream of USGS Gage Station 03144000 149

Table C.4 Calibrated parameters for the Pond Creek watershed upstream of USGS Gage Station 03302000 .149 


\section{Acknowledgements}

First and foremost, I would like to acknowledge the world's best graduate advisor, Dr. Veronica Webster Griffis. Many thanks go out to my committee members, Mike Hyslop and Dr. David Watkins. I'd also like to acknowledge the great mentors I've had over the years: Dr. Kathy Halvorsen, Dr. Mary Durfee, and Dave Dempsey. Angela Keranen and Amanda Cadwell are the administrative cream of the crop.

I'd like to thank my main man Jimmy Maltese for being there with love, humor, and confidence in my abilities, and for always reminding me when it's time to stop thesising and go to bed like a normal person. My sister Julie LaFond has obviously been there for me since birth, but especially these past two years for Friday night baking and procrastination. Jennifer Fuller is the ultimate tea-buddy. Patricia Spellman is a brimming encyclopedia and should be recognized as such. I love you all.

I would like to acknowledge the National Science Foundation (EAR-1053655) for feeding me, housing me, and paying for my Master's degree. Finally, I am forever grateful to the modeling groups, the Program for Climate Model Diagnosis and Intercomparison (PCMDI), and the World Climate Research Programme (WCRP) Working Group on Coupled Modelling (WGCM) for their roles in making available the WCRP CMIP3 multi-model dataset. Support of this dataset is provided by the Office of Science, U.S. Department of Energy. 


\section{Abstract}

Global climate change is predicted to have impacts on the frequency and severity of flood events. In this study, output from Global Circulation Models (GCMs) for a range of possible future climate scenarios was used to force hydrologic models for four case study watersheds built using the Soil and Water Assessment Tool (SWAT). GCM output was applied with either the "delta change" method or a bias correction. Potential changes in flood risk are assessed based on modeling results and possible relationships to watershed characteristics. Differences in model outputs when using the two different methods of adjusting GCM output are also compared. Preliminary results indicate that watersheds exhibiting higher proportions of runoff in streamflow are more vulnerable to changes in flood risk. The delta change method appears to be more useful when simulating extreme events as it better preserves daily climate variability as opposed to using bias corrected GCM output. 


\section{Introduction}

Understanding flood risk in the United States is essential for making decisions regarding land management, urban planning and disaster response. The possibility of floods of varying sizes as well as the location of floodplains influences building codes, insurance rates, and water conveyance system design. Failure to properly estimate risk could result in a large loss of life and/or property. Therefore, the science of flood risk must constantly be refined and rejuvenated so that society has the best possible information available with which to make decisions. In light of the effects of climate change, it is more important than ever to make sure flood risk is properly estimated. The research presented herein investigates impacts on flood risk resulting from various climate projections for case study watersheds across the Upper Midwest and Northeastern United States.

\subsection{Background}

Bulletin 17B (IACWD 1982) documents current standards for calculating flood risk in the United States. The procedure involves fitting a distribution to the historical flood record of the watershed of interest and using that distribution to determine future risk. The historical flood record consists of the annual maximum flood (AMF) series as recorded by a stream flow gage. For the purposes of this research, annual maximum floods or annual maximum flows refer to the maximum instantaneous flow recorded by a gage during each water year over the period of record. One key assumption is that AMF 
series are stationary, and thus the flood risk distribution does not change over time. However, based on the most recent climate science (IPCC 2013), flood risk distributions may very well be changing; it may not be sound to continue to use Bulletin 17B without serious investigation into the form of these changes and associated causes, and perhaps updates of the Bulletin 17B model to employ a nonstationary framework are warranted.

Global climate change is predicted to have impacts on a broad range of natural processes. Warmer average temperatures, severe droughts and severe storms are all part of the future climate predicted by the world's leading climate scientists (IPCC 2013). Of interest in regards to flood risk is the prediction of increased intensity and frequency of heavy precipitation events. Overall, precipitation overland has increased globally, as has runoff (Huntington 2006, IPCC 2013). In general, precipitation is trending upwards in the Northeastern United States as well as in other temperate zones (Huntington 2006, IPCC 2013). Theoretically, more extreme floods seem almost certain.

However, evidence in the historic record for increasing flood risk in the United States has been inconsistent at best, as has its link with increased precipitation. One study found upward trends in historical flood series in 25 out of 28 watersheds (Collins 2009). In another study, after looking at over 50 basins in the U.S. with at least 100 years of flood record and finding no evidence of a trend in the AMF series, Villarini et al. (2009) profoundly stated "it is easier to proclaim the demise of stationarity of flood peaks than to prove it through analyses of annual flood peak data". Other studies find trends in low and 
median flows but not high flows (Lins and Slack 1999, McCabe and Wolock 2002). The apparent paradox of an increase in heavy precipitation without a corresponding increase in heavy flow has a couple of possible explanations, one being that the sensitivity of flows to rainfall is lowest for high flows, and another being that heavy rainfall which occurs in the fall does not influence spring flows, which generally make up the AMF series (Small et al. 2006).

Whatever the state of current evidence, the possibility of future increased flood risk due to long-term climate change is likely enough to warrant further research. A lack of climate-driven increases in flood risk up to the present day does not preclude future influences. Updated statistical procedures for determining flood risk may become necessary, especially given projections for population growth, increased anthropogenic disturbances, and more extreme fluctuations in climate. Evaluating influences of climate on future flood risk projections is the focus of the research presented herein, which is part of a larger project for which the eventual goal is to develop a nonstationary framework for estimating flood risk in the United States.

\subsection{Previous Study}

The research presented herein builds on previous work in which statistical analyses were performed on the annual maximum flood records of hundreds of watersheds throughout the northeastern quadrant of the United States, each with at least 65 years of continuous record. The flood records of 256 "unimpaired" watersheds within the study region were 
analyzed (Fritsch 2012), and 143 "moderately impaired" sites were tested in the same fashion (Salvadori 2013). In this case, "unimpaired" watersheds are defined as watersheds where human activities do not influence flows, while "moderately impaired" watersheds have some degree of human impact (Fritsch 2012, Salvadori 2013). The gage location and degree of impairment of the associated watersheds is shown in Figure 2.1.

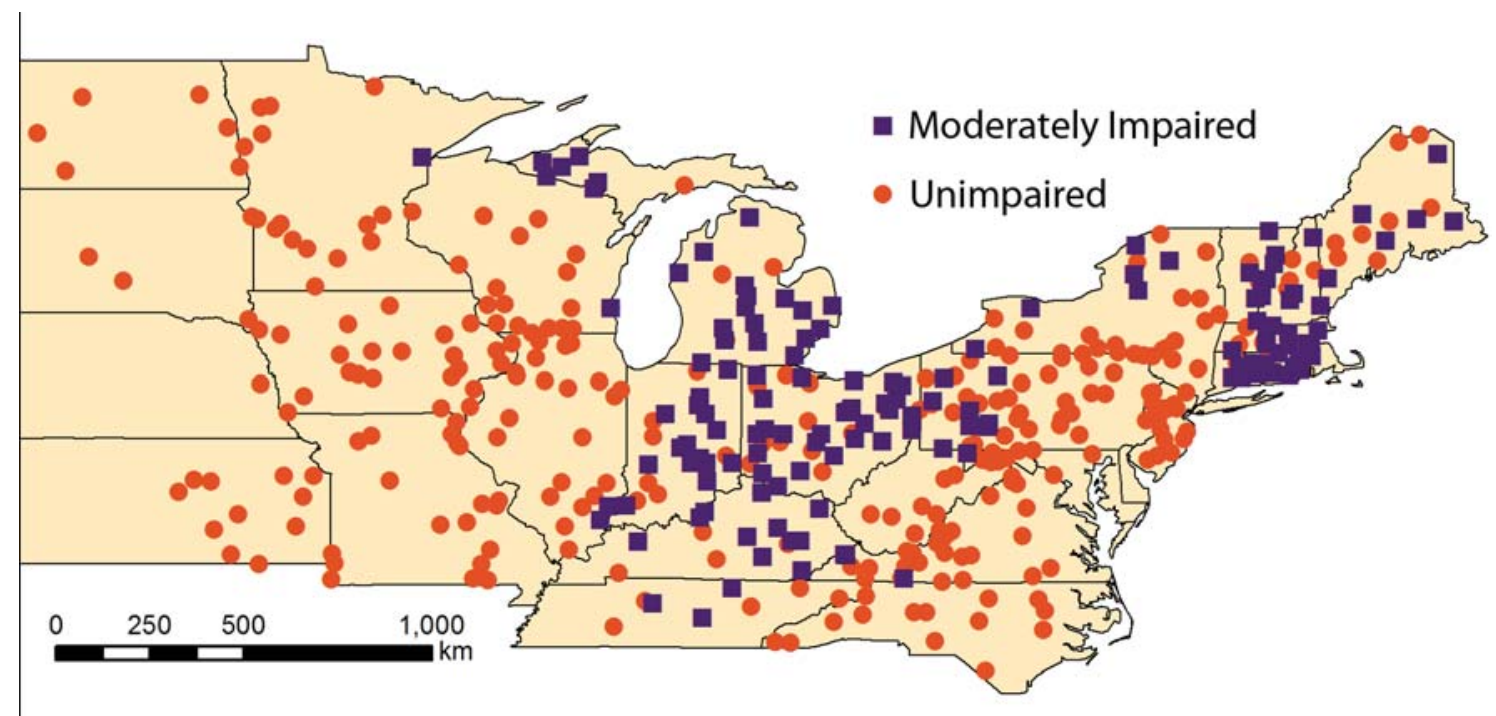

Figure 1.1 Location and designation (degree of impairment) of previously analyzed sites within the northeastern quadrant of the United States.

Each of the flood records were examined for long-term, gradual trends in the mean of the AMF series, as well the presence of "change points" where a significant abrupt shift in the mean flood magnitude occurred at one point in time. Flood records associated with those watersheds were also analyzed for correlation with various large-scale oceanicatmospheric climate patterns: Pacific Decadal Oscillation (PDO), Atlantic Multi-Decadal Oscillation (AMO), North Atlantic Oscillation (NAO), and El Nino Southern Oscillation 
(ENSO). Finally, flood records were analyzed for correlation with temperature and precipitation series over a range of lead times, and various anthropogenic influences were considered. (Fritsch 2012, Salvadori 2013)

The modified Mann-Kendall test (Yue and Wang 2002) was used to check for long-term trends, while the Pettitt (Pettitt 1979) test was used to identify change points. Of the 256 unimpaired sites considered, the flood records for 39 were found to have long-term trends significant at the $10 \%$ level, while 88 contained change points significant at the $10 \%$ level (Fritsch 2012). The flood records for 26 of the 143 moderately impaired sites showed a long-term trend significant at the $10 \%$ level, and 57 exhibited a change point significant at the 10\% level (Salvadori 2013).

Of the 39 flood records for unimpaired sites that exhibited long-term trends, 38 also contained a change point, and all of the moderately impaired sites with a trend also contained a change point. This implies that the results of the Mann-Kendall test are spurious as the "long-term" trends are likely explained by the change points given that the subseries before/after the abrupt shift tend not to exhibit significant trends (Fritsch 2012, Salvadori 2013). Overwhelmingly, the instance of true long-term trends in flood series is in agreement with the research previously cited (Lins and Slack 1999, McCabe and Wolock 2002, Villarini et al. 2009), namely that they are hard to find. 
The correlation between AMF series and climatic cycles with 3-, 6- and 9-month lead times was measured using Kendall's Tau for both unimpaired and moderately impaired watersheds. Among the 256 unimpaired watersheds, the highest percentage of statistically significant correlations was found between the 10-year moving average of the AMF series and AMO indices with a 3-month lead time. PDO was most highly correlated to the 10-year moving average of the AMF series using a 9-month lead time. PDO and AMO were equally correlated with a 6-month lead time (Fritsch 2012). For moderately impaired watersheds, AMO was also found to have the highest correlation with the 10year moving average of the AMF series for 3- and 6-month lead times, with AMO and PDO tied at a 9-month lead time (Salvadori 2013). In general, it seems that the AMO and PDO climatic indices are the most influential on AMF series; relatively few sites exhibited an association with NAO or ENSO (Fritsch 2012, Salvadori 2013). A summary of these results is presented in Table 1.1.

Table 1.1 Incidence of significant correlation (at 10\% level) between the 10-year moving average of AMF series and climatic indices with various lead times; proportions out of 256 unimpaired and 143 moderately impaired study sites.

\begin{tabular}{|l|rrr|rrr|}
\hline \multirow{2}{*}{ Lead Time: } & \multicolumn{3}{|c|}{ Unimpaired Sites } & \multicolumn{3}{c|}{ Impaired Sites } \\
\hline AMO & 3-mo & 6-mo & 9-mo & 3-mo & 6-mo & 9-mo \\
PDO & $44 \%$ & $48 \%$ & $41 \%$ & $48 \%$ & $46 \%$ & $47 \%$ \\
NAO & $39 \%$ & $48 \%$ & $53 \%$ & $34 \%$ & $38 \%$ & $47 \%$ \\
MEI* & $14 \%$ & $9 \%$ & $12 \%$ & $12 \%$ & $3 \%$ & $10 \%$ \\
NINO* & $10 \%$ & $17 \%$ & $35 \%$ & $3 \%$ & $12 \%$ & $24 \%$ \\
\hline
\end{tabular}

*Associated with ENSO 
While statistical analyses can quickly be performed on many sets of flood records from hundreds of watersheds, physical modeling is more involved and requires much more time and computational power. Therefore, only twelve watersheds were selected for more detailed analysis and modeling purposes, four of which (due to time constraints) are the subject of this thesis.

\subsection{Research Motivation}

To support the development of new statistical modeling methods, physical hydrologic modeling can be used to gain a deeper understanding of the flood risk projected under future climatic conditions. Projected future climate in the form of output from Global Circulation Models (GCMs) can be used to force hydrologic models in order to get a sense of differing flood risk under future climate conditions. The end goal of the research presented herein is to provide hydrologic model results that can be used as a benchmark against which to compare/develop updated statistical models. Through future research, variables such as land cover change, multi-decadal climatic oscillations and watershed characteristics can be incorporated into these models as well.

Hydrologic modeling with GCM output not only contributes to the task of updating statistical procedures for determining flood risk, it also adds to the body of knowledge regarding best practices for use of GCM output in conjunction with hydrologic modeling and impact assessment. In general, simulation of AMF series with physically based 
hydrologic models has been extremely limited. Prudhomme et al. (2002) used the CLASSIC (Climate and LAnduse Scenario Simulation on Catchments) model to simulate future daily flow series in the United Kingdom. Based on a peaks-over-threshold analysis of their model output, they conclude that increased flood magnitude and frequency are anticipated. A study employing the UBC model in Canada also showed a general increase in flood magnitude and frequency (Loukas et al. 2001), and increased flood risk in the Danube River was modeled using a program called LISFLOOD (Dankers et al. 2007). It is important to note that all three of these studies considered annual maximum daily flows, whereas our interest and study focuses on instantaneous peak flows which are employed for design event estimation.

This research is also important in that hydrologic modeling with ArcSWAT in an attempt to project future conditions has mainly focused on the overall water balance or monthly streamflow amounts of the watersheds of interest (Hanratty and Stefan 1998, Takle et al. 2005b, Zhang et al. 2007, Githui et al. 2009). Modeling extreme flow events, which occur instantaneously, is something relatively new, and of course has its own obstacles and weaknesses. But, the body of knowledge regarding application of GCMs and hydrologic models in terms of extreme events will be expanded herein.

\subsection{Research Objectives}

For this research, the Soil and Water Assessment Tool (Arnold et al. 1998, Srinivasan et al. 1998) extension to ESRI's ArcGIS (ArcSWAT) was used to model four case study 
watersheds in the Northeastern and Midwestern United States. Once developed, the models were forced with GCM output data obtained from the World Climate Research Programme's (WCRP's) Coupled Model Intercomparison Project phase 3 (CMIP3) multimodel dataset (http://gdo-dcp.ucllnl.org/downscaled_cmip_projections/ dcpInterface.html). This data includes daily values of minimum and maximum temperature as well as precipitation, gridded at a spatial scale of 1/8 of a degree. LogPearson Type 3 (LP3) distributions were fit to the modeled AMF series following general Bulletin 17B recommendations. Namely that the LP3 distribution be fit to the data by using method of moments for the log-transformed data. The LP3 distributions fir the modeled AMF series were compared to the distributions of observed AMF series in order to quantify the difference in projected flood risk.

In the course of this research, it was discovered that there are two ways in which the GCM data can be applied to the model, and that the results can be quite different in terms of not only the resulting AMF series but also the overall amounts of change in temperature and precipitation used as inputs to the physical hydrologic model. To that end, the resulting overall water balances, changes in precipitation and temperature, and modeled AMF distributions from the two methods are not only compared to the respective observed variables, but also to each other, in order to quantify the differences in projected flood risk when using the two climate data application methods. 
In summary, the objectives of this research are as follows:

1. Demonstrate use of hydrologic models forced by GCM output to provide future flood risk estimates.

2. Analyze the application of GCM data in two ways: (i) direct application with a bias correction of precipitation data; and, (ii) shift of an observed dataset (precipitation and temperature) using the "delta change method".

3. Interpret and understand differences in the climate data application methods in terms of: (i) overall average change in temperature and precipitation; (ii) daily distribution and variability of precipitation; and, (iii) impacts on modeled AMF distribution.

In the short term, this research is meant to contribute to the task of predicting what a future climate may look like, and how best to project associated flood risk. In the long term, it is meant to assist with development of new statistical procedures for estimating flood risk which incorporate changing watersheds and a changing climate. 


\section{Watershed Selection and Characteristics}

For the purposes of physical modeling, it was necessary to select case study watersheds which represent the diversity of the hundreds of watersheds previously analyzed. In this chapter, the selection process is described, and the selected watersheds are listed along with some important characteristics. As previously mentioned, a total of twelve watersheds were selected, however, only four are modeled herein.

\subsection{Watershed Selection Process}

A host of watershed characteristics were considered during the selection process, with the goal being to model as diverse a group of watersheds as possible. An attempt was made to include sites with a broad range of geography, land cover, climate and hydrology. Of the twelve sites selected, six are predominantly agricultural land, five are mainly forested, and one is urban. Three are located in Indiana, two in Ohio, and one each from Maine, New Jersey, West Virginia, Kentucky, Tennessee, Missouri and Minnesota. Four of the sites exhibit a long-term flow trend significant at the 10\% level (based on the modified Mann-Kendall test) and five contain a change point significant at the $10 \%$ level (based on the Pettitt test). In addition, the potential influence of large-scale oceanic-atmospheric patterns were taken into account when selecting watersheds for modeling; eight of the case study watersheds show a strong correlation to one or more climatic indices. Further,

only watersheds without major flow regulation due to dams or other man-made structures 
were considered due to relative ease of modeling and consideration of the influences of climate. Table 2.1 summarizes the physical and geographic characteristics of each watershed, while Table 2.2 summarizes current climate, association with climatic indices, presence of trends or change points, and degree of human influence (unimpaired vs. moderately impaired). Information of this nature was obtained from the GAGES II database (Falcone 2011).

Table 2.1 Physical characteristics of case study watersheds*.

\begin{tabular}{|c|c|c|c|c|c|c|c|}
\hline \multirow{2}{*}{ Station } & \multirow{2}{*}{ State } & \multirow{2}{*}{$\begin{array}{l}\text { Area } \\
\left(\mathbf{k m}^{2}\right)\end{array}$} & \multicolumn{3}{|c|}{ \% Land Cover } & \multicolumn{2}{|c|}{ Elevation (m) } \\
\hline & & & Forest & Ag & Urban & Min & Max \\
\hline 01013500 & $\mathrm{ME}$ & 2253 & $71 \%$ & $5 \%$ & $1 \%$ & 157 & 604 \\
\hline 01411000 & $\mathrm{NJ}$ & 145 & $31 \%$ & $8 \%$ & $33 \%$ & 17 & 63 \\
\hline 03069500 & WV & 1857 & $90 \%$ & $3 \%$ & $3 \%$ & 483 & 1480 \\
\hline 03093000 & $\mathrm{OH}$ & 252 & $48 \%$ & $32 \%$ & $9 \%$ & 271 & 408 \\
\hline 03144000 & $\mathrm{OH}$ & 363 & $56 \%$ & $38 \%$ & $6 \%$ & 231 & 377 \\
\hline 03302000 & KY & 167 & $28 \%$ & $1 \%$ & $69 \%$ & 114 & 272 \\
\hline 03329700 & IN & 714 & $4 \%$ & $87 \%$ & $8 \%$ & 168 & 262 \\
\hline 03363500 & IN & 772 & $7 \%$ & $85 \%$ & $7 \%$ & 232 & 370 \\
\hline 03421000 & $\mathrm{TN}$ & 1664 & $49 \%$ & $35 \%$ & $6 \%$ & 251 & 726 \\
\hline 04099510 & IN & 273 & $5 \%$ & $64 \%$ & $10 \%$ & 286 & 363 \\
\hline 05316500 & $\mathrm{MN}$ & 1617 & $1 \%$ & $81 \%$ & $6 \%$ & 301 & 607 \\
\hline 05501000 & MO & 923 & $22 \%$ & $67 \%$ & $5 \%$ & 138 & 266 \\
\hline
\end{tabular}

*Shaded rows correspond to the four case study watersheds investigated herein. 
Table 2.2 Climatic and human factors associated with case study watersheds*.

\begin{tabular}{|c|c|c|c|c|c|c|c|}
\hline Station & $\begin{array}{c}\text { Mean } \\
\text { Annual } \\
\text { Temp }^{\dagger} \\
\left({ }^{\circ} \mathrm{C}\right)\end{array}$ & $\begin{array}{c}\text { Mean } \\
\text { Annual } \\
\text { Precip }^{\dagger} \\
(\mathrm{cm})\end{array}$ & $\begin{array}{c}\% \text { of } \\
\text { Precip } \\
\text { as } \\
\text { Snow }^{\dagger \dagger}\end{array}$ & Impaired? & Trend? & $\begin{array}{l}\text { Change } \\
\text { Point? }\end{array}$ & $\begin{array}{c}\text { Correlation } \\
\text { w/ Climatic } \\
\text { Indices? }\end{array}$ \\
\hline 01013500 & 3.00 & 97.42 & $37 \%$ & No & & & Yes \\
\hline 01411000 & 12.16 & 117.01 & $14 \%$ & No & & & Yes \\
\hline 03069500 & 8.29 & 139.14 & $24 \%$ & No & + & 1954 & No \\
\hline 03093000 & 9.29 & 103.17 & $20 \%$ & Yes & & & Yes \\
\hline 03144000 & 9.85 & 102.23 & $18 \%$ & No & & & Yes \\
\hline 03302000 & 13.37 & 117.09 & $11 \%$ & Yes & + & 1962 & No \\
\hline 03329700 & 10.07 & 99.86 & $17 \%$ & Yes & & & No \\
\hline 03363500 & 10.33 & 106.51 & $17 \%$ & Yes & & & Yes \\
\hline 03421000 & 13.91 & 149.40 & $7 \%$ & Yes & & & Yes \\
\hline 04099510 & 8.68 & 94.19 & $21 \%$ & Yes & + & 1975 & No \\
\hline 05316500 & 6.96 & 66.99 & $15 \%$ & No & + & 1974 & Yes \\
\hline 05501000 & 11.79 & 97.75 & $11 \%$ & No & & 1972 & Yes \\
\hline
\end{tabular}

*Shaded rows correspond to the four case study watersheds investigated herein.

†Period of record 1971 - 2000; ${ }^{\dagger}$ Period of record 1901 - 2000

\subsection{Modeled Watersheds}

The four watersheds modeled in conjunction with this thesis are: the Fish River watershed upstream of USGS Gage Station 01013500 near Fort Kent, Maine; the Eagle Creek watershed upstream of USGS Gage Station 03093000 near Phalanx Station, Ohio; the Wakatomika Creek watershed upstream of USGS Gage Station 03144000 near Frazeysburg, Ohio; and the Pond Creek watershed upstream of USGS Gage Station 
03302000 near Louisville, Kentucky. These watersheds are highlighted in Tables 2.1 and 2.2. Following is a detailed description of each watershed.

\subsubsection{Fish River, Maine}

The Fish River watershed upstream of USGS Gage Station 01013500 near Fort Kent, Maine is the largest basin modeled herein with an area of 2,253 square kilometers.

Located near the Canadian border, the climate of this watershed is cool, with an average temperature of 3 degrees Celsius and an average annual precipitation of 97 centimeters. The topography is relatively mountainous-the basin ranges in elevation from 157 meters at its minimum to 604 meters at maximum. Accordingly, 37\% of the precipitation falls as snow (Falcone 2011).

This watershed is classified as "unimpaired" (Fritsch 2012) and is almost entirely pristine. Forest covers $71 \%$ of the watershed, and only $6 \%$ total has been developed for either urban or agricultural purposes. A full $6 \%$ of the basin's surface is open water, and another $6 \%$ is covered by wetlands. The system is characterized by an "upstream series of natural lakes" (Falcone 2011). A map showing the watershed's location and land cover distribution can be seen in Figure 2.1. 


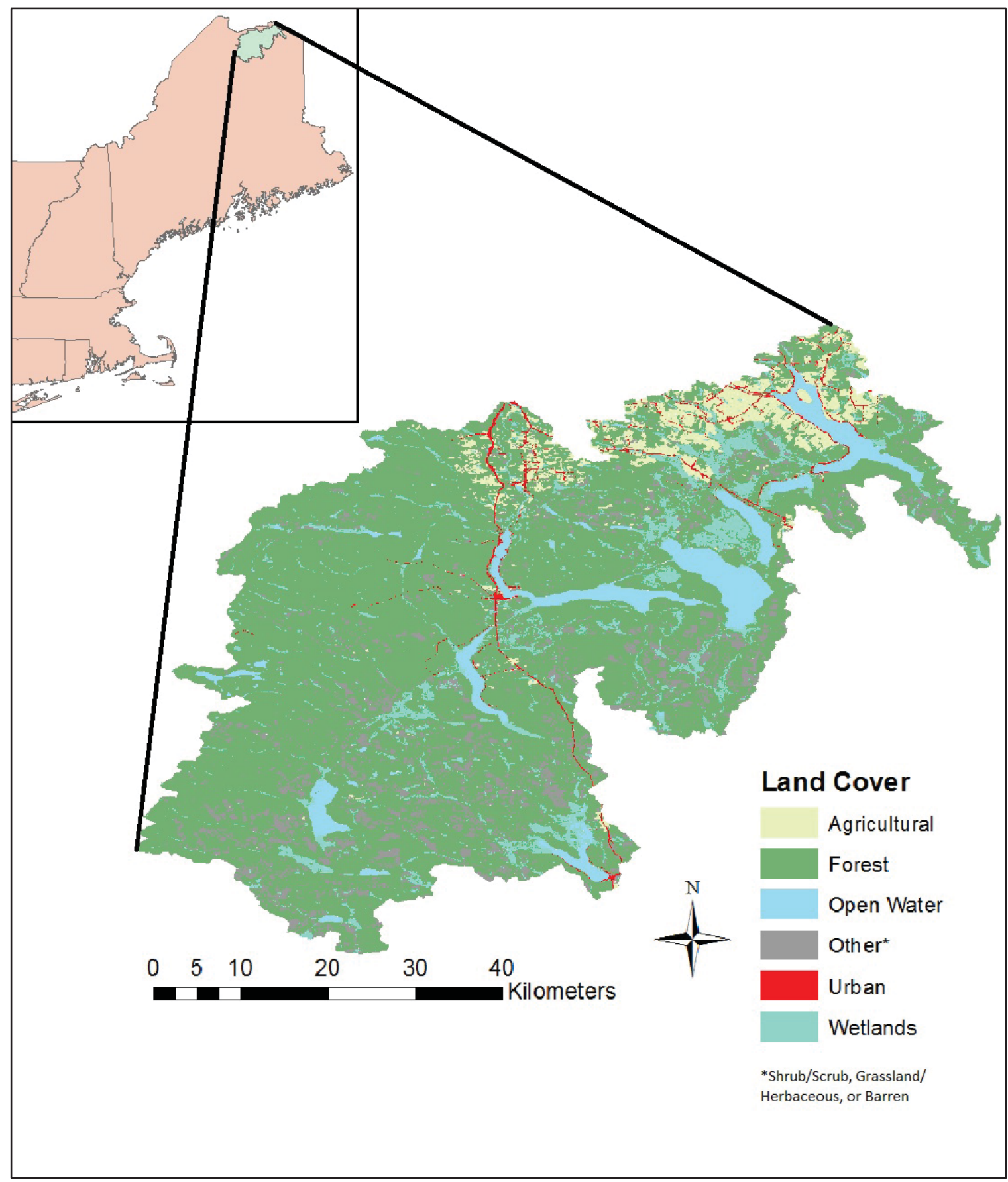

Figure 2.1 Map showing location and land cover distribution of the Fish River watershed upstream of USGS Gage Station 01013500. 
The daily hydrograph is rolling and cyclical (Figure 2.2), peaking during April or May in 82 out of 83 years, indicating a watershed dominated by snowmelt. A time series of the annual maximum flow record is shown in Figure 2.3. The AMF series is continuous from 1930 to $2012(\mathrm{~N}=83$ years) with a mean $(\overline{\mathrm{Q}})$ magnitude of about 245 cubic meters per second, a standard deviation $\left(\mathrm{S}_{\mathrm{Q}}\right)$ of 75 cubic meters per second, and a skew $\left(\mathrm{G}_{\mathrm{Q}}\right)$ of 0.84 . Table 2.3 provides additional summary statistics, including flow percentiles $\left(\mathrm{Q}_{\mathrm{p}}\right)$ derived from an LP3 distribution fit to the AMF series, for which $\alpha, \beta$, and $\tau$ denote the shape, scale and location parameters, respectively.

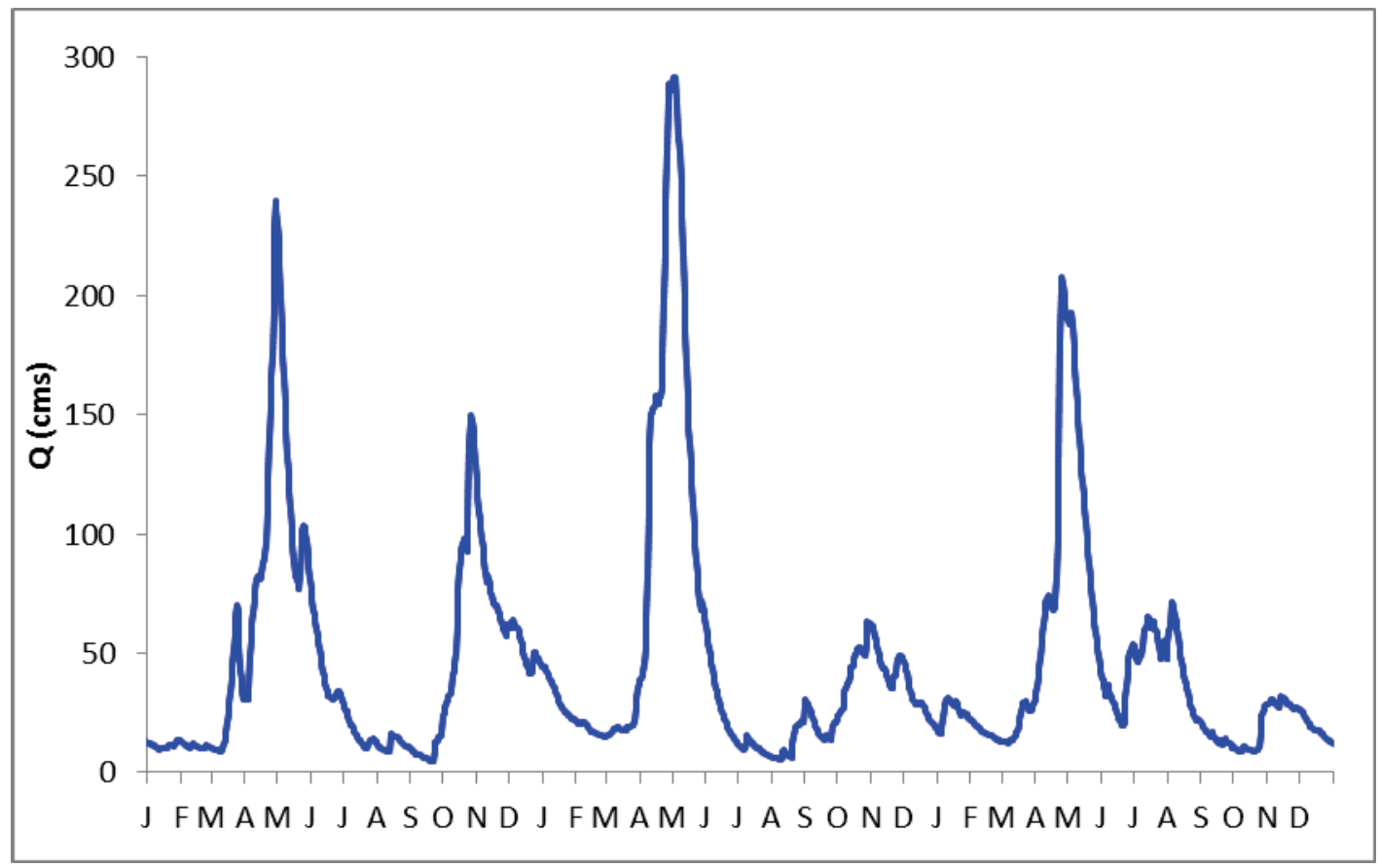

Figure 2.2 Sample hydrograph of daily flows at USGS Gage Station 01013500 from $1 / 1 / 1990$ to $12 / 31 / 1992$. 


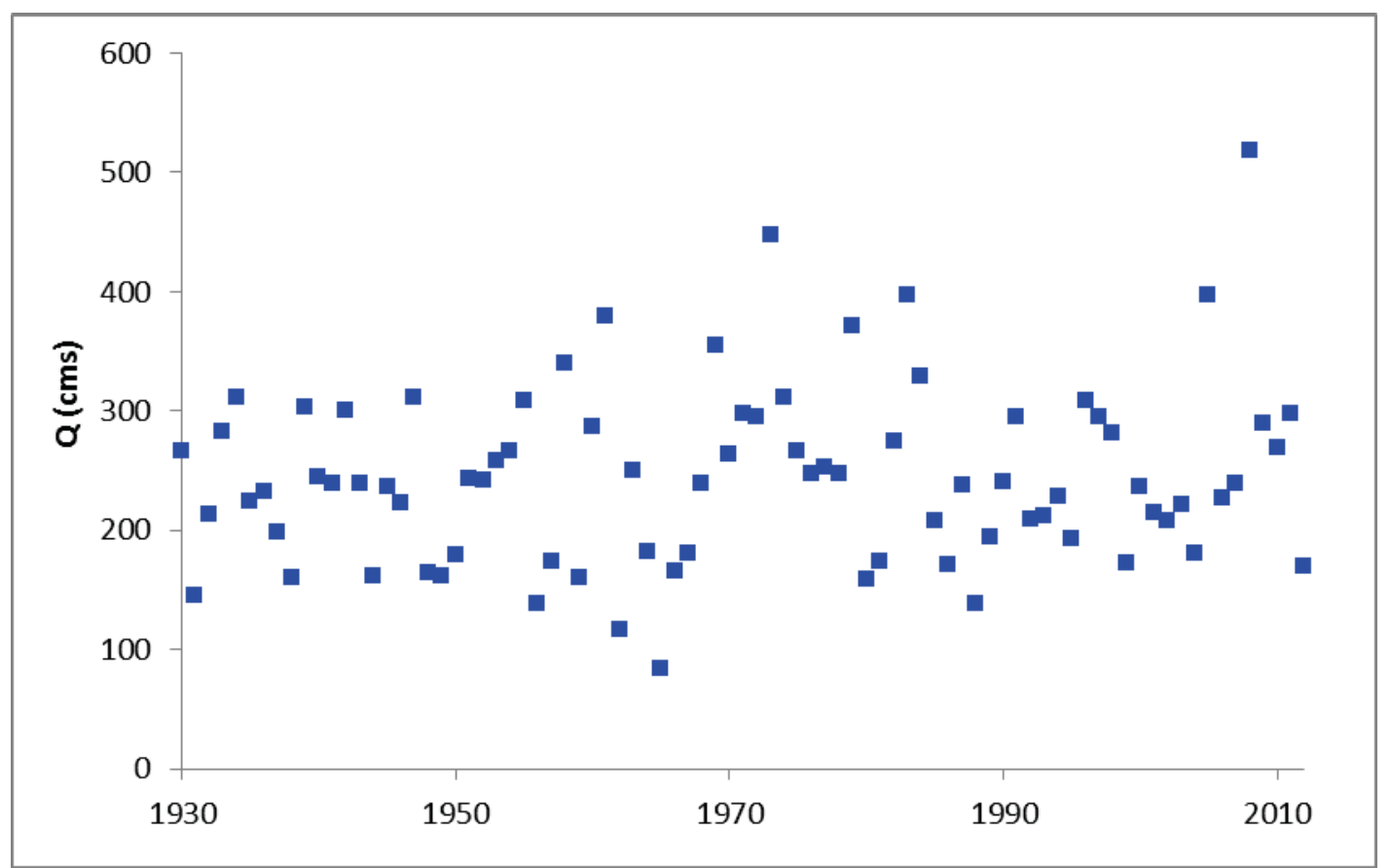

Figure 2.3 Annual maximum flows measured at USGS Gage Station 01013500 from 1930 to 2012.

Table 2.3 Summary statistics of annual maximum flows from 1930 to 2012, associated LP3 distribution parameters, and relevant flow percentiles at USGS Gage Station 01013500.

\begin{tabular}{|cr|cr|}
\hline \multicolumn{2}{|c|}{ Statistics and Parameters } & \multicolumn{2}{|c|}{ Flow Percentiles $\left(\mathbf{m}^{3} / \mathbf{s}\right)$} \\
\hline $\mathrm{N}$ & 83 & $\mathrm{Q}_{0.01}$ & 106.63 \\
$\overline{\mathrm{Q}}$ & 244.99 & $\mathrm{Q}_{0.02}$ & 118.24 \\
$\mathrm{~S}_{\mathrm{Q}}$ & 74.76 & $\mathrm{Q}_{0.10}$ & 156.32 \\
$\mathrm{G}_{\mathrm{Q}}$ & 0.84 & $\mathrm{Q}_{0.50}$ & 237.81 \\
$\alpha$ & 41.37 & $\mathrm{Q}_{0.90}$ & 343.32 \\
$\beta$ & -0.05 & $\mathrm{Q}_{0.98}$ & 418.12 \\
$\tau$ & 7.44 & $\mathrm{Q}_{0.99}$ & 446.38 \\
\hline
\end{tabular}

No trend or change point was detected in the flood record (Fritsch 2012). Statistical analyses conducted at the $10 \%$ significance level revealed that the standard deviation of 
the AMF series is correlated with AMO, and the average flood magnitude is correlated with PDO for lead times of 3- and 6-months; the standard deviation of the AMF series is correlated to both AMO and MEI with a 9-month lead time (Fritsch 2012).

\subsubsection{Eagle Creek, Ohio}

The Eagle Creek watershed upstream of USGS Gage Station 03093000 near Phalanx Station, Ohio has an area of 252 square kilometers. This watershed is relatively flat, with the elevation ranging from 271 to 478 meters. The average annual temperature of the basin is about 9 degrees Celsius, and the average annual precipitation is 103 centimeters. Roughly $20 \%$ of the precipitation falls as snow (Falcone 2011).

The basin is considered "moderately impaired" (Salvadori 2013) with two dams and a small amount of water withdrawal. The land cover is mixed, with $48 \%$ forested, $32 \%$ agricultural, and about $9 \%$ urban (Falcone 2011). A map showing the watershed's location and land cover distribution can be seen in Figure 2.4.

A portion of the daily flow hydrograph measured at the watershed outlet is shown in Figure 2.5. The AMF record, measured continuously from 1938 to 2012, is shown in Figure 2.6. The mean annual maximum flow is 82 cubic meters per second, the standard deviation is 33 cubic meters per second, and the skew is 1.70 . Summary statistics for the AMF series, parameters for the fitted LP3 distribution and associated flow percentiles are given in Table 2.4 . 


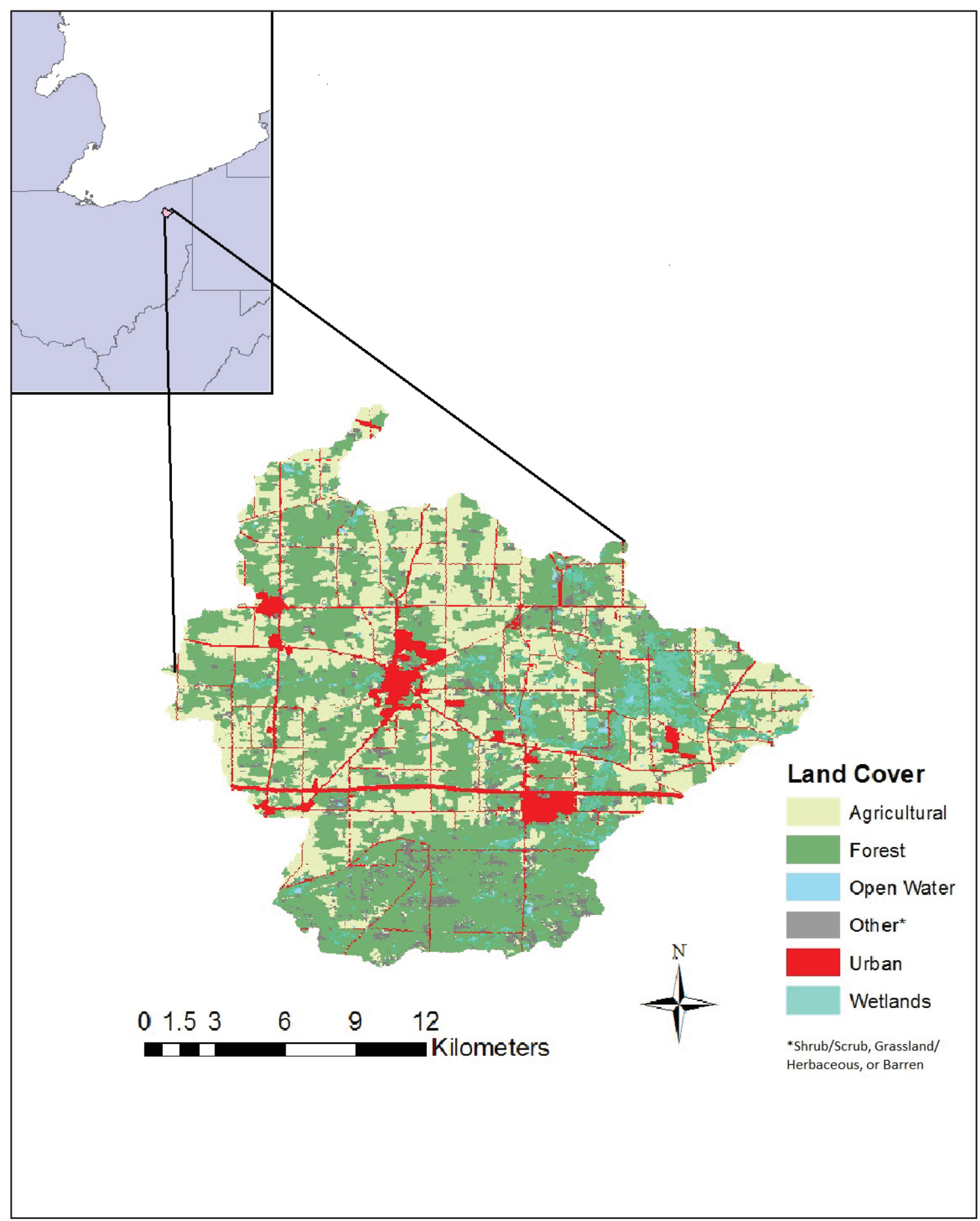

Figure 2.4 Map showing location and land cover distribution of the Eagle Creek watershed upstream of USGS Gage Station 03093000. 
No long-term trends or abrupt shifts were detected in the flood record of this watershed. When considering a 3- or 6-month lead time, the 10-year moving average of the AMF series correlates with the PDO, MEI and NINO indices at the 10\% significance level. In regards to a 9-month lead time, significant correlations were found between the 10-year moving average of the AMF series and the AMO, PDO, NAO, MEI, and NINO indices (Salvadori 2013).

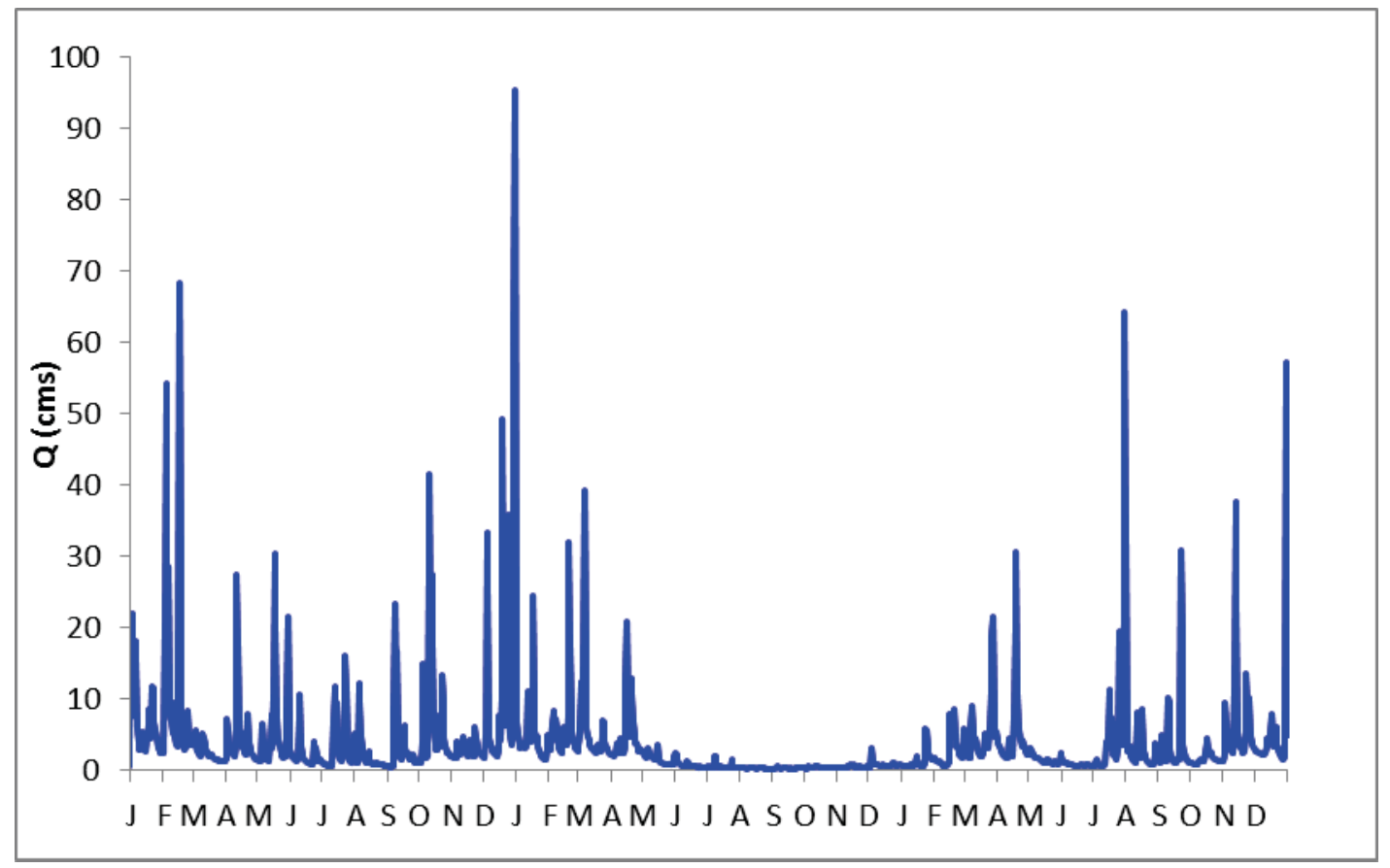

Figure 2.5 Sample hydrograph of daily flows at USGS Gage Station 03093000 from $1 / 1 / 1990$ to $12 / 31 / 1992$. 


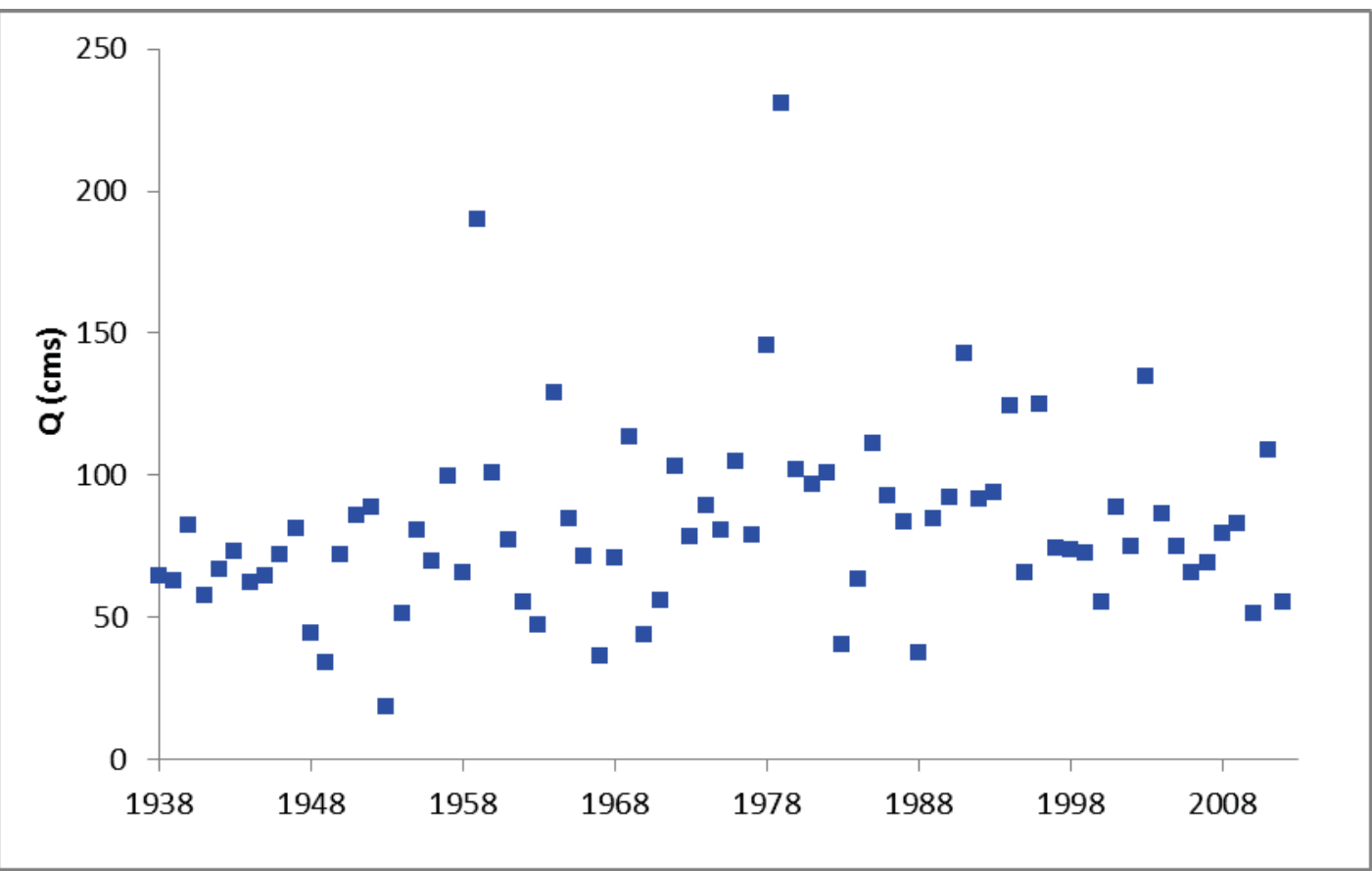

Figure 2.6 Annual maximum flows measured at USGS Gage Station 03093000 from 1938 to 2012.

Table 2.4 Summary statistics of annual maximum flows from 1938 to 2012, associated LP3 distribution parameters, and relevant flow percentiles at USGS Gage Station 03093000.

\begin{tabular}{|cr|lr|}
\hline \multicolumn{2}{|c|}{ Statistics and Parameters } & \multicolumn{2}{|c|}{ Flow Percentiles } \\
\hline $\mathrm{N}$ & 75 & $\mathrm{Q}_{0.01}$ & 27.51 \\
$\overline{\mathrm{Q}}$ & 82.48 & $\mathrm{Q}_{0.02}$ & 31.63 \\
$\mathrm{~S}_{\mathrm{Q}}$ & 33.15 & $\mathrm{Q}_{0.10}$ & 45.84 \\
$\mathrm{G}_{\mathrm{Q}}$ & 1.70 & $\mathrm{Q}_{0.50}$ & 78.77 \\
$\alpha$ & 23.30 & $\mathrm{Q}_{0.90}$ & 123.89 \\
$\beta$ & -0.08 & $\mathrm{Q}_{0.98}$ & 156.38 \\
$\tau$ & 6.22 & $\mathrm{Q}_{0.99}$ & 168.62 \\
\hline
\end{tabular}




\subsubsection{Wakatomika Creek, Ohio}

The Wakatomika Creek watershed upstream of USGS Gage Station 03144000 near

Frazeysburg, Ohio drains 363 square kilometers. The average temperature of the basin is around 10 degrees Celsius, and the average annual precipitation is 102 centimeters. $18 \%$ of the precipitation falls as snow (Falcone 2011). The elevation ranges from 231 to 377 meters. It is classified as "unimpaired" (Fritsch 2012), although its cover type is mixed, with $56 \%$ being forested, 38\% agricultural, and $6 \%$ urban (Falcone 2011). A map of the watershed's location and land cover is provided in Figure 2.7.

A sample of the daily flow hydrograph can be seen in Figure 2.8. The available continuous annual maximum flood record, from 1937 to 2012, is pictured in Figure 2.9. No trends or change points were detected in the flood record. The mean annual flood magnitude is 143 cubic meters per second, the standard deviation is 88 cubic meters per second, and the skew is 1.48 . Table 2.5 gives summary statistics of the flow record along with fitted LP3 parameters and relevant flow percentiles. The 10-year moving average of the AMF series is significantly correlated (10\% level) with PDO and MEI indices with a 3-month lead time; the averaged flows are significantly correlated with the PDO, MEI, and NAO indices with both 6- and 9-month lead times (Fritsch 2012). 


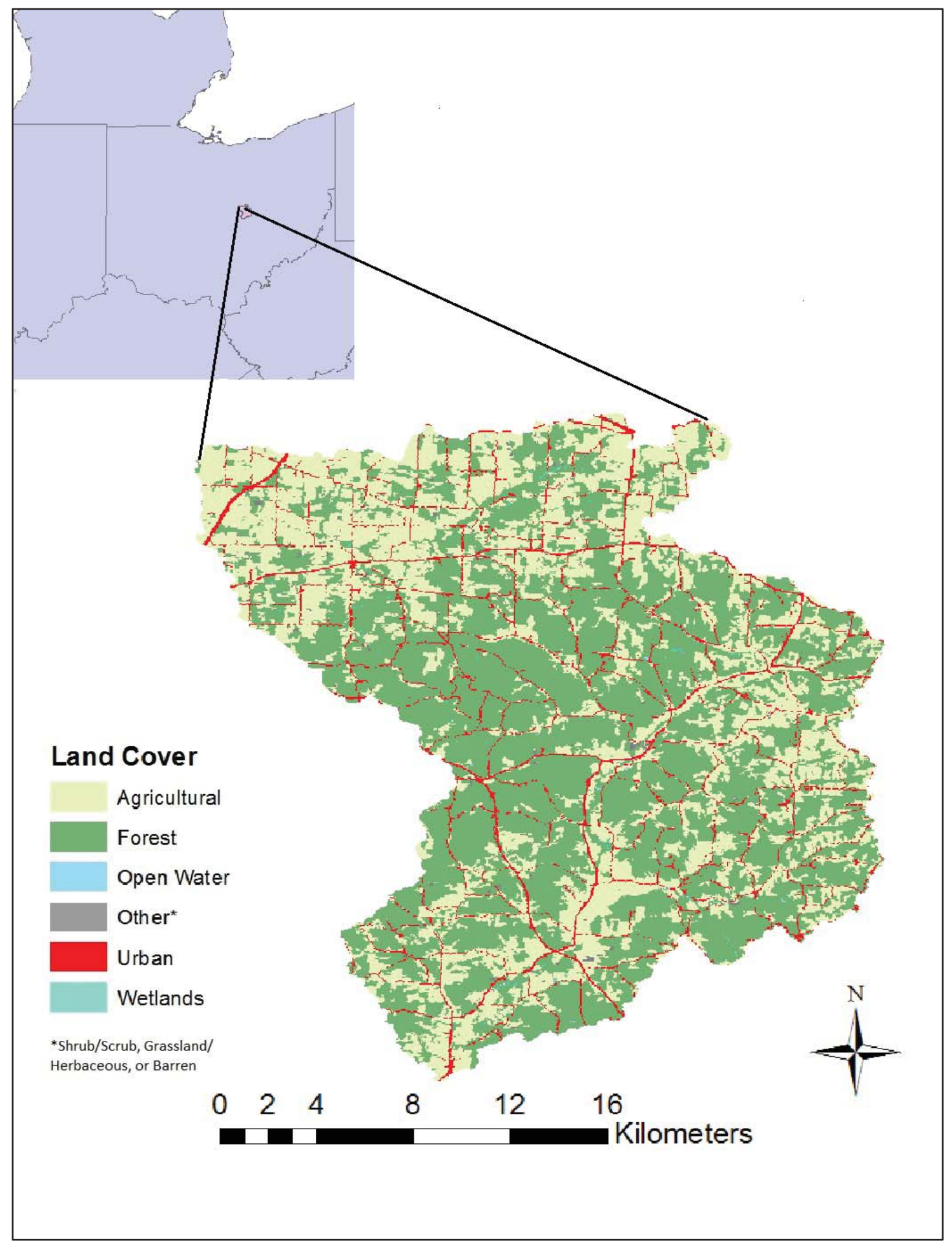

Figure 2.7 Map showing location and land cover distribution of the Wakatomika Creek watershed upstream of USGS Gage Station 03144000. 


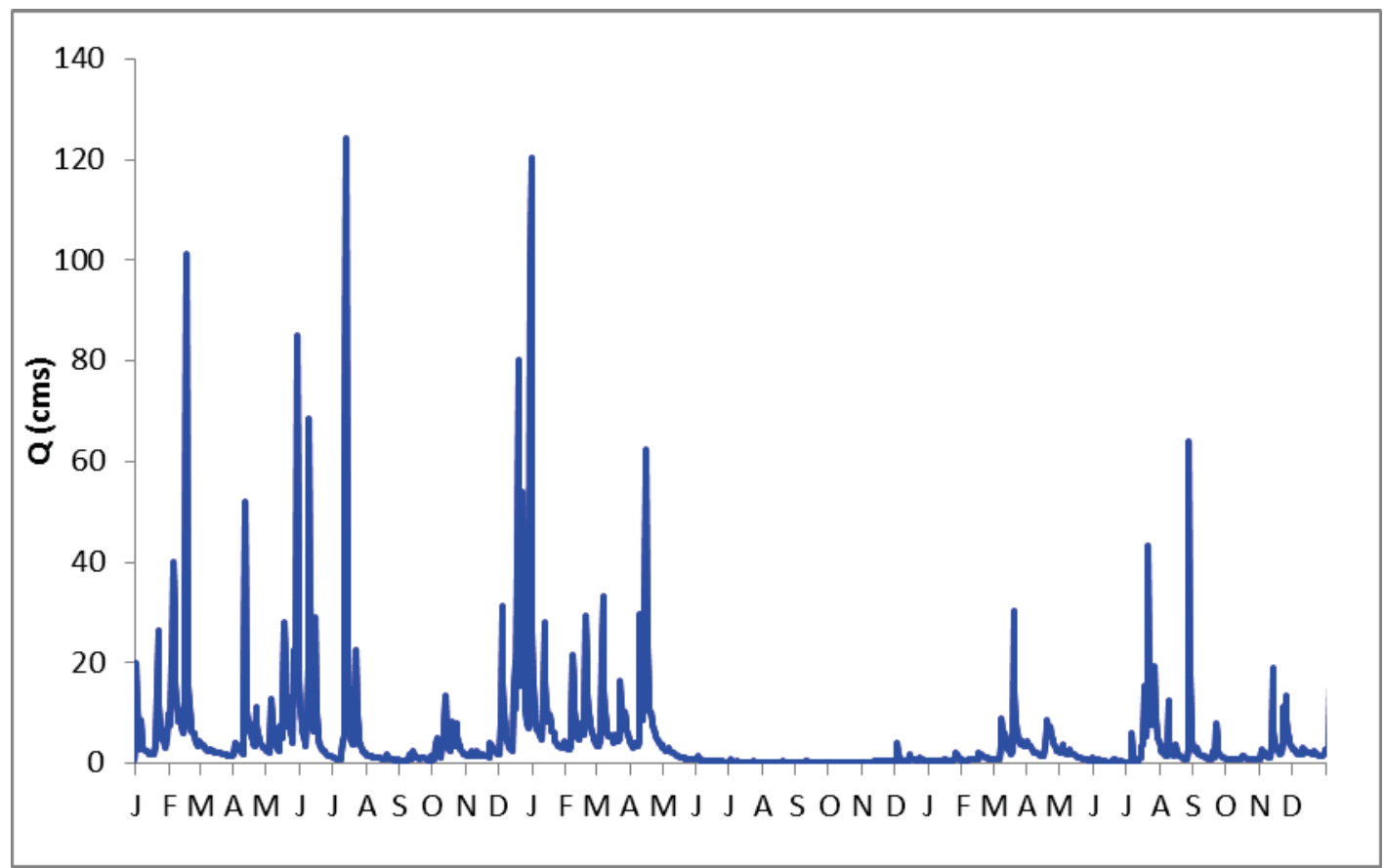

Figure 2.8 Sample hydrograph of daily flows at USGS Gage Station 03144000 from $1 / 1 / 1990$ to $12 / 31 / 1992$.

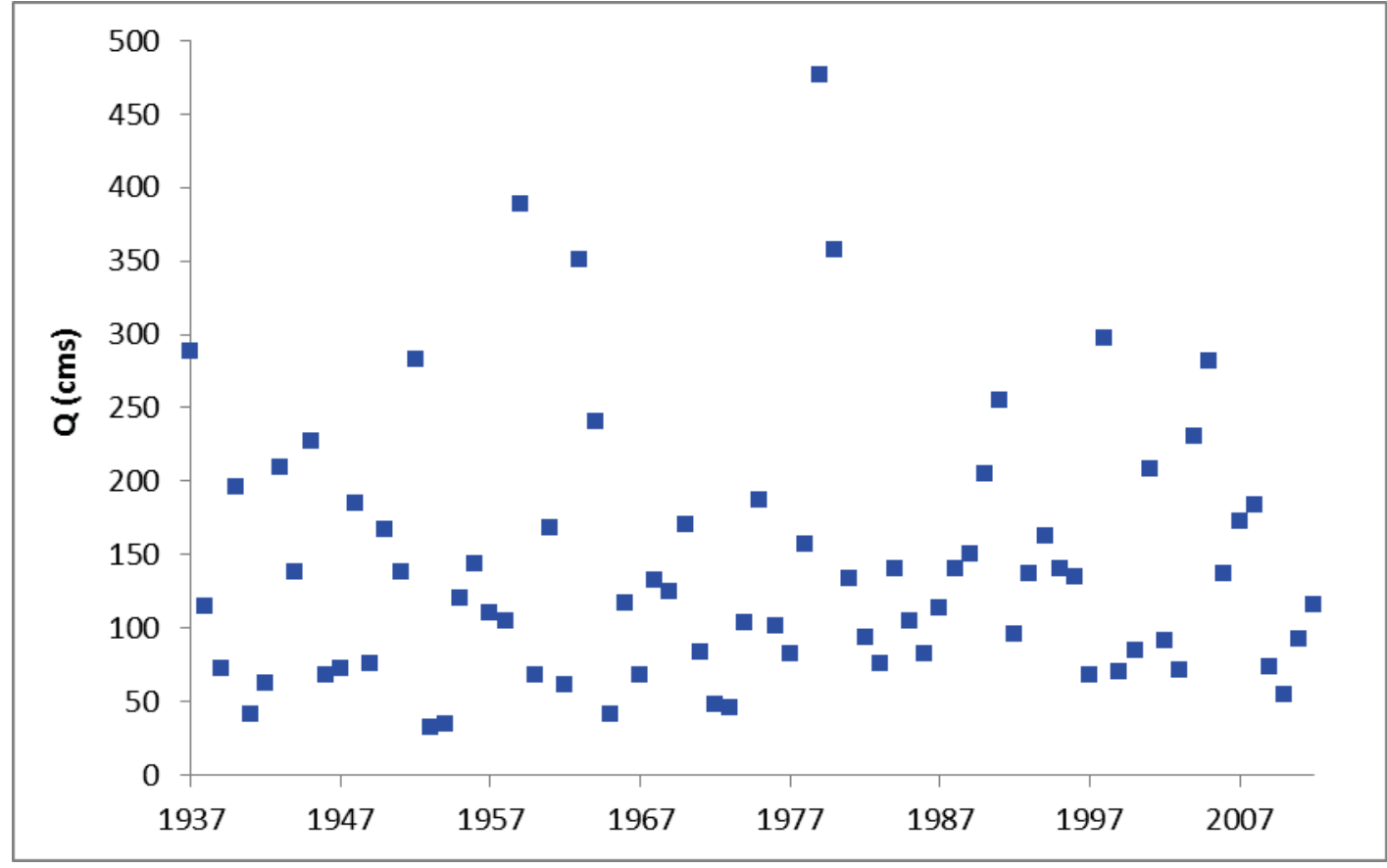

Figure 2.9 Annual maximum flows measured at USGS Gage Station 03144000 from 1937 to 2012. 
Table 2.5 Summary statistics of annual maximum flows from 1937 to 2012, associated LP3 distribution parameters, and relevant flow percentiles at USGS Gage Station 03144000.

\begin{tabular}{|cr|lr|}
\hline \multicolumn{2}{|c|}{ Statistics and Parameters } & \multicolumn{2}{|c|}{ Flow Percentiles } \\
\hline $\mathrm{N}$ & 76 & $\mathrm{Q}_{0.01}$ & 31.19 \\
$\overline{\mathrm{Q}}$ & 142.96 & $\mathrm{Q}_{0.02}$ & 36.50 \\
$\mathrm{~S}_{\mathrm{Q}}$ & 87.96 & $\mathrm{Q}_{0.10}$ & 57.09 \\
$\mathrm{G}_{\mathrm{Q}}$ & 1.48 & $\mathrm{Q}_{0.50}$ & 120.56 \\
$\alpha$ & 8690.20 & $\mathrm{Q}_{0.90}$ & 256.37 \\
$\beta$ & 0.01 & $\mathrm{Q}_{0.98}$ & 405.27 \\
$\tau$ & -49.84 & $\mathrm{Q}_{0.99}$ & 476.67 \\
\hline
\end{tabular}

\subsubsection{Pond Creek, Kentucky}

The Pond Creek watershed upstream of USGS Gage Station 03302000 near Louisville, Kentucky has the smallest drainage area at 167 square kilometers. The annual average temperature is near 13 degrees Celsius, and the annual average precipitation is 117 centimeters. Only $11 \%$ of the precipitation falls as snow (Falcone 2011). The minimum elevation of the basin is 114 meters and the maximum is 272 meters.

Pond Creek watershed is classified as "moderately impaired" (Salvadori 2013), and is the most developed of the four watersheds, with 7 dams, overwhelming development, and significant amounts of channel modification. It is $69 \%$ urban, $28 \%$ forested, and only about $1 \%$ agricultural (Falcone 2011). A map showing the land cover distribution is provided in Figure 2.10. 


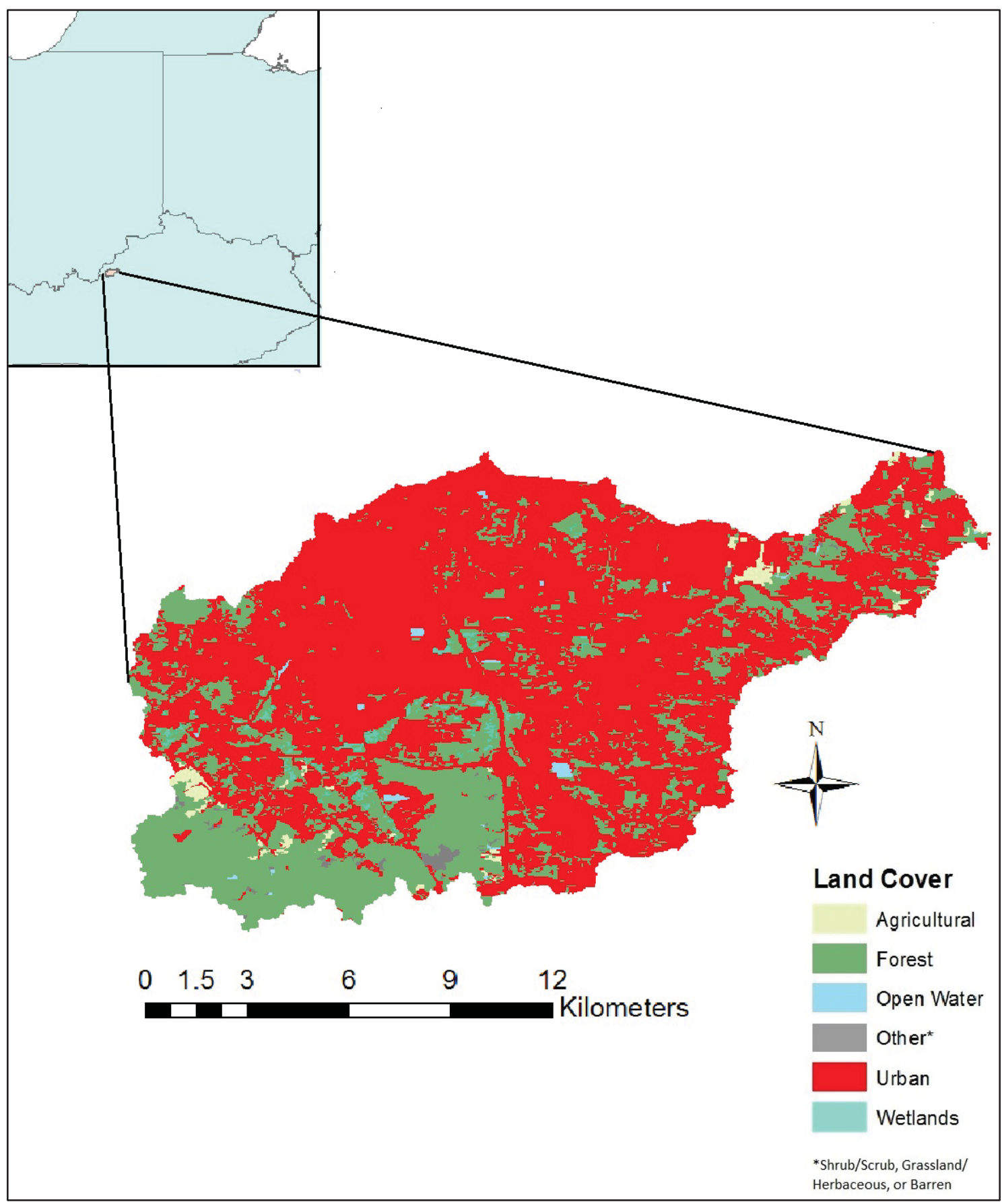

Figure 2.10 Map showing location and land cover distribution of the Pond Creek Watershed upstream of USGS Gage Station 03302000.

An example of the daily flow hydrograph for this watershed can be seen in Figure 2.11. A continuous annual maximum flood record for this site is available from 1945 to 2011, and 
is pictured in Figure 2.12. The magnitude of the mean annual flood is 92 cubic meters per second, the standard deviation is 40 cubic meters per second, and the skew is 1.03 . Table 2.6 summarizes flood record statistics and associated LP3 parameters and percentiles.

The Mann-Kendall test indicated a positive trend in the mean of the AMF series significant at the 5\% level. However, the Pettitt test revealed that a change point occurred in 1962, with a positive shift in the mean, which likely explains the Mann-Kendall results. Additionally, no trends were detected in the subseries before and after this change point. The 10-year moving average of the AMF series also does not exhibit significant correlation with any of the climatic indices considered (Salvadori 2013).

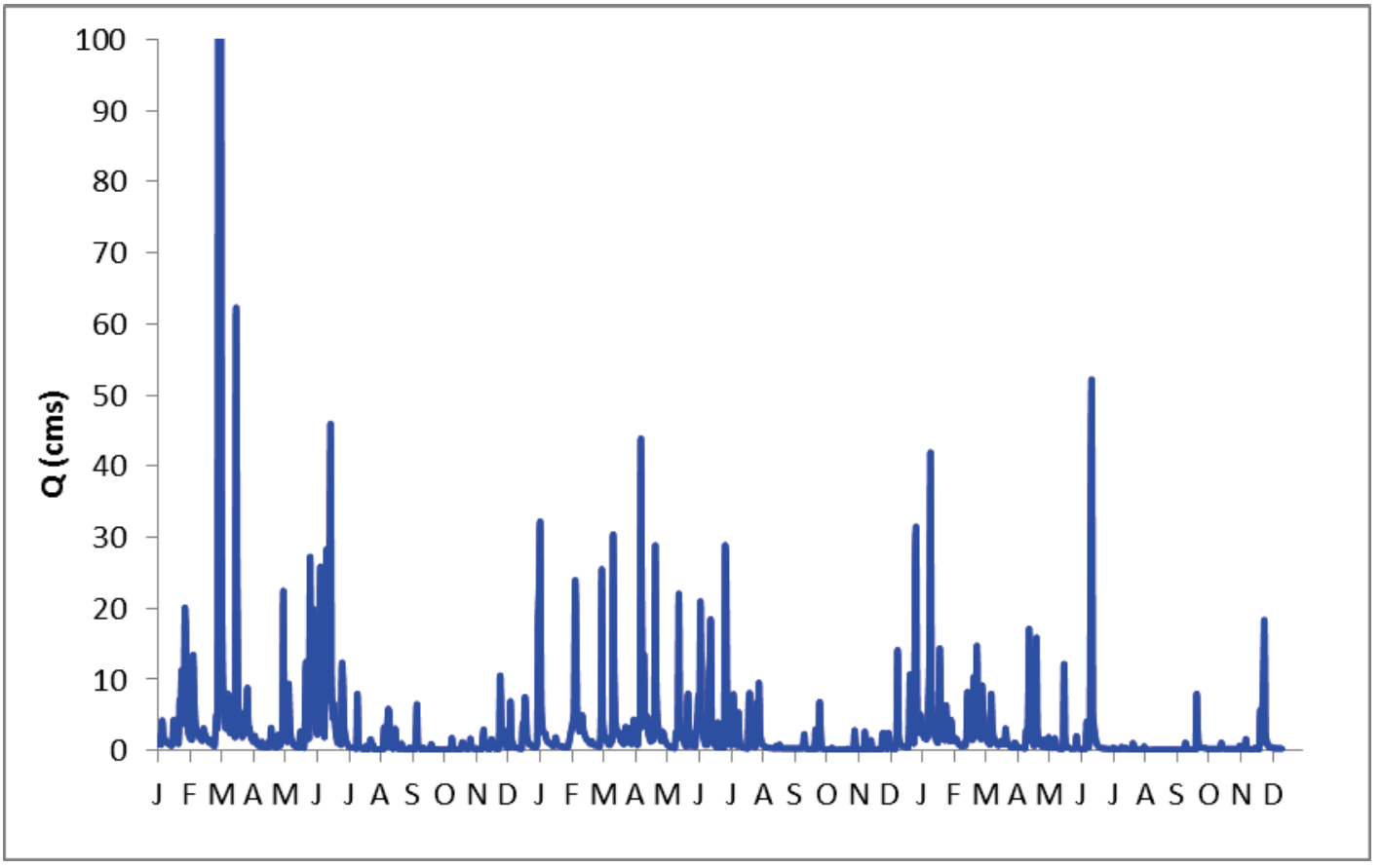

Figure 2.11 Sample hydrograph of daily flows at USGS Gage Station 03302000 from $1 / 1 / 1997$ to $12 / 31 / 1999$. 


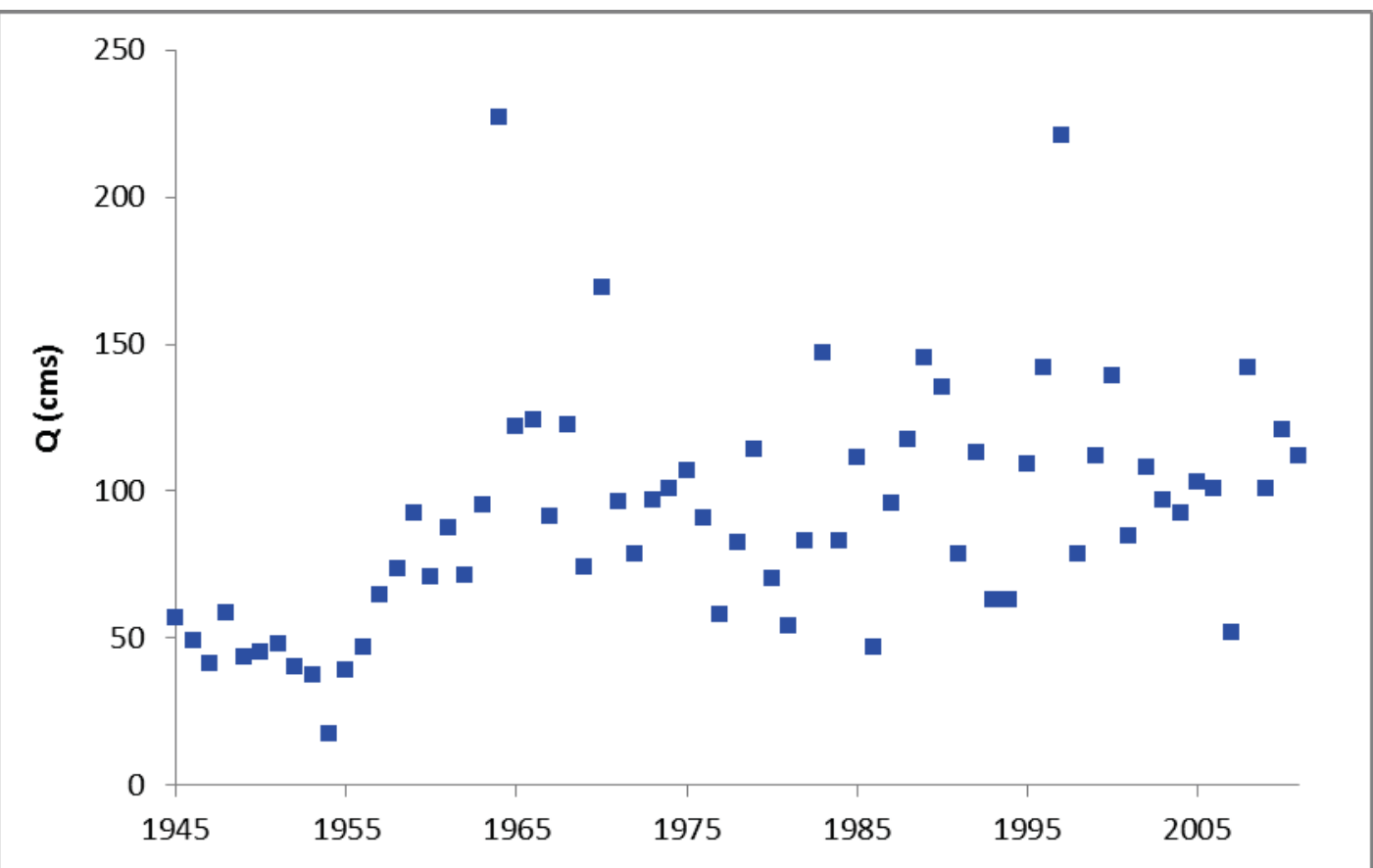

Figure 2.12 Annual maximum flows measured at USGS Gage Station 03302000 from 1945 to 2011.

Table 2.6 Summary statistics of annual maximum flows from 1945 to 2011, associated LP3 distribution parameters, and relevant flow percentiles at USGS Gage Station 03302000.

\begin{tabular}{|cr|lr|}
\hline \multicolumn{2}{|c|}{ Statistics and Parameters } & \multicolumn{2}{|c|}{ Flow Percentiles } \\
\hline $\mathrm{N}$ & 67 & $\mathrm{Q}_{0.01}$ & 23.81 \\
$\overline{\mathrm{Q}}$ & 91.86 & $\mathrm{Q}_{0.02}$ & 28.51 \\
$\mathrm{~S}_{\mathrm{Q}}$ & 39.74 & $\mathrm{Q}_{0.10}$ & 45.59 \\
$\mathrm{G}_{\mathrm{Q}}$ & 1.03 & $\mathrm{Q}_{0.50}$ & 87.39 \\
$\alpha$ & 11.22 & $\mathrm{Q}_{0.90}$ & 144.43 \\
$\beta$ & -0.14 & $\mathrm{Q}_{0.98}$ & 183.19 \\
$\tau$ & 5.95 & $\mathrm{Q}_{0.99}$ & 197.09 \\
\hline
\end{tabular}




\subsection{Relevance of Watershed Characteristics}

In summary, the case study watersheds chosen for modeling have a wide variability in terms of their physical characteristics, their flow records, and their correlation to climatic indices. These variables will be considered in conjunction with the results of modeling in Chapter 5. 


\section{GCMs/Gridded Weather Data}

The use of hydrologic modeling to anticipate future flood risk requires forcing based on some projection of future climate. This chapter gives an overview of the methods used to project climate, discusses the selection of representative models and scenarios, and specifies the different ways in which the climate data was altered before application.

\subsection{Overview of Projected Climate Data}

Global Circulation Models (GCMs) are numerical coupled models that take into account oceanic, atmospheric, and other variables in order to simulate the overall climate patterns of the planet (Zorita and Von Storch 1999). They provide good estimates of climate at a coarse scale, but are less accurate at finer-scale resolutions (Zorita and Von Storch 1999). This limitation must be somehow dealt with in order to model more localized processes, including hydrologic processes at the watershed scale (Wilby et al. 2004). The data must be "downscaled", or translated from a coarse grid of data to a finer grid. There are three main approaches to downscaling: dynamical downscaling, statistical downscaling (SDS), and the delta change method.

Dynamical downscaling involves the use of regional climate models (RCMs). These approaches take boundary conditions from GCM output and use them to force a smaller, higher resolution climate model. This method is effective but extremely computationally intensive (Fowler et al. 2007). 
Statistical downscaling links local climate variables and GCM output to create a statistical relationship used for simulating climate at finer scales. There are various methods of statistical downscaling in existence, all varying in complexity and efficacy (Wilby et al. 2004). The SDS approach uses relationships between historical GCM output and observed local climate, and applies these same relationships to future GCM output in order to predict future local climate (Wilby et al. 2004). One drawback of SDS is that it assumes relationships derived between global climatic variables and local climate will not change under future climate conditions (Wilby et al. 2004). Additionally, the statistical relationships often simplify the many complex physical processes at work (Hidalgo et al. 2008).

The delta change method is the most simplistic way of simulating future climate, and involves shifting the mean of an observed series by the average difference in model output between the corresponding observed time period and the desired future period for a specific area (Hamlet and Lettenmaier 1999, Hay et al. 2000, Wilby et al. 2004). The delta change method is useful when considering many different climate models and emissions scenarios at once, because it becomes impractical to downscale many sets of output; thus, the delta change method is more commonly used in impact assessments (Wilby et al. 2004). 
In the past, the nature of GCM output has been such that while capturing overall changes in climate well, it produces implausible daily values of precipitation and temperature. In a phenomenon known as the "drizzle effect", the GCM has the tendency to spread out the same amount of precipitation into a number of drizzles rather than one or two larger rain events (DeFlorio et al. 2013, Maurer et al. 2013). This can be remediated via the delta change method by simply applying the average monthly changes to an already observed series, hence the popularity of the delta change method (Hamlet and Lettenmaier 1999, Graham et al. 2007). The delta change method may be applied to an observed set of data using GCM output, RCM output, downscaled output, bias-corrected output, etc., as long as forecasted, hindcasted, and observed data are available. However, assuming the variability of the climate will remain stationary while the mean shifts, which is inconsistent with the predictions of climate scientists, is a limitation of the method. Yang et al. (2010) and Rasmussen et al. (2012) both found that the delta change method was lacking as far as capturing seasonal variability of precipitation, which certainly has an impact when considering extreme flow events. However, it is a useful tool for performing impact assessments of climate change when considering many different scenarios.

When not using the delta change method, further bias correction may still be required even after statistical or dynamical downscaling and preliminary bias correction of GCM data. This generally can be done by adjusting forecasts to account for differences between an observed series of data and a hindcasted series of the same time period. A specific method for doing this was recently recommended for the GCM data used in this research, 
and is discussed further in the following sections. As previously mentioned, this new method is applied alongside the delta change method for comparison.

\subsection{CMIP3 Climate Data}

All climate data used for modeling herein was obtained from the World Climate Research Programme's (WCRP's) Coupled Model Intercomparison Project phase 3 (CMIP3) multimodel dataset available online at http://gdo-dcp.ucllnl.org/downscaled_cmip_projections/ dcpInterface.html. Among other things, the website provides GCM output that has been previously bias corrected using a quantile-mapping method (on a monthly timestep) and downscaled using the method of constructed analogues to a resolution of $1 / 8$ degree (Brekke 2013). While this method has some limitations as far as reproducing the variability of precipitation, it has been shown to outperform other methods in regards to producing plausible stream flow values (Maurer et al. 2010). The "Bias Corrected Constructed Analogue" (BCCA) dataset was therefore selected for use herein, and associated climate projections will simply be referred to as CMIP3 data from here on out. It should be noted that CMIP5 was released during the course of this research; however, much of the modeling and analysis had already been completed by that point.

The daily data available from CMIP3 include gridded observed data for 1950-1999, hindcasted data for 1961-1999, and forecasted data for the periods of 2046-2065 and 2081-2100. The models available are cccma_cgcm3_1, cnrm_cm3,gfdl_cm2_0, gfdl_cm2_1, ips1_cm4, miroc3_2_medres, miub_echo_g, mpi_echam5, and 
mri_cgcm2_3_2a, and have been forced using either the A1b, B2, or B1 emissions scenario. In addition, multiple runs have been conducted for select model/emissions scenario combinations, resulting in a total of 53 simulated future datasets. The BCCA dataset is further described in Maurer et al. (2010).

\subsection{Selection of Representative Climate Projections}

A set of representative climate projections covering a range of GCM/emissions scenario combinations were selected to force the hydrologic model for each case study watershed. Out of the 53 combinations available, only 9 were selected per basin to reduce the computational burden. To make this selection, CMIP3 data sets for all 53 model/emissions scenario combinations were downloaded for each basin area for the forecast period of 2046-2065 and hindcast period of 1961-1999; observed data for the period of 1961-1999 were also obtained. The spatial mean of each data series over a given watershed was used for selection purposes.

Although the CMIP3 data has been bias corrected, the precipitation data is known to still exhibit a "dry bias" (Brekke 2013). Thus, an additional correction of the gridded data is required prior to input to the hydrologic model (discussed further in Section 3.4), and a correction must be applied to the spatially averaged data so that it can be used for selection purposes. For each watershed, average monthly differences in precipitation $\left(\mathrm{mm} /\right.$ day) and temperature $\left({ }^{\circ} \mathrm{C}\right)$ were calculated between the observed and corresponding hindcast period for each GCM/emissions scenario combination. These differences 
represent "bias correction factors", multiplicative for precipitation and additive for temperature, which were then applied to the forecasted future data.

Equation 3.1 shows the method of calculating the bias correction factor for daily precipitation in month $j\left(P C F_{j}\right)$ where $\left\{x_{j 1}, x_{j 2}, \ldots, x_{j n}\right\}$ is the set of all historical daily precipitation data available for month $j$ between 1961 and 1999, $\bar{x}_{j}$ is the average of all $n$ historical daily values, $\left\{y_{j 1}, y_{j 2}, \ldots, y_{j n}\right\}$ is the set of all hindcasted daily precipitation data available for month $j$ between 1961 and 1999, and $\bar{y}_{j}$ is the average of all $n$ hindcasted daily values. Equation 3.2 shows the application of the bias correction factor to a single day's forecasted precipitation value in month $j$. These equations are evaluated separately for each month of the year $(j=1,2, \ldots 12)$.

Eqn. 3.1 $P C F_{j}=\frac{\bar{x}_{j}}{\bar{y}_{j}}$

Eqn. 3.2 $\quad P_{\text {corrected }}(\mathrm{mm})=P_{\text {projected }}(\mathrm{mm}) * P C F_{j}$

While only the precipitation is known to be biased, the temperature was corrected here as well in the interest of being thorough. Equation 3.3 shows the method of calculating the bias correction factor for daily temperature in month $j\left(T C F_{j}\right)$, where $\left\{x_{j 1}, x_{j 2}, \ldots, x_{j n}\right\}$ is the set of all historical daily temperature data available for month $j$ between 1961 and $1999, \bar{x}_{j}$ is the average of all $n$ historical daily values, $\left\{y_{j 1}, y_{j 2}, \ldots, y_{j n}\right\}$ is the set of all hindcasted daily temperature data available for month $j$ between 1961 and 1999, and $\bar{y}_{j}$ is the average of all $n$ hindcasted daily values. Equation 3.4 shows the application of the 
bias correction factor to a single day's forecasted temperature value in month $j$. These equations are evaluated separately for both maximum and minimum temperature in each month of the year $(j=1,2, \ldots 12)$.

Eqn. $3.3 T C F_{j}=\bar{x}_{j}-\bar{y}_{j}$

Eqn. $3.4 \quad T_{\text {corrected }}\left({ }^{\circ} \mathrm{C}\right)=T_{\text {projected }}\left({ }^{\circ} \mathrm{C}\right)+T C F_{j}$

The overall average differences between the observed (1961-1999) and bias corrected forecast (2046-2065) values of temperature and precipitation for each of the 53

GCM/emissions scenario combinations were plotted (e.g., Figure 3.1) with percent (\%) change in precipitation on the $\mathrm{x}$-axis and absolute change in temperature on the $\mathrm{y}$-axis. The resulting "cloud" was used to select nine representative combinations for each watershed, with one nearest to the median value of all 53 combinations, one indicative of the median of each quadrant associated with warm/wet, warm/dry, cool/wet, and cool/dry scenarios, and four extreme scenarios. Figures 3.1 - 3.4 show the "cloud" produced for each watershed with the selected scenarios highlighted in pink. The actual combinations of GCM, emissions scenario, and run which each pink square represents are indicated in Tables $3.1-3.4$. 


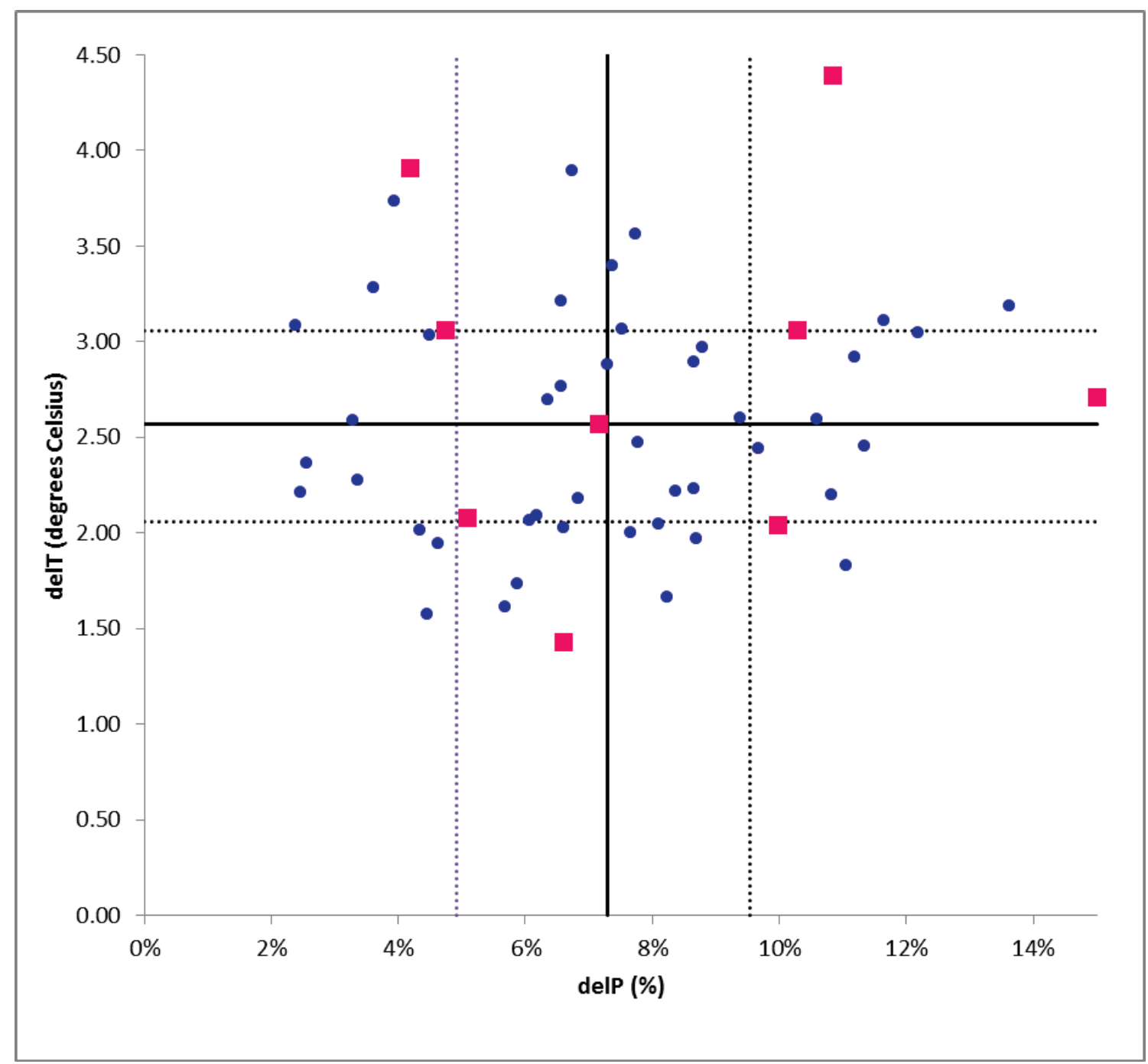

Figure 3.1 Absolute change in temperature and percent change in precipitation of 53 climate projections (bias corrected) for the Fish River watershed upstream of USGS Gage Station 01013500; pink squares denote the 9 representative scenarios. 


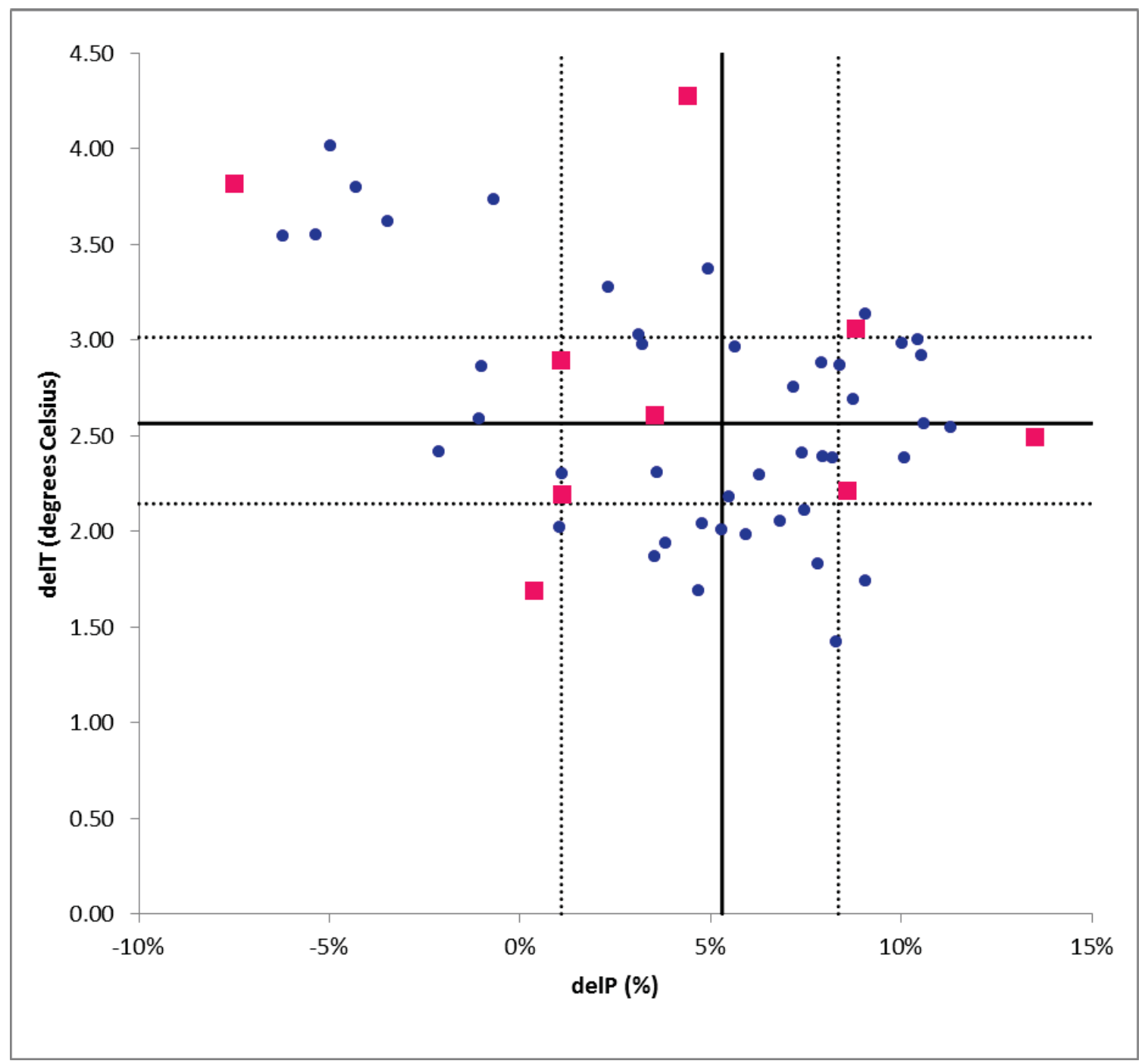

Figure 3.2 Absolute change in temperature and percent change in precipitation of 53 climate projections (bias corrected) for the Eagle Creek watershed upstream of USGS Gage Station 03093000; pink squares denote the 9 representative scenarios. 


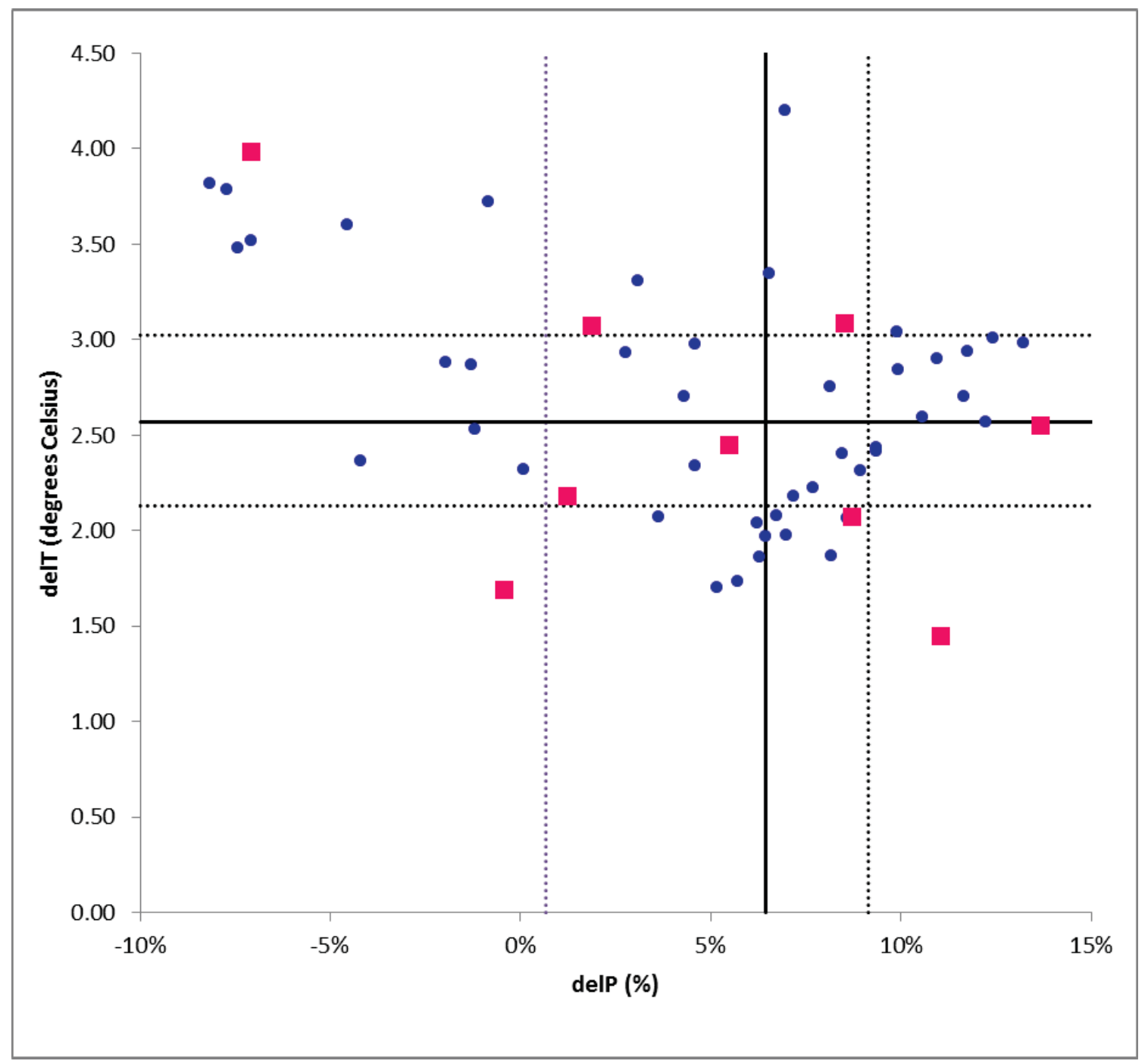

Figure 3.3 Absolute change in temperature and percent change in precipitation of 53 climate projections (bias corrected) for the Wakatomika Creek watershed upstream of USGS Gage Station 03144000; pink squares denote the 9 representative scenarios. 


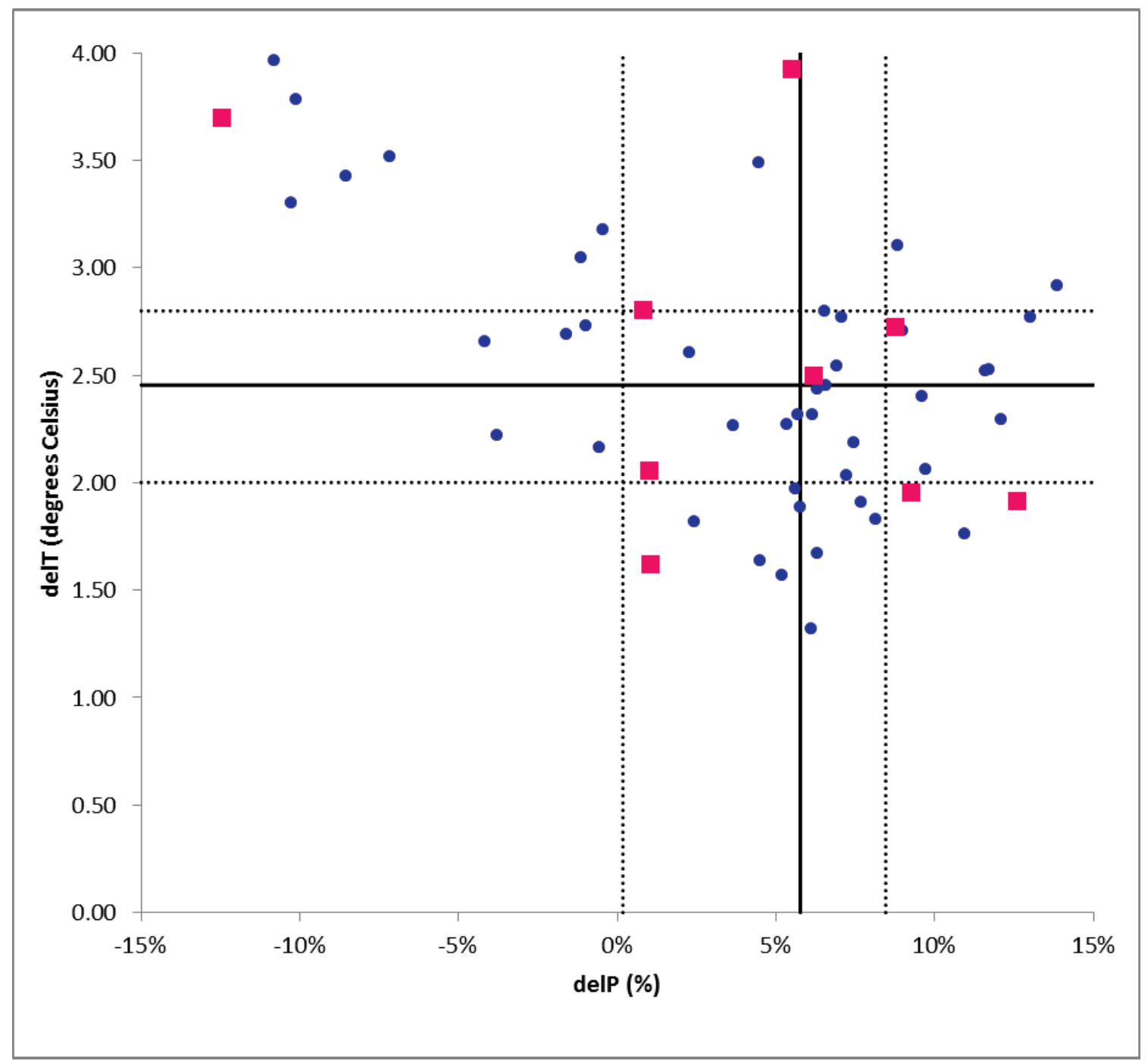

Figure 3.4 Absolute change in temperature and percent change in precipitation of 53 climate projections (bias corrected) for the Pond Creek watershed upstream of USGS Gage Station 03302000; pink squares denote the 9 representative scenarios. 


\subsection{Climate Data Application}

Full sets of gridded data (as opposed to the spatial means used in Section 3.3) were downloaded for each of the nine representative scenario/model combinations for each of the four case study watersheds. As noted in Section 3.3, a dry bias exists within the data and the discrepancy between the observed and hindcasted data require some sort of bias correction before gridded forecasted data can be used. Two methods were applied herein. First, akin to the process employed for GCM/emissions scenario selection, the bias correction factors for precipitation calculated at the basin scale (Equation 3.1) were applied to the gridded forecasted daily precipitation data for each watershed. This approach was recently recommended by the CMIP3 archiving team (Brekke 2013). The differences in temperature data between the observed and hindcasted period were minor (usually less than $0.25^{\circ} \mathrm{C}$ ), so the bias corrections were not applied to forecasted temperature data. Figure 3.5 contains a visual representation of this method.

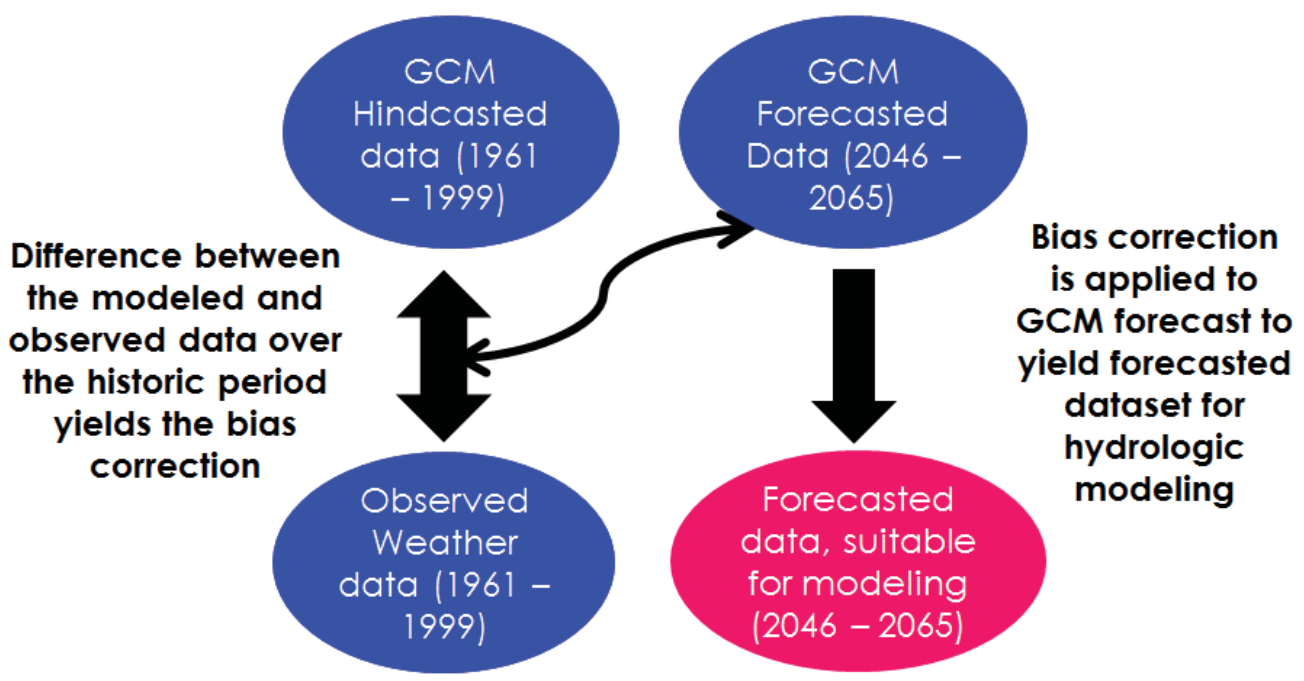

Figure 3.5 Visual representation of bias correction for climate data application. 
Second, the delta change method was applied as described in previous publications (Hamlet and Lettenmaier 1999, Hay et al. 2000, Graham et al. 2007). In this instance, for each GCM/emissions scenario combination, the average monthly differences (delta corrections) between hindcasted data for the period 1980-1999 and forecasted data for the period 2046-2065 were calculated (multiplicative for precipitation and additive for temperature), and applied to the observed dataset from 1980 to 1999.

Equation 3.5 shows the method of calculating the delta correction for daily precipitation in month $j\left(P D C_{j}\right)$ where $\left\{x_{j 1}, x_{j 2}, \ldots, x_{j n}\right\}$ is the set of all hindcasted daily data available for month $j$ between 1980 and 1999, $\bar{x}_{j}$ is the average of all $n$ hindcasted daily values, $\left\{y_{j 1}, y_{j 2}, \ldots, y_{j n}\right\}$ is the set of all forecasted daily precipitation data available for month $j$ between 2046 and 2065, and $\bar{y}_{j}$ is the average of all $n$ forecasted daily values. Equation 3.6 shows the application of the delta correction for a single day's precipitation value observed in month $j$. These equations are evaluated separately for each month of the year $(j=1,2, \ldots 12)$.

Eqn. $3.5 \quad P D C_{j}=\frac{\bar{y}_{j}}{\bar{x}_{j}}$

Eqn. $3.6 \quad P_{\text {corrected }}(\mathrm{mm})=P_{\text {observed }}(\mathrm{mm}) * P D C_{j}$

Equation 3.7 shows the method of calculating the delta correction for daily temperature in month $j\left(T D C_{j}\right)$, where $\left\{x_{j 1}, x_{j 2}, \ldots, x_{j n}\right\}$ is the set of all hindcasted daily data available for month $j$ between 1980 and $1999, \bar{x}_{j}$ is the average of all $n$ hindcasted daily values, $\left\{y_{j 1}\right.$, 
$\left.y_{j 2}, \ldots, y_{j n}\right\}$ is the set of all forecasted daily temperature data available for month $j$ between 2046 and 2065, and $\bar{y}_{j}$ is the average of all $n$ forecasted daily values. Equation 3.8 shows the application of the delta correction for a single day's temperature value observed in month $j$. These equations are evaluated separately for both maximum and minimum temperature in each month of the year $(j=1,2, \ldots 12)$.

Eqn. $3.7 T D C_{j}=\bar{y}_{j}-\bar{x}_{j}$

Eqn. 3.8 $\quad T_{\text {corrected }}\left({ }^{\circ} \mathrm{C}\right)=T_{\text {projected }}\left({ }^{\circ} \mathrm{C}\right)+T D C_{j}$

Figure 3.6 illustrates the delta change process. Whether the delta corrections should be calculated based on a longer control period (1961-1999, as is available) was considered; however, it was decided it would be more appropriate to simply employ the differences between the baseline period and the simulated future period. This is because the corrections are being applied to the 1980-1999 dataset in order to simulate a 2046-2065 dataset; thus, it makes more sense to calculate the corrections based on the differences between the 1980-1999 and 2045-2065 GCM projections.

It is important to note that the bias correction and delta change methods were applied to the same representative set of GCM/emissions scenarios selected based on differences calculated using spatially averaged observed data from 1961 to 1999 . This is consistent with the time period employed with the bias correction method. While it might have been more appropriate to select separate scenarios for the delta change method, given the 
difference in periods used to apply each method, the scenarios had to be equivalent in order to compare the two methods as discussed in Chapter 5.

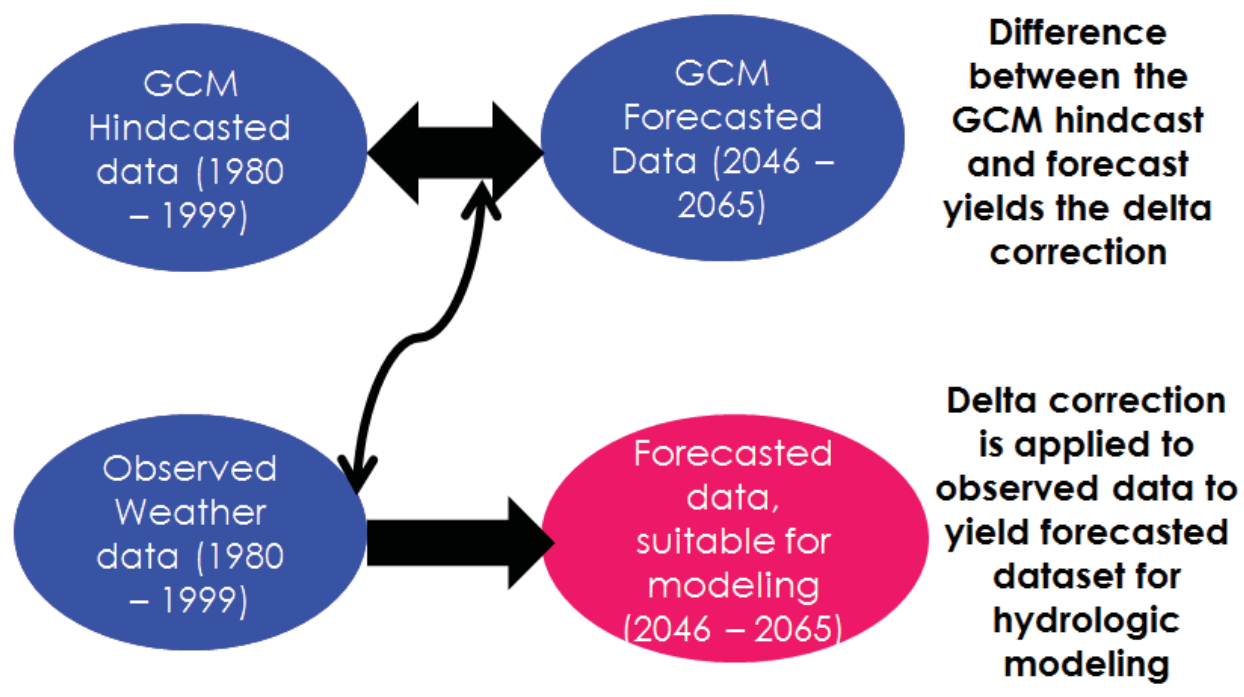

Figure 3.6 Visual representation of delta change method for climate data application.

It is also important to note that while the bias correction was only applied to precipitation data, the delta change method was applied to both temperature and precipitation data. This is due to the nature of the delta change method, as adjusted future series are created by shifting an observed series. On the contrary, the bias correction method is applied to an existing (simulated) future series, and thus the temperature does not need to be adjusted since differences between observed and hindcasted series are negligible anyhow.

Figures 3.7 and 3.8 show the effect of the respective data application methods on monthly precipitation averages. The solid blue line represents, in each case, the final set of data to be used in forcing the hydrologic model. The dashed blue line represents the dataset 
which was altered by either the bias or delta corrections in order to create the final dataset. The dashed and solid pink lines represent the two datasets used to calculate the needed bias or delta corrections.

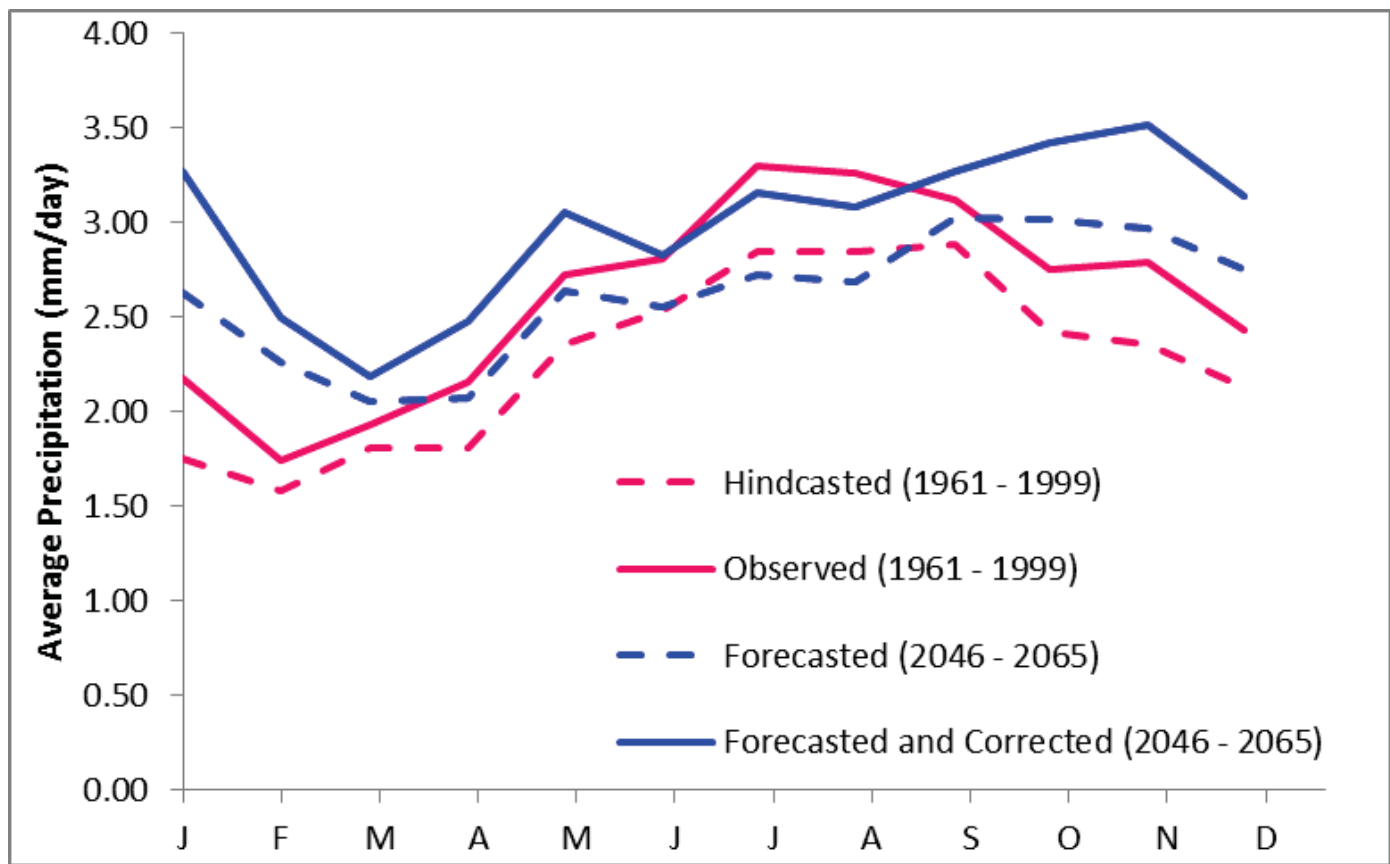

Figure 3.7 Monthly averaged observed, hindcasted, forecasted and bias corrected forecast precipitation ( $\mathrm{mm} /$ day) in the Fish River watershed (USGS Gage Station 01013500) corresponding to climate model cccma_cgcm3, emissions scenario a1b, and model run 3 . 


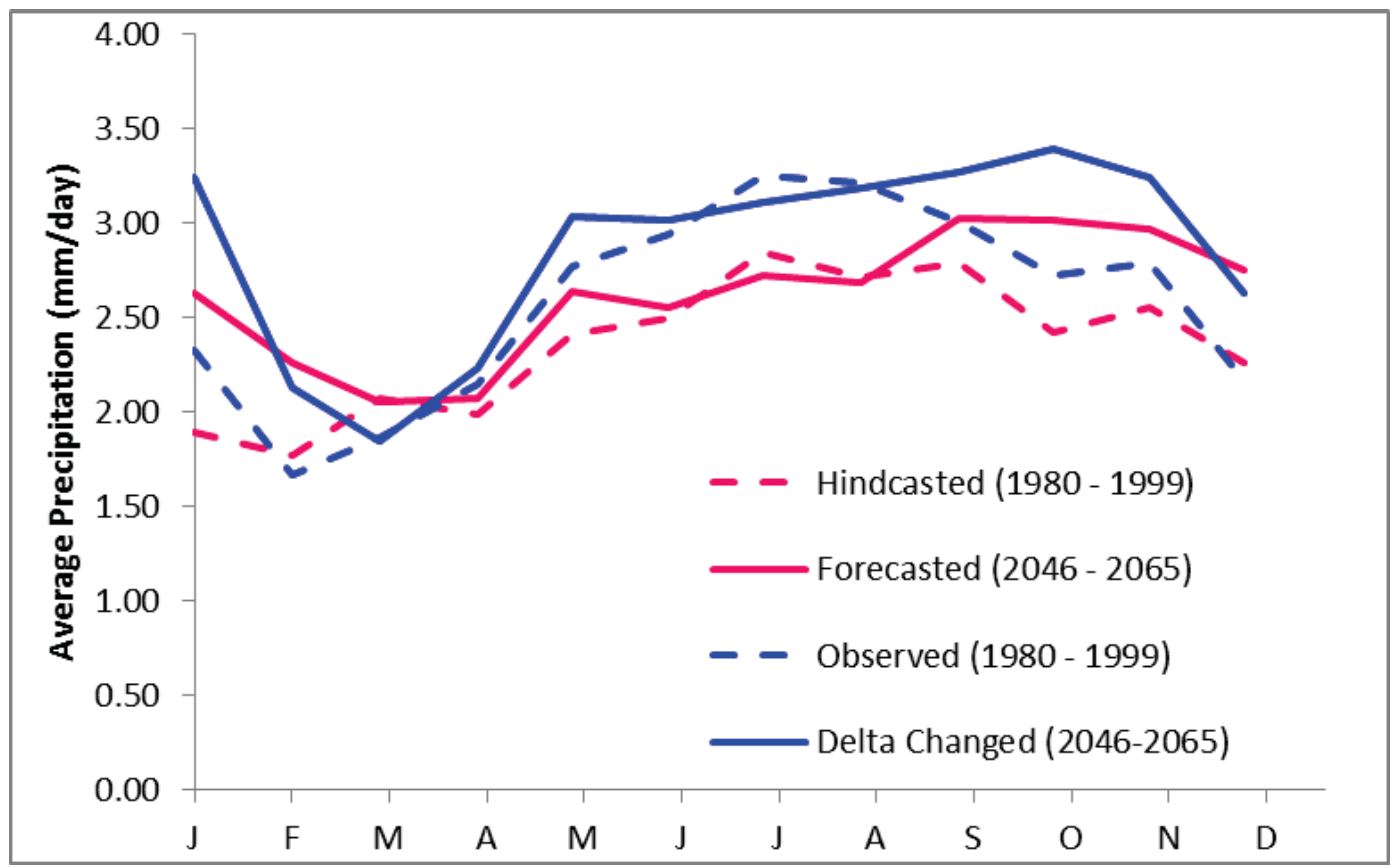

Figure 3.8 Monthly averaged hindcasted, forecasted, observed and delta changed precipitation ( $\mathrm{mm} /$ day) in the Fish River watershed (USGS Gage Station 01013500) corresponding to climate model cccma_cgcm3, emissions scenario a1b, and model run 3.

Tables 3.1 - 3.4 summarize, for each watershed, the nine selected combinations of GCMs, emissions scenarios, and runs, along with the corresponding overall changes in temperature and precipitation projected by each data application method. For both the bias correction method and the delta change method, the overall changes reported are relative to the period of 1961-1999 for consistency in comparison. Figures 3.9-3.16 illustrate the differences in the overall change projected by the two methods. In general, relatively similar changes in temperature are anticipated by the two methods, with a tendency for the bias corrected data to project mildly greater temperature changes. In regards to precipitation, an overall trend is not as clear, with the bias corrected data projecting larger total amounts of precipitation in two of the watersheds (01013500 and 03302000), a tendency for the delta change method to project larger total amounts of 
precipitation, if any, for watershed 03093000, and no discernible pattern for watershed 03144000.

Figures $3.17-3.20$ show clouds of $\Delta \mathrm{T}$ versus $\Delta \mathrm{P}$ similar to Figures $3.1-3.4$, except they show only the selected representative scenarios, and overlay the projected changes for the delta change method with those for the bias correction method. The bias correction data points are shown in blue, and the delta correction points are shown in pink. The median lines are the same as those utilized in Figures 3.1 - 3.4 based on the bias corrected data for all $53 \mathrm{GCM} / \mathrm{emission}$ scenario combinations. The purpose of Figures $3.17-3.20$ is to show the severity of the delta changed scenarios relative to the bias corrected scenarios. The results of hydrologic modeling (Chapter 5) will examine the two methods on a scenario-by-scenario basis, and consider the effects of the different scenario severities on modeled flows.

Table 3.5 contains the average monthly observed temperature and precipitation for the periods of 1961-1999 and 1980-1999 for each watershed, and Table 3.6 shows standard deviations for the same periods, corresponding to the time periods used for development of the bias and delta corrections, respectively. Relatively little difference is evident for either statistic between the two time periods, and no overarching patterns emerge. This is important because it suggests that there should be no large difference between the two data application methods due to the different observed time periods used to compute/apply them. For additional comparison, monthly averaged projected temperature 
and precipitation for the periods of 1961-1999, 1980-1999, and 2046-2065 are tabulated in Appendix A.

Table 3.1 Summary of selected GCM/emissions scenario/run combinations, and associated overall changes in temperature and precipitation projected by each climate data application method, relative to the baseline period of 1961-1999, for the Fish River watershed (USGS Gage Station 01013500).

\begin{tabular}{|c|c|c|c|c|c|}
\hline GCM & SRES & Run & Method & $\Delta \mathrm{T}\left({ }^{\circ} \mathrm{C}\right)$ & $\Delta \mathrm{P}(\%)$ \\
\hline \multirow{4}{*}{ cccma_cgcm3_1 } & \multirow{2}{*}{$\mathrm{a} 1 \mathrm{~b}$} & \multirow{2}{*}{3} & Bias Correction & 2.66 & $15.01 \%$ \\
\hline & & & Delta Change & 2.40 & $9.95 \%$ \\
\hline & \multirow{2}{*}{ b1 } & \multirow{2}{*}{2} & Bias Correction & 1.95 & $9.99 \%$ \\
\hline & & & Delta Change & 1.58 & $6.14 \%$ \\
\hline \multirow{2}{*}{ gfdl_cm2_1 } & \multirow{2}{*}{$\mathrm{a} 2$} & \multirow{2}{*}{1} & Bias Correction & 2.48 & $7.17 \%$ \\
\hline & & & Delta Change & 2.51 & $4.63 \%$ \\
\hline \multirow{4}{*}{ ipsl_cm4 } & \multirow{2}{*}{ alb } & \multirow[b]{2}{*}{1} & Bias Correction & 4.35 & $10.84 \%$ \\
\hline & & & Delta Change & 4.18 & $9.24 \%$ \\
\hline & \multirow{2}{*}{$\mathrm{a} 2$} & \multirow{2}{*}{1} & Bias Correction & 3.86 & $4.18 \%$ \\
\hline & & & Delta Change & 3.69 & $2.54 \%$ \\
\hline \multirow{2}{*}{ miroc3_2_medres } & \multirow{2}{*}{$\mathrm{b} 1$} & \multirow{2}{*}{2} & Bias Correction & 2.99 & $4.75 \%$ \\
\hline & & & Delta Change & 3.03 & $5.08 \%$ \\
\hline \multirow{2}{*}{ miub_echo_g } & \multirow{2}{*}{$\mathrm{a} 1 \mathrm{~b}$} & \multirow{2}{*}{2} & Bias Correction & 2.98 & $10.29 \%$ \\
\hline & & & Delta Change & 2.71 & $7.39 \%$ \\
\hline \multirow{4}{*}{ mri_cgcm2_3_2a } & \multirow{2}{*}{$\mathrm{a} 2$} & \multirow{2}{*}{5} & Bias Correction & 1.93 & $5.08 \%$ \\
\hline & & & Delta Change & 1.87 & $3.45 \%$ \\
\hline & \multirow{2}{*}{ b1 } & \multirow[b]{2}{*}{1} & Bias Correction & 1.28 & $6.60 \%$ \\
\hline & & & Delta Change & 1.14 & $8.08 \%$ \\
\hline
\end{tabular}


Table 3.2 Summary of selected GCM/emissions scenario/run combinations, and associated overall changes in temperature and precipitation projected by each climate data application method, relative to the baseline period of 1961-1999, for the Eagle Creek watershed (USGS Gage Station 03093000).

\begin{tabular}{|c|c|c|c|c|c|}
\hline GCM & SRES & Run & Method & $\Delta \mathrm{T}\left({ }^{\circ} \mathrm{C}\right)$ & $\Delta \mathrm{P}(\%)$ \\
\hline \multirow{4}{*}{ cccma_cgcm3_1 } & \multirow{2}{*}{$\mathrm{a} 2$} & \multirow{2}{*}{2} & Bias Correction & 3.01 & $8.79 \%$ \\
\hline & & & Delta Change & 2.73 & $11.36 \%$ \\
\hline & \multirow{2}{*}{ b1 } & \multirow{2}{*}{2} & Bias Correction & 2.15 & $1.11 \%$ \\
\hline & & & Delta Change & 1.86 & $3.38 \%$ \\
\hline \multirow{2}{*}{ cnrm_cm3 } & \multirow{2}{*}{$\mathrm{a} 1 \mathrm{~b}$} & \multirow{2}{*}{1} & Bias Correction & 2.42 & $13.50 \%$ \\
\hline & & & Delta Change & 2.22 & $14.61 \%$ \\
\hline \multirow{2}{*}{ gfdl_cm2 } & \multirow{2}{*}{$\mathrm{a} 2$} & \multirow{2}{*}{1} & Bias Correction & 2.56 & $3.55 \%$ \\
\hline & & & Delta Change & 2.57 & $7.70 \%$ \\
\hline \multirow{2}{*}{ ipsl_cm4 } & \multirow{2}{*}{$\mathrm{a} 1 \mathrm{~b}$} & \multirow{2}{*}{1} & Bias Correction & 4.24 & $4.38 \%$ \\
\hline & & & Delta Change & 4.04 & $4.96 \%$ \\
\hline \multirow{2}{*}{ miroc3_2_medres } & \multirow{2}{*}{ alb } & \multirow{2}{*}{1} & Bias Correction & 3.78 & $-7.49 \%$ \\
\hline & & & Delta Change & 3.61 & $-5.09 \%$ \\
\hline \multirow{2}{*}{ mpi_echam5 } & \multirow{2}{*}{$\mathrm{a} 2$} & \multirow{2}{*}{1} & Bias Correction & 2.20 & $8.58 \%$ \\
\hline & & & Delta Change & 2.10 & $8.20 \%$ \\
\hline \multirow{2}{*}{ mri_cgcm2_3_2a } & \multirow{2}{*}{ b1 } & \multirow{2}{*}{4} & Bias Correction & 1.70 & $0.36 \%$ \\
\hline & & & Delta Change & 1.59 & $4.98 \%$ \\
\hline \multirow{2}{*}{ ipsl_cm4 } & \multirow{2}{*}{ b1 } & \multirow{2}{*}{1} & Bias Correction & 2.86 & $1.07 \%$ \\
\hline & & & Delta Change & 2.66 & $1.58 \%$ \\
\hline
\end{tabular}


Table 3.3 Summary of selected GCM/emissions scenario/run combinations, and associated overall changes in temperature and precipitation projected by each climate data application method, relative to the baseline period of 1961-1999, for the Wakatomika Creek watershed (USGS Gage Station 03144000).

\begin{tabular}{|c|c|c|c|c|c|}
\hline GCM & SRES & Run & Method & $\Delta \mathrm{T}\left({ }^{\circ} \mathrm{C}\right)$ & $\Delta \mathrm{P}(\%)$ \\
\hline \multirow{6}{*}{ cccma_cgcm3_1 } & \multirow{2}{*}{$\mathrm{a} 1 \mathrm{~b}$} & \multirow{2}{*}{1} & Bias Correction & 3.06 & $8.52 \%$ \\
\hline & & & Delta Change & 2.79 & $4.89 \%$ \\
\hline & \multirow{4}{*}{ b1 } & \multirow{2}{*}{1} & Bias Correction & 2.05 & $8.71 \%$ \\
\hline & & & Delta Change & 1.77 & $5.13 \%$ \\
\hline & & \multirow{2}{*}{2} & Bias Correction & 2.15 & $1.22 \%$ \\
\hline & & & Delta Change & 1.89 & $2.43 \%$ \\
\hline \multirow{2}{*}{ cnrm_cm3 } & \multirow{2}{*}{$\mathrm{a} 1 \mathrm{~b}$} & \multirow{2}{*}{1} & Bias Correction & 2.48 & $13.65 \%$ \\
\hline & & & Delta Change & 2.28 & $13.41 \%$ \\
\hline \multirow{2}{*}{ gfdl_cm2_1 } & \multirow{2}{*}{$\mathrm{a} 1 \mathrm{~b}$} & \multirow{2}{*}{1} & Bias Correction & 3.01 & $1.86 \%$ \\
\hline & & & Delta Change & 3.03 & $4.76 \%$ \\
\hline \multirow{2}{*}{ miroc3_2_medres } & \multirow{2}{*}{ a1b } & \multirow{2}{*}{2} & Bias Correction & 3.96 & $-7.08 \%$ \\
\hline & & & Delta Change & 4.04 & $-7.14 \%$ \\
\hline \multirow{6}{*}{ mri_cgcm2_3_2a } & \multirow{2}{*}{$\mathrm{a} 2$} & \multirow{2}{*}{2} & Bias Correction & 2.38 & $5.48 \%$ \\
\hline & & & Delta Change & 2.52 & $4.59 \%$ \\
\hline & \multirow{4}{*}{ b1 } & \multirow{2}{*}{3} & Bias Correction & 1.40 & $11.04 \%$ \\
\hline & & & Delta Change & 1.11 & $7.73 \%$ \\
\hline & & \multirow{2}{*}{4} & Bias Correction & 1.67 & $-0.45 \%$ \\
\hline & & & Delta Change & 1.60 & $1.90 \%$ \\
\hline
\end{tabular}


Table 3.4 Summary of selected GCM/emissions scenario/run combinations, and associated overall changes in temperature and precipitation projected by each climate data application method, relative to the baseline period of 1961-1999, for the Pond Creek watershed (USGS Gage Station 03302000).

\begin{tabular}{|c|c|c|c|c|c|}
\hline GCM & SRES & Run & Method & $\Delta \mathrm{T}\left({ }^{\circ} \mathrm{C}\right)$ & $\Delta \mathrm{P}(\%)$ \\
\hline \multirow{6}{*}{ cccma_cgcm3_1 } & \multirow{2}{*}{ a2 } & \multirow{2}{*}{3} & Bias Correction & 2.72 & $8.76 \%$ \\
\hline & & & Delta Change & 2.67 & $1.72 \%$ \\
\hline & \multirow{4}{*}{ b1 } & \multirow{2}{*}{2} & Bias Correction & 2.01 & $1.02 \%$ \\
\hline & & & Delta Change & 1.86 & $-4.38 \%$ \\
\hline & & \multirow{2}{*}{3} & Bias Correction & 1.95 & $9.25 \%$ \\
\hline & & & Delta Change & 1.90 & $2.51 \%$ \\
\hline \multirow{2}{*}{ cnrm_cm3 } & \multirow{2}{*}{$\mathrm{a} 1 \mathrm{~b}$} & \multirow{2}{*}{1} & Bias Correction & 2.48 & $6.19 \%$ \\
\hline & & & Delta Change & 2.23 & $2.30 \%$ \\
\hline \multirow{2}{*}{ ipsl_cm4 } & \multirow{2}{*}{$\mathrm{a} 1 \mathrm{~b}$} & \multirow{2}{*}{1} & Bias Correction & 3.88 & $5.49 \%$ \\
\hline & & & Delta Change & 3.75 & $-1.00 \%$ \\
\hline \multirow{4}{*}{$\begin{array}{c}\text { miroc3_2 } \\
\text { _medres }\end{array}$} & \multirow{2}{*}{ alb } & \multirow{2}{*}{1} & Bias Correction & 3.68 & $-12.45 \%$ \\
\hline & & & Delta Change & 3.62 & $-16.71 \%$ \\
\hline & \multirow{2}{*}{ b1 } & \multirow{2}{*}{2} & Bias Correction & 2.80 & $0.80 \%$ \\
\hline & & & Delta Change & 2.84 & $-5.62 \%$ \\
\hline \multirow{4}{*}{$\begin{array}{c}\text { mri_cgcm } 2 \\
-3 \_2 \mathrm{a}\end{array}$} & \multirow{2}{*}{ a2 } & \multirow{2}{*}{1} & Bias Correction & 1.90 & $12.58 \%$ \\
\hline & & & Delta Change & 1.82 & $7.53 \%$ \\
\hline & \multirow{2}{*}{ b1 } & & Bias Correction & 1.63 & $1.03 \%$ \\
\hline & & & Delta Change & 1.52 & $-2.40 \%$ \\
\hline
\end{tabular}




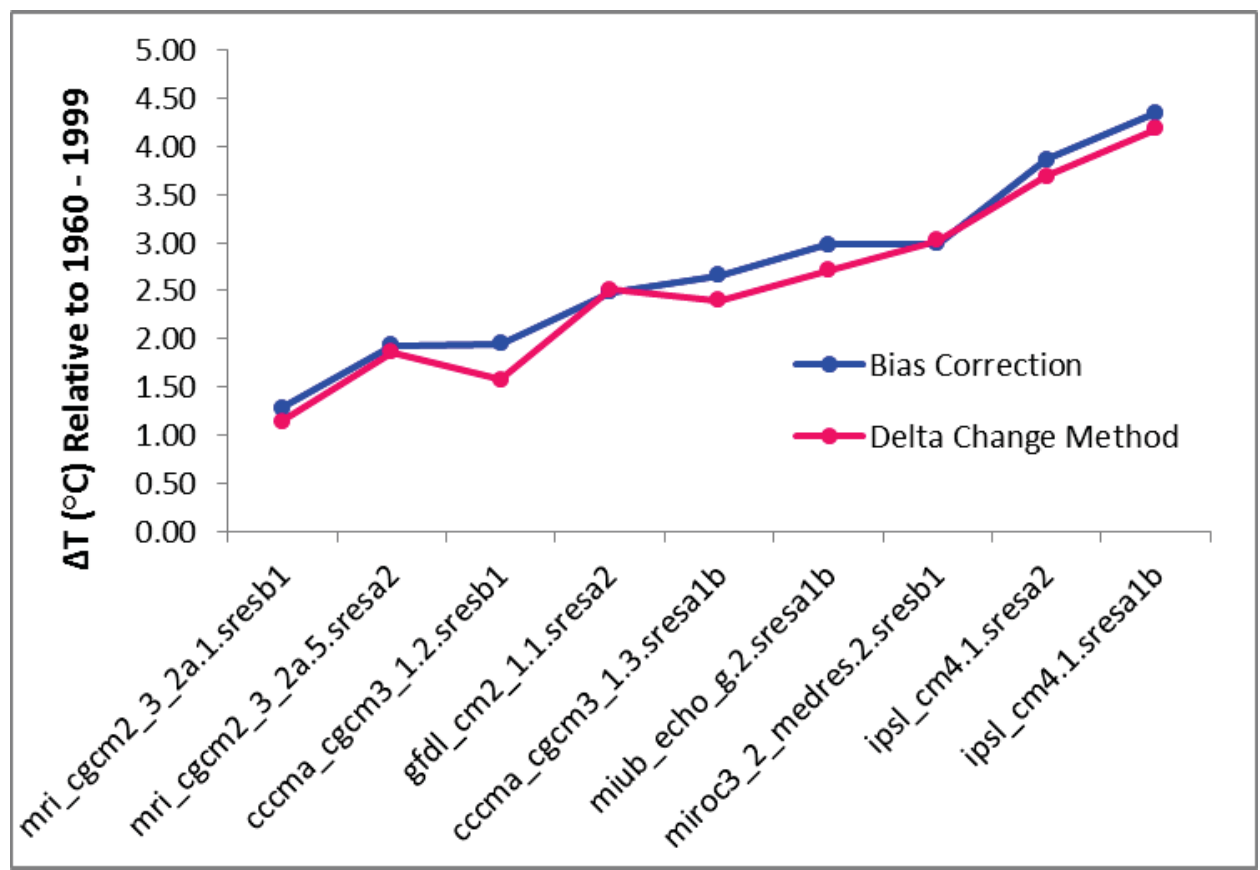

Figure 3.9 Overall changes in temperature projected by each data application method, relative to the baseline period of 1961-1999, for the nine representative climate scenarios for the Fish River watershed (USGS Gage Station 01013500).

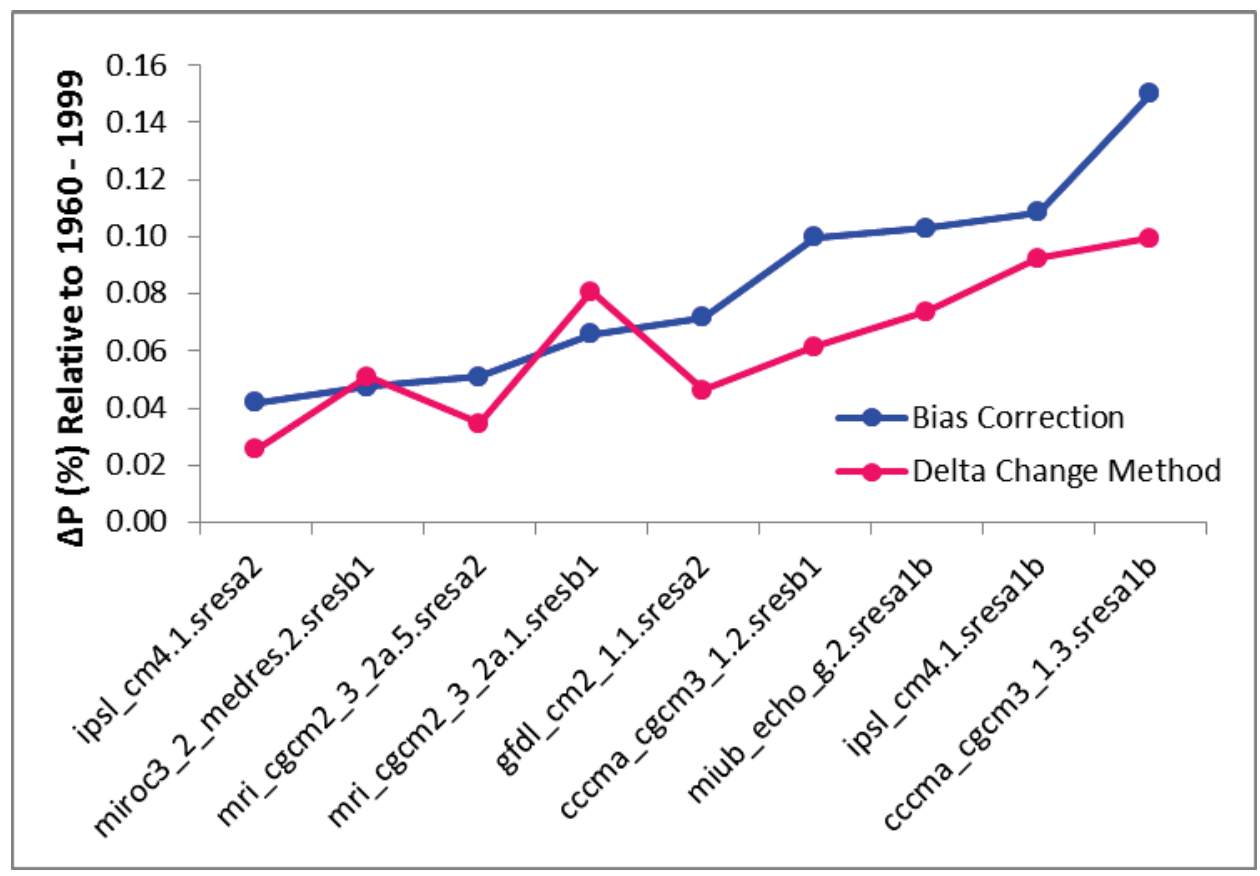

Figure 3.10 Overall changes in precipitation projected by each data application method, relative to the baseline period of 1961-1999, for the nine representative climate scenarios for the Fish River watershed (USGS Gage Station 01013500). 


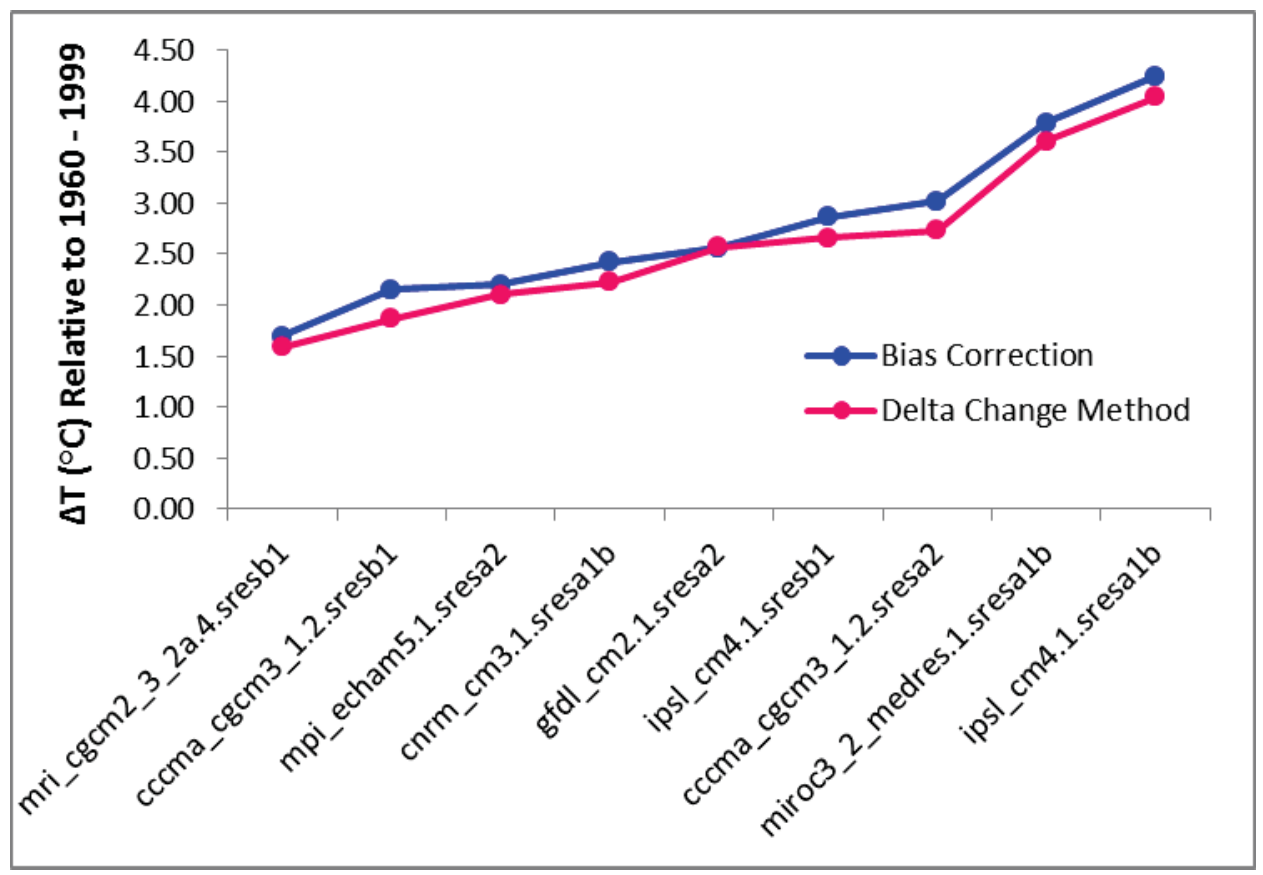

Figure 3.11 Overall changes in temperature projected by each data application method, relative to the baseline period of 1961-1999, for the nine representative climate scenarios for the Eagle Creek watershed (USGS Gage Station 03093000).

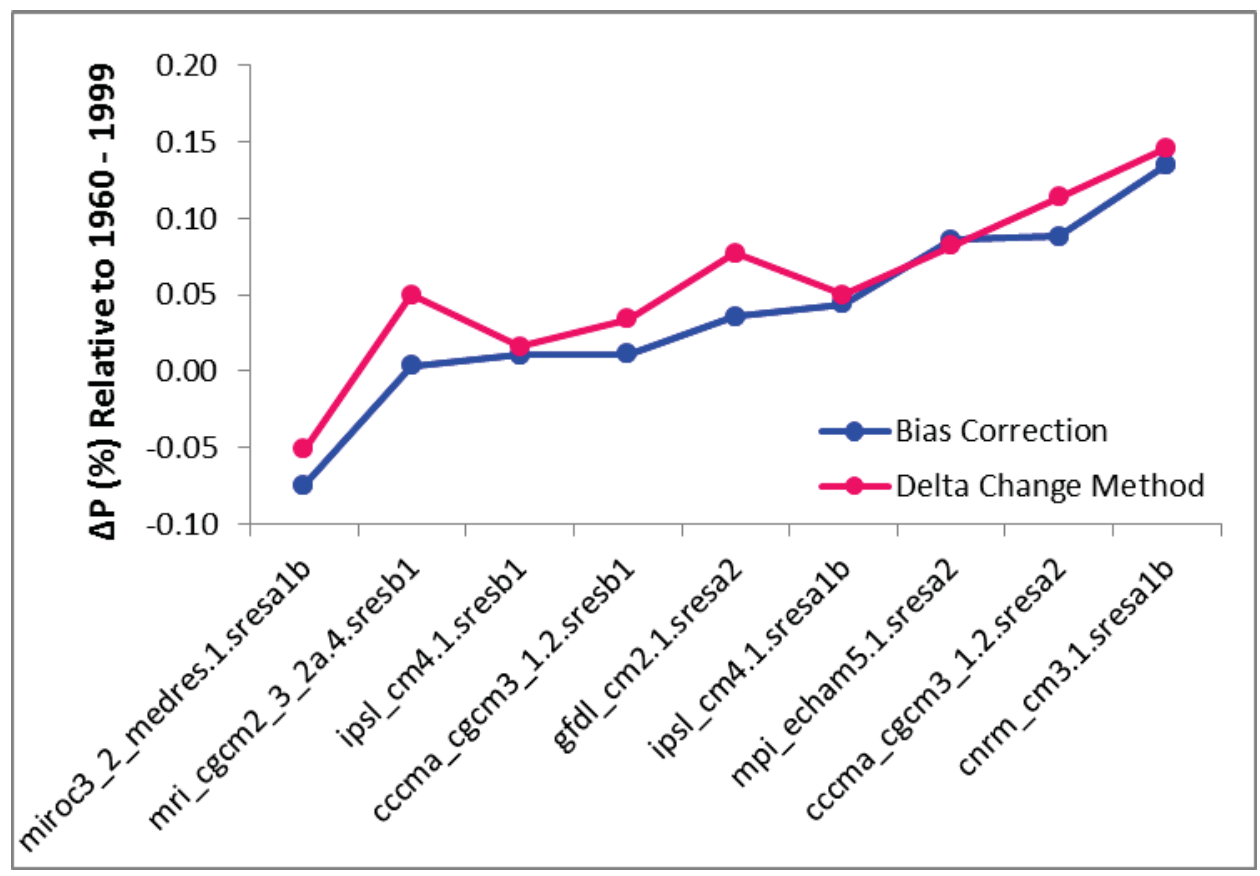

Figure 3.12 Overall changes in precipitation projected by each data application method, relative to the baseline period of 1961-1999, for the nine representative climate scenarios for the Eagle Creek watershed (USGS Gage Station 03093000). 


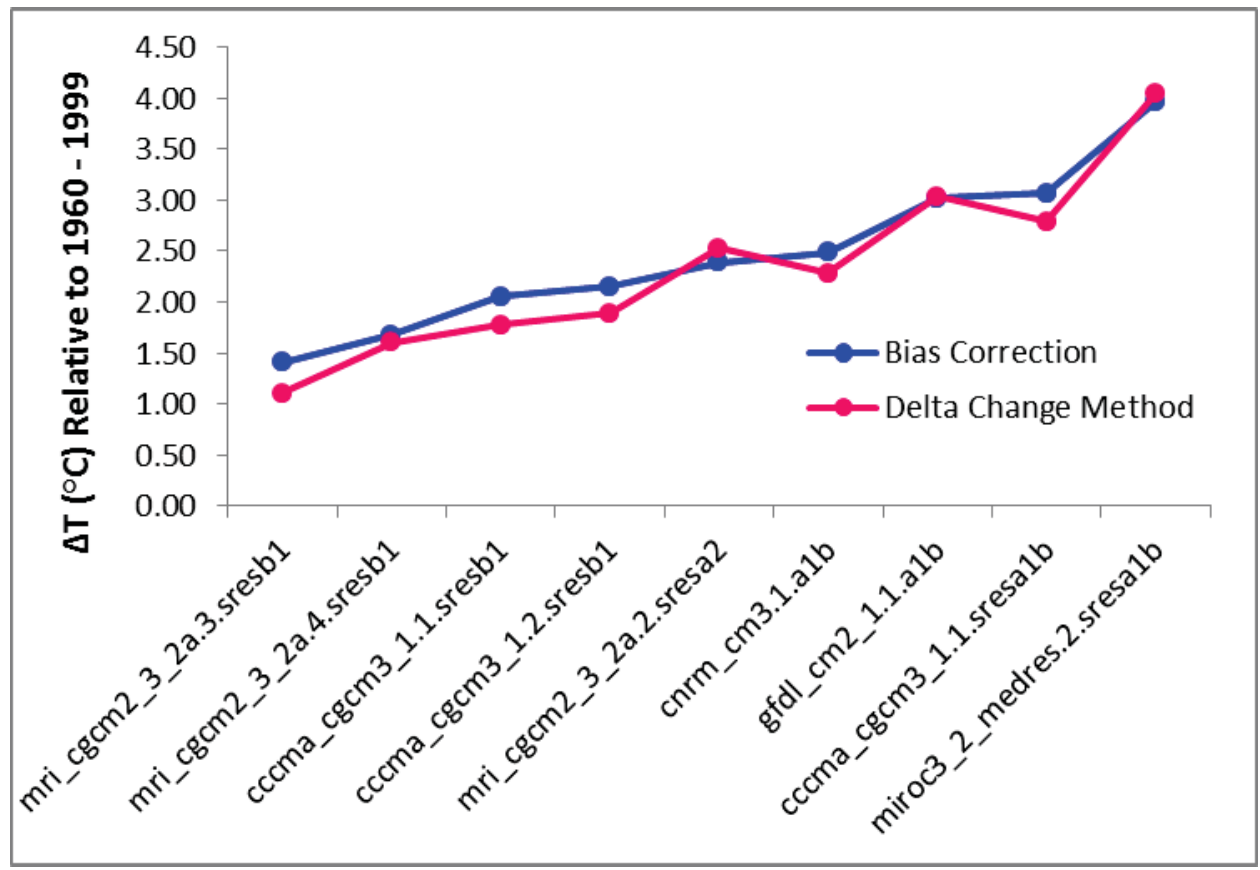

Figure 3.13 Overall changes in temperature projected by each data application method, relative to the baseline period of 1961-1999, for all selected GCM/emissions scenario/run combinations, for the Wakatomika Creek watershed (USGS Gage Station 03144000).

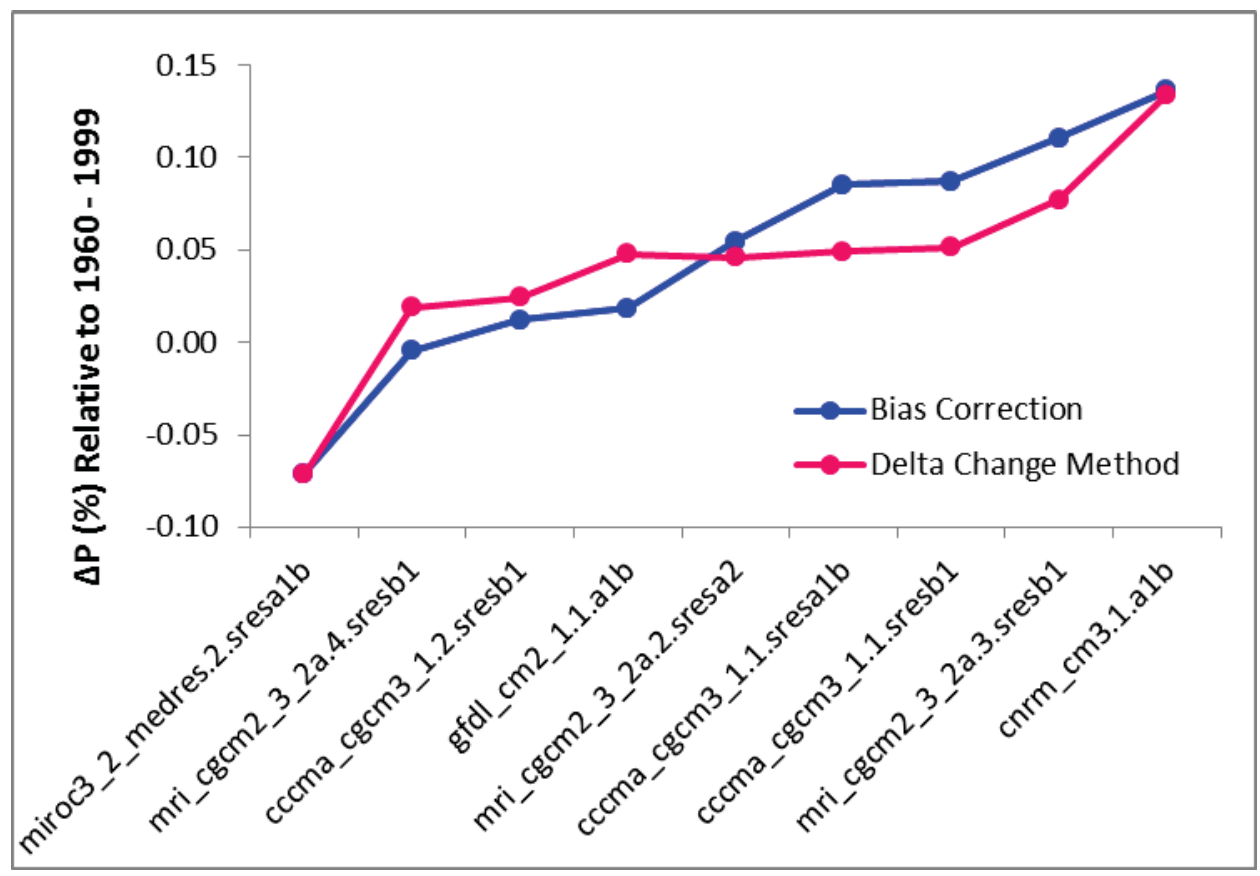

Figure 3.14 Overall changes in precipitation projected by each data application method, relative to the baseline period of 1961-1999, for all selected GCM/emissions scenario/run combinations, for the Wakatomika Creek watershed (USGS Gage Station 03144000). 


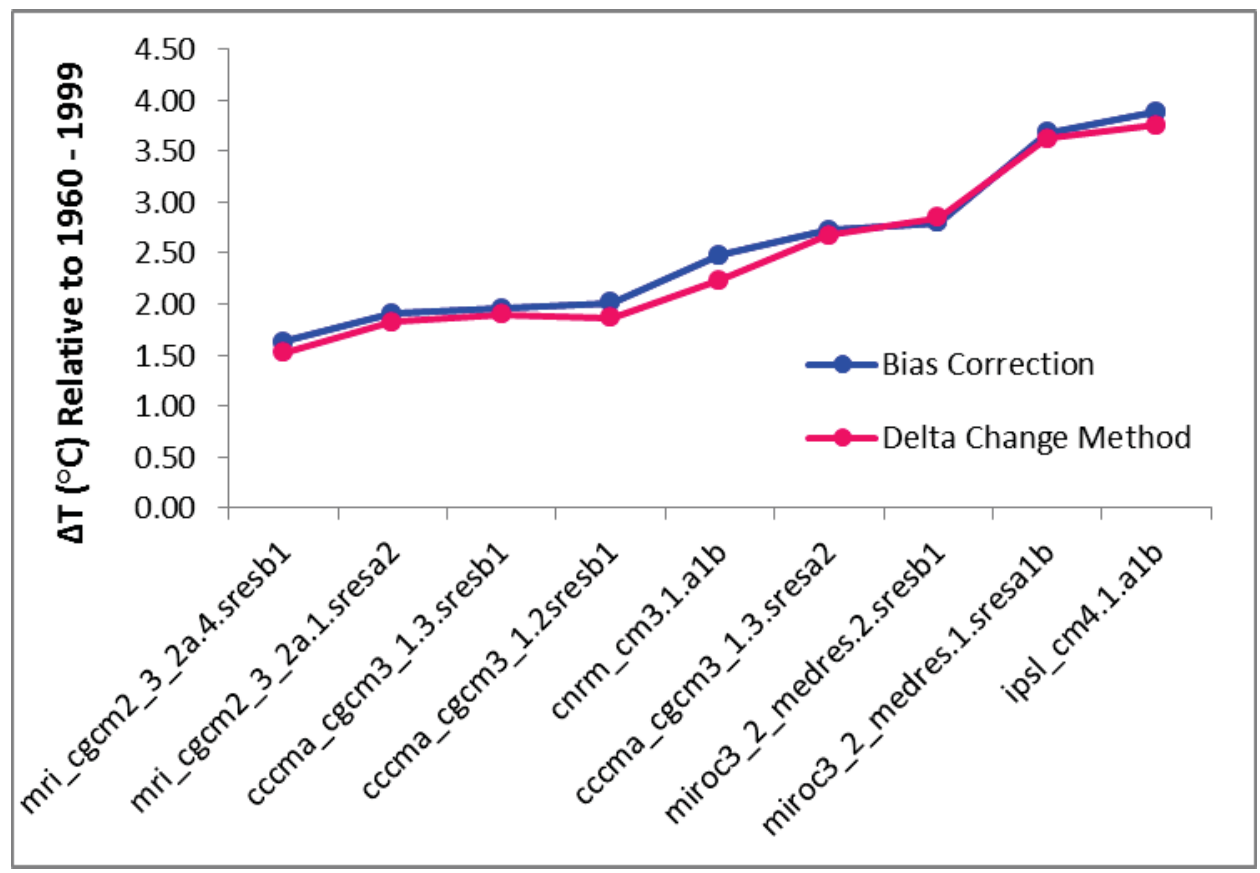

Figure 3.15 Overall changes in temperature projected by each data application method, relative to the baseline period of 1961-1999, for all selected GCM/emissions scenario/run combinations, for the Pond Creek watershed (USGS Gage Station 03302000).

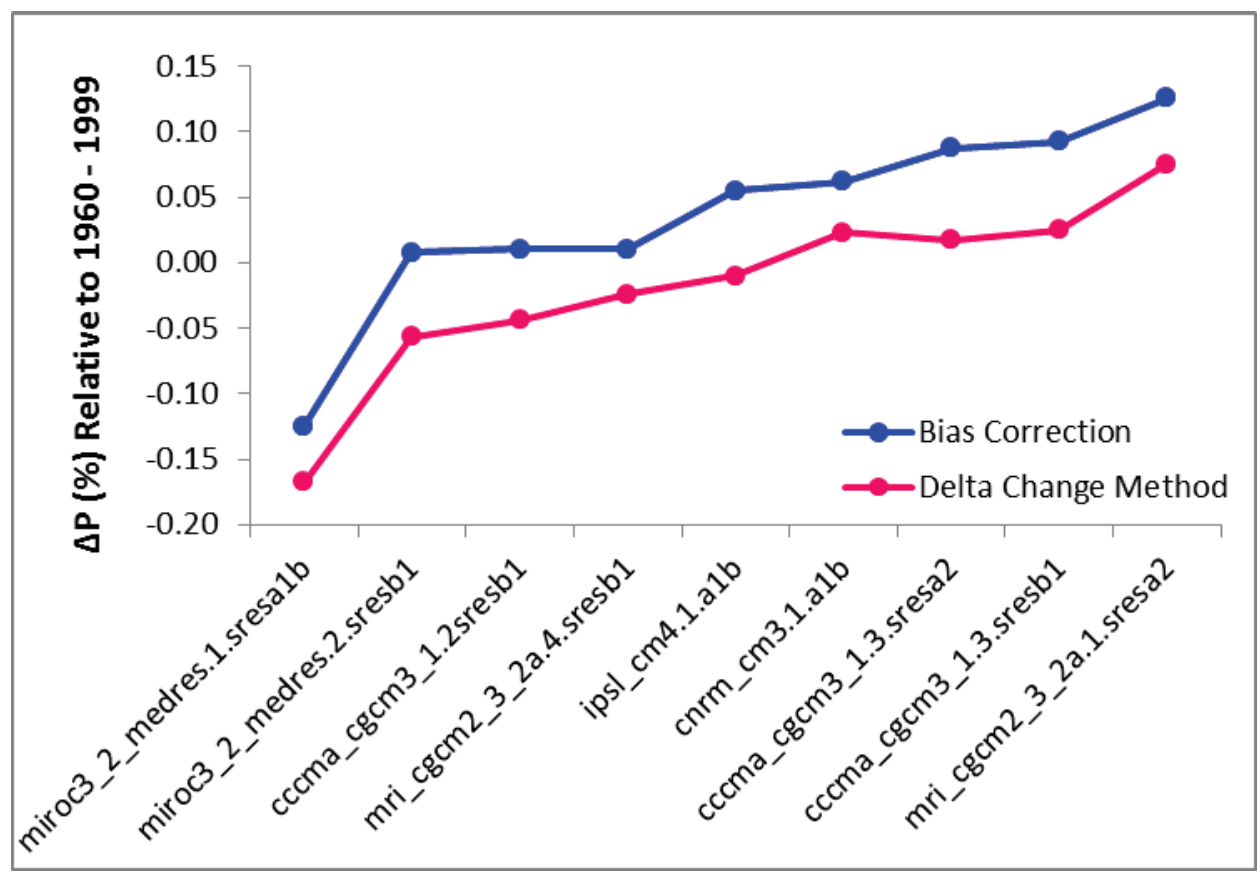

Figure 3.16 Overall changes in precipitation projected by each data application method, relative to the baseline period of 1961-1999, for all selected GCM/emissions scenario/run combinations, for the Pond Creek watershed (USGS Gage Station 03302000). 


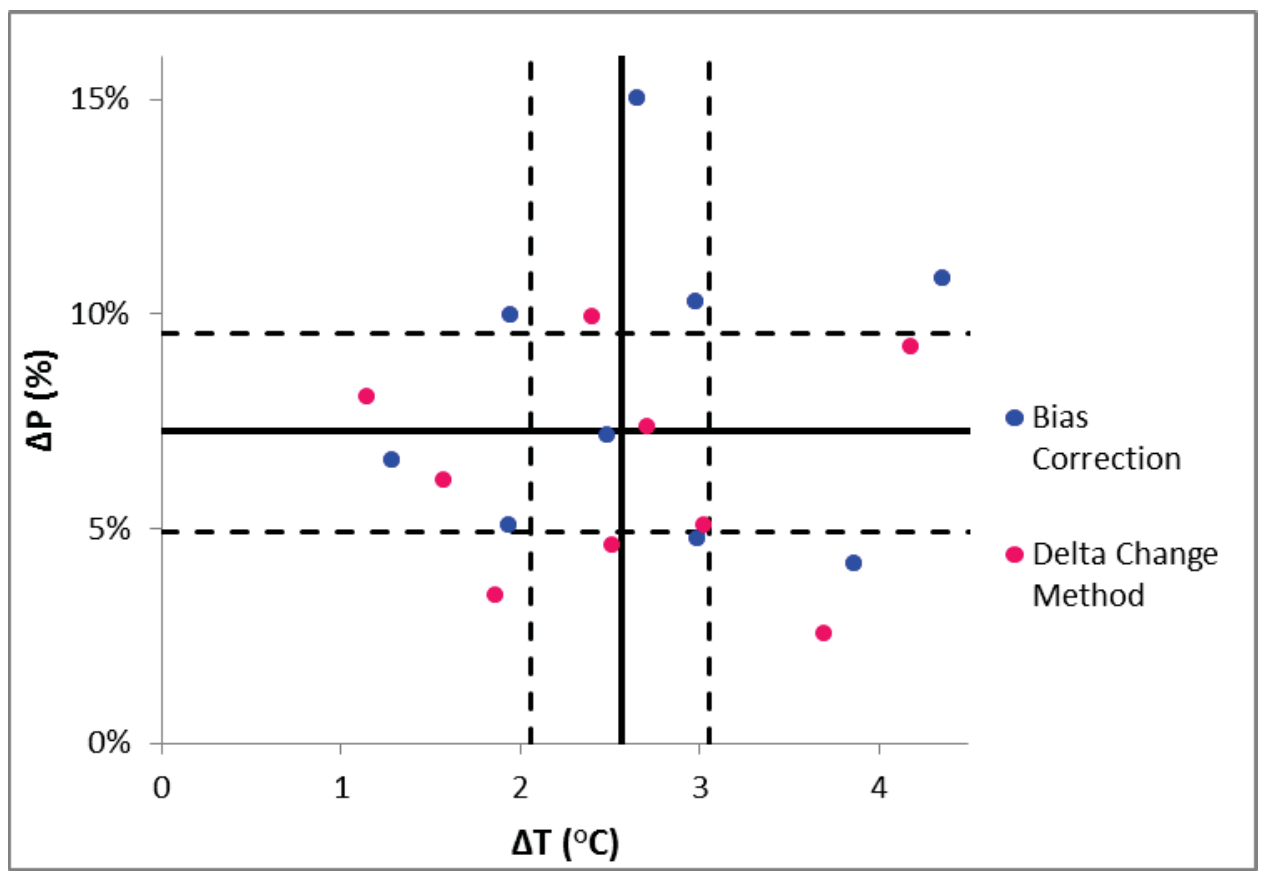

Figure 3.17 Absolute change in temperature and percent change in precipitation for both bias corrected and delta changed data of 9 representative climate projections for the Fish River watershed upstream of USGS Gage Station 01013500.

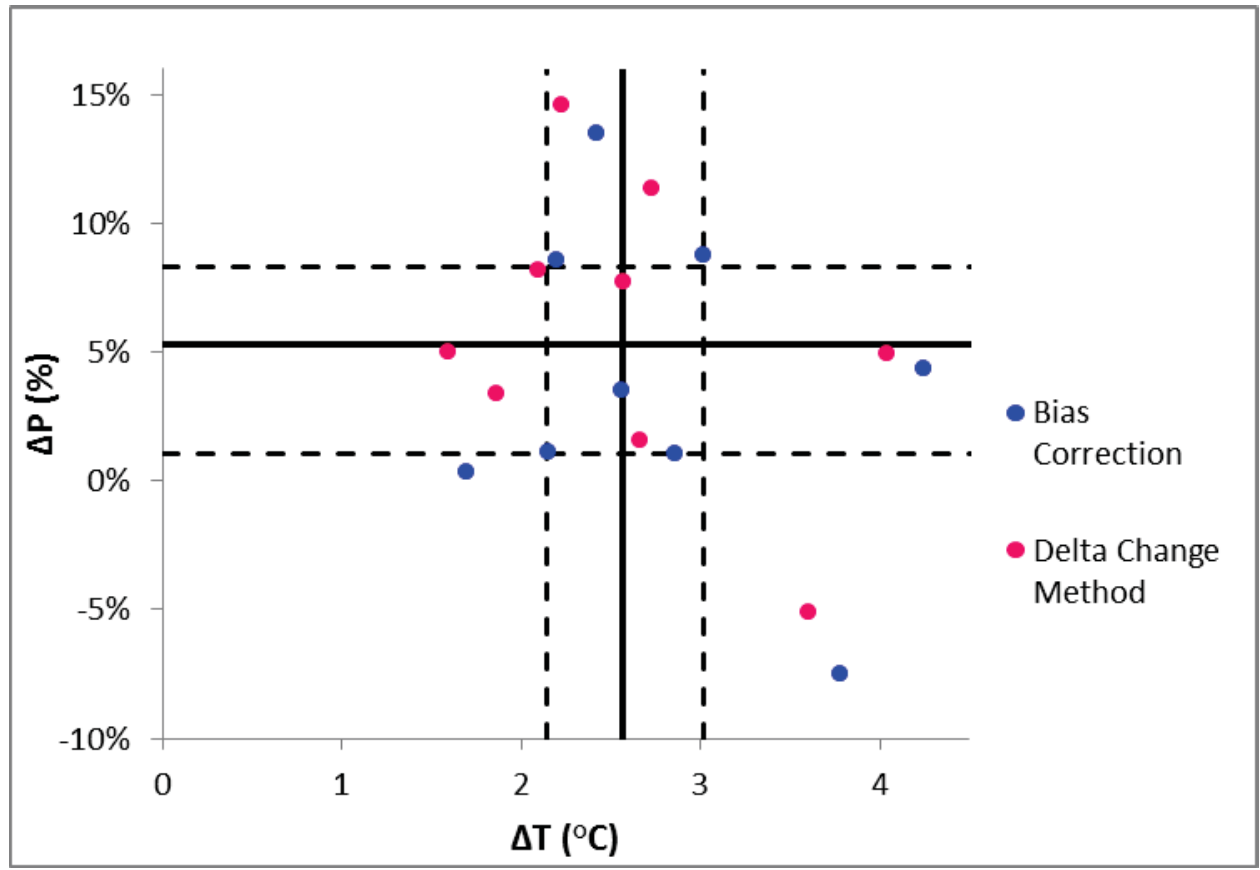

Figure 3.18 Absolute change in temperature and percent change in precipitation for both bias corrected and delta changed data of 9 representative climate projections for the Eagle Creek watershed upstream of USGS Gage Station 03093000. 


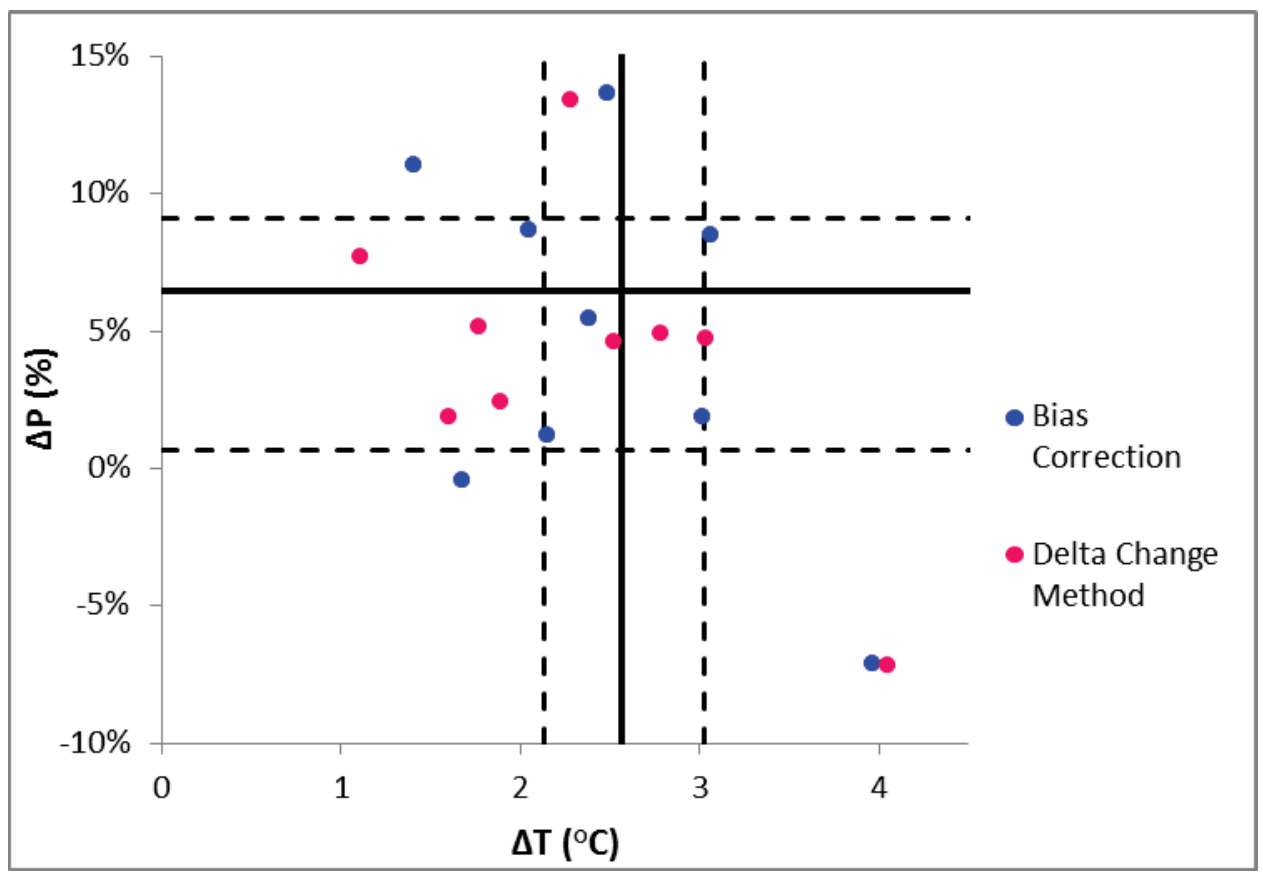

Figure 3.19 Absolute change in temperature and percent change in precipitation for both bias corrected and delta changed data of 9 representative climate projections for the Wakatomika Creek watershed upstream of USGS Gage Station 03144000.

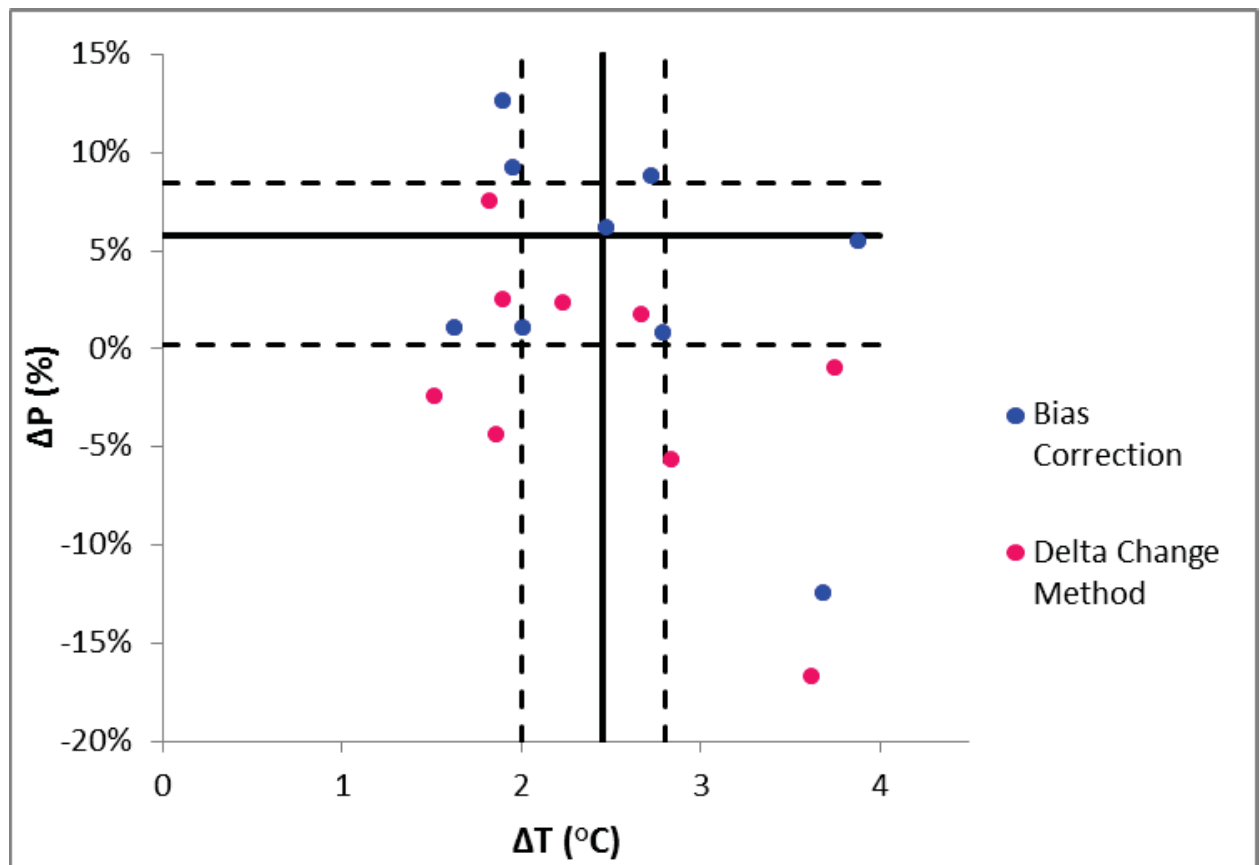

Figure 3.20 Absolute change in temperature and percent change in precipitation for both bias corrected and delta changed data of 9 representative climate projections for the Pond Creek watershed upstream of USGS Gage Station 03302000. 
Table 3.5 Means of observed daily temperature $\left({ }^{\circ} \mathrm{C}\right)$ and precipitation $(\mathrm{mm})$ calculated for each month and each watershed over the periods of 1961-1999 and 1980-1999.

\begin{tabular}{|c|c|c|c|c|c|c|c|c|c|}
\hline & \multicolumn{2}{|c|}{01013500} & \multicolumn{2}{|c|}{03093000} & \multicolumn{2}{|c|}{03144000} & \multicolumn{2}{|c|}{03302000} \\
\hline & & $\mathbf{T}$ & $\mathbf{P}$ & $\mathbf{T}$ & $\mathbf{P}$ & $\mathbf{T}$ & $\mathbf{P}$ & $\mathbf{T}$ & $\mathbf{P}$ \\
\hline \multirow{12}{*}{ 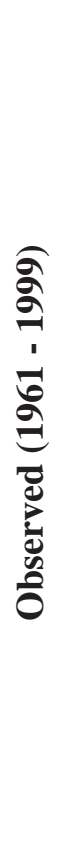 } & $\mathbf{J}$ & -13.85 & 2.18 & -3.95 & 1.89 & -3.62 & 2.06 & 0.36 & 2.58 \\
\hline & $\mathbf{F}$ & -12.44 & 1.74 & -2.55 & 1.77 & -1.89 & 1.99 & 2.67 & 2.94 \\
\hline & $\mathbf{M}$ & -5.61 & 1.93 & 2.76 & 2.43 & 3.71 & 2.68 & 8.05 & 3.83 \\
\hline & $\mathbf{A}$ & 1.97 & 2.16 & 8.87 & 2.84 & 9.50 & 3.04 & 13.64 & 3.46 \\
\hline & $\mathbf{M}$ & 9.43 & 2.72 & 14.67 & 2.86 & 15.14 & 3.29 & 18.68 & 3.86 \\
\hline & $\mathbf{J}$ & 15.14 & 2.81 & 19.49 & 3.18 & 19.99 & 3.39 & 23.21 & 3.31 \\
\hline & $\mathbf{J}$ & 17.73 & 3.30 & 21.75 & 3.23 & 22.10 & 3.60 & 25.35 & 3.54 \\
\hline & $\mathbf{A}$ & 16.37 & 3.26 & 20.86 & 2.73 & 21.16 & 2.95 & 24.52 & 2.88 \\
\hline & $\mathbf{S}$ & 11.34 & 3.12 & 17.14 & 3.02 & 17.43 & 2.55 & 20.83 & 2.62 \\
\hline & $\mathbf{O}$ & 5.31 & 2.75 & 11.02 & 2.29 & 11.05 & 2.00 & 14.45 & 2.31 \\
\hline & $\mathbf{N}$ & -1.53 & 2.79 & 5.09 & 2.75 & 5.16 & 2.70 & 8.43 & 3.04 \\
\hline & D & -9.76 & 2.43 & -0.8 & 2.3 & -0.60 & 2.29 & 3.01 & 3.14 \\
\hline \multirow{12}{*}{ 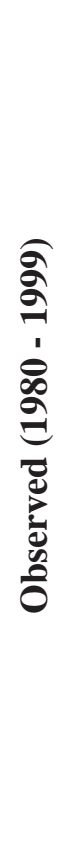 } & $\mathbf{J}$ & -14.1 & 2.33 & -3.3 & 1.9 & -2.9 & 2.12 & 0.99 & 2.52 \\
\hline & $\mathbf{F}$ & -12.25 & 1.66 & -1.72 & 1.8 & -1.02 & 2.09 & 3.37 & 3.01 \\
\hline & M & -5.91 & 1.86 & 2.60 & 2.3 & 3.5 & 2.50 & 7.87 & 3.44 \\
\hline & $\mathbf{A}$ & 2.40 & 2.15 & 8.99 & 2.8 & 9.51 & 2.92 & 13.35 & 3.05 \\
\hline & $\mathbf{M}$ & 9.71 & 2.77 & 14.68 & 2.97 & 15.15 & 3.54 & 18.68 & 4.09 \\
\hline & $\mathbf{J}$ & 14.88 & 2.94 & 19.47 & 3.36 & 20.04 & 3.69 & 23.30 & 3.42 \\
\hline & $\mathbf{J}$ & 17.69 & 3.25 & 22.07 & 3.40 & 22.45 & 3.68 & 25.79 & 3.19 \\
\hline & $\mathbf{A}$ & 16.58 & 3.22 & 21.02 & 2.78 & 21.33 & 2.82 & 24.80 & 2.59 \\
\hline & $\mathbf{S}$ & 11.39 & 3.01 & 17.01 & 3.10 & 17.31 & 2.31 & 20.83 & 2.18 \\
\hline & O & 5.05 & 2.72 & 10.82 & 2.40 & 10.91 & 2.07 & 14.46 & 2.35 \\
\hline & $\mathbf{N}$ & -1.65 & 2.79 & 5.05 & 2.96 & 5.19 & 2.91 & 8.52 & 3.06 \\
\hline & D & -9.58 & 2.17 & -0.60 & 2.32 & -0.35 & 2.32 & 3.02 & 3.11 \\
\hline
\end{tabular}


Table 3.6 Standard deviations of observed daily temperature $\left({ }^{\circ} \mathrm{C}\right)$ and precipitation $(\mathrm{mm})$ calculated for each month/watershed over the periods of 1961-1999 and 1980-1999.

\begin{tabular}{|c|c|c|c|c|c|c|c|c|c|}
\hline & \multicolumn{2}{|c|}{01013500} & \multicolumn{2}{|c|}{03093000} & \multicolumn{2}{|c|}{03144000} & \multicolumn{2}{|c|}{03302000} \\
\hline & & $\mathbf{T}$ & $\mathbf{P}$ & $\mathbf{T}$ & $\mathbf{P}$ & $\mathbf{T}$ & $\mathbf{P}$ & $\mathbf{T}$ & $\mathbf{P}$ \\
\hline \multirow{12}{*}{ 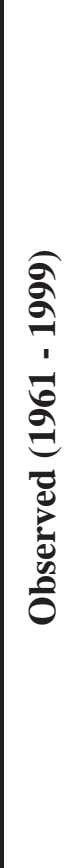 } & $\mathbf{J}$ & 9.71 & 3.79 & 7.95 & 3.24 & 8.36 & 3.82 & 8.45 & 5.68 \\
\hline & $\mathbf{F}$ & 10.05 & 3.23 & 8.11 & 3.06 & 8.35 & 3.88 & 8.50 & 6.71 \\
\hline & $\mathbf{M}$ & 9.32 & 3.45 & 8.42 & 3.96 & 8.59 & 4.72 & 8.57 & 8.54 \\
\hline & $\mathbf{A}$ & 7.27 & 3.62 & 8.53 & 4.34 & 8.65 & 4.96 & 8.43 & 6.84 \\
\hline & $\mathbf{M}$ & 8.36 & 4.41 & 8.25 & 4.43 & 8.33 & 5.12 & 7.64 & 7.61 \\
\hline & $\mathbf{J}$ & 8.04 & 4.17 & 7.64 & 5.12 & 7.64 & 5.75 & 6.87 & 5.85 \\
\hline & $\mathbf{J}$ & 7.45 & 4.93 & 7.10 & 5.61 & 7.17 & 5.92 & 6.44 & 7.03 \\
\hline & $\mathbf{A}$ & 7.59 & 5.35 & 7.08 & 4.96 & 7.31 & 5.29 & 6.69 & 5.72 \\
\hline & $\mathbf{S}$ & 7.75 & 5.63 & 7.65 & 5.73 & 8.12 & 5.42 & 7.59 & 6.44 \\
\hline & $\mathbf{O}$ & 7.08 & 4.97 & 7.73 & 4.05 & 8.51 & 4.12 & 8.22 & 5.90 \\
\hline & $\mathbf{N}$ & 6.77 & 4.63 & 7.02 & 4.65 & 7.66 & 4.73 & 7.80 & 5.78 \\
\hline & D & 8.64 & 4.26 & 7.25 & 3.79 & 7.70 & 4.13 & 7.90 & 6.54 \\
\hline \multirow{12}{*}{ 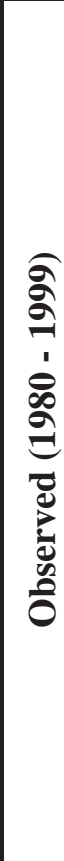 } & $\mathbf{J}$ & 9.76 & 4.16 & 7.68 & 3.37 & 8. & 4.09 & 8. & 5.79 \\
\hline & $\mathbf{F}$ & 10.14 & 3.11 & 7.84 & 2.95 & 8.14 & 3.92 & 8.50 & 7.04 \\
\hline & $\mathbf{M}$ & 9.46 & 3.48 & 8.52 & 3.91 & 8.61 & 4.16 & 8.58 & 7.84 \\
\hline & $\mathbf{A}$ & 7.26 & 3.43 & 8.35 & 4.37 & 8.59 & 4.88 & 8.41 & 5.66 \\
\hline & $\mathbf{M}$ & 8.34 & 4.42 & 8.06 & 4.46 & 8.14 & 5.37 & 7.55 & 7.54 \\
\hline & $\mathbf{J}$ & 8.00 & 4.47 & 7.54 & 5.56 & 7.50 & 6.43 & 6.85 & 6.06 \\
\hline & $\mathbf{J}$ & 7.40 & 4.85 & 6.96 & 6.06 & 6.97 & 6.21 & 6.40 & 6.86 \\
\hline & $\mathbf{A}$ & 7.59 & 5.60 & 6.96 & 5.29 & 7.21 & 5.56 & 6.76 & 5.22 \\
\hline & $\mathbf{S}$ & 7.69 & 5.33 & 7.49 & 5.58 & 8.05 & 4.83 & 7.78 & 5.07 \\
\hline & $\mathbf{O}$ & 6.94 & 4.74 & 7.47 & 4.18 & 8.35 & 4.32 & 8.18 & 5.97 \\
\hline & $\mathbf{N}$ & 6.68 & 4.67 & 6.90 & 5.14 & 7.59 & 5.01 & 7.79 & 5.71 \\
\hline & D & 8.73 & 3.79 & 7.37 & 3.69 & 7.81 & 4.30 & 8.08 & 6.58 \\
\hline
\end{tabular}




\section{Hydrologic Modeling with ArcSWAT}

The Soil and Water Assessment Tool (SWAT) (Arnold et al. 1998, Srinivasan et al. 1998 ) is the hydrologic model employed in this study. Now available as an interface with ArcGIS called ArcSWAT, it allows hydrologic models to be built quickly and easily. This chapter provides an overview of the SWAT model, reviews its use in hydrologic modeling, and presents the specific methodology applied to the case study watersheds investigated herein.

\subsection{Model Overview and Background}

SWAT is a physically-based hydrologic model that uses spatial and climatic data to model runoff (Arnold et al. 1998). Basic required inputs include land cover, elevation, slope, and soil characteristics. The model analyzes the spatial inputs, and divides the watershed accordingly into "hydrologic response units" (or HRUs) that are assumed to have a homogenous hydrologic response. A time series of temperature and precipitation data can either be provided by the user or generated by SWAT.

Within each HRU, a water balance equation representing the land phase of the hydrologic cycle (Equation 4.1) is used on a daily time step, and accounts for initial and final soil water contents $\left(\mathrm{SW}_{\mathrm{o}}\right.$ and $\mathrm{SW}_{\mathrm{t}}$, respectively), precipitation $\left(\mathrm{R}_{\text {day }}\right)$, surface runoff $\left(\mathrm{Q}_{\text {surf }}\right)$, evapotranspiration $\left(\mathrm{E}_{\mathrm{a}}\right)$, percolation $\left(\mathrm{w}_{\text {seep }}\right)$, and groundwater return flow or base flow 
$\left(\mathrm{Q}_{\mathrm{gw}}\right)$ (Neitsch et al. 2009). Surface runoff is calculated using the SCS curve number equation (USDA-SCS, 1972). SWAT calculates potential evapotranspiration using the users' choice of method; the Penman-Monteith method is the default and was maintained for this research. Percolation is calculated within each soil layer, and occurs if the soil's water content on a given day exceeds the soil's water content at field capacity, the underlying layer is not saturated, and the soil is not frozen. Groundwater return flow, or base flow, occurs if water storage in the shallow aquifer exceeds a specified threshold.

Eqn 4.1: $\quad S W_{t}=S W_{o}+\sum_{i=1}^{t}\left(R_{\text {day }}-Q_{\text {surf }}-E_{a}-w_{\text {seep }}-Q_{g w}\right)$

The resulting flow from each HRU is routed through the stream network of the watershed to the outlet using one of two routing methods; the variable storage routing method or the Muskingum method. The default method of variable storage routing was chosen here. Manning's Equation is used to define flow rate and velocity (Arnold et al. 1998). SWAT also allows the user to calibrate or specify hundreds of other variables, such as groundwater flow characteristics and snowmelt patterns, in order to fine-tune the model.

SWAT output from calibrated models has been shown to compare reasonably well to gaged streamflows in the United States (e.g. Srinivasan et al. 1998, Takle et al. 2005), and it has been used numerous times to simulate flow under climate change conditions (e.g. Hanratty and Stefan 1998, Stone et al. 2003, Takle et al. 2005b, Zhang et al. 2007, Ficklin et al. 2009, Githui et al. 2009). However, most studies considered average 
streamflow or water yield on a monthly or yearly time scale, while the interest of the research herein is annual maximum instantaneous flows. As mentioned in Chapter 1, studies using other modeling software have also been carried out, but again, the flows simulated and considered were annual maximum daily flows as opposed to instantaneous peak flows (Loukas et al. 2002, Prudhomme et al. 2002, Dankers et al. 2007). Simulating AMF series with SWAT is relatively new, as is simulating instantaneous peak flows in general, reiterating the need for this research.

One general limitation of SWAT is its ability to model groundwater flow, which may be overcome by pairing it with groundwater models such as MODFLOW (Tuppad et al. 2011), but it was determined that since the main interest of this research was instantaneous peak flows which are largely influenced by runoff rather than groundwater, this extra model coupling was not necessary.

\subsection{Acquisition and Manipulation of Spatial Data}

Watershed boundaries were extracted from the GAGES II (Falcone 2011) watershed boundary dataset. Using ArcGIS, these watershed boundaries were then buffered by one kilometer, and used to clip all spatial data. Spatial data needed to characterize watershed properties include soil type, elevation, and land cover parameters. Statewide Gridded Soil Survey Geographic (gSSURGO) databases were obtained from the NRCS Geospatial Data Gateway. Digital Elevation Models (DEMs) from the National Elevation Dataset (NED) $($ Gesch 2002, 2007) with a resolution of 1/3 ArcSecond (approximately 10 
meters) were obtained from the National Map Viewer. NLCD layers from 1992 (Vogelmann et al. 2001) in a 30 meter ArcGrid format were also downloaded using the National Map Viewer, and subsequently converted to shapefiles for input to ArcSWAT. The 1992 NLCD dataset was used to model all watersheds, and calibration periods corresponded to this timeframe. Land cover layers are shown on the maps in Section 2.2, and Appendix B contains figures of DEMs and soil layers used for each watershed.

\subsection{Model Building}

ArcSWAT has the capability to delineate a watershed and define streamlines based on the input DEM and a specified pour point (e.g. gage location), or the user may specify the watershed boundary and streamlines themselves. Watershed boundaries available from the GAGES II dataset (Falcone 2011) were overlaid with ArcSWAT-delineated watershed boundaries, and no significant difference was apparent. Computational problems are minimized when ArcSWAT delineates watersheds, so In this case, ArcSWAT was allowed to delineate and define the watershed and its main flow conduits. Soil and land cover were reclassified using existing SWAT databases that include information on NLCD codes and NRCS Soil Survey codes. Slopes derived based on the 10 m DEM were divided into two subclasses: "mild" (1-10\% slopes) and "sloped" (10\% slopes and above). This division is considered reasonable based on previous research which demonstrates that model accuracy does not increase proportionally with the number of slope classes (Yacoub and Foguet 2012). 
SWAT uses soil, slope, and land cover to divide a watershed into hydrologic response units (or HRUs), each of which has a relatively homogeneous response to runoff. A watershed may be modeled as a single unit using a lumped approach, or multiple HRUs can be employed to provide a more accurate representation of the watershed's response. In the latter case, overland and subsurface flows are calculated within each HRU separately, and then the program uses the variable storage method and Manning's Equation to route the flow through the main channel. If multiple HRUs are specified, the user may also specify thresholds for land cover, soil and slope at which very minimal percentages are eliminated; this may be necessary in large watersheds to avoid excessive computation time. Multiple HRUs per subbasin were allowed in the applications herein, and thresholds were all set at 0 , meaning no minimal soils, slopes or land cover types were eliminated, in order to obtain maximum possible accuracy.

\subsection{Calibration}

Based on the availability of continuous daily data for the case study watersheds, a calibration period of 1987 to 1995 (with 1987 and 1988 serving as warm-up years) was employed, and the model was validated for the period of 1996-1999 (following a warmup period of 1980-1995). Watershed 03302000 was the exception as fewer years of continuous data were available; therefore, it was calibrated using the period of 1996-1999 (with 1996 as a warm-up year) and validated using the period of 1990-1992 (following warm-up from 1980 to 1989). The selected time periods are consistent with the use of the 1992 NLCD dataset. For each watershed, gridded observed climate data for the 
calibration and validation periods was downloaded from the CMIP3 dataset and imported into ArcSWAT. Modeled daily flows at the watershed outlet were compared against observed daily data obtained for the relevant USGS gage station (USGS 2012).

Calibration was performed using the SWAT Calibration and Uncertainty Procedures (SWAT-CUP) autocalibration software available from Neprash Technology. The Sequential Uncertainty Fitting Version 2 (SUFI-2) algorithm was chosen based on results provided by Yang et al. (2008) which demonstrate that SUFI-2 is able to reach the same level of calibration in fewer simulations than the other two algorithms available in SWAT-CUP - Generalized Likelihood Uncertainty Estimation (GLUE) and the Parameter Solution (ParaSol) program. The Nash-Sutcliffe model efficiency (NSE) coefficient was chosen as the objective function for calibration based on widespread use in other applications of SWAT (e.g. Jha et al. 2004, Zhang et al. 2007, Yang et al. 2008, Ficklin et al. 2009).

Ten core parameters were calibrated in all watersheds: runoff curve number, alpha baseflow factor, groundwater delay, soil hydraulic conductivity, soil available water content, soil evaporation compensation factor, Manning's $\mathrm{n}$ in the main channel, soil hydraulic conductivity in the main channel, threshold water level in shallow aquifer for base flow, and a groundwater revap coefficient. These parameters were chosen because of their basic importance in determining runoff. Watershed 01013500 was determined to have an extremely snowmelt dominated flow pattern, so snow parameters were also 
calibrated for this watershed. Complete lists and descriptions of calibrated parameters, and their value employed for modeling herein, are provided for each watershed in Appendix C. SUFI-2 works by slowly narrowing down the range of uncertainty on each of the modeled parameters (Abbaspour et al. 2007). The models were calibrated until the range of uncertainty on the parameters was relatively small as compared to the overall range of the parameter (less than 5\% in most cases).

There is of course a limit to the ability of model calibration to capture the true physical processes at work in the watersheds (Beven and Smith 2014). SWAT-CUP does not seek to use the most accurate parameter values, but rather those that maximize the objective function. However, physical accuracy as far as is possible was certainly the aim when calibrating. There are absolute bounds on the parameters which are based in reality, and these are listed along with the calibration values in Appendix C. Additionally, parameters which are spatially variable (runoff curve number, soil hydraulic conductivity, and soil available water content) were first determined using the spatial inputs to the model (soil and land cover layers), and then calibrated by way of a multiplier, which could be applied to values across the watershed among the various HRUs while maintaining variability.

Goodness-of-fit measures for each of the four watersheds (NSE and $\mathrm{R}^{2}$ ) over both the calibration and validation periods are reported in Table 4.1, and hydrographs for the modeled and observed data over the validation periods are shown in Figures 4.1 - 4.4. The models could be reasonably calibrated, but there were some issues matching 
modeled peak flows with observed. Obviously the peak flows are the focus of the research, so some sort of correction to account for model bias was required. This was done in the form of quantile mapping, and is further discussed in Section 4.5.

Table 4.1 Goodness-of-fit measures for the calibration of four modeled watersheds.

\begin{tabular}{|l|c|c|c|c|}
\hline \multirow{2}{*}{ Watershed } & \multicolumn{2}{|c|}{ Calibration } & \multicolumn{2}{c|}{ Validation } \\
\cline { 2 - 5 } & NSE & $\mathbf{R}^{\mathbf{2}}$ & NSE & $\mathbf{R}^{\mathbf{2}}$ \\
\hline 01013500 & 0.688 & 0.712 & 0.756 & 0.790 \\
\hline 03093000 & 0.423 & 0.442 & 0.454 & 0.499 \\
\hline 03144000 & 0.561 & 0.567 & 0.640 & 0.657 \\
\hline 03302000 & 0.395 & 0.435 & 0.399 & 0.402 \\
\hline
\end{tabular}

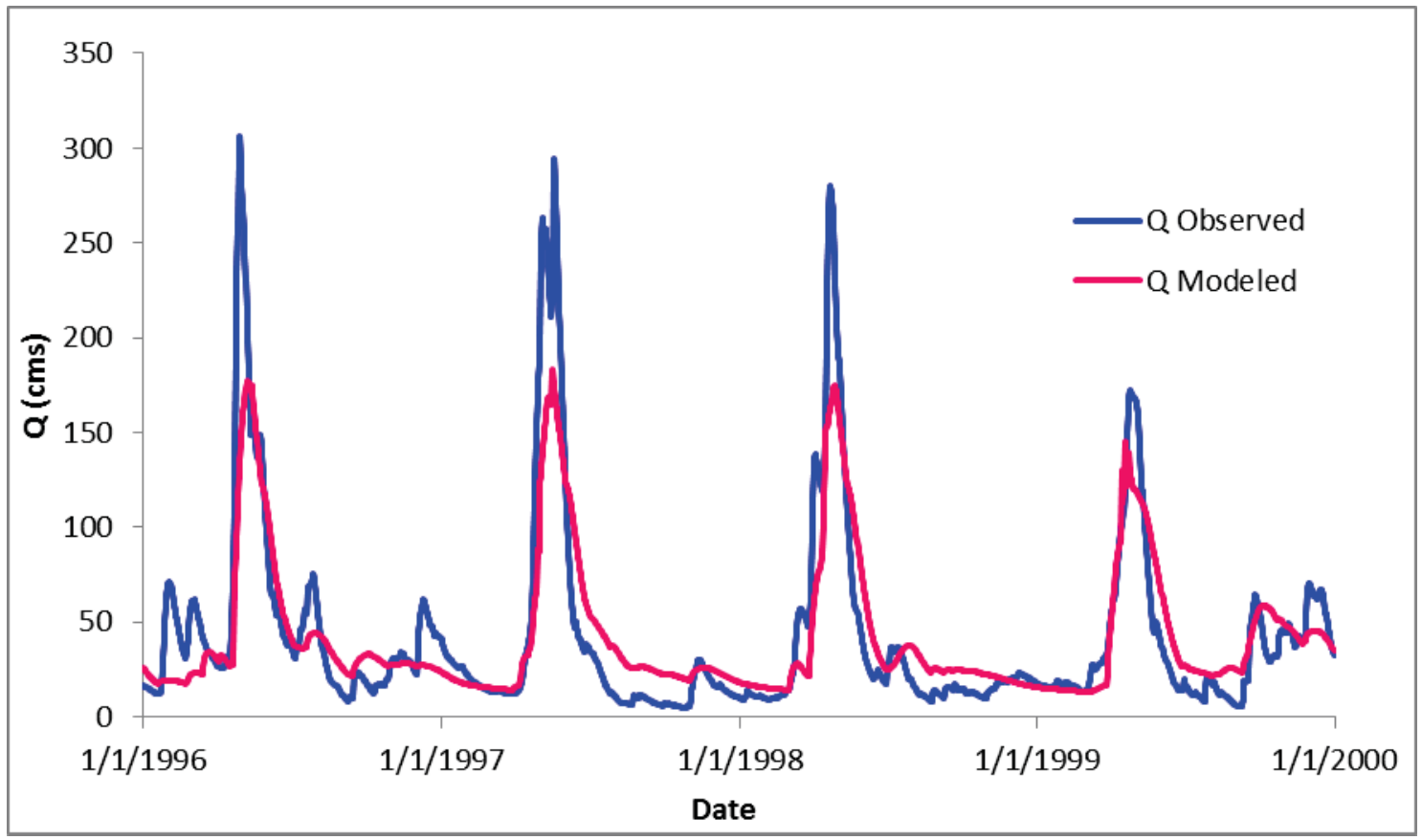

Figure 4.1 Observed and modeled daily flows over the validation period 1/1/1996 12/31/1999 for the Fish River watershed (USGS Gage Station 01013500). 


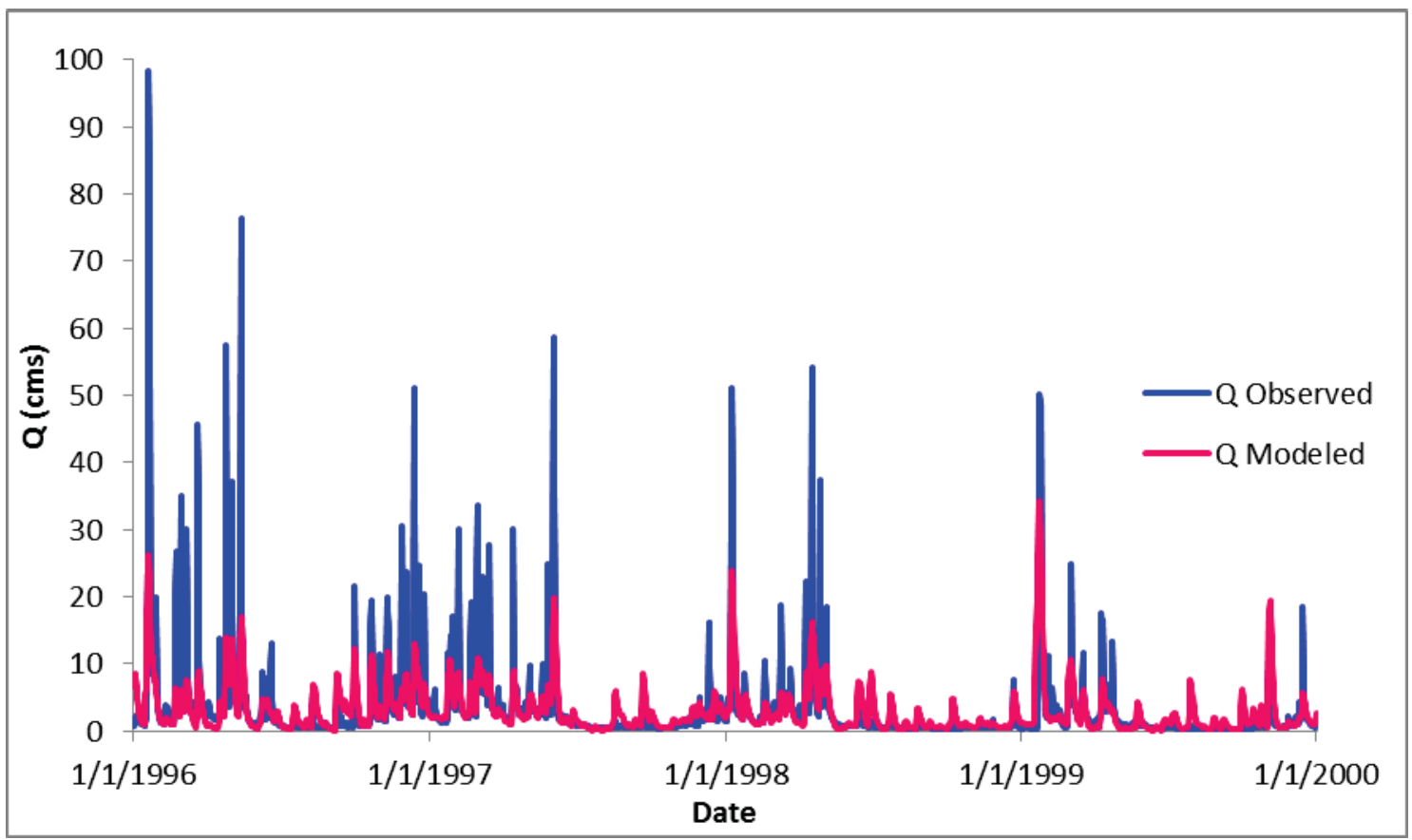

Figure 4.2 Observed and modeled daily flows over the validation period 1/1/1996 12/31/1999 for the Eagle Creek watershed (USGS Gage Station 03093000).

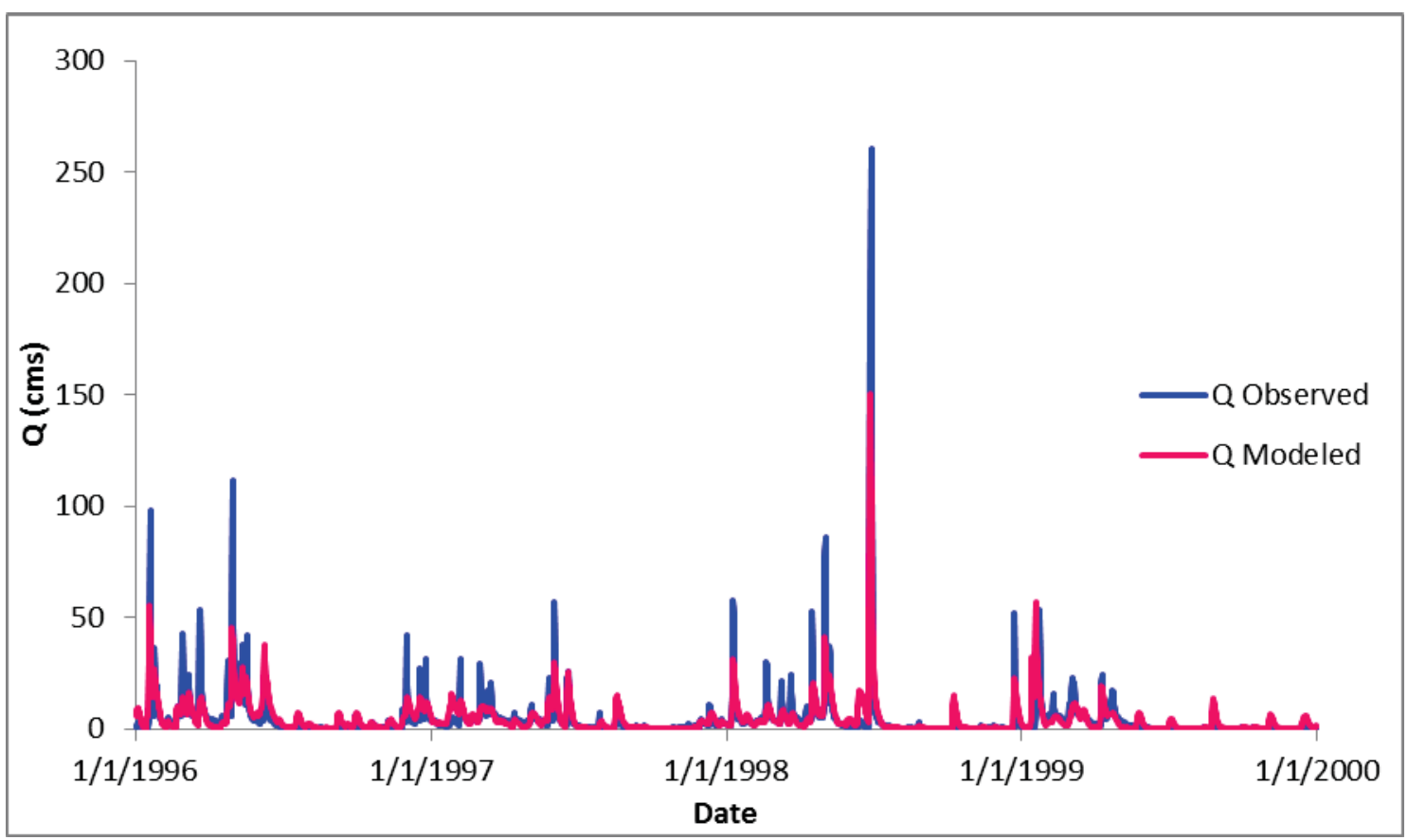

Figure 4.3 Observed and modeled daily flows over the validation period 1/1/1996 12/31/1999 for the Wakatomika Creek watershed (USGS Gage Station 03144000). 


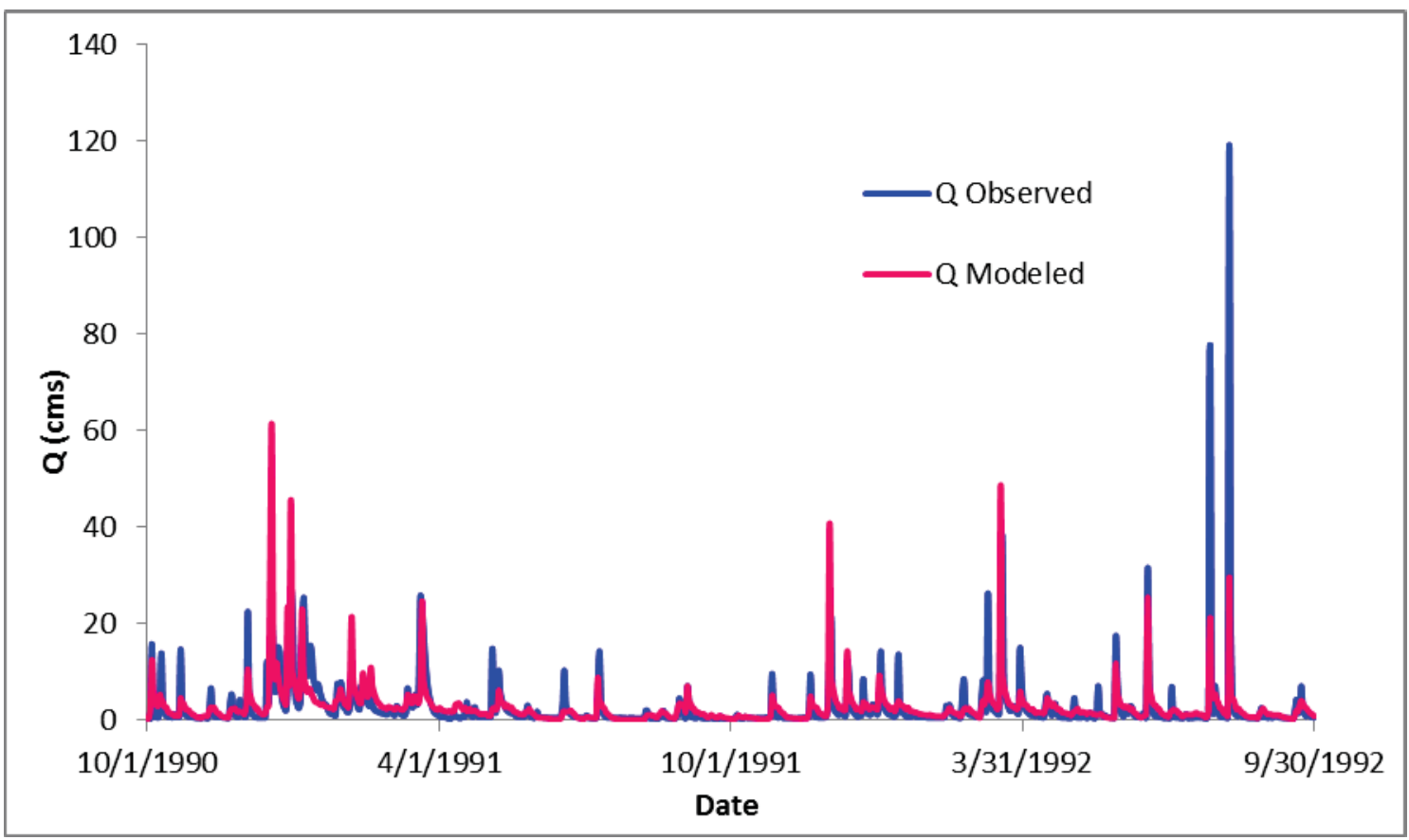

Figure 4.4 Observed and modeled daily flows over the validation period 10/1/1990 9/30/1992 for the Pond Creek watershed (USGS Gage Station 03302000).

\subsection{Projection of Flood Series}

Projected and bias-corrected climate data (prepared as discussed in Chapter 3) for the period of 2046-2065 was imported into the calibrated models in order to simulate future flow series under each of the nine representative future GCM/emissions scenario combinations. For each combination, the SWAT model was forced using climate data adjusted by both the bias-correction and delta change methods, thereby resulting in 18 simulations for each watershed. The 2046 climate data was duplicated in each case in order to provide the model a warm-up year.

Model output includes average daily flow; these values were converted to instantaneous peak flows using a procedure described by Fill and Steiner (2003). This procedure takes a 
3-day series of daily flow values and uses a simple statistical conversion to calculate the peak instantaneous flow for the second day. Fill and Steiner (2003) clearly demonstrated this method to be an improvement upon anything else in the literature, and therefore is reasonable to use herein.

As noted above, the calibrated SWAT models do not adequately capture peak daily flows, and thereby, will not yield good estimates of instantaneous peak flows. Therefore, a form of quantile mapping was used to further correct model output and account for model bias. The purpose of quantile mapping is to find a transformation such that after this transformation, the distribution of a modeled variable $\left(X_{m}\right)$ matches the distribution of an observed variable $\left(X_{o}\right)$. The basic form of this transformation is given by:

Eqn. $4.2 \quad X_{o}=F^{-1}\left(F_{m}\left(X_{m}\right)\right)$

where $F_{m}$ is the cumulative distribution function (CDF) of $X_{m}$, and $F^{-1}$ is the inverse CDF corresponding to $X_{o}$ (Gudmundsson et al. 2012).

Quantile map transformations were calculated based on the differences between the logPearson type 3 (LP3) distributions fit to the observed AMF series from 1980 to 1999 and the modeled AMF series produced using observed gridded climate data corresponding to the same period. The LP3 distributions were fit to the data using the Method of Moments in log space, and thus differences between quantiles of the associated Pearson Type 3 (log space) distributions provide the necessary transformation. An empirical form of 
quantile mapping was used, which means that a transformation was calculated at each fitted percentile of the AMF distributions, represented by a plotting position $\left(P_{i}\right)$ calculated using Blom's formula:

Eqn. $4.3 \quad P_{i}=\left(i-\frac{3}{8}\right) /\left(N+\frac{1}{4}\right)$

where $i$ is the rank of an observation in a set of $N$ total observations (Blom 1958). Here $N$ $=20$ years given the time period of 1980-1999.

The resulting transformations were then applied to the logs of the modeled AMF series produced using projected climate data (2046-2065), assuming that the model bias for the future period is equivalent to that of 1980-1999. The LP3 distribution fit to the transformed future series was the final output used for impact analysis and comparison to the LP3 distribution fit to the observed data in the historic period. Figures $4.5-4.8$ show the different distributions produced for the modeled and observed AMF series over the historic period and illustrate the need for a quantile mapping correction procedure. 


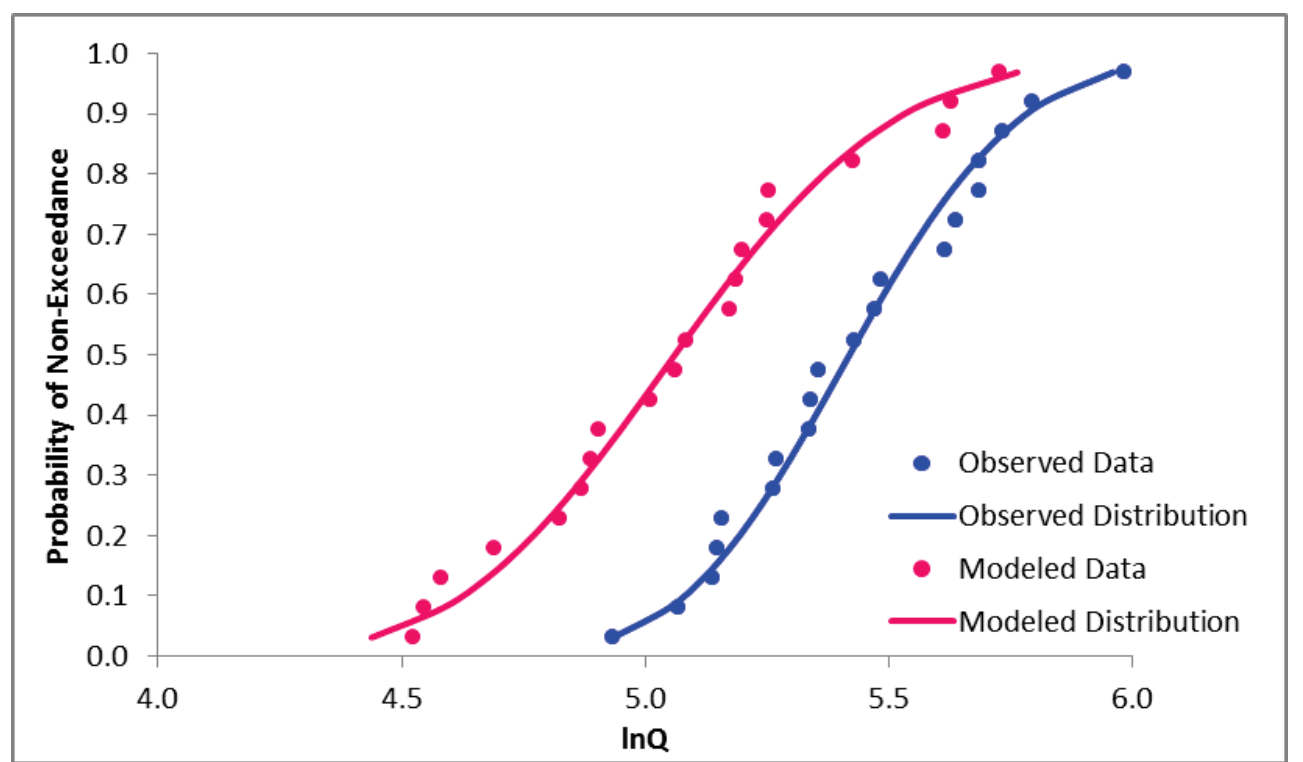

Figure 4.5 LP3 distributions (P3 in log space) fit to observed and modeled AMF series over the period of 1980-1999 for the Fish River watershed (USGS Gage Station 01013500).

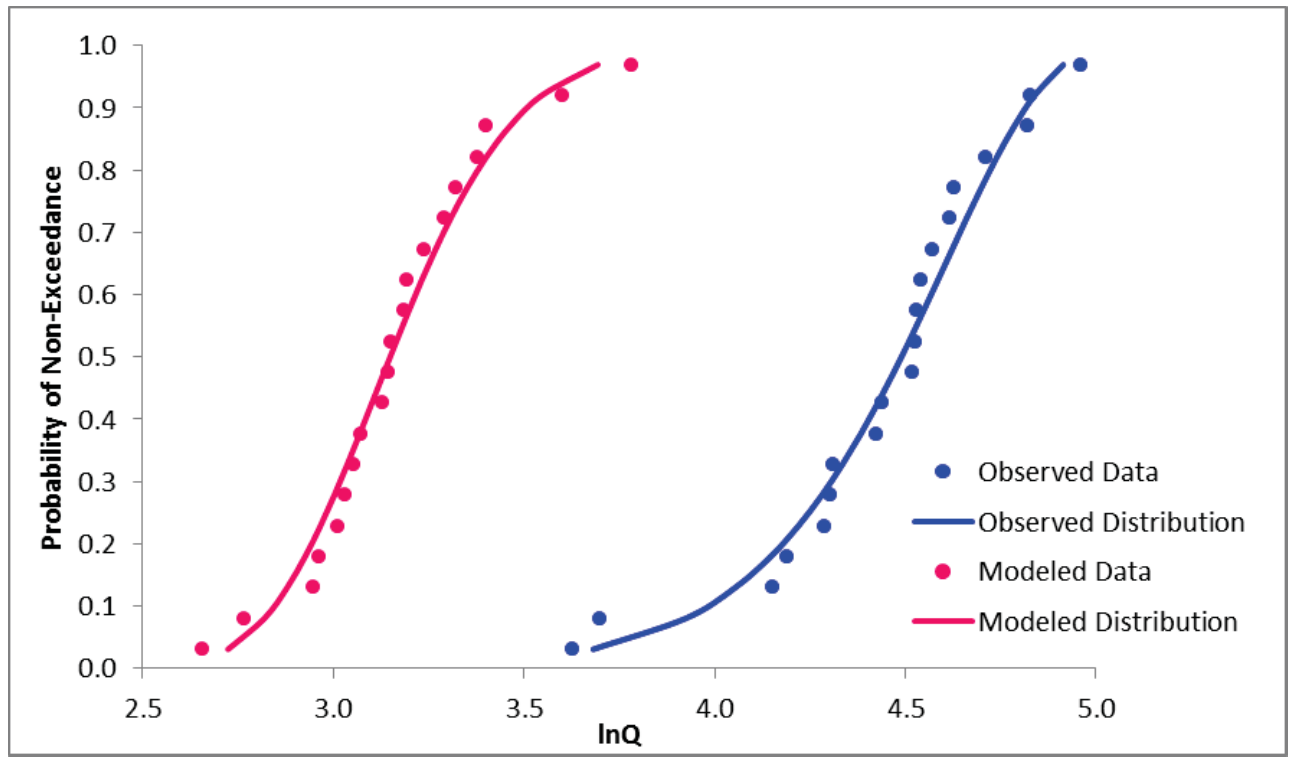

Figure 4.6 LP3 distributions (P3 in log space) fit to observed and modeled AMF series over the period of 1980-1999 for the Eagle Creek watershed (USGS Gage Station 03093000). 


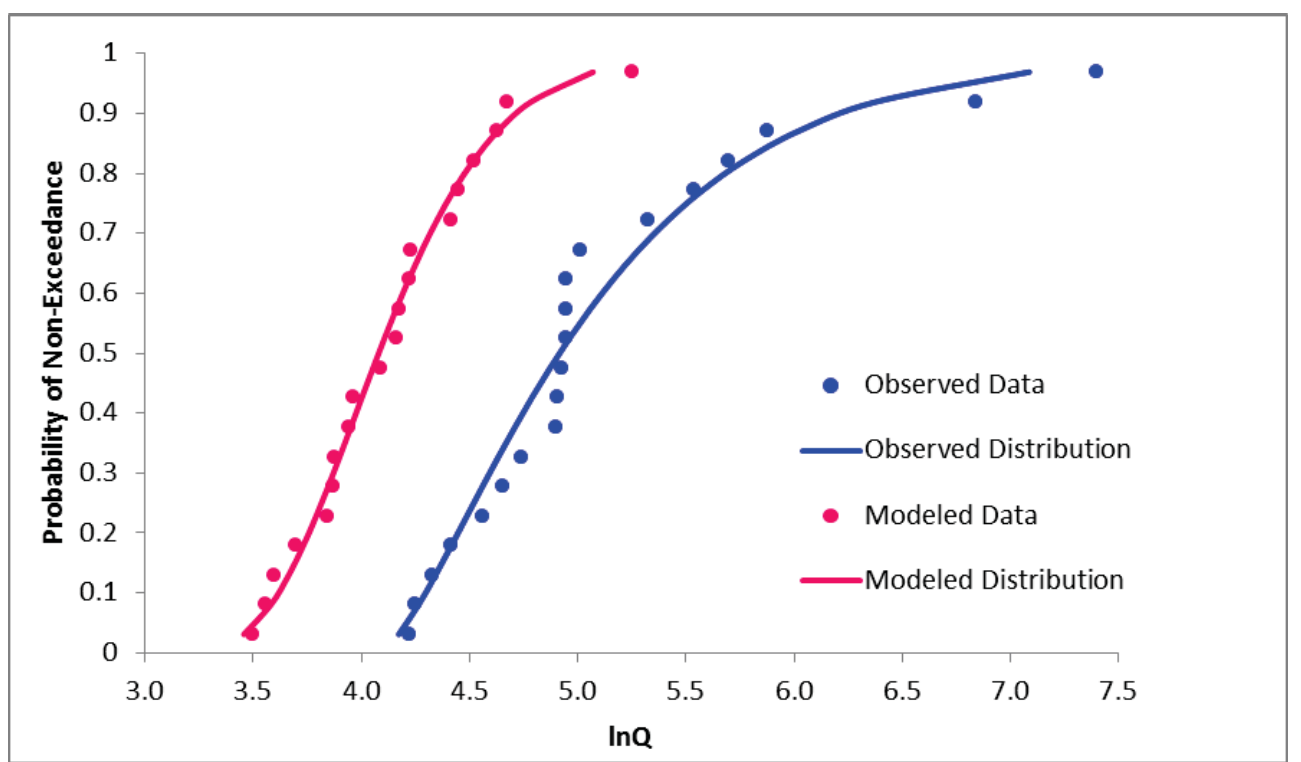

Figure 4.7 LP3 distributions (P3 in log space) fit to observed and modeled AMF series over the period of 1980-1999 for the Wakatomika Creek watershed (USGS Gage Station 03144000).

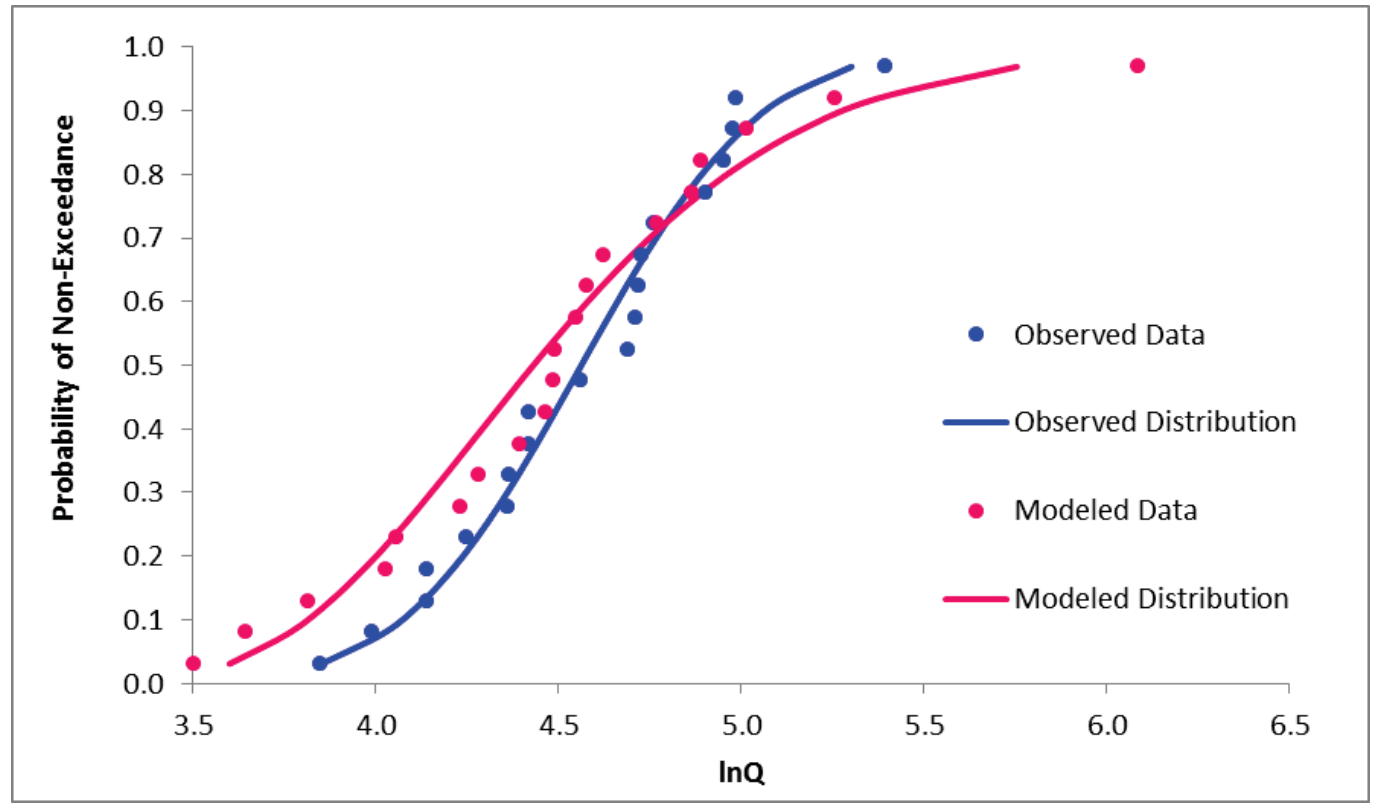

Figure 4.8 LP3 distributions (P3 in log space) fit to observed and modeled AMF series over the period of 1980-1999 for the Pond Creek watershed (USGS Gage Station 03302000). 


\section{Results of Hydrologic Modeling}

The first four sections of this chapter provide detailed results of the application of the calibrated SWAT models with projected climate data to estimate future flood risk in each of the four case study watersheds. Future flood risk associated with each representative future climate scenario is estimated based on a LP3 distribution fit to the projected AMF series following adjustment via quantile mapping as discussed in Chapter 4. Differences between flood risk estimates obtained using the two data application methods (bias correction versus delta change) are discussed for each watershed individually, and then general observations on patterns and trends are made in the final section of the chapter. Where possible, the estimated future flood risk is contrasted with anticipated watershed response given physical watershed parameters.

\subsection{USGS Gage 01013500}

Summary statistics for the observed (1980-1999) and projected (2046-2065) AMF series for the Fish River watershed are reported in Table 5.1 for each of the nine representative future climate scenarios; selected flow percentiles of the corresponding LP3 distributions are shown in Table 5.2. The latter results for the bias correction and delta change methods are visually displayed across the range of percentiles considered in Figures 5.1 and 5.2, respectively. 
Table 5.1 Summary statistics of observed and modeled AMF series for the Fish River watershed (USGS Gage Station 01013500) and associated changes in temperature and precipitation projected under nine representative future scenarios.

\begin{tabular}{|lcc|cr|rrr|}
\hline GCM & SRES & $\mathbf{R u n}$ & $\begin{array}{c}\Delta \mathbf{T} \\
\left({ }^{\circ} \mathbf{C}\right)\end{array}$ & $\begin{array}{c}\Delta \mathbf{P} \\
(\boldsymbol{\%})\end{array}$ & $\begin{array}{c}\overline{\mathbf{Q}} \\
(\mathbf{c m s})\end{array}$ & $\begin{array}{c}\mathbf{S}_{\mathbf{Q}} \\
(\mathbf{c m s})\end{array}$ & $\mathbf{G}_{\mathbf{Q}}$ \\
\hline & & & Modeled $(2046-2065)$ & with & Bias & Correction \\
\hline ips1_cm4 & a2 & 1 & 3.9 & 4.2 & 200.1 & 41.2 & 0.4 \\
miroc3_2_medres & b1 & 2 & 3.0 & 4.7 & 232.4 & 28.8 & 0.5 \\
mri_cgcm2_3_2a & a2 & 5 & 1.9 & 5.1 & 221.4 & 35.5 & 0.1 \\
mri_cgcm2_3_2a & b1 & 1 & 1.3 & 6.6 & 254.4 & 20.0 & -0.4 \\
gfdl_cm2_1 & a2 & 1 & 2.5 & 7.2 & 245.6 & 44.4 & 0.1 \\
cccma_cgcm3_2 & b1 & 2 & 1.9 & 10.0 & 235.7 & 58.6 & -0.1 \\
miub_echo_g & a1b & 2 & 3.0 & 10.3 & 264.9 & 61.8 & 0.5 \\
ips1_cm4 & a1b & 1 & 4.4 & 10.8 & 194.5 & 34.2 & -0.7 \\
cccma_cgcm3_1 & a1b & 3 & 2.7 & 15.0 & 294.1 & 40.3 & -1.3 \\
\hline & & & Modeled $(2046-2065)$ & with Delta Change \\
\hline ipsl_cm4 & a2 & 1 & 3.7 & 2.5 & 170.3 & 39.8 & 0.9 \\
miroc3_2_medres & b1 & 2 & 3.0 & 5.1 & 183.1 & 50.9 & 1.4 \\
mri_cgcm2_3_2a & a2 & 5 & 1.9 & 3.5 & 202.2 & 54.9 & 1.6 \\
mri_cgcm2_3_2a & b1 & 1 & 1.1 & 8.1 & 266.2 & 74.0 & 1.4 \\
gfdl_cm2_1 & a2 & 1 & 2.5 & 4.6 & 196.6 & 47.6 & 1.1 \\
cccma_cgcm3_2 & b1 & 2 & 1.6 & 6.1 & 221.6 & 55.8 & 1.0 \\
miub_echo_g & a1b & 2 & 2.7 & 7.4 & 214.5 & 55.5 & 0.8 \\
ips1_cm4 & a1b & 1 & 4.2 & 9.2 & 178.0 & 44.6 & 1.0 \\
cccma_cgcm3_1 & a1b & 3 & 2.4 & 10.0 & 223.0 & 57.7 & 0.6 \\
\hline & & Observed $(1980-1999):$ & 235.7 & 66.2 & 0.7 \\
\hline
\end{tabular}


Table 5.2 Flow percentiles (cms) of LP3 distributions fit to observed AMF series for the Fish River watershed (USGS Gage Station 01013500) and modeled AMF series for the nine representative future climate scenarios each applied using two methods.

\begin{tabular}{|c|c|c|c|c|c|c|c|}
\hline GCM & SRES & Run & $\mathbf{Q}_{0.01}$ & $\mathbf{Q}_{0.10}$ & $\mathbf{Q}_{0.50}$ & $\mathbf{Q}_{0.90}$ & $Q_{0.99}$ \\
\hline & & & \multicolumn{5}{|c|}{ Modeled (2046-2065) with Bias Correction } \\
\hline ips1_cm4 & a2 & 1 & 119.5 & 150.2 & 196.8 & 255.0 & 312.4 \\
\hline miroc3_2_medres & b1 & 2 & 175.0 & 197.4 & 230.3 & 270.3 & 309.6 \\
\hline mri_cgcm2_3_2a & $\mathrm{a} 2$ & 5 & 147.9 & 177.3 & 219.4 & 268.6 & 314.3 \\
\hline mri_cgcm2_3_2a & b1 & 1 & 202.2 & 227.8 & 255.9 & 279.0 & 293.6 \\
\hline gfdl_cm2_1 & $\mathrm{a} 2$ & 1 & 146.0 & 188.7 & 245.5 & 303.2 & 347.5 \\
\hline cccma_cgcm3_2 & b1 & 2 & 115.9 & 161.9 & 232.1 & 315.8 & 391.4 \\
\hline miub_echo_g & $\mathrm{a} 1 \mathrm{~b}$ & 2 & 147.3 & 190.7 & 259.1 & 347.7 & 438.1 \\
\hline ipsl_cm4 & $\mathrm{a} 1 \mathrm{~b}$ & 1 & 100.5 & 147.1 & 199.9 & 234.4 & 247.3 \\
\hline \multirow[t]{2}{*}{ cccma_cgcm3_1 } & $\mathrm{a} 1 \mathrm{~b}$ & 3 & 167.5 & 237.7 & 304.8 & 335.2 & 341.0 \\
\hline & & & \multicolumn{5}{|c|}{ Modeled (2046-2065) with Delta Change } \\
\hline ipsl_cm4 & $\mathrm{a} 2$ & 1 & 112.6 & 128.5 & 161.9 & 222.7 & 310.4 \\
\hline miroc3_2_medres & b1 & 2 & 123.2 & 135.5 & 169.5 & 246.9 & 382.7 \\
\hline mri_cgcm2_3_2a & $\mathrm{a} 2$ & 5 & 138.7 & 151.4 & 187.4 & 270.5 & 416.6 \\
\hline mri_cgcm2_3_2a & b1 & 1 & 164.5 & 191.4 & 249.9 & 361.3 & 530.6 \\
\hline gfdl_cm2_1 & $\mathrm{a} 2$ & 1 & 133.7 & 148.9 & 185.2 & 258.3 & 373.0 \\
\hline cccma_cgcm3_2 & b1 & 2 & 144.4 & 164.4 & 209.0 & 294.6 & 424.5 \\
\hline miub_echo_g & $\mathrm{a} 1 \mathrm{~b}$ & 2 & 129.3 & 154.6 & 203.9 & 288.3 & 404.0 \\
\hline ipsl_cm4 & $\mathrm{a} 1 \mathrm{~b}$ & 1 & 107.9 & 129.4 & 170.0 & 237.0 & 325.7 \\
\hline cccma_cgcm3_1 & $\mathrm{a} 1 \mathrm{~b}$ & 3 & 128.8 & 158.5 & 213.1 & 300.9 & 413.8 \\
\hline \multicolumn{3}{|c|}{ Observed (1980-1999): } & 124.2 & 160.7 & 225.5 & 324.7 & 445.9 \\
\hline
\end{tabular}




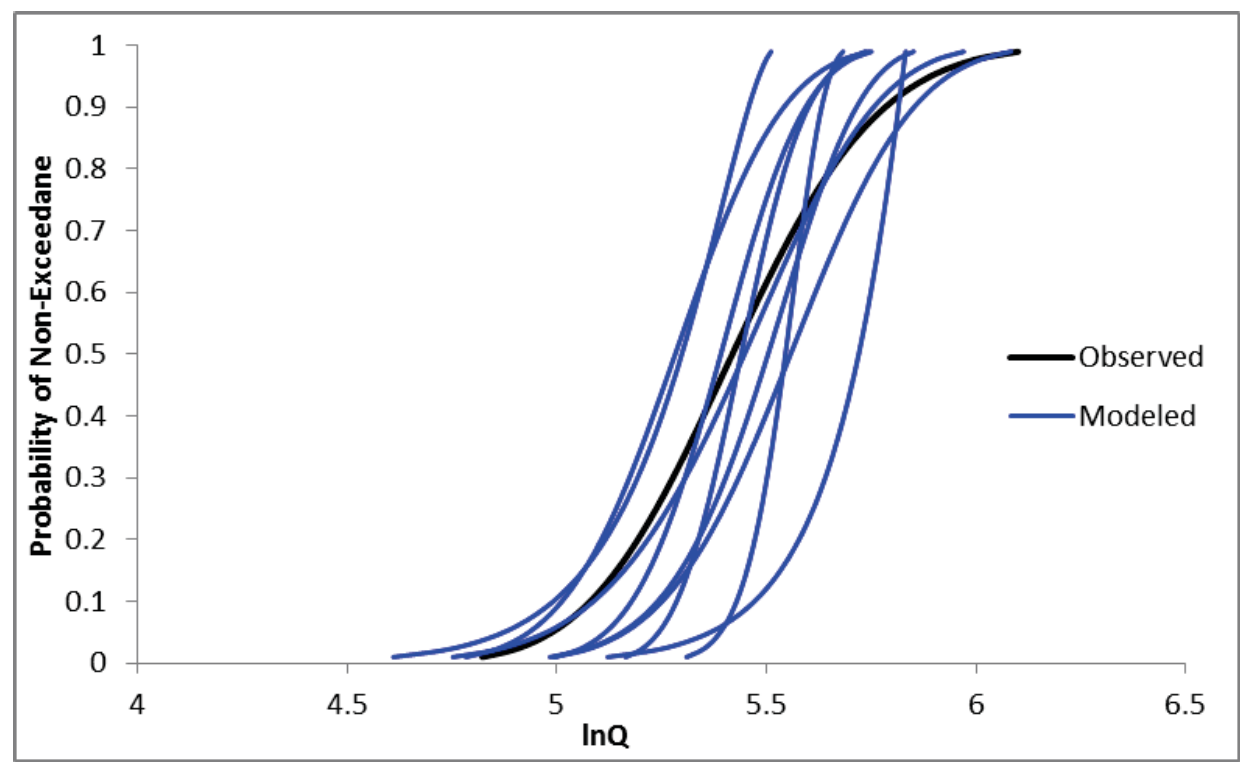

Figure 5.1 LP3 distributions (log space) produced using projected bias corrected climate data overlaid with the LP3 distribution fit to observed AMF for the Fish River watershed (USGS Gage Station 01013500).

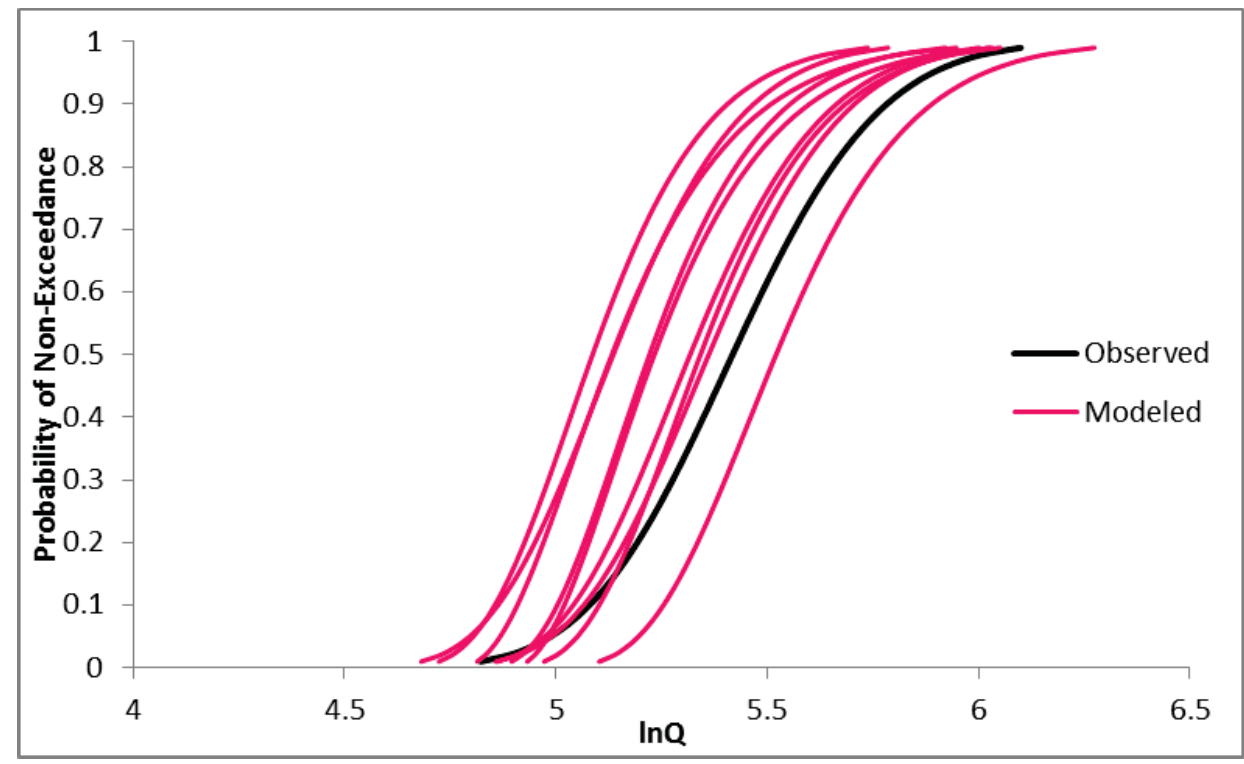

Figure 5.2 LP3 distributions (log space) produced using delta changed climate data overlaid with the LP3 distribution fit to observed AMF for the Fish River watershed (USGS Gage Station 01013500). 
For this watershed, the bias correction method generally (in 8 out of 9 scenarios) produces an AMF with a higher mean than that of the delta change method. Further, the means of the AMF produced using the delta change method are generally (in 8 out of 9 scenarios) lower than that observed over the historic period, whereas only half (5 out of 9) of the means produced using the bias correction method are lower than the mean of the observed peak flows.

For both climate data methods, a positive correlation is apparent between overall change in precipitation and mean peak flow. On the contrary, temperature appears to have a negative correlation with mean peak flow. This is particularly evident in scenario ipsl_cm4.1.a1b. While having a relatively large increase in precipitation, this scenario also exhibits the largest increase in temperature, and produces much lower flows than scenarios with comparable changes in precipitation, but smaller changes in temperature. It makes sense for this watershed to be sensitive to temperature, as it is dominated by snowmelt and is also the most vegetated, which perhaps increases the amount of evapotranspiration. Increased temperatures could cause reduced snowpack in winter and increased evapotranspiration in the summer, which would both lower flows.

Overall, both climate data application methods project flood distributions with reduced variability compared to that observed over the historic period. However, in general the standard deviation produced using the delta change method is greater than that produced using bias correction. Further, the skews of the modeled AMF produced using the delta 
change are more consistent with the historical value than those of the AMF series produced using the bias correction, suggesting that the delta change method produces more realistic future scenarios.

Across the board, the bias correction method produces distributions with higher flows at the $50^{\text {th }}$ percentile as opposed to those produced with the delta change method, with similar results at the $90^{\text {th }}$ percentile in all but 3 scenarios. However, the delta change method produces higher values at the $99^{\text {th }}$ percentile in all but 2 scenarios. There seems to be a tendency for the bias correction method to produce distributions with greater flow values than the delta change method at the lower percentiles, but for the distributions to "cross" somewhere between the $50^{\text {th }}$ and $99^{\text {th }}$ percentiles. Relative to the distribution for the observed AMF, 6 distributions produced with the bias corrected climate data start with higher flow values than the observed at lower percentiles and then cross to lower values than observed at higher percentiles. On the contrary, 8 out of 9 distributions produced by the delta change method give lower flow values than observed at most percentiles.

While it is difficult to discern a trend in flow percentiles based on changes in precipitation, it is interesting to note that the mri_cgcm2_3_2a.1.b1 scenario produces the highest flood risk and also has the smallest increase in temperature when considering both the bias correction and delta change methods, while the ipsl_cm4 scenarios have the greatest increase in temperature and produce the lowest flood risk. It would seem that 
overall change in precipitation does impact mean peak flow for this watershed, but that temperature is more of an influence when considering peak flow percentiles. This phenomenon may be attributable to the snowmelt dominated nature of the watershed.

Figures 5.3 - 5.5 show a comparison of the fitted LP3 distributions for the observed AMF and the modeled AMF obtained with the two climate data application methods for the median, driest, and wettest climate scenarios considered, respectively, with respect to projected changes in precipitation. These three sets of distributions follow the general pattern observed for the watershed; the bias correction method produces greater flows than the delta change method for the bulk of the distributions, except for extremes in the upper tails. The distribution produced for the ccma_cgcm3_1.3.a1b (wettest) scenario when using the bias correction method (Figure 5.5) exhibits a nearly asymptotic approach to an upper bound, which is uncharacteristic and possibly introduced by either the bias corrected climate data or the quantile mapping procedure. 


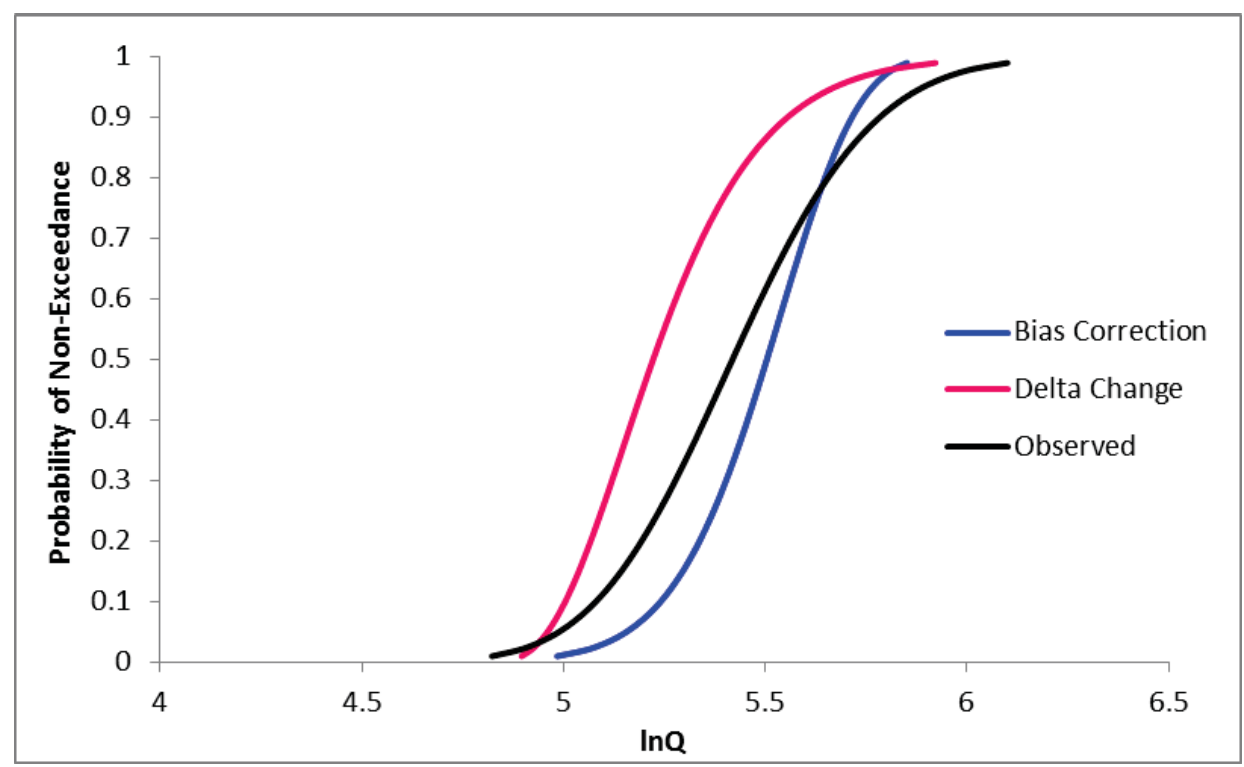

Figure 5.3 LP3 distributions (log space) of observed (1980-1999) and modeled (20462065) AMF series using two different climate data methods and the median future climate scenario (gfdl_cm2.1.a2) for the Fish River Watershed (USGS Gage Station 01013500).

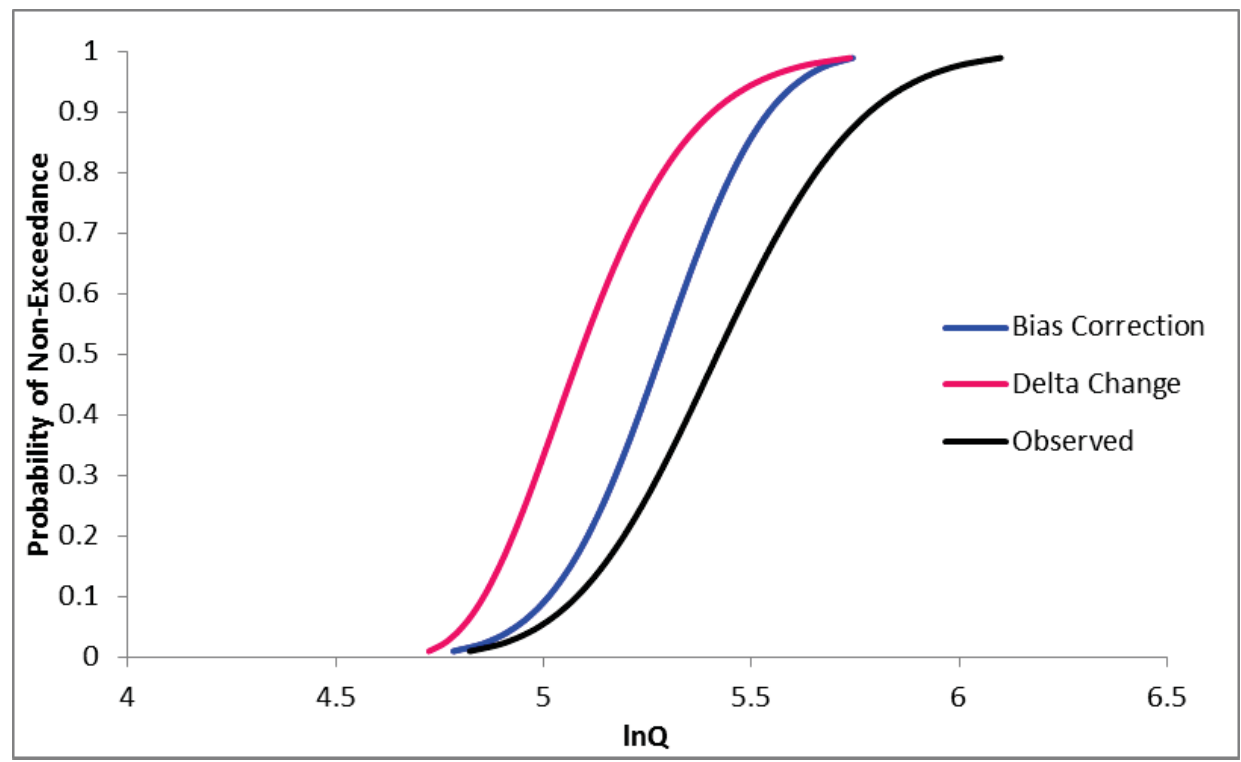

Figure 5.4 LP3 distributions (log space) of observed (1980-1999) and modeled (20462065) AMF series using the two different climate data methods and the driest future climate scenario (ipsl_cm4.1.a2) for the Fish River Watershed (USGS Gage Station 01013500). 


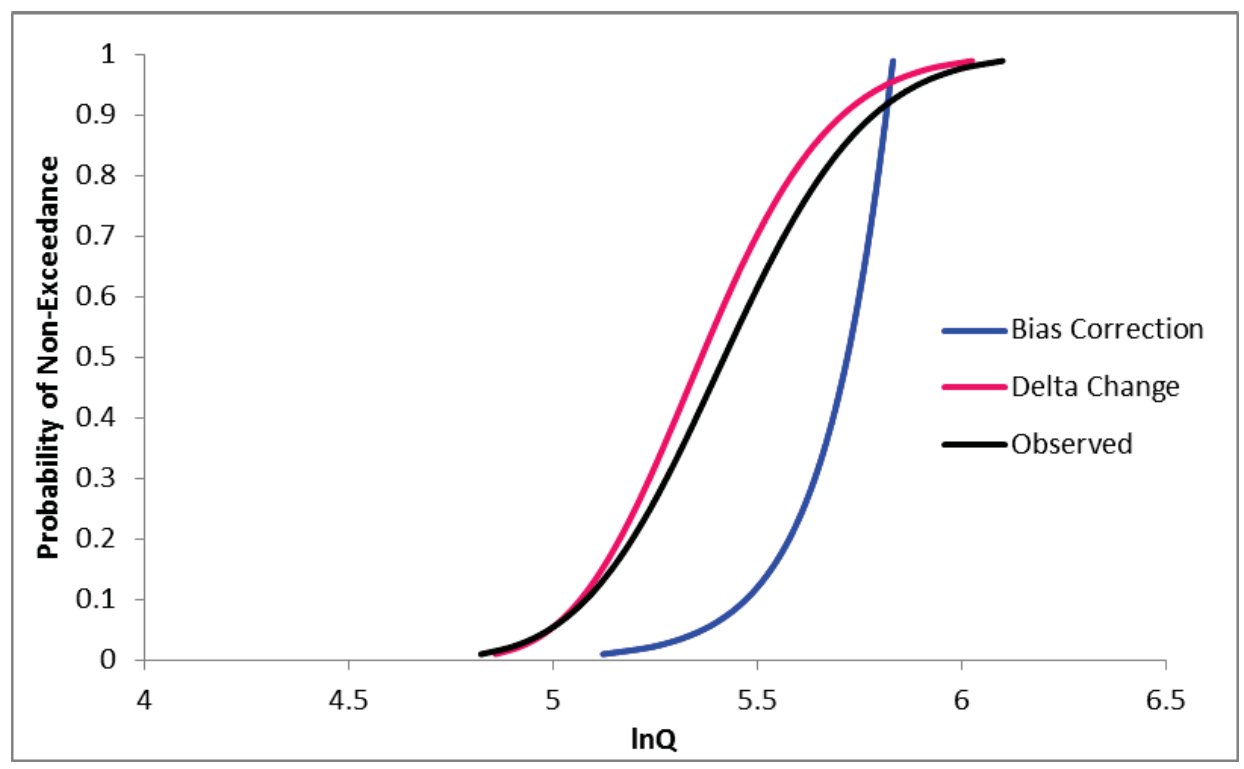

Figure 5.5 LP3 distributions (log space) of observed (1980-1999) and modeled (20462065) AMF series using two different climate data methods and the wettest future climate scenario (cccma_cgcm3_1.3.a1b) for the Fish River Watershed (USGS Gage Station 01013500).

In general, the majority of modeling results point towards reduced flood risk in the future, and even more so when the delta change method is used. Changes in temperature are strong enough to outweigh the influence of changes in precipitation in some scenarios. These outcomes are reasonable for this watershed, given that for this watershed, yearly peak flows are highly dependent on snowmelt. Warmer future temperatures could decrease snow accumulation during the winter and therefore decrease flow magnitudes.

Regarding the differences between the distributions produced by the bias correction and delta change methods, this watershed is anomalous in that the bias correction method produces greater flow magnitudes in general, while the delta change method consistently produces greater flow magnitudes in the other three watersheds. However, the delta 
change method still clearly produces a more variable range of high flows, which is consistent with results from the other three watersheds.

\subsection{USGS Gage 03093000}

Summary statistics for the observed (1980-1999) and projected (2046-2065) AMF series for the Eagle Creek watershed are reported in Table 5.3 for each of the nine representative future climate scenarios. In every case, the mean of the AMF series produced using the delta change method is greater than that obtained using the bias correction method for the same scenario. In addition, the majority of the means produced by the bias correction method are lower than the mean of the observed AMF series, while the means produced by the delta change method are generally larger than the observed value. As was observed for the previous watershed, increases in precipitation tend to result in larger means. Also, increased temperature significantly decreases mean peak flow when considering the ips1_cm4.1.a1b scenario, but only when using the bias correction data application method. 
Table 5.3 Summary statistics of observed and modeled AMF series for the Eagle Creek watershed (USGS Gage Station 03093000) and associated changes in temperature and precipitation projected under nine representative future scenarios.

\begin{tabular}{|c|c|c|c|c|c|c|c|}
\hline GCM & SRES & Run & $\begin{array}{c}\Delta \mathbf{T} \\
\left({ }^{\circ} \mathbf{C}\right)\end{array}$ & $\begin{array}{c}\Delta \mathbf{P} \\
(\%)\end{array}$ & $\begin{array}{c}\overline{\mathbf{Q}} \\
(\mathbf{c m s})\end{array}$ & $\begin{array}{c}\mathrm{S}_{\mathbf{Q}} \\
(\mathrm{cms})\end{array}$ & $\mathbf{G}_{\mathbf{Q}}$ \\
\hline & & & \multicolumn{5}{|c|}{ Modeled (2046-2065) with Bias Correction } \\
\hline miroc3_2_medres & alb & 1 & 3.8 & -7.49 & 59.0 & 18.4 & 1.4 \\
\hline mri_cgcm2_3_2a & b1 & 4 & 1.7 & 0.36 & 64.0 & 18.7 & 0.2 \\
\hline ipsl_cm4 & b1 & 1 & 2.9 & 1.07 & 62.7 & 22.4 & 0.1 \\
\hline cccma_cgcm3_1 & b1 & 2 & 2.1 & 1.11 & 70.3 & 21.9 & -0.1 \\
\hline gfdl_cm2 & a2 & 1 & 2.6 & 3.55 & 77.3 & 39.7 & 1.4 \\
\hline ipsl_cm4 & $\mathrm{a} 1 \mathrm{~b}$ & 1 & 4.2 & 4.38 & 67.8 & 19.0 & -0.4 \\
\hline mpi_echam5 & a2 & 1 & 2.2 & 8.58 & 76.1 & 28.0 & 0.3 \\
\hline cccma_cgcm3_1 & a2 & 2 & 3.0 & 8.79 & 121.8 & 162.9 & 4.1 \\
\hline \multirow[t]{2}{*}{ cnrm_cm3 } & $\mathrm{a} 1 \mathrm{~b}$ & 1 & 2.4 & 13.50 & 77.1 & 27.8 & 0.2 \\
\hline & & & \multicolumn{5}{|c|}{ Modeled (2046-2065) with Delta Change } \\
\hline miroc3_2_medres & $\mathrm{a} 1 \mathrm{~b}$ & 1 & 3.6 & -5.09 & 79.4 & 41.0 & 1.3 \\
\hline mri_cgcm2_3_2a & b1 & 4 & 1.6 & 4.98 & 90.1 & 23.7 & -0.4 \\
\hline ipsl_cm4 & b1 & 1 & 2.7 & 1.58 & 83.6 & 38.3 & 1.9 \\
\hline cccma_cgcm3_1 & b1 & 2 & 1.9 & 3.38 & 84.9 & 30.9 & 0.8 \\
\hline gfdl_cm2 & $\mathrm{a} 2$ & 1 & 2.6 & 7.70 & 89.6 & 27.6 & 0.0 \\
\hline ipsl_cm4 & $\mathrm{a} 1 \mathrm{~b}$ & 1 & 4.0 & 4.96 & 93.0 & 42.7 & 1.2 \\
\hline mpi_echam5 & a2 & 1 & 2.1 & 8.20 & 93.7 & 32.7 & 0.5 \\
\hline cccma_cgcm3_1 & $\mathrm{a} 2$ & 2 & 2.7 & 11.36 & 123.1 & 90.8 & 2.9 \\
\hline cnrm_cm3 & $\mathrm{a} 1 \mathrm{~b}$ & 1 & 2.2 & 14.61 & 101.6 & 31.4 & -0.1 \\
\hline \multicolumn{5}{|c|}{ Observed (1980-1999): } & 88.6 & 26.5 & 0.0 \\
\hline
\end{tabular}


In regards to the variability of peak flows, the values of the standard deviation resulting from use of the delta change method are higher than those produced by the bias correction in most scenarios. Standard deviations produced by the bias correction method are lower than that of the observed AMF series roughly half of the time, while most standard deviations produced by the delta change method are greater than that for the historic period. As previously noted, the latter case is more consistent with predictions by the IPCC (2013). Skews do not seem more reasonable with one method versus the other; the values are roughly equally distributed around the observed skew value of 0 for both methods, so it is not possible to say which method is more realistic in this watershed.

Select flow percentiles of the LP3 distributions fit to the observed (1980-1999) and projected (2046-2065) AMF series for the Eagle Creek watershed are provided in Table 5.4. These results are visually displayed in Figures 5.6 and 5.7 across the range of percentiles considered for the bias correction and delta change methods, respectively. In 7 of the 9 scenarios, distributions produced by the delta change method yield greater flow values than those obtained using the bias correction method at all percentiles. In the other two scenarios, the delta change method produces higher flows than the bias correction method in all but the upper flow percentiles. Most distributions produced using bias corrected climate data give lower peak flow values than the observed distribution throughout, and most distributions produced using the delta change method have higher flow values than observed at the upper percentiles of the distribution, with mixed results in the lower percentiles. 
Table 5.4 Flow percentiles (cms) of LP3 distributions fit to observed AMF series for the Eagle Creek watershed (USGS Gage Station 03093000) and modeled AMF series for nine representative future climate scenarios each applied using two methods.

\begin{tabular}{|c|c|c|c|c|c|c|c|}
\hline GCM & SRES & Run & $\mathbf{Q}_{0.01}$ & $\mathbf{Q}_{0.10}$ & $\mathbf{Q}_{0.50}$ & $\mathbf{Q}_{0.90}$ & $\mathbf{Q}_{0.99}$ \\
\hline & & & \multicolumn{5}{|c|}{ Modeled (2046-2065) with Bias Correction } \\
\hline miroc3_2_medres & $\mathrm{a} 1 \mathrm{~b}$ & 1 & 26.9 & 38.1 & 57.0 & 82.8 & 110.0 \\
\hline mri_cgcm2_3_2a & b1 & 4 & 24.4 & 40.0 & 63.8 & 88.6 & 106.0 \\
\hline ipsl_cm4 & b1 & 1 & 20.3 & 35.0 & 60.8 & 94.0 & 123.9 \\
\hline cccma_cgcm3_1 & b1 & 2 & 24.3 & 41.7 & 69.7 & 100.3 & 122.5 \\
\hline gfdl_cm2 & $\mathrm{a} 2$ & 1 & 20.9 & 36.2 & 69.4 & 129.6 & 211.4 \\
\hline ipsl_cm4 & alb & 1 & 24.6 & 42.1 & 68.3 & 93.2 & 108.4 \\
\hline mpi_echam5 & a2 & 1 & 25.0 & 42.1 & 73.0 & 115.1 & 156.4 \\
\hline cccma_cgcm3_1 & $\mathrm{a} 2$ & 2 & 45.9 & 49.1 & 73.0 & 210.3 & 942.1 \\
\hline \multirow[t]{2}{*}{ cnrm_cm3 } & alb & 1 & 23.2 & 42.2 & 75.3 & 115.3 & 147.9 \\
\hline & & & \multicolumn{5}{|c|}{ Modeled (2046-2065) with Delta Change } \\
\hline miroc3_2_medres & a1b & 1 & 24.6 & 38.3 & 69.5 & 133.6 & 237.9 \\
\hline mri_cgcm2_3_2a & b1 & 4 & 31.6 & 57.2 & 92.7 & 119.6 & 130.5 \\
\hline ipsl_cm4 & b1 & 1 & 29.9 & 45.1 & 76.2 & 131.9 & 210.3 \\
\hline cccma_cgcm3_1 & b1 & 2 & 32.9 & 49.7 & 80.5 & 126.7 & 179.6 \\
\hline gfdl_cm2 & $\mathrm{a} 2$ & 1 & 34.3 & 54.8 & 88.0 & 127.5 & 161.1 \\
\hline ipsl_cm4 & alb & 1 & 34.8 & 49.9 & 82.9 & 149.3 & 256.4 \\
\hline mpi_echam5 & $\mathrm{a} 2$ & 1 & 35.7 & 55.3 & 89.8 & 138.2 & 189.0 \\
\hline cccma_cgcm3_1 & a2 & 2 & 44.7 & 57.3 & 95.9 & 214.7 & 528.4 \\
\hline cnrm_cm3 & $\mathrm{a} 1 \mathrm{~b}$ & 1 & 30.2 & 59.1 & 103.6 & 142.1 & 160.6 \\
\hline \multicolumn{3}{|c|}{ Observed (1980-1999): } & 30.4 & 53.6 & 89.1 & 123.5 & 144.4 \\
\hline
\end{tabular}

The results produced under the cccma_cgcm3_1.2.a2 scenario stand out significantly in that for both climate data application methods they correspond to the largest mean peak flow value and extremely large percentiles are produced in the upper tail of the 
distributions. Additionally, this scenario produces quite large standard deviations and large positive skews relative to others. Further, the one distribution in Figure 5.6 that appears to asymptotically approach a lower bound corresponds to the cccma_cgcm3_1.2.a2 scenario as modeled with bias corrected climate data.

Overall, the results do not suggest a strong relationship between change in precipitation and peak flow percentiles except around the median $\left(\mathrm{Q}_{0.50}\right)$, and no clear influence of temperature is apparent. The influence of precipitation is consistent between this watershed and the last; it is related to mean peak flow but not necessarily peak flow percentiles other than the median. However, temperature seems to play less of a role in this watershed, likely due to decreased snowmelt impact.

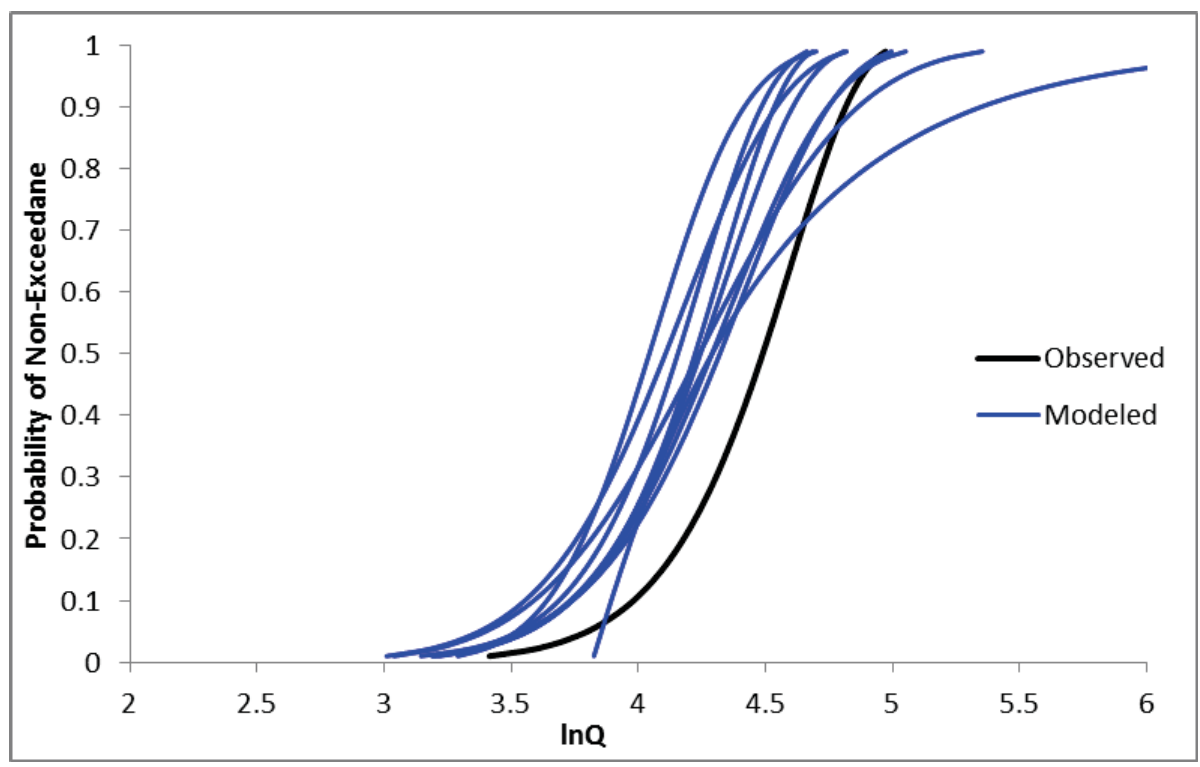

Figure 5.6 LP3 distributions (log space) produced using projected bias corrected climate data overlaid with the distribution fit to the observed AMF series for the Eagle Creek watershed (USGS Gage Station 03093000). 


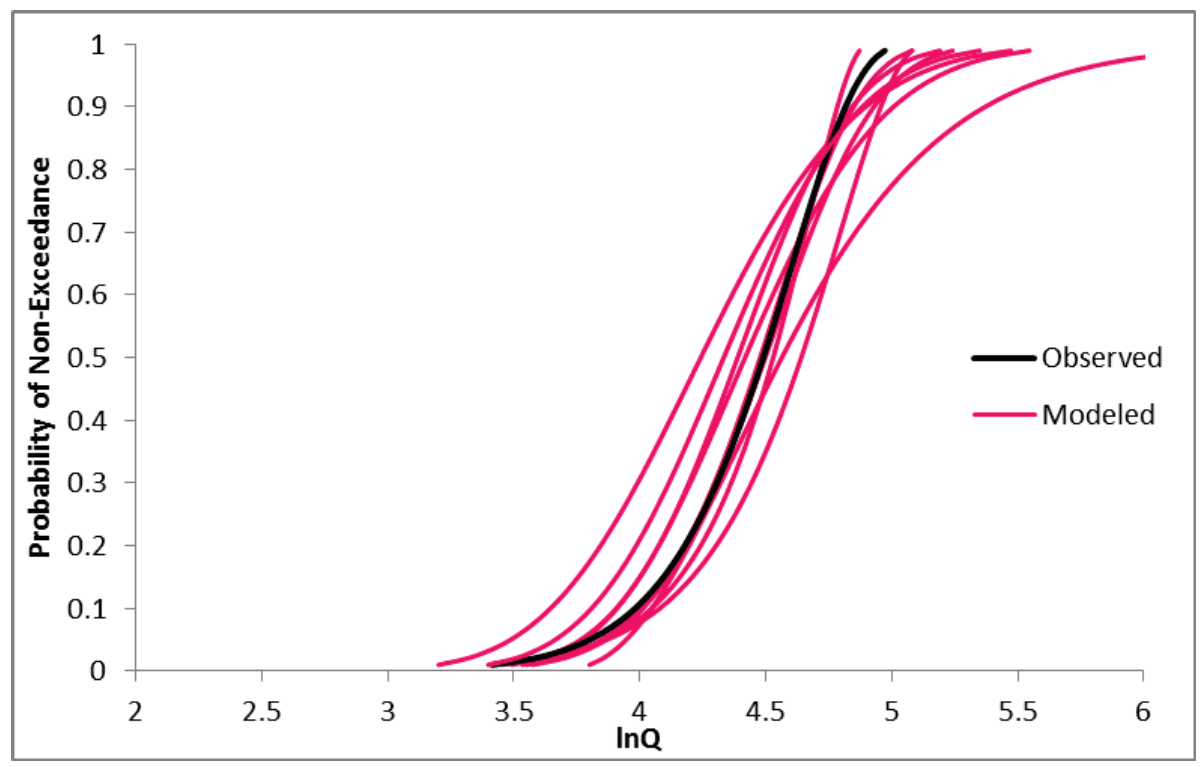

Figure 5.7 LP3 distributions (log space) produced using delta changed climate data overlaid with the distribution fit to the observed AMF series for the Eagle Creek watershed (USGS Gage Station 03093000).

Figures 5.8 - 5.10 show a comparison of the fitted LP3 distributions for the observed AMF series and the modeled AMF series obtained with the two climate data application methods for the median, driest, and wettest climate scenarios considered, respectively. Under the median scenario, relatively no change in flood risk is projected when using delta changed climate data. Under the driest scenario, lower annual maximum flows are projected by both methods at most percentiles, with the delta change method surpassing the observed flows in the upper percentiles. The wettest scenario gives a modeled distribution produced with bias corrected data that consistently falls short of observed flows, with the converse being true for the distribution produced with delta changed data. 


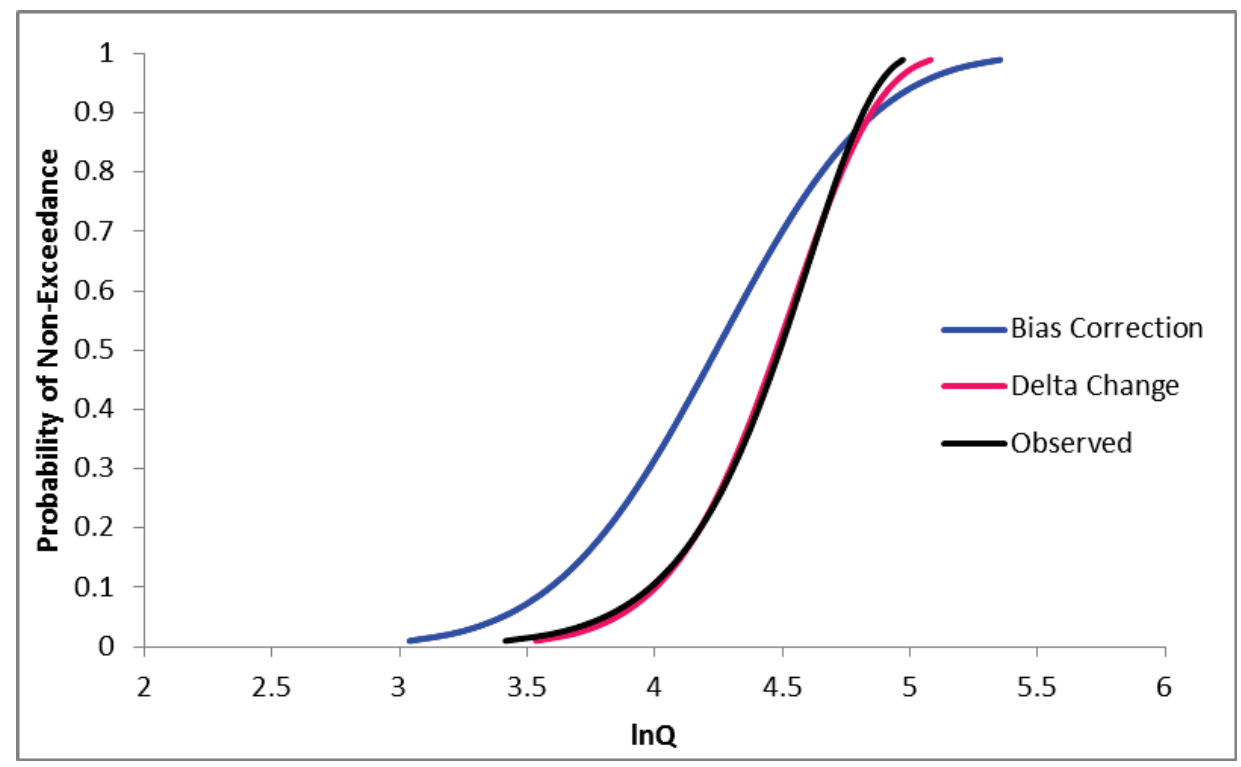

Figure 5.8 LP3 distributions (log space) of observed (1980-1999) and modeled (20462065) AMF series using two different climate data methods and the median future climate scenario (gfdl_cm2.1.a2) for the Eagle Creek Watershed (USGS Gage Station 03093000).

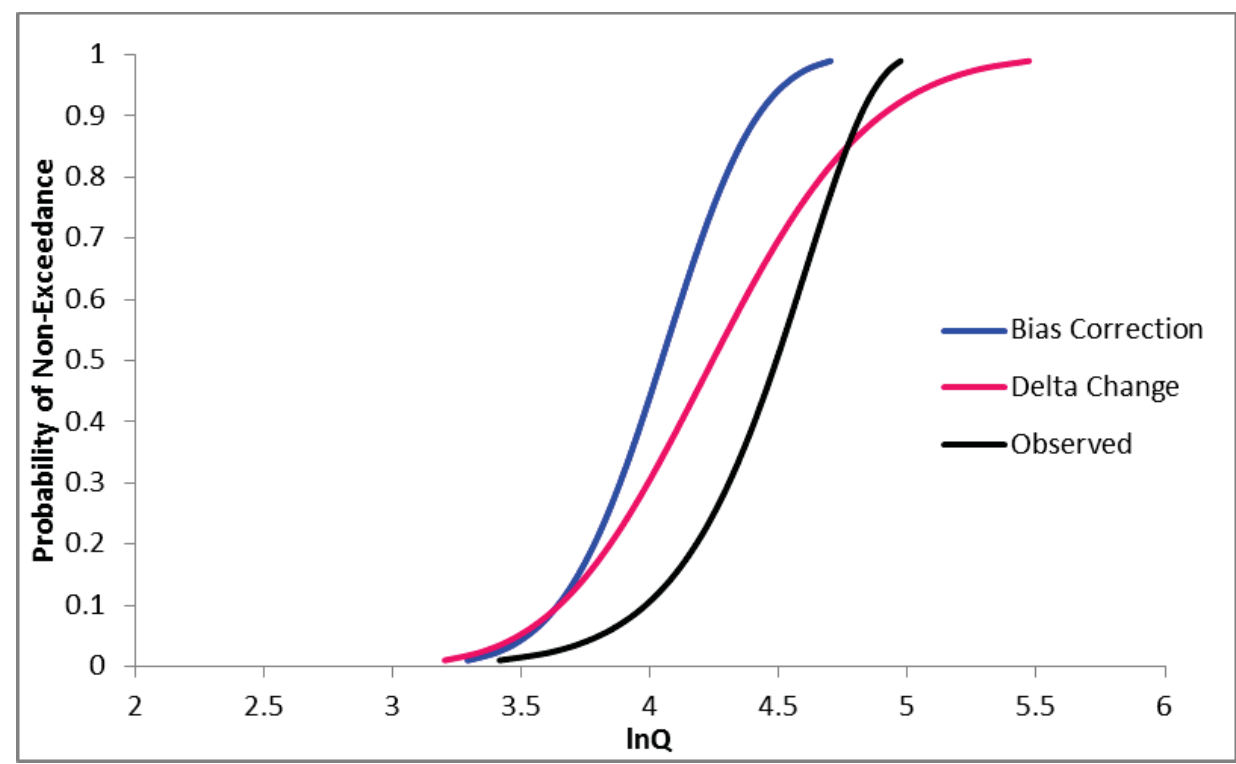

Figure 5.9 LP3 distributions (log space) of observed (1980-1999) and modeled (20462065) AMF series using two different climate data methods and the driest future climate scenario (miroc3_2_medres.1.a1b) for the Eagle Creek Watershed (USGS Gage Station 03093000). 


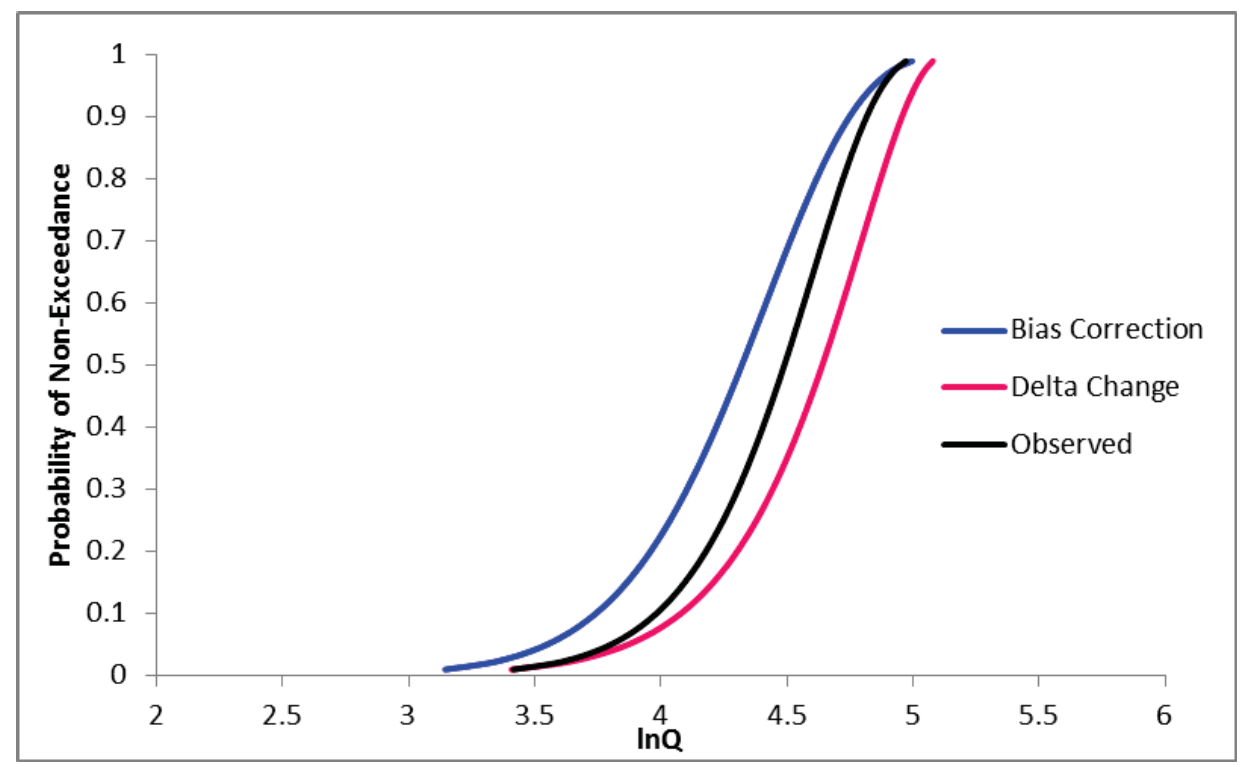

Figure 5.10 LP3 distributions (log space) of observed (1980-1999) and modeled (20462065) AMF series using two different climate data methods and the wettest future climate scenario (cnrm_cm3.1.a1b) for the Eagle Creek Watershed (USGS Gage Station 03093000).

In general, the delta change method consistently produces distributions with higher flow values and greater variation than the bias correction method. The mean peak flows and standard deviations produced by the bias correction method are generally smaller than those of the AMF series observed in the historic period, while those produced by the delta change method are generally higher than observed, the latter of which seems more reasonable as previously noted. For this watershed, precipitation also has a greater impact on mean peak flows than temperature, which makes sense because snowmelt is not a major factor. 


\subsection{USGS Gage 03144000}

Summary statistics for the observed (1980-1999) and projected (2046-2065) AMF series for the Wakatomika Creek watershed are reported in Table 5.5. For all nine future climate scenarios considered, the mean of the AMF series produced using the delta changed climate data is higher than that produced using the bias corrected data. The means of the AMF series produced using the bias corrected data are also lower than the mean of the observed AMF series in every case, while those produced by the delta change method are lower than observed in 7 of the 9 cases. Generally, increased precipitation results in increased mean peak flow; however, changes in temperature do not appear to significantly affect mean peak flow.

The standard deviations of the modeled AMF series are generally higher for the delta change method than the bias correction method. The standard deviation produced by the bias corrected data is lower than that of the observed AMF series in every case; similar results are observed in most scenarios for the standard deviations produced by the delta changed data. When using the delta change method, the modeled skew is generally higher than that of the observed AMF series and higher than the corresponding modeled skew using the bias correction method. The majority of the skews produced using the bias correction method are less than that of the observed AMF series. 
Table 5.5 Summary statistics of observed and modeled AMF series for the Wakatomika Creek watershed (USGS Gage Station 03144000) and associated changes in temperature and precipitation projected under nine representative future scenarios.

\begin{tabular}{|c|c|c|c|c|c|c|c|}
\hline GCM & SRES & Run & $\begin{array}{c}\Delta \mathbf{T} \\
\left({ }^{\circ} \mathbf{C}\right)\end{array}$ & $\begin{array}{c}\Delta P \\
(\%)\end{array}$ & $\begin{array}{c}\overline{\mathbf{Q}} \\
(\mathbf{c m s})\end{array}$ & $\begin{array}{c}\mathbf{S}_{\mathrm{Q}} \\
(\mathrm{cms})\end{array}$ & $\mathbf{G}_{\mathbf{Q}}$ \\
\hline & & & \multicolumn{5}{|c|}{ Modeled (2046-2065) with Bias Correction } \\
\hline miroc3_2_medres & $\mathrm{a} 1 \mathrm{~b}$ & 2 & 4.0 & -7.1 & 133.1 & 198.3 & 3.7 \\
\hline mri_cgcm2_3_2a & b1 & 4 & 1.7 & -0.4 & 122.9 & 136.8 & 2.7 \\
\hline cccma_cgcm3_1 & b1 & 2 & 2.2 & 1.2 & 147.6 & 145.8 & 2.7 \\
\hline gfdl_cm2_1 & $\mathrm{a} 1 \mathrm{~b}$ & 1 & 3.0 & 1.9 & 164.9 & 179.6 & 2.3 \\
\hline mri_cgcm2_3_2a & $\mathrm{a} 2$ & 2 & 2.4 & 5.5 & 129.5 & 136.2 & 2.4 \\
\hline cccma_cgcm3_1 & $\mathrm{a} 1 \mathrm{~b}$ & 1 & 3.1 & 8.5 & 168.7 & 170.4 & 2.0 \\
\hline cccma_cgcm3_1 & b1 & 1 & 2.0 & 8.7 & 203.1 & 310.9 & 3.8 \\
\hline mri_cgcm2_3_2a & b1 & 3 & 1.4 & 11.0 & 188.4 & 211.8 & 2.7 \\
\hline \multirow[t]{2}{*}{ cnrm_cm3 } & alb & 1 & 2.5 & 13.7 & 241.8 & 342.7 & 3.3 \\
\hline & & & \multicolumn{5}{|c|}{ Modeled (2046-2065) with Delta Change } \\
\hline miroc3_2_medres & $\mathrm{a} 1 \mathrm{~b}$ & 2 & 4.0 & -7.1 & 197.3 & 321.8 & 3.9 \\
\hline mri_cgcm2_3_2a & b1 & 4 & 1.6 & 1.9 & 254.1 & 362.9 & 3.6 \\
\hline cccma_cgcm3_1 & b1 & 2 & 1.9 & 2.4 & 218.9 & 241.7 & 2.8 \\
\hline gfdl_cm2_1 & $\mathrm{a} 1 \mathrm{~b}$ & 1 & 3.0 & 4.8 & 237.6 & 261.4 & 2.5 \\
\hline mri_cgcm2_3_2a & $\mathrm{a} 2$ & 2 & 2.5 & 4.6 & 223.7 & 271.3 & 3.0 \\
\hline cccma_cgcm3_1 & $\mathrm{a} 1 \mathrm{~b}$ & 1 & 2.8 & 4.9 & 250.1 & 300.5 & 3.2 \\
\hline cccma_cgcm3_1 & b1 & 1 & 1.8 & 5.1 & 238.7 & 302.5 & 3.4 \\
\hline mri_cgcm2_3_2a & b1 & 3 & 1.1 & 7.7 & 282.5 & 390.2 & 3.4 \\
\hline cnrm_cm3 & $\mathrm{a} 1 \mathrm{~b}$ & 1 & 2.3 & 13.4 & 308.3 & 434.5 & 3.6 \\
\hline \multicolumn{5}{|c|}{ Observed (1980-1999): } & 263.5 & 374.2 & 3.1 \\
\hline
\end{tabular}

Select flow percentiles of the LP3 distributions fit to the observed (1980-1999) and projected (2046-2065) AMF series for the Wakatomika Creek watershed are shown in 
Table 5.6. These results are visually displayed in Figures 5.11 and 5.12 for the bias correction and delta change methods, respectively, across the range of percentiles considered. For every scenario and at every percentile, the distributions produced by the delta change method suggest greater flood risk than those produced by the bias correction method. Most distributions produced with the bias corrected data project decreased annual maximum flows than those observed in the historic period across the range of percentiles. The distributions produced by the delta change data are varied, but if they surpass the observed distribution, it is usually at mid and upper percentiles. Overall, peak flow values seem to be positively correlated to change in precipitation at all percentiles other than the $99^{\text {th }}$; no clear relationship to changes in temperature may be discerned.

Figures 5.13 - 5.15 show a comparison of the fitted LP3 distributions for the observed AMF series and the modeled AMF series obtained with the two climate data application methods for the median, driest, and wettest climate scenarios considered, respectively. The percentiles of the modeled AMF series are all lower than those of the observed AMF series in both the driest and median scenarios regardless of the climate data application method employed, while increased flood risk is projected under the wettest scenario when using the delta change method only.

Overall, the results for this watershed suggest that flood risk may be reduced, and if they are increased, it will be for very extreme floods at the upper end of their respective distributions. Change in precipitation, again, seems to have an influence, in this case 
usually on the amount of flood risk reduction. Again, the delta change method

consistently produces distributions with higher flows and greater variability in flows than the bias correction method.

Table 5.6 Flow percentiles (cms) of LP3 distributions fit to observed AMF series for the Wakatomika Creek watershed (USGS Gage Station 03144000) and modeled AMF series for nine representative future climate scenarios each applied using two methods.

\begin{tabular}{|lcc|ccccc|}
\hline GCM & SRES & Run & $\mathbf{Q}_{\mathbf{0 . 0 1}}$ & $\mathbf{Q}_{\mathbf{0 . 1 0}}$ & $\mathbf{Q}_{\mathbf{0 . 5 0}}$ & $\mathbf{Q}_{\mathbf{0 . 9 0}}$ & $\mathbf{Q}_{\mathbf{0 . 9 9}}$ \\
\hline & & & Modeled $(2046-2065)$ with & Bias Correction \\
\hline miroc3_2_medres & a1b & 2 & 25.0 & 33.4 & 70.1 & 261.8 & 1265.8 \\
mri_cgcm2_3_2a & b1 & 4 & 18.3 & 31.6 & 77.8 & 254.8 & 842.1 \\
cccma_cgcm3_1 & b1 & 2 & 25.5 & 43.6 & 101.4 & 297.2 & 857.9 \\
gfdl_cm2_1 & a1b & 1 & 23.8 & 40.3 & 100.2 & 348.8 & 1269.2 \\
mri_cgcm2_3_2a & a2 & 2 & 17.2 & 32.0 & 83.1 & 273.4 & 870.5 \\
cccma_cgcm3_1 & a1b & 1 & 20.0 & 39.6 & 108.6 & 363.2 & 1136.1 \\
cccma_cgcm3_1 & b1 & 1 & 36.7 & 49.8 & 106.3 & 398.6 & 1907.8 \\
mri_cgcm2_3_2a & b1 & 3 & 32.1 & 50.2 & 115.7 & 386.6 & 1406.3 \\
cnrm_cm3 & a1b & 1 & 26.7 & 46.9 & 127.8 & 515.6 & 2217.1 \\
\hline & & & Modeled $(2046-2065)$ with & Delta Change \\
\hline miroc3_2_medres & a1b & 2 & 44.6 & 52.4 & 96.8 & 366.9 & 2097.8 \\
mri_cgcm2_3_2a & b1 & 4 & 43.7 & 61.4 & 135.7 & 511.2 & 2384.1 \\
cccma_cgcm3_1 & b1 & 2 & 38.6 & 59.9 & 136.3 & 447.8 & 1600.1 \\
gfdl_cm2_1 & a1b & 1 & 39.0 & 61.9 & 145.2 & 492.7 & 1808.4 \\
mri_cgcm2_3_2a & a2 & 2 & 39.1 & 57.8 & 130.0 & 457.9 & 1863.9 \\
cccma_cgcm3_1 & a1b & 1 & 44.5 & 67.2 & 151.1 & 507.7 & 1906.0 \\
cccma_cgcm3_1 & b1 & 1 & 50.4 & 68.6 & 140.9 & 469.8 & 1899.6 \\
mri_cgcm2_3_2a & b1 & 3 & 51.2 & 70.5 & 152.1 & 566.6 & 2648.2 \\
cnrm_cm3 & a1b & 1 & 72.5 & 88.9 & 168.0 & 588.7 & 2840.4 \\
\hline Observed (1980-1999): & 61.5 & 73.4 & 136.3 & 500.6 & 2682.8 \\
\hline
\end{tabular}




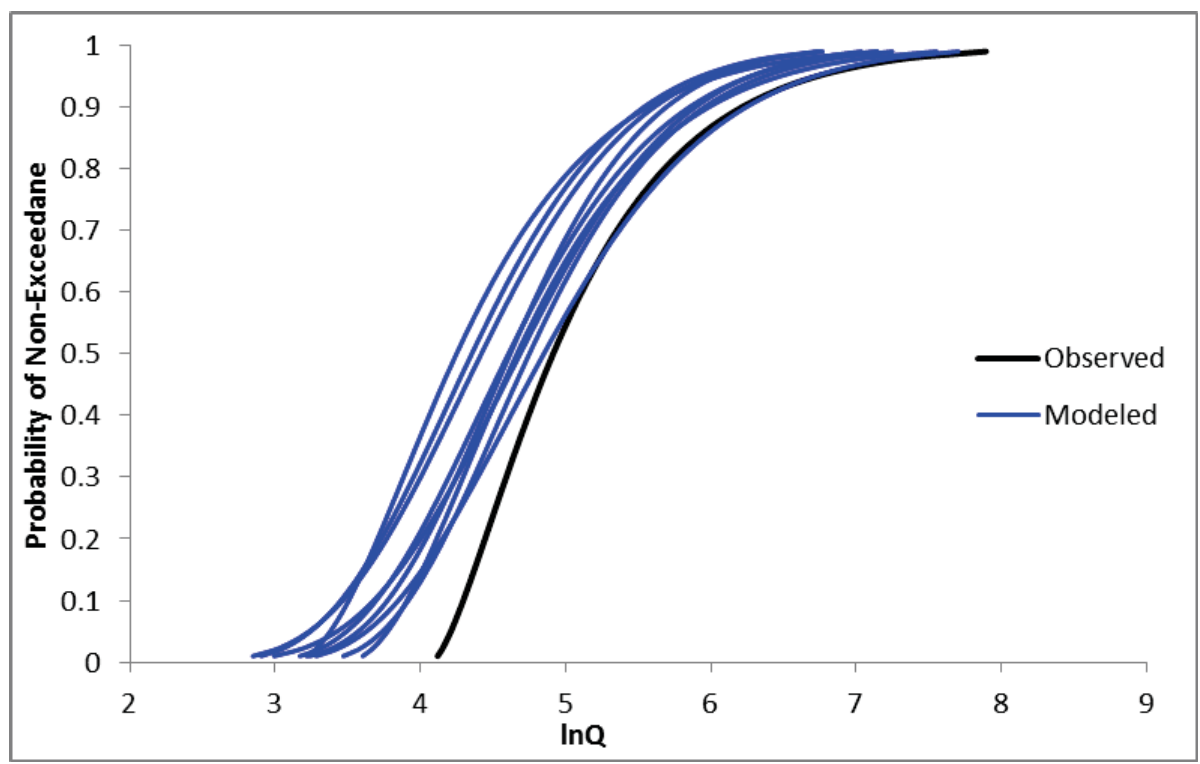

Figure 5.11 LP3 distributions (log space) produced using projected bias corrected climate data overlaid with the distribution fit to the observed AMF series for the Wakatomika Creek watershed (USGS Gage Station 03144000).

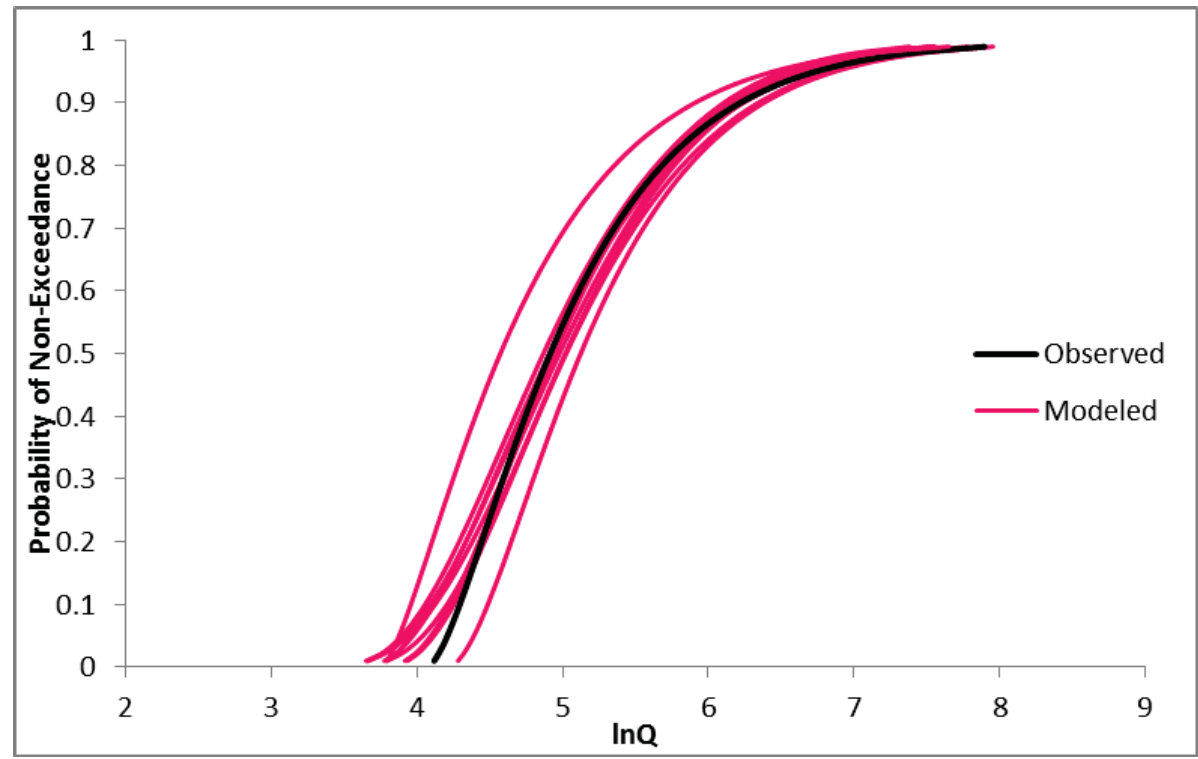

Figure 5.12 LP3 distributions (log space) produced using delta changed climate data overlaid with the distribution fit to the observed AMF series for the Wakatomika Creek watershed (USGS Gage Station 03144000). 


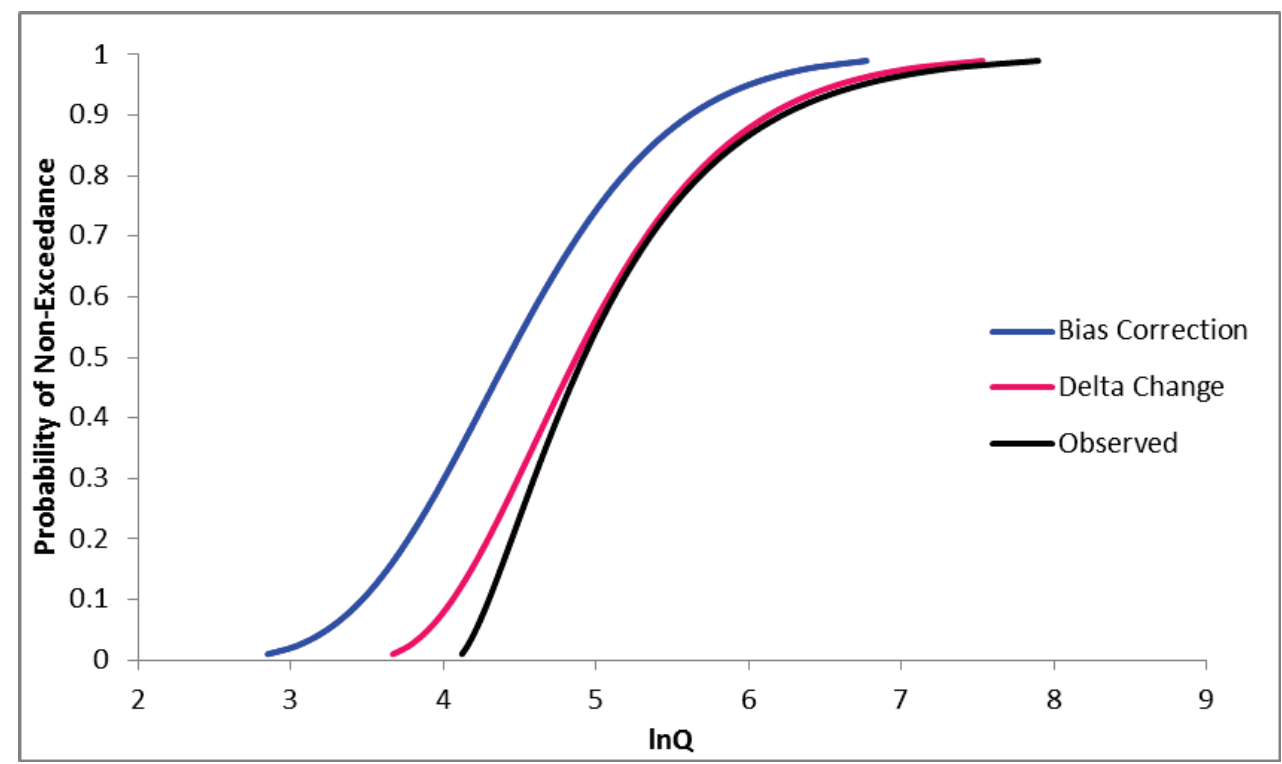

Figure 5.13 LP3 distributions (log space) of observed (1980-1999) and modeled (20462065) AMF series using two different climate data methods and the median future climate scenario (mri_cgcm2_3_2a.2.a2) for the Wakatomika Creek Watershed (USGS Gage Station 03144000).

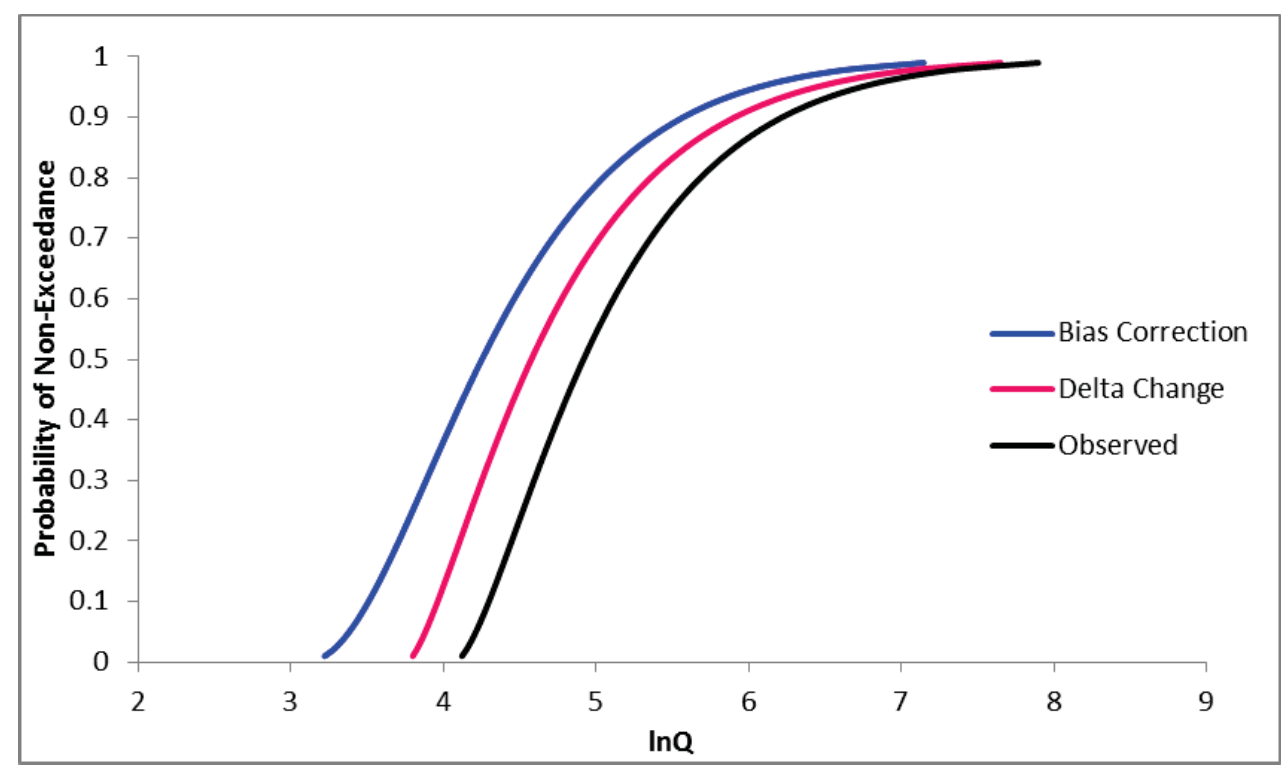

Figure 5.14 LP3 distributions (log space) of observed (1980-1999) and modeled (20462065) AMF series using two different climate data methods and the driest future climate scenario (miroc3_2_medres.2.a1b) for the Wakatomika Creek Watershed (USGS Gage Station 03144000). 


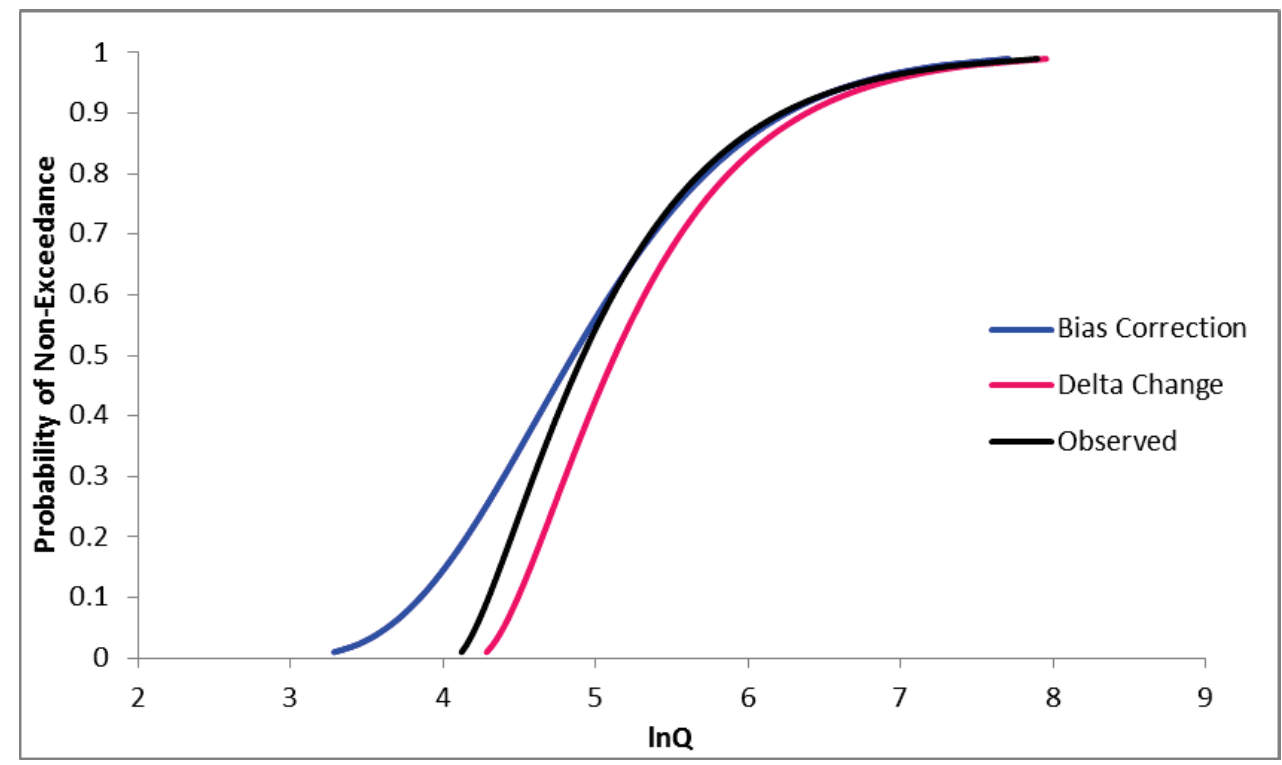

Figure 5.15 LP3 distributions (log space) of observed (1980-1999) and modeled (20462065) AMF series using two different climate data methods and the wettest future climate scenario (cnrm_cm3.1.a1b) for the Wakatomika Creek Watershed (USGS Gage Station 03144000).

\subsection{USGS Gage 03302000}

Summary statistics for the observed (1980-1999) and projected (2046-2065) AMF series for the Pond Creek watershed are reported in Table 5.7. The means of the future peak flow series generated when using the delta change method are consistently greater (in all 9 cases) than those produced using the bias correction method. Most of the AMF series produced with the delta changed data exhibit higher mean peak flows than that of the observed AMF series, while most of those produced using bias corrected data yield mean peak flows less than that for the historic period. Mean peak flows produced using the bias correction method do not appear to be correlated with change in precipitation, whereas there is a clear association between change in precipitation and mean peak flow when 
considering results from the delta change method. Results of neither method exhibit a relationship with temperature.

Table 5.7 Summary statistics of observed and modeled AMF series for the Pond Creek watershed (USGS Gage Station 03302000) and associated changes in temperature and precipitation projected under nine representative future scenarios.

\begin{tabular}{|c|c|c|c|c|c|c|c|}
\hline GCM & SRES & Run & $\begin{array}{c}\Delta \mathbf{T} \\
\left({ }^{\circ} \mathbf{C}\right)\end{array}$ & $\begin{array}{l}\Delta \mathrm{P} \\
(\%)\end{array}$ & $\begin{array}{c}\overline{\mathbf{Q}} \\
(\mathbf{c m s})\end{array}$ & $\begin{array}{c}\mathrm{S}_{\mathrm{Q}} \\
(\mathrm{cms})\end{array}$ & $\mathbf{G}_{\mathbf{Q}}$ \\
\hline & & & \multicolumn{5}{|c|}{ Modeled (2046-2065) with Bias Correction } \\
\hline miroc3_2_medres & $\mathrm{a} 1 \mathrm{~b}$ & 1 & 3.7 & -12.4 & 84.4 & 25.7 & -0.8 \\
\hline miroc3_2_medres & b1 & 2 & 2.8 & 0.8 & 87.9 & 22.5 & -1.1 \\
\hline cccma_cgcm3_1 & b1 & 2 & 2.0 & 1.0 & 103.3 & 22.6 & -2.1 \\
\hline mri_cgcm $2 \_3 \_2 a$ & b1 & 4 & 1.6 & 1.0 & 66.6 & 14.9 & -1.7 \\
\hline ipsl_cm4 & $\mathrm{a} 1 \mathrm{~b}$ & 1 & 3.9 & 5.5 & 74.9 & 28.4 & 0.4 \\
\hline cnrm_cm3 & alb & 1 & 2.5 & 6.2 & 123.6 & 41.7 & -0.1 \\
\hline cccma_cgcm3_1 & $\mathrm{a} 2$ & 3 & 2.7 & 8.8 & 101.0 & 27.8 & -0.1 \\
\hline cccma_cgcm3_1 & b1 & 3 & 2.0 & 9.2 & 95.6 & 27.4 & -1.2 \\
\hline \multirow[t]{2}{*}{ mri_cgcm2_3_2a } & $\mathrm{a} 2$ & 1 & 1.9 & 12.6 & 97.5 & 8.0 & -0.1 \\
\hline & & & \multicolumn{5}{|c|}{ Modeled (2046-2065) with Delta Change } \\
\hline miroc3_2_medres & $\mathrm{a} 1 \mathrm{~b}$ & 1 & 3.6 & -16.7 & 92.6 & 61.8 & 2.4 \\
\hline miroc3_2_medres & b1 & 2 & 2.8 & -5.6 & 95.8 & 47.4 & 1.9 \\
\hline cccma_cgcm3_1 & b1 & 2 & 1.9 & -4.4 & 108.2 & 57.8 & 2.4 \\
\hline mri_cgcm2_3_2a & b1 & 4 & 1.5 & -2.4 & 103.6 & 42.1 & 1.6 \\
\hline ipsl_cm4 & $\mathrm{a} 1 \mathrm{~b}$ & 1 & 3.8 & -1.0 & 101.3 & 56.5 & 2.4 \\
\hline $\mathrm{cnrm}_{-} \mathrm{cm} 3$ & $\mathrm{a} 1 \mathrm{~b}$ & 1 & 2.2 & 2.3 & 124.4 & 62.3 & 2.8 \\
\hline cccma_cgcm3_1 & $\mathrm{a} 2$ & 3 & 2.7 & 1.7 & 112.3 & 59.1 & 1.9 \\
\hline cccma_cgem3_1 & b1 & 3 & 1.9 & 2.5 & 124.9 & 55.5 & 1.2 \\
\hline mri_cgcm2 _3_2a & $\mathrm{a} 2$ & 1 & 1.8 & 7.5 & 130.1 & 60.3 & 1.3 \\
\hline \multicolumn{5}{|c|}{ Observed (1980-1999): } & 103.5 & 41.3 & 1.1 \\
\hline
\end{tabular}


Standard deviations of the modeled AMF series are greater when using the delta change method as opposed to the bias correction method in all cases. Most scenarios yield peak flow series with a standard deviation less than that of the observed AMF series when the bias corrected climate data is employed. Conversely, all scenarios yield future peak flow series with a standard deviation greater than that of the observed data when using the delta change method, which seems more plausible. In addition, the skews of modeled AMF series seem more reasonable when considering scenarios modeled using the delta change method, as they are all positive, which is consistent with that of the observed AMF series. On the contrary, the bias correction method produces mostly negative skews which do not seem as realistic.

Select flow percentiles of the LP3 distributions fit to the observed (1980-1999) and projected (2046-2065) AMF series for the Pond Creek watershed are shown in Table 5.8. At the $90^{\text {th }}$ and $99^{\text {th }}$ percentiles, all distributions produced by the delta change method yield higher flows than the distributions produced by the bias correction method. Results are mixed in the lower percentiles. A similar pattern emerges when comparing against the distribution fit to the observed AMF series. In the upper tail of the distribution, the majority of the percentiles produced by the bias correction method are lower than those for the historic period, while the percentiles produced by the delta change method are higher than observed. 
Table 5.8 Flow percentiles of LP3 distributions fit to observed AMF series for the Pond Creek watershed (USGS Gage Station 03302000) and modeled AMF series for nine representative future climate scenarios each applied using two methods.

\begin{tabular}{|lcc|ccccc|}
\hline GCM & SRES & Run & $\mathbf{Q}_{\mathbf{0 . 0 1}}$ & $\mathbf{Q}_{\mathbf{0 . 1 0}}$ & $\mathbf{Q}_{\mathbf{0 . 5 0}}$ & $\mathbf{Q}_{\mathbf{0 . 9 0}}$ & $\mathbf{Q}_{\mathbf{0 . 9 9}}$ \\
\hline & & & \multicolumn{4}{c}{ Modeled $(2046-2065)$ with } & Bias Correction \\
\hline miroc3_2_medres & a1b & 1 & 18.9 & 46.7 & 89.3 & 115.2 & 120.9 \\
miroc3_2_medres & b1 & 2 & 22.7 & 54.4 & 94.8 & 110.5 & 111.9 \\
cccma_cgcm3_1 & b1 & 2 & 26.5 & 68.5 & 113.3 & 122.1 & 122.3 \\
mri_cgcm2_3_2a & b1 & 4 & 23.3 & 44.3 & 70.1 & 83.8 & 86.6 \\
ipsl_cm4 & a1b & 1 & 26.9 & 42.0 & 70.5 & 114.6 & 166.6 \\
cnrm_cm3 & a1b & 1 & 44.8 & 71.8 & 119.1 & 182.9 & 246.0 \\
cccma_cgcm3_1 & a2 & 3 & 39.7 & 64.5 & 101.2 & 137.7 & 161.9 \\
cccma_cgcm3_1 & b1 & 3 & 19.6 & 53.8 & 103.4 & 125.1 & 127.5 \\
mri_cgcm2_3_2a & a2 & 1 & 78.5 & 87.2 & 97.7 & 107.8 & 115.5 \\
\hline & & & Modeled $(2046-2065)$ with & Delta Change \\
\hline miroc3_2 _medres & a1b & 1 & 11.2 & 32.7 & 85.8 & 161.2 & 219.8 \\
miroc3_2 _medres & b1 & 2 & 23.6 & 45.3 & 89.4 & 155.8 & 225.1 \\
cccma_cgcm3_1 & b1 & 2 & 25.3 & 50.5 & 101.5 & 174.9 & 246.1 \\
mri_cgcm2_3_2a & b1 & 4 & 36.7 & 57.8 & 97.5 & 158.1 & 228.2 \\
ips1_cm4 & a1b & 1 & 35.0 & 50.8 & 87.6 & 168.3 & 311.2 \\
cnrm_cm3 & a1b & 1 & 64.2 & 75.0 & 107.0 & 192.1 & 376.9 \\
cccma_cgcm3_1 & a2 & 3 & 30.2 & 52.7 & 101.0 & 187.5 & 303.3 \\
cccma_cgcm3_1 & b1 & 3 & 35.8 & 63.1 & 116.8 & 198.9 & 289.6 \\
mri_cgcm2_3_2a & a2 & 1 & 23.8 & 58.8 & 128.3 & 205.0 & 250.7 \\
\hline & & & & 58.7 & 95.9 & 158.7 & 241.7 \\
\hline
\end{tabular}

These results are visually displayed in Figures 5.16 and 5.17 for the bias correction and delta change methods, respectively. These figures clearly show how the delta change method consistently produces distributions with greater flow values than observed at the 100 
higher percentiles, and how the bias corrected GCM data produces the opposite (lower flow values than observed at higher percentiles). In addition, a relationship to precipitation is more apparent in results produced by the delta change method as opposed to the bias correction method.

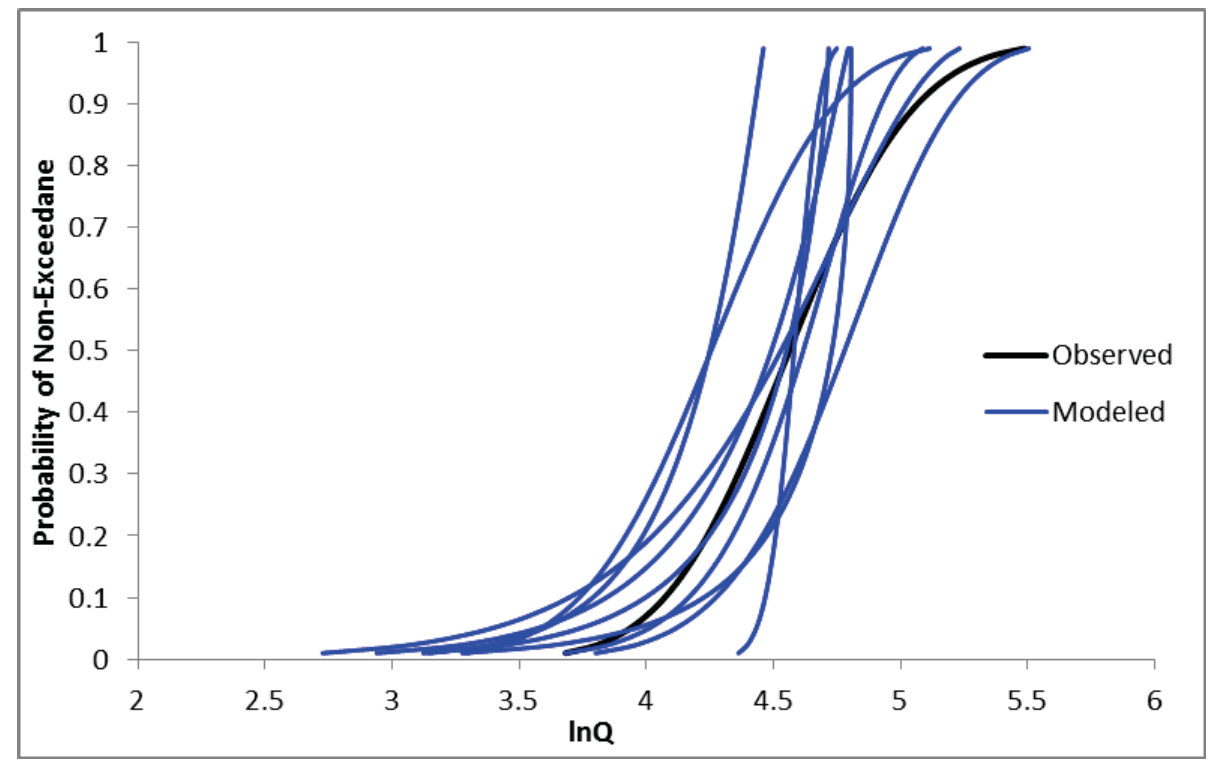

Figure 5.16 LP3 distributions (log space) produced using projected bias corrected climate data overlaid with the distribution fit to the observed AMF series for the Pond Creek watershed (USGS Gage Station 03302000). 


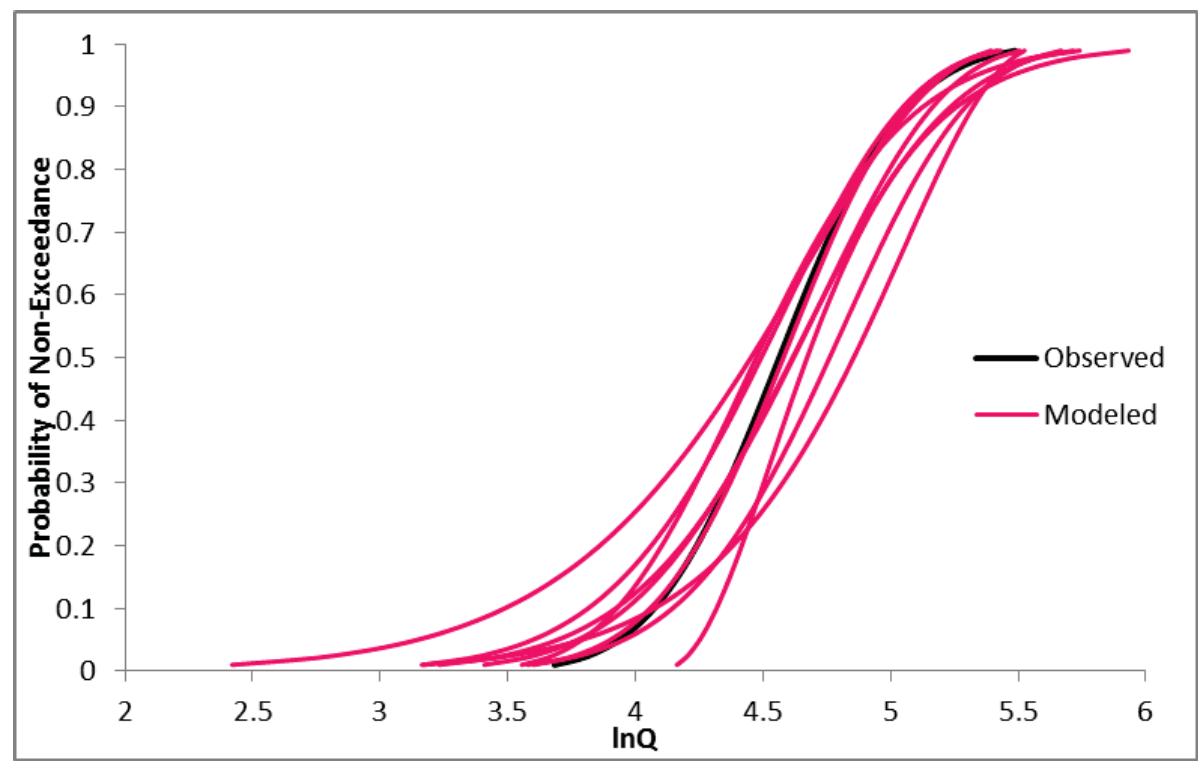

Figure 5.17 LP3 distributions (log space) produced using delta changed climate data overlaid with the distribution fit to the observed AMF series for the Eagle Creek watershed (USGS Gage Station 03302000).

Figures $5.18-5.20$ show a comparison of the fitted LP3 distributions for observed AMF series and modeled AMF series obtained with the two climate data application methods for the median, driest, and wettest climate scenarios considered, respectively. A strange upper bound on the distribution produced by the bias correction method is seen for scenario miroc3_2_medres.1.a1b. This is the only scenario for which the bias correction method projects a decrease in precipitation, and thus reduced flood risk is anticipated as the results suggest. However, the fitted distribution is extreme and unrealistic with values approaching an asymptote at an upper bound. 
Modeled distributions for the Pond Creek watershed indicate a general increase in flood risk under future climate scenarios when using the delta change method; results are mixed when the bias correction method is employed. As noted for other watersheds, the delta change method again produces higher flows and projects greater variability in future flows than the bias correction method. Further, skews of AMF series produced using the delta change method are more comparable to those for the observed AMF series, which makes it seem like a more realistic method of climate data application when modeling future flood risk.

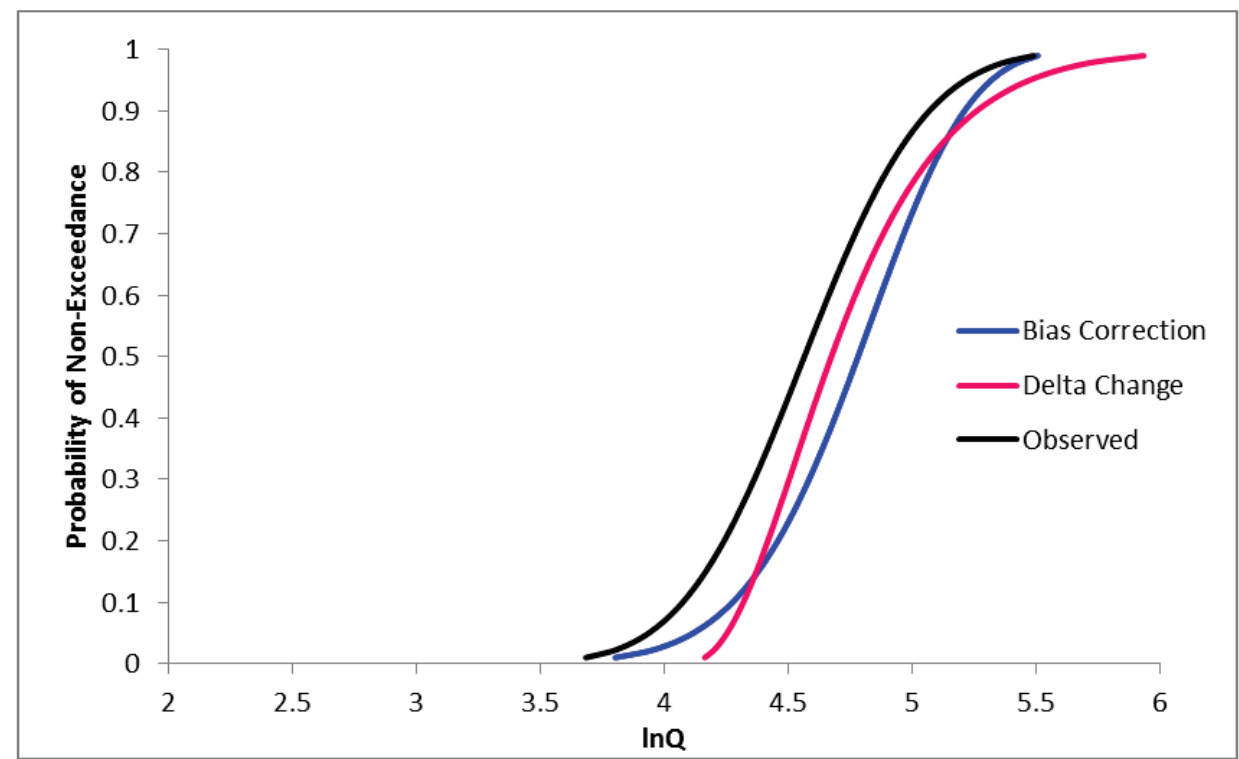

Figure 5.18 LP3 distributions (log space) of observed (1980-1999) and modeled (20462065) AMF series using two different climate data methods and the median future climate scenario (cnrm_cm3.1.a1b) for the Pond Creek Watershed (USGS Gage Station 03302000). 


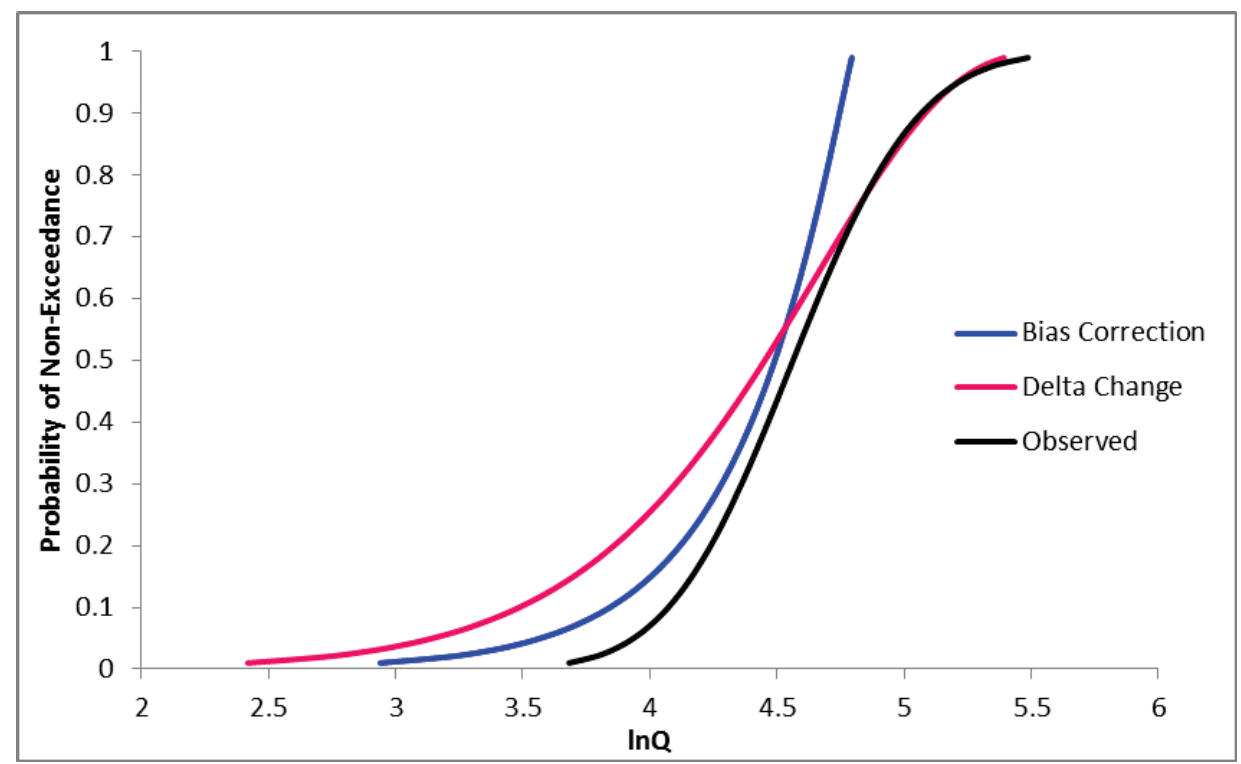

Figure 5.19 LP3 distributions (log space) of observed (1980-1999) and modeled (20462065) AMF series using two different climate data methods and the driest future climate scenario (miroc3_2_medres.1.a1b) for the Pond Creek Watershed (USGS Gage Station 03302000).

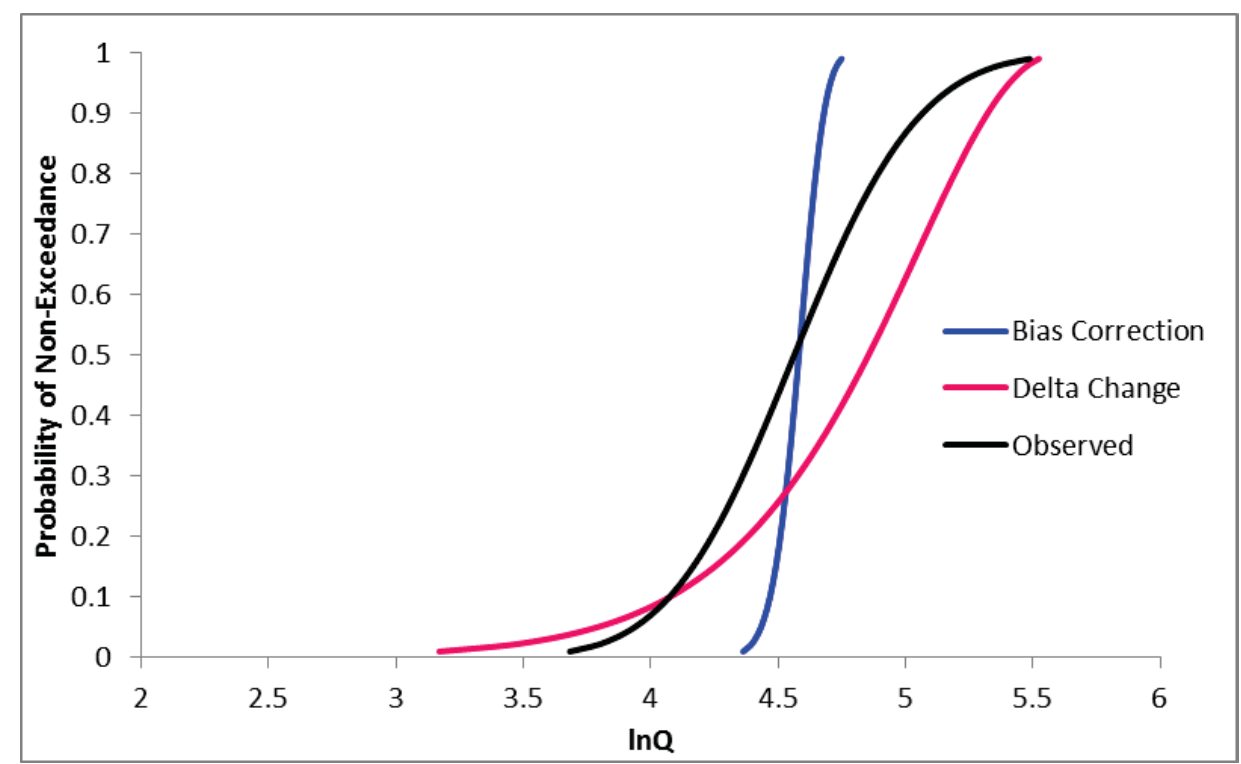

Figure 5.20 LP3 distributions (log space) of observed (1980-1999) and modeled (20462065) AMF series using two different climate data methods and the wettest future climate scenario (mri_cgcm2_3_2a.1.a2) for the Pond Creek Watershed (USGS Gage Station 03302000). 


\subsection{Results across Watersheds}

This section serves to identify any trends and patterns that were observed across all modeled watersheds, to analyze the differences between the four regarding their modeling responses, and attempt to explain some of those differences with physical watershed characteristics.

\subsubsection{Modeled Flood Risk vs. Observed}

The results of the modeling in terms of implications for changes in flood risk are obviously different when considering the two different methods of climate data application. When comparing the results based on the delta change method across the watersheds considered, the mean peak flows appear to have a relationship to precipitation in every case. The Fish River watershed, likely due to reduced snowpack, exhibited a decrease in peak flow magnitude, while increased peak flow magnitude was generally evident in two of the other three watersheds (relative to precipitation increase, so, barring extremely dry scenarios), especially in the upper tail of the distributions. Two of the watersheds generally showed a decrease in the variability of peak flows, and two showed an increase in the variability of peak flows.

On the contrary, the results produced using the bias correction method are quite different from those obtained using the delta change method. While three of the four watersheds still exhibit a relationship between mean peak flow and precipitation, the magnitude of the mean peak flow and standard deviation are consistently lower than the values computed for the observed AMF series. 
It is important to note that different $\mathrm{GCM} / \mathrm{emissions}$ scenario/run combinations were generally modeled in each of the four watersheds. And, the differences in modeling response to similar projections for changes in temperature and precipitation are of course attributable to the different hydrologic characteristics of the watersheds. A basic analysis of differences in runoff contribution is shown in Table 5.9. Results reported for the modeled AMF series consist of the mean of the AMF series produced using both the bias correction (BC) and delta change (DC) methods averaged across each of the nine representative climate scenarios considered. The means of the AMF series for both the historic and future periods are scaled by watershed area to allow for comparison across the four watersheds which vary considerably in size, and therefore, peak flow magnitude. In this way, greater percentages represent a watershed where a greater portion of the peak flows consist of runoff, suggesting a flashier response consistent with watersheds with larger degrees of barren land or impermeable surface.

Table 5.9 Land cover distribution, scaled observed mean peak flow values, and scaled modeled mean peak flow values for the four case study watersheds.

\begin{tabular}{|c|c|c|c|c|c|c|}
\hline \multirow{3}{*}{$\begin{array}{l}\text { USGS Gage } \\
\text { Station }\end{array}$} & \multicolumn{3}{|c|}{ Watershed Land Cover (\%) } & \multicolumn{3}{|c|}{$\begin{array}{c}\text { Mean Peak Flow scaled by } \\
\text { Watershed Area (\%) }\end{array}$} \\
\hline & \multirow{2}{*}{ Forest } & \multirow{2}{*}{ Agricultural } & \multirow[b]{2}{*}{ Urban } & \multirow{2}{*}{ Observed } & \multicolumn{2}{|c|}{ Modeled } \\
\hline & & & & & BC & DC \\
\hline 01013500 & 71.5 & 4.8 & 1.1 & 10.5 & 10.6 & 9.2 \\
\hline 03093000 & 48.2 & 32.4 & 8.7 & 35.2 & 29.8 & 37.0 \\
\hline 03144000 & 55.9 & 37.6 & 5.7 & 72.6 & 45.9 & 67.7 \\
\hline 03302000 & 27.9 & 1.1 & 69.3 & 62.0 & 55.5 & 66.1 \\
\hline
\end{tabular}


The Fish River watershed (USGS Gage 01013500) has the lowest proportion of runoff, likely due to its forested and pristine condition. Average base flow index as reported in GAGES II (Falcone 2011) is 53.6, 38.6, 36.9, and 22.9 for watersheds upstream of USGS Gage Stations 01013500, 03093000, 03144000, and 03302000, respectively. A higher base flow index indicates higher levels of recharge and groundwater contribution to flows. Thus, it makes sense that the most unaltered watershed with the lowest level of runoff (01013500) has the highest base flow index.

One would expect the most urbanized watershed (USGS Gage 03302000) to have the highest proportion of runoff, however, it does not. It is interesting to note that the Wakatomika Creek watershed (USGS Gage 03144000) has the greatest percent slope at 7.1\%, followed by the Fish River watershed (USGS Gage 01013500) at 6.9\%, and the Pond Creek (USGS Gage 03302000) and Eagle Creek (USGS Gage 03093000) watersheds at $2.5 \%$ and $1.8 \%$, respectively (Falcone 2011). The Wakatomika Creek watershed (USGS Gage 03144000) has the steepest slope and lowest base flow index, and perhaps this explains why it has the highest proportion of runoff. The mild slope of the Pond Creek watershed (USGS Gage 03302000) could explain the lower than expected relative proportion of runoff. 
Urban stormwater management methods (urban forestry, rain gardens, etc.) may also help to explain the lower proportion of runoff in the urban watershed, however, no detailed information on this aspect of the urbanization is available in GAGES II. Likewise, agricultural drainage methods could serve to increase runoff in the more agricultural watersheds.

Regardless, the three watersheds experiencing substantial urbanization and/or agricultural use exhibit far higher proportions of flow than the pristine watershed. Most importantly to this research, those watersheds that experience a higher proportion of runoff are also projected to experience a greater change in flood risk. This suggests that more runoffheavy watersheds are, in general, more vulnerable to the impacts of climate change with respect to potential increases or decreases in flood risk.

\subsubsection{The Delta Change Method vs. Bias Corrected GCM Data}

One pattern that can be seen across all four watersheds is the tendency for the delta change method to produce peak flow series with greater variability than those produced by the bias correction method. These results may possibly be attributed to the tendency of the bias corrected GCM data to do a poor job simulating daily rainfall values, as discussed in Chapter 3. It seems that the GCMs may "spread out" the precipitation - i.e., the same amount of rainfall may fall in a number of drizzle days according to a GCM, while an observed set of climate data (on which the delta changed method is based) may more accurately include large amounts of rainfall occurring over a shorter period of time 
(DeFlorio et al. 2013, Maurer et al. 2013). This drizzle effect could perhaps be due in part to errors in the GCMs themselves, or it could be introduced during the initial downscaling and bias correcting procedures. The quantile mapping bias correction is applied at a monthly time step (Brekke 2013), and a daily time step may be better.

Additionally, in three of the four watersheds, the delta change method overwhelmingly produced higher flows in general. Annual maximum flow distributions produced using the delta changed climate data made it seem much more likely for flood magnitudes to increase based on an increase in precipitation, especially at the upper tails of the distributions, which is consistent with what one would expect based on the predictions of climate scientists (IPCC 2013). The exception was the Fish River watershed, which seems to produce annual peak flows due to snowmelt, and perhaps higher temperatures are reducing snow accumulation, thus decreasing the flow magnitudes during the melt.

The delta change method also produced more reasonable estimates of skew for the Fish River and Pond Creek watersheds, with no discernible difference between the methods for the other two watersheds. Finally, the delta change method did not produce any unusual peak flow distributions that asymptotically approached upper or lower bounds, which happened quite a few times when using bias corrected GCM data. In general, the delta change method appears to be superior to using bias corrected GCM data when modeling future flood risk. 


\section{Conclusions}

Referring back to Chapter 1, the stated objectives for this research were to:

1. Demonstrate use of hydrologic models forced by GCM output to provide future flood risk estimates.

2. Analyze the application of GCM data in two ways: (i) direct application with a bias correction of precipitation data; and, (ii) shift of an observed dataset using the delta change method.

3. Interpret and understand differences in the climate data application methods in terms of: (i) overall average change in temperature and precipitation; (ii) daily distribution and variability of precipitation; and, (iii) impacts on modeled AMF distribution.

In regards to the first objective, four hydrologic models built using ArcSWAT were successfully forced with a host of projected climate data in order to provide future

estimates of flood risk. Overall, the results based on the use of the delta change method are reasonably consistent with climate scientists' predictions of increased peak flow magnitudes and variability, with the exception of the snowmelt-dominated watershed. Hydrologic modeling, when used on a larger scale (i.e. more than four watersheds as considered herein) and with improved calibrations appears as though it may be a useful tool for assessing possible changes in flood risk. 
When using the autocalibrator, as discussed in Chapter 4, the parameters were bounded and guided manually in order to fit realistic watershed characteristics as well as possible. However, more thorough and time-intensive research into the unique hydrologic mechanisms in each watershed could possibly improve calibration. A pre-calibration sensitivity analysis may be appropriate, as well as use of information in the GAGES II database (and others) to guide the parameter bounds.

Leading into Objectives 2 and 3, major differences were evident between projected AMF series obtained via forcing of the hydrologic models by the GCM bias correction and delta change methods, even though only modest differences in overall changes in temperature and precipitation are observed between the two correction methods. The delta change method appears to provide a more reasonable degree of variability in precipitation under future scenarios, and therefore more reasonable daily flow values are simulated, as needed for modeling of peak flows.

Flood risk is of course affected by more than long-term global climate change, and future models may be more useful when also considering the impacts of land cover change. Including land cover projections in the models could provide a more accurate range of flood risk to be anticipated in the future. This is especially necessary given that the preliminary results suggest that more developed watersheds are more vulnerable to changes in flood risk. Of course, the results herein are limited with only four case study watersheds considered, and thus this should be explored further in future research. 
Overall, the work herein demonstrates that future estimates of flood risk can be derived from hydrologic models forced by GCM projections. However, the results of these four models cannot be used to draw any broad conclusions about flood risk in general, nor can the individual models be used to directly predict flood risk in their respective watersheds. They can only be used as a tool to illustrate what may happen over a range of plausible future scenarios.

With more case study watersheds and better models, modeling results could be used in conjunction with regressions involving land cover and other physical watershed characteristics to incorporate long-term climate change into statistical models, and potentially update Bulletin 17B. A larger scale study is needed in order to obtain results that can truly be useful in determining the overarching impacts of climate change on flood risk in the Northeastern and Upper Midwestern U.S. as well as anticipated impacts in specific watersheds. 


\section{References}

Abbaspour, K.C., M. Vejdani and S. Haghighat, (2007), SWAT-CUP calibration and uncertainty programs for SWAT, In MODSIM 2007 International Congress on Modelling and Simulation, Modelling and Simulation Society of Australia and New Zealand.

Arnold, J.G., R. Srinivasan, R.S. Muttiah and J.R. Williams (1998), Large Area Hydrologic Modeling and Assessment Part I: Model Development, Journal of the American Water Resources Association, 34, 73 - 89.

Arnold, J.G., J.R. Kiniry, R. Srinivasan, J.R. Williams, E.B. Haney and S.L. Neitsch (2009), Soil and Water Assessment Tool Input/Output File Documentation Version 2009, Texas Water Resources Institute, Texas A\&M University, College Station, Texas.

Beven, K. and P. Smith (2014), Concepts of Information Content and Likelihood in Parameter Calibration for Hydrological Simulation Models, Journal of Hydrologic Engineering, doi: 10.1061/(ASCE)HE.1943-5584.0000991.

Blom, G. (1958), Statistical Estimates and Transformed Beta Variables, John Wiley and Sons, New York, New York.

Brekke, L (2013), Errata for “Downscaled CMIP3 and CMIP5 Climate and Hydrology Projections: Release of Downscaled CMIP5 Climate Projections, Comparison with preceding Information, and Summary of User Needs", available at <ftp://gdodcp.ucllnl.org/pub/dcp/archive/bcca/Errata.ClimateDownscalingDocumentation. 130717 .pdf $>$, accessed 07/2013.

Collins, M.J. (2009), Evidence for changing flood risk in New England since the late 20th century, Journal of the American Water Resources Association, 45, 279 - 290.

Dankers, R., O.B. Christensen, L. Feyen, M. Kalas, and A. de Roo (2007), Evaluation of very high-resolution climate model data for simulating flood hazards in the Upper Danube Basin, Journal of Hydrology, 347, 319 - 331.

DeFlorio, M.J., D.W. Pierce, D.R. Cayan, and A.J. Miller (2013), Western U.S. Extreme Precipitation Events and Their Relation to ENSO and PDO in CCSM4, Journal of Climate, 26, 4231 - 4243.

Falcone, J. (2011) GAGES-II: geospatial attributes of gages for evaluating streamflow, Digital spatial data set, available at <http://water.usgs.gov/GIS/metadata/usgswrd/ XML/gagesII_Sept2011.xml>, accessed 09/2012. 
Ficklin, D.L., Y. Luo, E. Luedeling, and M. Zhang (2009), Climate change sensitivity assessment of a highly agricultural watershed using SWAT, Journal of Hydrology, 374, $16-29$.

Fill, H.D. and A. A. Steiner (2003), Estimating Instantaneous Peak Flow from Mean Daily Flow Data, Journal of Hydrologic Engineering, 8, 365 - 369.

Fowler, H.J., S. Blenkinsop and C. Tebaldi (2007), Linking climate change modeling to impacts studies: recent advances in downscaling techniques for hydrological modeling, International Journal of Climatology, 27, 1547 - 1578.

Fritsch, C.E. (2012) Evaluation of Flood Risk in Response to Climate Variability, MS thesis, Department of Civil and Environmental Engineering, Michigan Technological University, Houghton, MI.

Gesch, D.B. (2007) The National Elevation Dataset, in Digital Elevation Model Technologies and Applications: The DEM Users Manual, 2nd Edition, edited by D. Maune, Bethesda, Maryland, American Society for Photogrammetry and Remote Sensing, $99-118$.

Gesch, D., M. Oimoen, S. Greenlee, C. Nelson, M. Steuck, and D. Tyler (2002), The National Elevation Dataset, Photogrammetric Engineering and Remote Sensing, 68, 5 11.

Githui, F., W. Gitau, F. Mutua and W. Bauwens (2009), Climate change impact on SWAT simulated streamflow in western Kenya, International Journal of Climatology, $29,1823-1834$.

Graham, L.P., J. Andreasson and B. Carlsson (2007), Assessing climate change impacts on hydrology from an ensemble of regional climate models, model scales and linking methods - a case study on the Lule River basin, Climatic Change, 81, 293 - 307.

Gudmundsson, L., J.B. Bremnes, J.E. Haugen and T.E. Skaugen (2012), Technical note: Downscaling RCM precipitation to the station scale using quantile mapping - a comparison of methods, Hydrology and Earth System Sciences, 16, 3383 - 3390.

Hamlet, A.F. and D.P. Lettenmaier (1999), Effects of Climate Change on Hydrology and Water Resources in the Columbia River Basin, Journal of the American Water Resources Association, 35, 1597 - 1623.

Hanratty, M.P. and H.G. Stefan (1998), Simulating Climate Change Effects in a Minnesota Agricultural Watershed, Journal of Environmental Quality, 27, 1524 - 1532. 
Hay, L.E., R.L. Wilby and G.H. Leavesley (2000), A Comparison of Delta Change and Downscaled GCM Scenarios for Three Mountainous Basins in the United States, Journal of the American Water Resources Association, 36, 387 - 397.

Hidalgo, H.G., M.D. Dettinger and D.R. Cayan (2008), Downscaling with Constructed Analogues: Daily Precipitation and Temperature Fields over the United States, California Energy Commission, Public Interest Energy Research Program, Sacramento, California.

Huntington, T.G. (2006), Evidence for intensification of the global water cycle: Review and synthesis, Journal of Hydrology, 319, $83-95$.

Interagency Committee on Water Data (IACWD) (1982), Bulletin 17B (revised and corrected), in Guidelines For Determining Flood Flow Frequency, 28, Hydrologic Subcommission, Washington, D.C.

Intergovernmental Panel on Climate Change (IPCC) (2013), Summary for Policy Makers, in Climate Change 2013: The Physical Science Basis, contribution of Working Group I to the Fifth Assessment Report of the Intergovernmental Panel on Climate Change, edited by Stocker, T.F., D. Qin, G. K. Plattner, M. Tignor, S. K. Allen, J. Boschung, A. Nauels, Y. Xia, V. Bex and P.M. Midgley, Cambridge University Press, Cambridge, United Kingdom and New York, New York.

Jha, M., Z. Pan, E.S. Takle and R. Gu (2004), Impacts of climate change on streamflow in the Upper Mississippi River Basin: A regional climate model perspective, Journal of Geophysical Research, 109, D09105.

Lins, H.F. and J.R. Slack (1999), Streamflow trends in the United States, Geophysical Research Letters, 26, 227 - 230.

Loukas, A., L. Vasiliades and N.R. Dalezios (2002), Potential climate change impacts on flood producing mechanisms in southern British Columbia, Canada using the CGCMA1 simulation results, Journal of Hydrology, 259, 163 - 188.

Maurer, E.P., H.G. Hidalgo, T. Das, M.D. Dettinger and D.R. Cayan (2010), The utility of daily large-scale climate data in the assessment of climate change impacts on daily streamflow in California, Hydrology and Earth System Sciences, 14, 1125 - 1138.

Maurer, E.P., T. Das and D.R. Cayan (2013), Errors in climate model daily precipitation and temperature output: time invariance and implications for bias correction, Hydrology and Earth System Sciences, 17, 2147 - 2159.

McCabe, G.J. and D.M. Wolock (2002), A step increase in streamflow in the conterminous United States, Geophysical Research Letters, 29, L02185. 
Neitsch, S.L., J.G. Arnold, J.R. Kiniry and J.R. Williams (2009) Soil and Water Assessment Tool Theoretical Documentation: Version 2009, Texas Water Resources Institute, Texas A\&M, College Station, Texas.

Pettitt, A. N. (1979), A non-parametric approach to the change-point problem, Journal of Applied Statistics, 28, 126 - 135.

Prudhomme, C., N. Reynard and S. Crooks (2002), Downscaling of global climate models for flood frequency analysis: where are we now?, Hydrological Processes, 16, $1137-1150$.

Rasmussen, J., T.O. Sonnenborg, S. Stisen, L.P. Seaby, B. Christensen and K. Hinsby (2012), Climate change effects on irrigation demands and minimum stream discharge: impact of bias-correction method, Hydrology and Earth System Sciences, 16, 4675 4691.

Salvadori, N.M. (2013) Evaluation of Non-Stationarity in Annual Maximum Flood Series of Moderately Impaired Watersheds in the Upper Midwest and Northeastern United States, MS thesis, Department of Civil and Environmental Engineering, Michigan Technological University, Houghton, MI.

Small, D., S. Islam, and R.M. Vogel (2006), Trends in precipitation and streamflow in the eastern U.S.: Paradox or perception?, Geophysical Research Letters, 33, L03403.

Soil Survey Staff. Gridded Soil Survey Geographic (gSSURGO) Database for State name, United States Department of Agriculture, Natural Resources Conservation Service, Available online at <http://datagateway.nrcs.usda.gov/>, accessed August 2013.

Srinivasan, R., T.S. Ramanarayanan, J.G. Arnold and S.T. Bednarz (1998), Large Area Hydrologic Modeling and Assessment Part II: Model Application, Journal of the American Water Resources Association, 34, 91 - 101.

Stone, M.C., Hotchkiss, R.H. and L.O. Mearns (2003), Water yield responses to high and low spatial resolution climate change scenarios in the Missouri River Basin, Geophysical Research Letters, 30, 1186 - 1190.

Takle, E.S., M. Jha, and C.J. Anderson (2005), Hydrological cycle in the upper Mississippi River basin: 20th century simulations by multiple GCMs, Geophysical Research Letters, 32, L18407. 
Takle, E.S., M. Jha, C.J. Anderson, and P.W. Gassman (2005b), Climate Change Impacts on the Hydrology of the Upper Mississippi River Basin as Determined by an Ensemble of GCMs, in $18^{\text {th }}$ Conference on Climate Variability and Change.

Tuppad,P., K.R. Douglas-Mankin, T. Lee, R. Srinivasan, and J.G. Arnold (2011), Soil and Water Assessment Tool (SWAT) Hydrologic/Water Quality Model: Extended Capability and Wider Adoption, Transactions of the American Society of Agricultural and Biological Engineers, 54, 1677 - 1684.

USDA-SCS (1972), Chapter 4-10, Section 4: Hydrology, in National Engineering Handbook, USDA-SCS, Washington, D.C.

U.S. Geological Survey (USGS) (2012), National Water Information System data available on the World Wide Web (USGS Water Data for the Nation), available online at <http://waterdata.usgs.gov/nwis/>, accessed 09/2012.

Villarini, G., F. Serinaldi, J.A. Smith and W.F. Krajewski (2009), On the stationarity of annual flood peaks in the continental United States during the $20^{\text {th }}$ century, Water Resources Research, 45, W08417.

Vogelmann, J.E., S.M. Howard, L. Yang, C. R. Larson, B. K. Wylie, and J. N. Van Driel (2001), Completion of the 1990's National Land Cover Data Set for the conterminous United States, Photogrammetric Engineering and Remote Sensing, 67, 650 - 662.

Wilby, R.L., S.P. Charles, E. Zorita, B. Timbal, P. Whetton and L.O. Mearns (2004), Guidelines for Use of Climate Scenarios Developed from Statistical Downscaling Methods, Supporting material of the Intergovernmental Panel on Climate Change, available from the DDC of IPCC TGCIA, 27.

Yacoub, C. and A.P. Foguet (2012), Slope effects on SWAT modeling in a mountainous basin, Journal of Hydrologic Engineering, 18, 1663 - 1673.

Yang, J., P. Reichert, K.C. Abbaspour, J. Xia, \& H. Yang (2008), Comparing uncertainty analysis techniques for a SWAT application to the Chaohe Basin in China, Journal of Hydrology, 358, $1-23$.

Yang, W., J. Andreasson, L.P. Graham, J. Olsson, J. Rosberg and F. Wetterhall (2010), Distribution-based scaling to improve usability of regional climate model projections for hydrological climate change impacts studies, Hydrology Research, 41, 211 - 229.

Yue, S., and C.Y. Wang (2002), The applicability of pre-whitening to eliminate the influence of serial correlation on the Mann-Kendall test, Water Resources Research, $38,4-1-4-7$. 
Zhang, X., R. Srinivasan and F. Hao (2007), Predicting Hydrologic Response to Climate Change in the Luohe River Basin Using the SWAT Model, Transactions of the American Society of Agricultural and Biological Engineers, 50, 901 - 910.

Zorita, E. and H. Von Storch (1999), The Analog Method as a Simple Statistical Downscaling Technique: Comparison with More Complicated Methods, Journal of Climate, 12, 2474 - 2489. 


\section{Appendix A. Monthly Averaged Climate Model Output}

This appendix includes monthly averaged projected temperature and precipitation for the periods of 1961-1999, 1980-1999, and 2046-2065 for purposes of comparison and to

provide more information on how corrections of climate data were performed. Results are tabulated by watershed. 
Table A.1 Monthly averages of hindcasted gridded precipitation (mm/day) for the Fish River watershed (USGS Gage Station 01013500) calculated over the periods of 19611999 and 1980-1999.

\begin{tabular}{|c|c|c|c|c|c|c|c|c|c|c|}
\hline & GCM: & 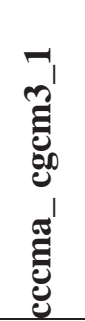 & 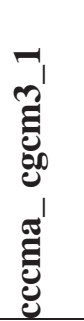 & $\begin{array}{l}\vec{J}^{\prime} \\
\mathfrak{E}^{\prime} \\
\vec{J}^{\prime}\end{array}$ & 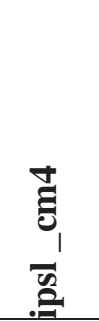 & 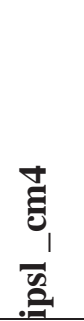 & 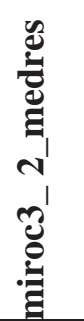 & 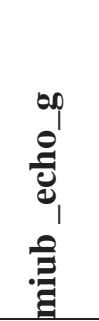 & 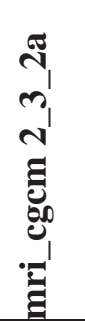 & 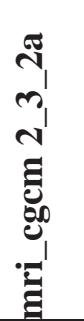 \\
\hline \multicolumn{2}{|c|}{$\begin{array}{c}\text { Emissions } \\
\text { Scenario: }\end{array}$} & $\mathbf{a} 1 \mathbf{b}$ & b1 & a2 & $\mathbf{a} 1 \mathbf{b}$ & $\mathbf{a} 2$ & b1 & $\mathbf{a} 1 \mathbf{b}$ & $\mathbf{a} 2$ & b1 \\
\hline \multicolumn{2}{|r|}{ Run: } & 3 & 2 & 1 & 1 & 1 & 2 & 2 & 5 & 1 \\
\hline \multirow{12}{*}{ 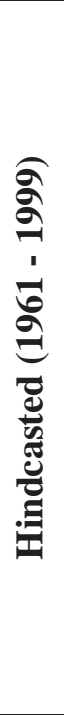 } & $\mathbf{J}$ & 1.75 & 1.77 & 1.79 & 1.75 & 1.75 & 1.83 & 1.77 & 1.75 & 1.65 \\
\hline & $\mathbf{F}$ & 1.58 & 1.56 & 1.54 & 1.65 & 1.65 & 1.54 & 1.63 & 1.53 & 1.52 \\
\hline & $\mathbf{M}$ & 1.81 & 1.86 & 1.71 & 1.75 & 1.75 & 1.68 & 1.62 & 1.64 & 1.72 \\
\hline & $\mathbf{A}$ & 1.81 & 1.85 & 1.87 & 1.81 & 1.81 & 1.74 & 1.90 & 1.78 & 1.85 \\
\hline & $\mathbf{M}$ & 2.35 & 2.22 & 2.17 & 2.28 & 2.28 & 2.38 & 2.42 & 2.12 & 2.14 \\
\hline & $\mathbf{J}$ & 2.54 & 2.59 & 2.62 & 2.56 & 2.56 & 2.54 & 2.54 & 2.56 & 2.56 \\
\hline & $\mathbf{J}$ & 2.84 & 2.86 & 2.92 & 2.74 & 2.74 & 2.93 & 2.85 & 2.87 & 2.81 \\
\hline & $\mathbf{A}$ & 2.84 & 2.75 & 2.65 & 2.56 & 2.56 & 2.83 & 2.94 & 2.79 & 2.81 \\
\hline & $\mathbf{S}$ & 2.88 & 2.93 & 2.74 & 2.78 & 2.78 & 2.83 & 2.77 & 2.84 & 2.78 \\
\hline & O & 2.42 & 2.38 & 2.56 & 2.51 & 2.51 & 2.54 & 2.52 & 2.57 & 2.51 \\
\hline & $\mathbf{N}$ & 2.36 & 2.35 & 2.42 & 2.34 & 2.34 & 2.44 & 2.41 & 2.30 & 2.36 \\
\hline & D & 2.13 & 2.14 & 1.95 & 2.16 & 2.16 & 2.00 & 2.01 & 1.87 & 1.99 \\
\hline \multirow{12}{*}{ 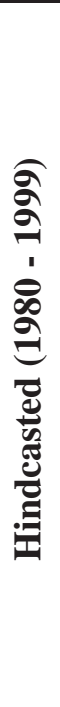 } & $\mathbf{J}$ & 1.89 & 1.94 & 1.90 & 1.85 & 1.85 & 1.70 & 1.82 & 1.77 & 1.69 \\
\hline & $\mathbf{F}$ & 1.77 & 1.63 & 1.48 & 1.51 & 1.51 & 1.64 & 1.79 & 1.57 & 1.46 \\
\hline & $\mathbf{M}$ & 2.07 & 1.89 & 1.87 & 1.72 & 1.72 & 1.57 & 1.46 & 1.54 & 1.51 \\
\hline & A & 1.99 & 1.90 & 1.83 & 1.83 & 1.83 & 1.79 & 2.09 & 1.69 & 1.61 \\
\hline & $\mathbf{M}$ & 2.42 & 2.23 & 2.18 & 2.23 & 2.23 & 2.25 & 2.28 & 1.92 & 2.10 \\
\hline & $\mathbf{J}$ & 2.49 & 2.44 & 2.69 & 2.57 & 2.57 & 2.48 & 2.70 & 2.62 & 2.48 \\
\hline & $\mathbf{J}$ & 2.84 & 2.81 & 3.05 & 2.72 & 2.72 & 2.88 & 3.03 & 2.73 & 2.82 \\
\hline & A & 2.71 & 2.74 & 2.46 & 2.64 & 2.64 & 2.74 & 2.83 & 2.85 & 2.80 \\
\hline & $\mathbf{S}$ & 2.79 & 3.11 & 2.79 & 3.07 & 3.07 & 2.89 & 3.16 & 2.95 & 2.79 \\
\hline & $\mathbf{O}$ & 2.42 & 2.63 & 2.74 & 2.57 & 2.57 & 2.49 & 2.51 & 2.72 & 2.43 \\
\hline & $\mathbf{N}$ & 2.55 & 2.44 & 2.49 & 2.30 & 2.30 & 2.50 & 2.43 & 2.46 & 2.33 \\
\hline & D & 2.26 & 2.17 & 1.92 & 2.05 & 2.05 & 2.05 & 1.87 & 2.03 & 2.13 \\
\hline
\end{tabular}


Table A.2 Monthly averages of hindcasted gridded temperature $\left({ }^{\circ} \mathrm{C}\right)$ for the Fish River watershed (USGS Gage Station 01013500) calculated over the periods of 1961-1999 and 1980-1999.

\begin{tabular}{|c|c|c|c|c|c|c|c|c|c|c|}
\hline & GCM: & 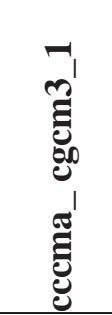 & 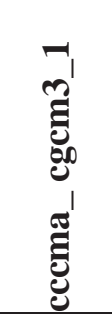 & $\begin{array}{l}\vec{J} \\
\tilde{E}^{\prime} \\
\vec{J}^{\prime}\end{array}$ & $\begin{array}{l}\stackrel{\vec{z}}{\tilde{U}_{1}} \\
\overline{\tilde{\omega}}_{\mathbf{z}}\end{array}$ & 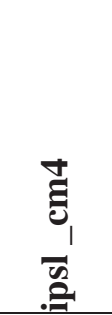 & 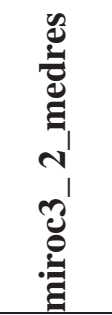 & 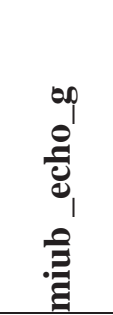 & 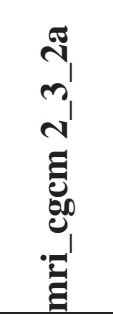 & 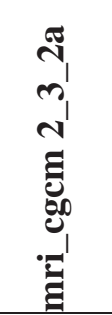 \\
\hline \multicolumn{2}{|c|}{$\begin{array}{l}\text { Emissions } \\
\text { Scenario: }\end{array}$} & a1b & b1 & a2 & a1b & a2 & b1 & a1b & a2 & b1 \\
\hline \multicolumn{2}{|r|}{ Run: } & 3 & 2 & 1 & 1 & 1 & 2 & 2 & 5 & 1 \\
\hline \multirow{12}{*}{ 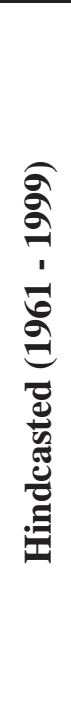 } & $\mathbf{J}$ & -13.81 & -13.90 & -13.94 & -13.79 & -13.79 & -13.83 & -13.81 & -14.00 & -13.99 \\
\hline & $\mathbf{F}$ & -12.43 & -12.51 & -12.52 & -12.43 & -12.43 & -12.33 & -12.41 & -12.48 & -12.45 \\
\hline & $\mathbf{M}$ & -5.56 & -5.71 & -5.64 & -5.70 & -5.70 & -5.70 & -5.59 & -5.73 & -5.65 \\
\hline & A & 1.99 & 1.79 & 1.84 & 1.83 & 1.83 & 1.79 & 1.80 & 1.76 & 1.68 \\
\hline & M & 9.34 & 9.18 & 9.26 & 9.23 & 9.23 & 9.14 & 9.25 & 9.23 & 9.14 \\
\hline & $\mathbf{J}$ & 14.96 & 15.04 & 14.93 & 15.09 & 15.09 & 14.99 & 15.05 & 14.88 & 14.94 \\
\hline & $\mathbf{J}$ & 17.61 & 17.61 & 17.63 & 17.63 & 17.63 & 17.64 & 17.58 & 17.52 & 17.55 \\
\hline & A & 16.24 & 16.27 & 16.29 & 16.32 & 16.32 & 16.31 & 16.29 & 16.17 & 16.16 \\
\hline & $\mathbf{S}$ & 11.28 & 11.33 & 11.29 & 11.29 & 11.29 & 11.20 & 11.19 & 11.28 & 11.24 \\
\hline & O & 5.33 & 5.33 & 5.33 & 5.42 & 5.42 & 5.37 & 5.27 & 5.26 & 5.20 \\
\hline & $\mathbf{N}$ & -1.61 & -1.59 & -1.57 & -1.54 & -1.54 & -1.54 & -1.60 & -1.61 & -1.64 \\
\hline & D & -9.84 & -9.85 & -9.85 & -9.74 & -9.74 & -9.79 & -9.88 & -9.89 & -9.85 \\
\hline \multirow{12}{*}{ 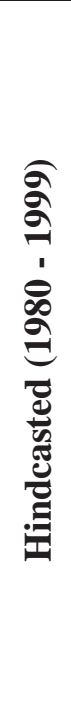 } & $\mathbf{J}$ & -13.39 & -13.07 & -14.13 & -13.68 & -13.68 & -13.64 & -13.33 & -13.68 & -13.73 \\
\hline & $\mathbf{F}$ & -11.98 & -12.27 & -12.43 & -12.29 & -12.29 & -12.46 & -12.21 & -12.35 & -11.83 \\
\hline & M & -5.04 & -5.51 & -5.54 & -5.40 & -5.40 & -6.05 & -5.50 & -5.31 & -5.67 \\
\hline & A & 2.02 & 2.37 & 1.72 & 2.24 & 2.24 & 1.66 & 2.05 & 1.67 & 1.96 \\
\hline & M & 9.73 & 9.95 & 9.18 & 9.39 & 9.39 & 9.80 & 9.59 & 9.39 & 9.42 \\
\hline & $\mathbf{J}$ & 15.50 & 15.40 & 15.10 & 15.48 & 15.48 & 14.98 & 15.38 & 15.05 & 15.13 \\
\hline & $\mathbf{J}$ & 17.91 & 18.02 & 17.74 & 17.73 & 17.73 & 17.47 & 17.73 & 17.43 & 17.63 \\
\hline & A & 16.29 & 16.94 & 16.19 & 16.55 & 16.55 & 16.40 & 16.73 & 16.15 & 16.29 \\
\hline & $\mathbf{S}$ & 11.61 & 11.89 & 11.54 & 11.46 & 11.46 & 11.58 & 11.51 & 11.45 & 11.55 \\
\hline & $\mathbf{O}$ & 5.41 & 5.44 & 5.41 & 5.58 & 5.58 & 5.37 & 5.86 & 5.46 & 5.70 \\
\hline & $\mathbf{N}$ & -1.57 & -1.08 & -1.45 & -0.88 & -0.88 & -1.46 & -1.03 & -1.26 & -1.39 \\
\hline & D & -9.28 & -9.50 & -9.52 & -9.94 & -9.94 & -9.97 & -9.41 & -8.99 & -9.26 \\
\hline
\end{tabular}


Table A.3 Monthly averages of forecasted gridded precipitation ( $\mathrm{mm} / \mathrm{day}$ ) for the Fish River watershed (USGS Gage Station 01013500) calculated over the period of 2046-2065.

\begin{tabular}{|c|c|c|c|c|c|c|c|c|c|c|}
\hline \multicolumn{2}{|c|}{ GCM: } & 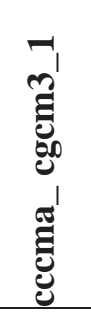 & 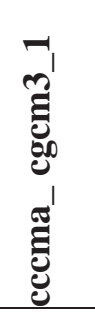 & 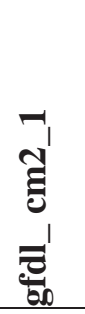 & 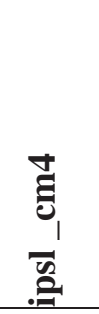 & 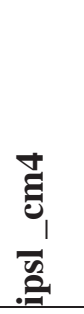 & 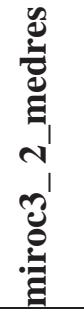 & 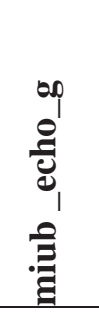 & 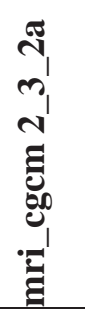 & 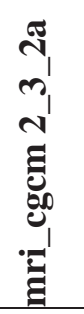 \\
\hline \multicolumn{2}{|c|}{$\begin{array}{l}\text { Emissions } \\
\text { Scenario: }\end{array}$} & a1b & b1 & $\mathbf{a} 2$ & a1b & a2 & b1 & a1b & a2 & b1 \\
\hline \multicolumn{2}{|c|}{ Run: } & 3 & 2 & 1 & 1 & 1 & 2 & 2 & 5 & 1 \\
\hline \multirow{12}{*}{ 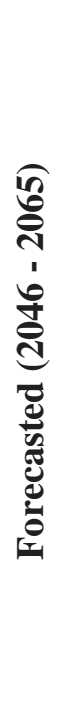 } & $\mathbf{J}$ & 2.63 & 2.22 & 2.18 & 2.71 & 2.20 & 1.92 & 1.89 & 1.95 & 1.98 \\
\hline & $\mathbf{F}$ & 2.26 & 2.12 & 1.90 & 2.02 & 1.85 & 1.90 & 2.11 & 1.76 & 1.65 \\
\hline & $\mathbf{M}$ & 2.05 & 1.82 & 1.75 & 1.79 & 1.92 & 1.64 & 2.28 & 1.59 & 1.76 \\
\hline & A & 2.07 & 2.22 & 2.45 & 1.49 & 1.83 & 1.78 & 2.06 & 1.96 & 1.96 \\
\hline & $\mathbf{M}$ & 2.64 & 2.65 & 2.70 & 2.33 & 1.92 & 2.57 & 2.46 & 2.18 & 2.38 \\
\hline & $\mathbf{J}$ & 2.56 & 2.66 & 2.34 & 2.94 & 2.28 & 3.03 & 2.27 & 2.30 & 2.93 \\
\hline & $\mathbf{J}$ & 2.72 & 2.80 & 2.48 & 3.05 & 2.93 & 2.77 & 2.75 & 3.12 & 2.83 \\
\hline & $\mathbf{A}$ & 2.69 & 2.64 & 2.79 & 2.61 & 2.83 & 3.21 & 2.47 & 2.59 & 2.88 \\
\hline & $\mathbf{S}$ & 3.03 & 3.00 & 2.81 & 2.97 & 2.58 & 2.58 & 3.02 & 3.21 & 2.89 \\
\hline & $\mathbf{O}$ & 3.01 & 2.69 & 2.65 & 2.84 & 2.65 & 2.54 & 2.99 & 2.34 & 2.70 \\
\hline & $\mathbf{N}$ & 2.97 & 2.79 & 2.32 & 2.50 & 2.60 & 2.15 & 3.14 & 2.87 & 2.67 \\
\hline & D & 2.75 & 2.35 & 2.40 & 2.57 & 2.38 & 2.49 & 2.70 & 2.07 & 1.82 \\
\hline
\end{tabular}


Table A.4 Monthly averages of forecasted gridded temperature $\left({ }^{\circ} \mathrm{C}\right)$ for the Fish River watershed (USGS Gage Station 01013500) calculated over the period of 2046-2065.

\begin{tabular}{|c|c|c|c|c|c|c|c|c|c|c|}
\hline \multicolumn{2}{|c|}{ GCM: } & 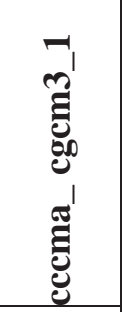 & 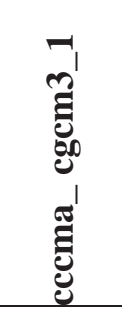 & 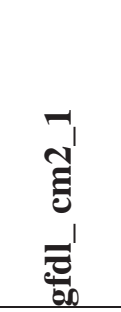 & 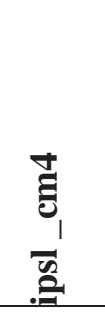 & 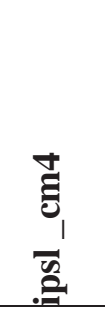 & 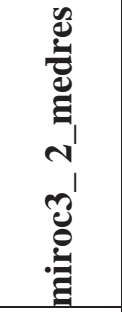 & 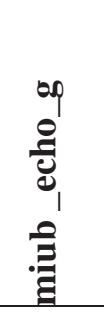 & 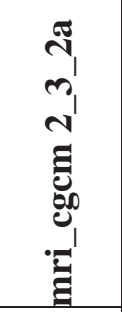 & 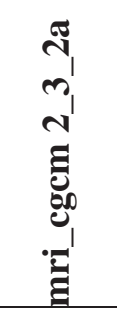 \\
\hline \multicolumn{2}{|c|}{$\begin{array}{l}\text { Emissions } \\
\text { Scenario: }\end{array}$} & a1b & b1 & a2 & a1b & a2 & b1 & a1b & a2 & b1 \\
\hline \multicolumn{2}{|r|}{ Run: } & 3 & 2 & 1 & 1 & 1 & 2 & 2 & 5 & 1 \\
\hline \multirow{12}{*}{ 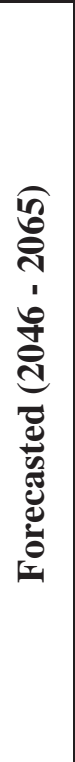 } & $\mathbf{J}$ & -10.48 & -11.61 & -10.46 & -8.51 & -9.74 & -10.60 & $\begin{array}{l}-9.67 \\
\end{array}$ & -11.86 & -11.54 \\
\hline & $\mathbf{F}$ & -7.82 & -10.07 & -9.44 & -7.48 & -8.54 & -9.70 & -9.16 & -9.29 & -11.73 \\
\hline & $\mathbf{M}$ & -3.40 & -3.53 & -4.15 & -1.69 & -2.05 & -2.68 & -4.17 & -3.98 & -5.20 \\
\hline & $\mathbf{A}$ & 4.31 & 3.38 & 5.43 & 6.26 & 6.26 & 5.66 & 3.40 & 3.28 & 3.14 \\
\hline & M & 11.66 & 11.34 & 11.03 & 13.94 & 13.00 & 12.97 & 11.51 & 10.30 & 10.18 \\
\hline & $\mathbf{J}$ & 17.57 & 17.00 & 17.07 & 18.63 & 18.26 & 17.74 & 17.99 & 16.85 & 16.28 \\
\hline & $\mathbf{J}$ & 20.20 & 19.36 & 20.38 & 21.65 & 21.19 & 20.81 & 20.97 & 19.36 & 19.47 \\
\hline & $\mathbf{A}$ & 18.70 & 18.59 & 18.82 & 20.10 & 19.81 & 19.33 & 19.43 & 17.88 & 17.73 \\
\hline & $\mathbf{S}$ & 13.69 & 13.24 & 14.29 & 14.85 & 15.27 & 13.84 & 14.37 & 13.12 & 12.59 \\
\hline & 0 & 7.69 & 7.40 & 6.93 & 9.38 & 9.03 & 8.15 & 8.53 & 7.14 & 6.70 \\
\hline & $\mathbf{N}$ & 1.01 & 0.48 & 0.26 & 3.36 & 3.14 & 1.04 & 2.15 & 0.96 & -0.23 \\
\hline & D & $\begin{array}{l}-7.02 \\
\end{array}$ & -8.11 & -6.20 & -4.15 & -5.13 & -6.67 & -5.54 & -6.35 & -8.00 \\
\hline
\end{tabular}


Table A.5 Monthly averages of hindcasted gridded precipitation ( $\mathrm{mm} /$ day) for the Eagle Creek watershed (USGS Gage Station 03093000) calculated over the periods of 19611999 and 1980-1999.

\begin{tabular}{|c|c|c|c|c|c|c|c|c|c|c|}
\hline \multicolumn{2}{|c|}{ GCM: } & 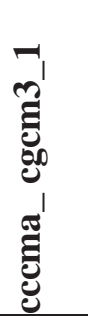 & 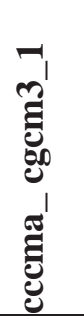 & 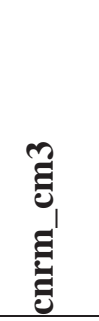 & 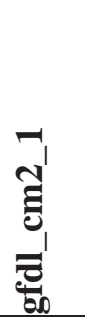 & 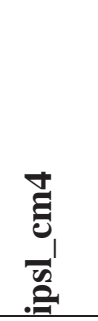 & 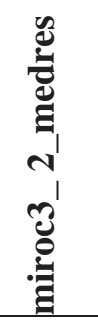 & 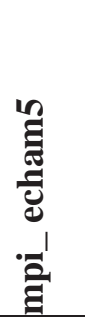 & 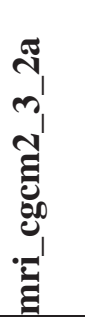 & 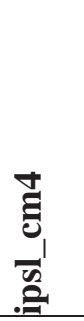 \\
\hline \multicolumn{2}{|c|}{$\begin{array}{c}\text { Emissions } \\
\text { Scenario: }\end{array}$} & a2 & b1 & a1b & a2 & a1b & a1b & a2 & b1 & b1 \\
\hline \multicolumn{2}{|c|}{ Run: } & 2 & 2 & 1 & 1 & 1 & 1 & 1 & 4 & 1 \\
\hline \multirow{12}{*}{ 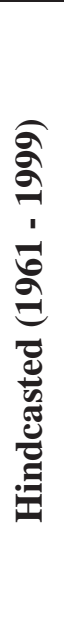 } & $\mathbf{J}$ & 1.61 & 1.61 & 1.78 & 1.56 & 1.60 & 1.60 & 1.63 & 1.57 & 1.60 \\
\hline & $\mathbf{F}$ & 1.59 & 1.59 & 1.61 & 1.70 & 1.63 & 1.66 & 1.61 & 1.71 & 1.63 \\
\hline & $\mathbf{M}$ & 2.17 & 2.17 & 2.15 & 2.02 & 2.11 & 2.12 & 2.11 & 2.07 & 2.11 \\
\hline & A & 2.31 & 2.31 & 2.30 & 2.34 & 2.41 & 2.35 & 2.33 & 2.31 & 2.41 \\
\hline & $\mathbf{M}$ & 2.26 & 2.26 & 2.25 & 2.26 & 2.29 & 2.29 & 2.24 & 2.24 & 2.29 \\
\hline & $\mathbf{J}$ & 2.48 & 2.48 & 2.26 & 2.18 & 2.17 & 2.25 & 2.21 & 2.43 & 2.17 \\
\hline & $\mathbf{J}$ & 2.18 & 2.18 & 2.22 & 2.15 & 2.18 & 2.33 & 2.32 & 2.33 & 2.18 \\
\hline & A & 2.07 & 2.07 & 1.99 & 2.01 & 2.02 & 1.83 & 2.03 & 2.04 & 2.02 \\
\hline & $\mathbf{S}$ & 2.15 & 2.15 & 2.12 & 2.13 & 2.22 & 2.20 & 2.29 & 2.35 & 2.22 \\
\hline & O & 2.06 & 2.06 & 1.94 & 2.14 & 1.99 & 2.08 & 2.08 & 2.12 & 1.99 \\
\hline & $\mathbf{N}$ & 2.32 & 2.32 & 2.25 & 2.22 & 2.17 & 2.29 & 2.22 & 2.26 & 2.17 \\
\hline & D & 1.94 & 1.94 & 2.07 & 1.90 & 1.98 & 1.97 & 1.93 & 2.00 & 1.98 \\
\hline \multirow{12}{*}{ 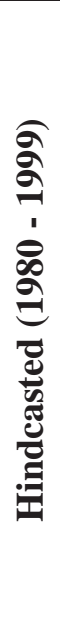 } & $\mathbf{J}$ & 1.73 & 1.73 & 1.89 & 1.71 & 1.76 & 1.53 & 1.59 & 1.74 & 1.76 \\
\hline & $\mathbf{F}$ & 1.52 & 1.52 & 1.60 & 1.69 & 1.69 & 1.58 & 1.58 & 1.81 & 1.69 \\
\hline & $\mathbf{M}$ & 2.25 & 2.25 & 2.17 & 2.16 & 2.19 & 2.20 & 2.23 & 2.06 & 2.19 \\
\hline & A & 2.39 & 2.39 & 2.42 & 2.33 & 2.60 & 2.30 & 2.47 & 2.45 & 2.60 \\
\hline & M & 2.10 & 2.10 & 2.32 & 2.28 & 2.31 & 2.46 & 2.38 & 2.01 & 2.31 \\
\hline & $\mathbf{J}$ & 2.48 & 2.48 & 2.27 & 2.24 & 2.13 & 2.33 & 2.27 & 2.34 & 2.13 \\
\hline & $\mathbf{J}$ & 2.16 & 2.16 & 2.17 & 1.99 & 2.41 & 2.46 & 2.52 & 2.21 & 2.41 \\
\hline & A & 2.05 & 2.05 & 2.09 & 2.05 & 1.96 & 1.92 & 2.16 & 1.92 & 1.96 \\
\hline & $S$ & 2.20 & 2.20 & 2.17 & 1.93 & 2.39 & 2.00 & 2.30 & 2.37 & 2.39 \\
\hline & 0 & 2.10 & 2.10 & 1.96 & 2.12 & 2.06 & 2.14 & 2.24 & 2.10 & 2.06 \\
\hline & $\mathbf{N}$ & 2.45 & 2.45 & 2.35 & 2.08 & 2.01 & 2.21 & 2.15 & 2.11 & 2.01 \\
\hline & D & 1.87 & 1.87 & 2.02 & 1.82 & 1.93 & 1.91 & 1.92 & 2.02 & 1.93 \\
\hline
\end{tabular}


Table A.6 Monthly averages of hindcasted gridded temperature $\left({ }^{\circ} \mathrm{C}\right)$ for the Eagle Creek watershed (USGS Gage Station 03093000) calculated over the periods of 1961-1999 and 1980-1999.

\begin{tabular}{|c|c|c|c|c|c|c|c|c|c|c|}
\hline & YCM: & 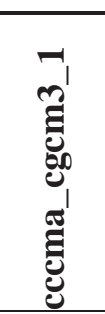 & 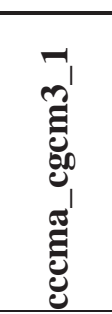 & 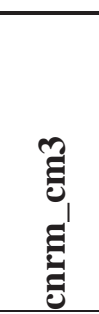 & 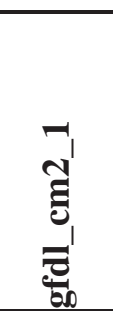 & 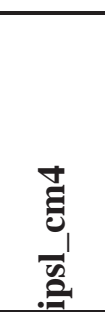 & 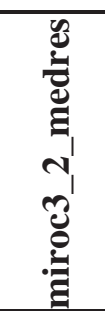 & 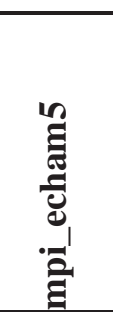 & 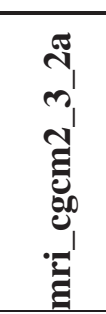 & 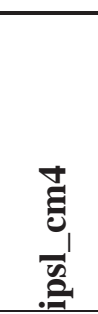 \\
\hline \multicolumn{2}{|c|}{$\begin{array}{l}\text { Emissions } \\
\text { Scenario: }\end{array}$} & a2 & b1 & a1b & a2 & a1b & a1b & a2 & b1 & b1 \\
\hline \multicolumn{2}{|r|}{ Run: } & 2 & 2 & 1 & 1 & 1 & 1 & 1 & 4 & 1 \\
\hline \multirow{12}{*}{ 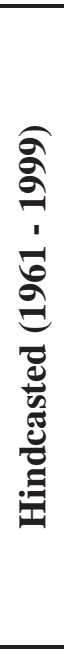 } & $\mathbf{J}$ & -3.93 & -3.93 & -3.95 & -3.95 & -3.91 & -4.02 & -3.88 & -3.97 & -3.91 \\
\hline & $\mathbf{F}$ & -2.65 & -2.65 & -2.63 & -2.64 & -2.57 & -2.51 & -2.56 & -2.47 & -2.57 \\
\hline & $\mathbf{M}$ & 2.64 & 2.64 & 2.64 & 2.66 & 2.64 & 2.70 & 2.68 & 2.67 & 2.64 \\
\hline & A & 8.69 & 8.69 & 8.67 & 8.73 & 8.73 & 8.85 & 8.71 & 8.85 & 8.73 \\
\hline & M & 14.56 & 14.56 & 14.70 & 14.65 & 14.65 & 14.78 & 14.66 & 14.75 & 14.65 \\
\hline & $\mathbf{J}$ & 19.53 & 19.53 & 19.59 & 19.58 & 19.52 & 19.60 & 19.60 & 19.55 & 19.52 \\
\hline & $\mathbf{J}$ & 21.85 & 21.85 & 21.81 & 21.84 & 21.81 & 21.82 & 21.82 & 21.86 & 21.81 \\
\hline & $\mathbf{A}$ & 20.92 & 20.92 & 20.89 & 20.87 & 20.86 & 20.86 & 20.87 & 20.87 & 20.86 \\
\hline & S & 17.09 & 17.09 & 17.06 & 17.07 & 17.09 & 16.93 & 17.20 & 17.08 & 17.09 \\
\hline & 0 & 10.93 & 10.93 & 10.89 & 10.94 & 10.96 & 10.94 & 10.97 & 11.02 & 10.96 \\
\hline & $\mathbf{N}$ & 4.96 & 4.96 & 4.83 & 5.03 & 5.05 & 4.98 & 5.11 & 5.00 & 5.05 \\
\hline & D & -0.81 & -0.81 & -0.99 & -0.92 & -0.84 & -0.98 & -0.95 & -0.79 & -0.84 \\
\hline \multirow{12}{*}{ 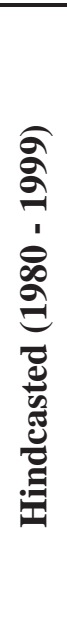 } & $\mathbf{J}$ & -3.26 & -3.26 & -3.35 & -4.23 & -3.79 & -3.93 & -3.49 & -3.58 & -3.79 \\
\hline & $\mathbf{F}$ & -2.60 & -2.60 & -2.53 & -2.46 & -2.30 & -2.32 & -2.16 & -1.98 & -2.30 \\
\hline & $\mathbf{M}$ & 2.92 & 2.92 & 3.31 & 2.80 & 3.67 & 3.50 & 2.91 & 2.95 & 3.67 \\
\hline & A & 9.38 & 9.38 & 9.27 & 9.09 & 9.83 & 9.18 & 8.96 & 9.23 & 9.83 \\
\hline & $\mathbf{M}$ & 15.00 & 15.00 & 14.83 & 14.60 & 14.74 & 14.86 & 14.79 & 14.98 & 14.74 \\
\hline & $\mathbf{J}$ & 20.19 & 20.19 & 19.74 & 20.01 & 19.82 & 19.86 & 19.56 & 19.88 & 19.82 \\
\hline & $\mathbf{J}$ & 22.11 & 22.11 & 22.44 & 22.07 & 22.03 & 22.12 & 22.15 & 22.25 & 22.03 \\
\hline & $\mathbf{A}$ & 21.52 & 21.52 & 21.36 & 21.02 & 21.29 & 21.19 & 20.89 & 21.10 & 21.29 \\
\hline & $\mathbf{S}$ & 17.82 & 17.82 & 17.13 & 17.35 & 17.11 & 17.20 & 17.20 & 17.37 & 17.11 \\
\hline & 0 & 11.04 & 11.04 & 10.89 & 10.71 & 11.04 & 11.56 & 11.25 & 11.26 & 11.04 \\
\hline & $\mathbf{N}$ & 5.63 & 5.63 & 5.03 & 5.26 & 5.37 & 5.41 & 5.66 & 4.98 & 5.37 \\
\hline & D & -0.37 & -0.37 & 0.19 & -0.27 & -0.40 & -0.56 & -0.50 & -1.13 & -0.40 \\
\hline
\end{tabular}


Table A.7 Monthly averages of forecasted gridded precipitation ( $\mathrm{mm} / \mathrm{day})$ for the Eagle Creek watershed (USGS Gage Station 03093000) calculated over the period of 2046-2065.

\begin{tabular}{|c|c|c|c|c|c|c|c|c|c|c|}
\hline \multicolumn{2}{|r|}{ GCM: } & 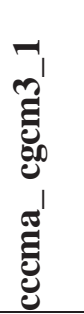 & 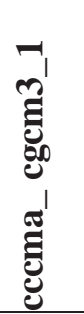 & 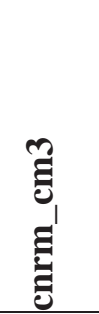 & 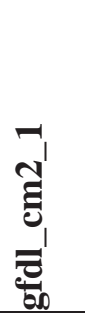 & 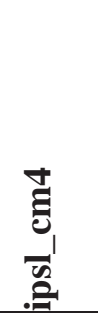 & 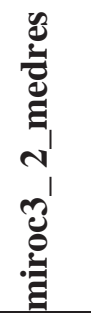 & 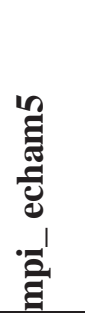 & 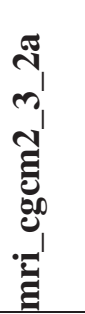 & 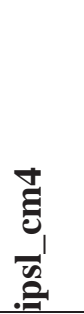 \\
\hline \multicolumn{2}{|c|}{$\begin{array}{c}\text { Emissions } \\
\text { Scenario: }\end{array}$} & a2 & b1 & a1b & a2 & a1b & a1b & a2 & b1 & b1 \\
\hline & Run: & 2 & 2 & 1 & 1 & 1 & 1 & 1 & 4 & 1 \\
\hline \multirow{12}{*}{ 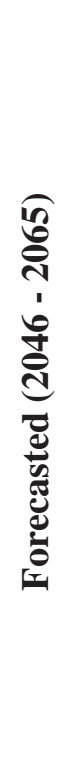 } & $\mathbf{J}$ & 2.10 & 1.61 & 1.79 & 1.90 & 1.96 & 1.59 & 2.04 & 1.62 & 1.71 \\
\hline & $\mathbf{F}$ & 2.29 & 1.86 & 1.85 & 1.98 & 1.85 & 1.92 & 1.83 & 1.89 & 1.40 \\
\hline & $\mathbf{M}$ & 2.53 & 2.33 & 2.68 & 2.14 & 2.01 & 2.28 & 2.28 & 1.87 & 2.24 \\
\hline & A & 2.62 & 2.97 & 2.56 & 2.79 & 2.05 & 2.53 & 2.73 & 2.58 & 2.54 \\
\hline & $\mathbf{M}$ & 2.61 & 2.13 & 2.40 & 2.71 & 2.13 & 2.36 & 2.42 & 2.35 & 2.20 \\
\hline & $\mathbf{J}$ & 2.18 & 2.12 & 2.75 & 1.94 & 2.08 & 1.60 & 2.29 & 2.48 & 1.97 \\
\hline & $\mathbf{J}$ & 1.95 & 1.77 & 2.38 & 1.94 & 2.59 & 1.63 & 2.27 & 2.28 & 2.21 \\
\hline & $\mathbf{A}$ & 2.22 & 2.21 & 2.22 & 1.84 & 2.08 & 1.55 & 2.19 & 2.10 & 2.01 \\
\hline & $\mathbf{S}$ & 2.44 & 1.99 & 2.58 & 2.07 & 1.95 & 1.69 & 2.32 & 2.39 & 2.03 \\
\hline & O & 1.65 & 1.90 & 2.38 & 2.34 & 2.24 & 2.14 & 2.54 & 2.07 & 2.00 \\
\hline & $\mathbf{N}$ & 2.86 & 2.68 & 2.37 & 2.02 & 2.35 & 2.11 & 2.19 & 1.92 & 2.38 \\
\hline & D & 2.08 & 2.05 & 2.29 & 2.06 & 2.57 & 2.03 & 2.18 & 1.98 & 2.38 \\
\hline
\end{tabular}


Table A.8 Monthly averages of forecasted gridded temperature $\left({ }^{\circ} \mathrm{C}\right)$ for the Eagle Creek watershed (USGS Gage Station 03093000) calculated over the period of 2046-2065.

\begin{tabular}{|c|c|c|c|c|c|c|c|c|c|c|}
\hline \multicolumn{2}{|c|}{ GCM: } & 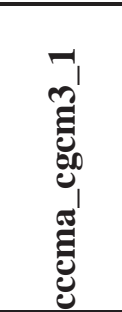 & 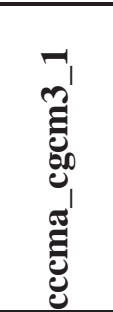 & 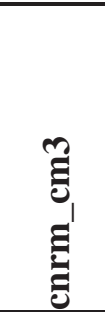 & 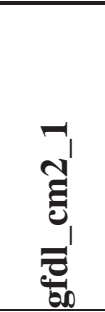 & 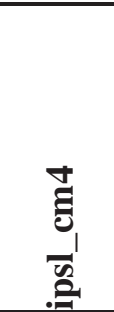 & 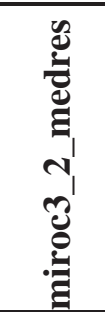 & 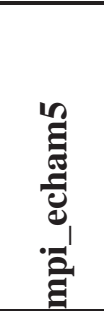 & 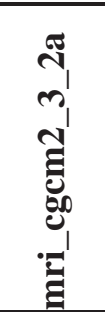 & 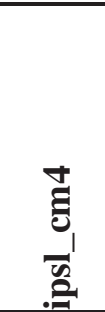 \\
\hline \multicolumn{2}{|c|}{$\begin{array}{c}\text { Emissions } \\
\text { Scenario: } \\
\end{array}$} & a2 & b1 & a1b & a2 & a1b & a1b & a2 & b1 & b1 \\
\hline \multicolumn{2}{|r|}{ Run: } & 2 & 2 & 1 & 1 & 1 & 1 & 1 & 4 & 1 \\
\hline \multirow{12}{*}{ 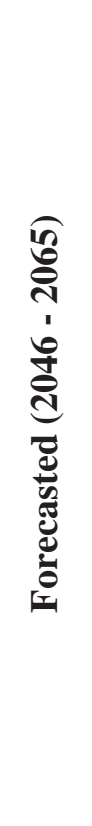 } & $\mathbf{J}$ & -1.47 & -2.83 & -0.75 & 1.55 & 0.29 & -0.81 & -1.71 & -1.85 & 0.03 \\
\hline & $\mathbf{F}$ & 1.50 & -0.33 & -1.45 & -0.44 & 3.33 & 1.76 & -1.18 & -1.62 & 0.11 \\
\hline & M & 6.36 & 5.55 & 4.20 & 2.60 & 7.64 & 7.25 & 3.88 & 3.42 & 5.52 \\
\hline & A & 11.97 & 11.47 & 10.82 & 11.20 & 13.74 & 13.40 & 10.16 & 10.27 & 11.88 \\
\hline & M & 17.58 & 17.39 & 17.19 & 17.11 & 19.08 & 18.20 & 16.83 & 16.28 & 18.04 \\
\hline & $\mathbf{J}$ & 22.49 & 21.70 & 22.58 & 22.49 & 22.73 & 22.67 & 21.44 & 21.59 & 21.68 \\
\hline & $\mathbf{J}$ & 24.38 & 3.75 & 24.32 & 25.01 & 5.11 & 25.70 & 24.57 & 3.67 & 23.94 \\
\hline & A & 23.57 & 23.01 & 23.71 & 24.90 & 24.67 & 24.86 & 23.65 & 21.74 & 23.46 \\
\hline & $S$ & 20.20 & 19.63 & 20.86 & 21.10 & 20.87 & 21.41 & 19.86 & 18.89 & 20.65 \\
\hline & O & 14.47 & 13.68 & 13.25 & 13.19 & 14.99 & 14.34 & 13.74 & 13.14 & 14.25 \\
\hline & $\mathbf{N}$ & 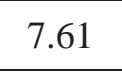 & - & 73 & 7.05 & 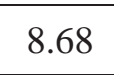 & 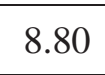 & 7.72 & 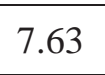 & 6.50 \\
\hline & D & 1.94 & 0.03 & 1.29 & 2.48 & 4.25 & 2.2 & 1.72 & 1.51 & 2.59 \\
\hline
\end{tabular}


Table A.9 Monthly averages of hindcasted gridded precipitation ( $\mathrm{mm} /$ day) for the Wakatomika Creek watershed (USGS Gage Station 03144000) calculated over the periods of 1961-1999 and 1980-1999.

\begin{tabular}{|c|c|c|c|c|c|c|c|c|c|c|}
\hline \multicolumn{2}{|c|}{ GCM: } & 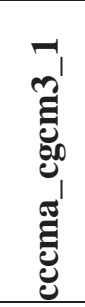 & 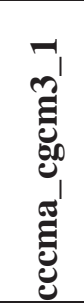 & 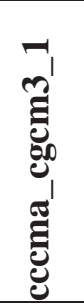 & 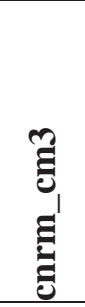 & 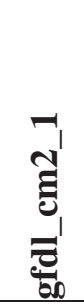 & 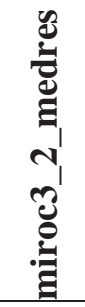 & 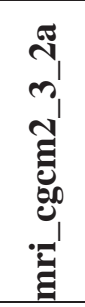 & 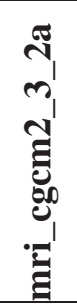 & 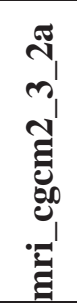 \\
\hline \multicolumn{2}{|c|}{$\begin{array}{l}\text { Emissions } \\
\text { Scenario: }\end{array}$} & a1b & b1 & b1 & a1b & a1b & a1b & $\mathbf{a} 2$ & b1 & b1 \\
\hline & Run: & 1 & 1 & 2 & 1 & 1 & 2 & 2 & 3 & 4 \\
\hline \multirow{12}{*}{ 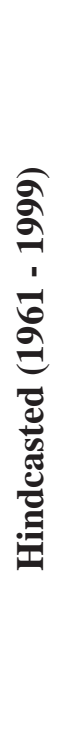 } & $\mathbf{J}$ & 1.75 & 1.75 & 1.68 & 1.82 & 1.59 & 1.77 & 1.73 & 1.54 & 1.56 \\
\hline & $\mathbf{F}$ & 1.81 & 1.81 & 1.68 & 1.68 & 1.83 & 1.84 & 1.61 & 1.75 & 1.86 \\
\hline & $\mathbf{M}$ & 2.23 & 2.23 & 2.37 & 2.35 & 2.18 & 2.24 & 2.33 & 2.19 & 2.22 \\
\hline & $\mathbf{A}$ & 2.50 & 2.50 & 2.52 & 2.52 & 2.51 & 2.52 & 2.68 & 2.56 & 2.52 \\
\hline & $\mathbf{M}$ & 2.55 & 2.55 & 2.51 & 2.47 & 2.51 & 2.54 & 2.55 & 2.57 & 2.58 \\
\hline & $\mathbf{J}$ & ' & 2.50 & 2.57 & 2.39 & 2.46 & 2.31 & 2.49 & 2.40 & 2.51 \\
\hline & $\mathbf{J}$ & 2.37 & 2.37 & 2.40 & 2.40 & 2.46 & 2.48 & 2.31 & 2.41 & 2.50 \\
\hline & A & 2.08 & 2.08 & 2.03 & 1.93 & 2.00 & 1.91 & 2.06 & 1.99 & 2.03 \\
\hline & $\mathbf{S}$ & 2.01 & 2.01 & 1.89 & 1.78 & 1.85 & 1.77 & 1.96 & 1.95 & 1.95 \\
\hline & O & 1.71 & 1.71 & 1.70 & 1.74 & 1.79 & 1.80 & 1.76 & 1.81 & 1.70 \\
\hline & $\mathbf{N}$ & 2.05 & 2.05 & 2.08 & 2.03 & 2.06 & 2.16 & 2.13 & 2.10 & 2.13 \\
\hline & D & 1.86 & 1.86 & 1.97 & 1.93 & 1.92 & 1.87 & 1.93 & 1.96 & 2.01 \\
\hline \multirow{12}{*}{ 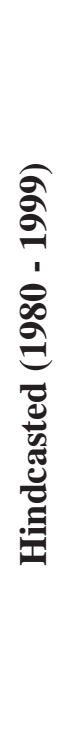 } & $\mathbf{J}$ & 1.84 & 1.84 & 1.78 & 1.93 & 1.72 & 1.86 & 1.73 & 1.61 & 1.71 \\
\hline & $\mathbf{F}$ & 2.05 & 2.05 & 1.61 & 1.59 & 1.78 & 1.95 & 1.73 & 1.87 & 2.07 \\
\hline & $\mathbf{M}$ & 2.37 & 2.37 & 2.46 & 2.30 & 2.28 & 2.32 & 2.26 & 2.36 & 2.22 \\
\hline & A & 2.55 & 2.55 & 2.56 & 2.67 & 2.52 & 2.53 & 2.91 & 2.64 & 2.64 \\
\hline & $\mathbf{M}$ & 2.69 & 2.69 & 2.21 & 2.48 & 2.61 & 2.54 & 2.61 & 2.76 & 2.43 \\
\hline & $\mathbf{J}$ & 2.42 & 2.42 & 2.52 & 2.44 & 2.44 & 2.22 & 2.54 & 2.40 & 2.43 \\
\hline & $\mathbf{J}$ & 2.60 & 2.60 & 2.40 & 2.36 & 2.10 & 2.55 & 2.21 & 2.28 & 2.28 \\
\hline & A & 2.27 & 2.27 & 2.00 & 2.06 & 2.05 & 1.70 & 2.00 & 1.97 & 1.99 \\
\hline & $\mathbf{S}$ & 2.12 & 2.12 & 2.06 & 1.85 & 1.63 & 1.70 & 1.96 & 2.06 & 1.90 \\
\hline & $\mathbf{O}$ & 1.75 & 1.75 & 1.70 & 1.76 & 1.77 & 2.02 & 1.87 & 1.90 & 1.67 \\
\hline & $\mathbf{N}$ & 2.08 & 2.08 & 2.17 & 2.09 & 1.93 & 2.15 & 2.39 & 2.42 & 2.00 \\
\hline & D & 1.95 & 1.95 & 1.95 & 1.91 & 1.89 & 2.09 & 1.96 & 2.17 & 2.06 \\
\hline
\end{tabular}


Table A.10 Monthly averages of hindcasted gridded temperature $\left({ }^{\circ} \mathrm{C}\right)$ for the Wakatomika Creek watershed (USGS Gage Station 03144000) calculated over the periods of 1961-1999 and 1980-1999.

\begin{tabular}{|c|c|c|c|c|c|c|c|c|c|c|}
\hline \multicolumn{2}{|c|}{ GCM: } & 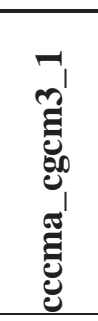 & 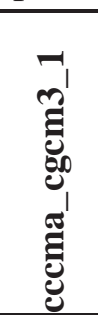 & 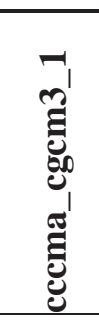 & 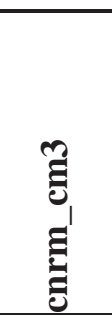 & 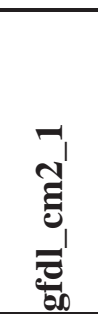 & 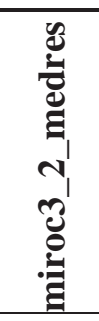 & 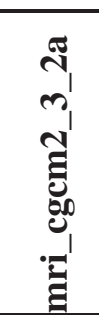 & 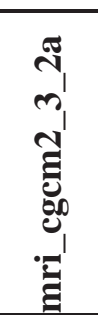 & 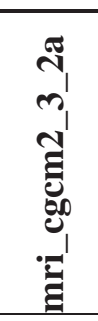 \\
\hline \multicolumn{2}{|c|}{$\begin{array}{l}\text { Emissions } \\
\text { Scenario: }\end{array}$} & a1b & b1 & b1 & a1b & a1b & a1b & a2 & b1 & b1 \\
\hline & Run: & 1 & 1 & 2 & 1 & 1 & 2 & 2 & 3 & 4 \\
\hline \multirow{12}{*}{ 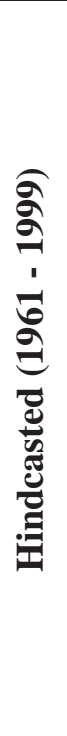 } & $\mathbf{J}$ & 3.62 & -3.62 & -3.54 & -3.63 & -3.62 & -3.74 & -3.70 & -3.77 & -3.65 \\
\hline & $\mathbf{F}$ & -1.94 & -1.94 & -1.98 & -2.00 & -2.01 & -1.89 & -2.13 & -1.96 & -1.84 \\
\hline & M & 3.68 & 3.68 & 3.60 & 3.56 & 3.56 & 3.75 & 3.60 & 3.65 & 3.59 \\
\hline & $\mathbf{A}$ & 9.45 & 9.45 & 9.30 & 9.33 & 9.35 & 9.46 & 9.45 & 9.45 & 9.47 \\
\hline & M & 15.10 & 15.10 & 15.04 & 15.13 & 15.08 & 15.09 & 15.16 & 15.11 & 15.20 \\
\hline & $\mathbf{J}$ & 20.00 & 20.00 & 20.04 & 20.07 & 20.02 & 20.05 & 20.05 & 20.06 & 20.04 \\
\hline & $\mathbf{J}$ & 22.20 & 22.20 & 22.19 & 22.16 & 22.17 & 22.16 & 22.18 & 22.16 & 22.20 \\
\hline & A & 21.25 & 21.25 & 21.20 & 21.22 & 21.15 & 21.18 & 21.19 & 21.19 & 21.14 \\
\hline & $\mathbf{S}$ & 17.40 & 17.40 & 17.39 & 17.35 & 17.36 & 17.35 & 17.42 & 17.31 & 17.33 \\
\hline & O & 10.93 & 10.93 & 10.97 & 10.96 & 10.99 & 11.00 & 10.99 & 11.03 & 11.03 \\
\hline & $\mathbf{N}$ & 5.03 & 5.03 & 5.08 & 4.94 & 5.11 & 5.08 & 4.92 & 5.08 & 5.07 \\
\hline & D & .62 & -0.62 & -0.55 & -0.76 & -0.71 & -0.62 & -0.78 & -0.66 & -0.59 \\
\hline \multirow{12}{*}{ 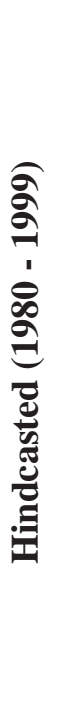 } & $\mathbf{J}$ & -2.91 & -2.91 & -2.81 & -3.01 & -3.92 & -3.84 & -3.63 & -3.78 & -3.22 \\
\hline & $\mathbf{F}$ & -0.55 & -0.55 & -1.94 & -1.82 & -1.75 & -1.96 & -1.63 & -1.44 & -1.30 \\
\hline & M & 3.94 & 3.94 & 3.84 & 4.24 & 3.75 & 3.44 & 3.71 & 4.39 & 3.91 \\
\hline & A & 9.94 & 9.94 & 9.94 & 9.92 & 9.76 & 10.04 & 9.15 & 10.05 & 9.89 \\
\hline & M & 15.59 & 15.59 & 15.37 & 15.36 & 15.07 & 15.28 & 14.98 & 15.71 & 15.37 \\
\hline & $\mathbf{J}$ & 20.37 & 20.37 & 20.65 & 20.21 & 20.44 & 19.97 & 19.86 & 20.32 & 20.33 \\
\hline & $\mathbf{J}$ & 22.23 & 22.23 & 22.45 & 22.76 & 22.40 & 22.17 & 22.25 & 22.54 & 22.59 \\
\hline & $\mathbf{A}$ & 21.43 & 21.43 & 21.72 & 21.68 & 21.40 & 21.54 & 21.52 & 21.56 & 21.42 \\
\hline & $\mathbf{S}$ & 18.07 & 18.07 & 18.16 & 17.52 & 17.60 & 17.59 & 17.58 & 17.80 & 17.58 \\
\hline & O & 11.01 & 11.01 & 11.07 & 10.97 & 10.78 & 11.37 & 11.45 & 11.61 & 11.27 \\
\hline & $\mathbf{N}$ & 5.72 & 5.72 & 5.78 & 5.06 & 5.35 & 5.08 & 4.94 & 5.99 & 5.06 \\
\hline & D & -0.38 & -0.38 & -0.12 & 0.48 & -0.04 & -0.61 & -0.82 & -0.14 & -0.98 \\
\hline
\end{tabular}

129 
Table A.11 Monthly averages of forecasted gridded precipitation ( $\mathrm{mm} /$ day) for the Wakatomika Creek watershed (USGS Gage Station 03144000) calculated over the period of 2046-2065.

\begin{tabular}{|c|c|c|c|c|c|c|c|c|c|c|}
\hline \multicolumn{2}{|c|}{ GCM: } & 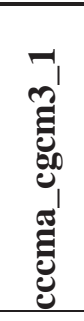 & 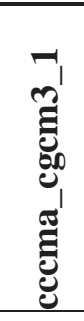 & 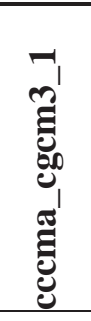 & 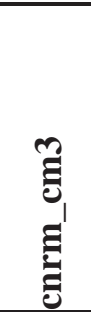 & 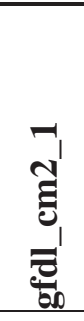 & 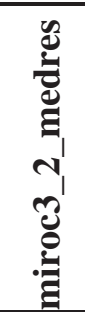 & 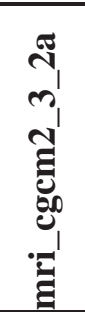 & 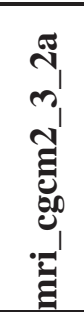 & 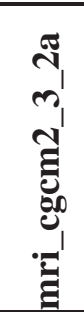 \\
\hline \multicolumn{2}{|c|}{$\begin{array}{l}\text { Emissions } \\
\text { Scenario: }\end{array}$} & a1b & b1 & b1 & a1b & a1b & a1b & $\mathbf{a} 2$ & b1 & b1 \\
\hline \multicolumn{2}{|c|}{ Run: } & 1 & 1 & 2 & 1 & 1 & 2 & 2 & 3 & 4 \\
\hline \multirow{12}{*}{ 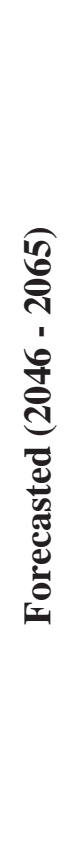 } & $\mathbf{J}$ & 1.91 & 1.68 & 1.59 & 1.86 & 2.10 & 1.76 & 1.60 & 1.78 & 1.69 \\
\hline & $\mathbf{F}$ & 2.06 & 1.80 & 2.00 & 2.17 & 1.90 & 1.99 & 1.82 & 1.83 & 1.97 \\
\hline & $\mathbf{M}$ & 2.70 & 2.50 & 2.64 & 2.80 & 2.66 & 2.65 & 2.61 & 2.78 & 2.02 \\
\hline & A & 3.19 & 3.10 & 3.17 & 3.06 & 3.12 & 2.36 & 2.64 & 2.71 & 2.84 \\
\hline & $\mathbf{M}$ & 2.48 & 3.02 & 2.09 & 2.83 & 2.79 & 2.18 & 2.83 & 2.46 & 2.49 \\
\hline & $\mathbf{J}$ & 2.43 & 2.42 & 2.21 & 3.05 & 2.06 & 2.36 & 2.38 & 2.78 & 2.70 \\
\hline & $\mathbf{J}$ & 2.08 & 2.41 & 2.05 & 2.41 & 2.00 & 1.95 & 2.31 & 2.53 & 2.34 \\
\hline & A & 2.35 & 2.25 & 2.27 & 2.05 & 1.62 & 1.17 & 2.33 & 2.34 & 2.03 \\
\hline & $\mathbf{S}$ & 1.84 & 1.88 & 1.68 & 2.10 & 2.02 & 1.35 & 2.36 & 2.20 & 1.97 \\
\hline & O & 1.46 & 1.75 & 1.65 & 2.01 & 1.58 & 1.92 & 1.57 & 2.10 & 1.85 \\
\hline & $\mathbf{N}$ & 2.70 & 2.27 & 2.53 & 2.04 & 1.89 & 1.97 & 2.34 & 2.16 & 1.67 \\
\hline & D & 2.56 & 2.57 & 2.00 & 2.17 & 2.08 & 2.10 & 2.13 & 2.37 & 1.93 \\
\hline
\end{tabular}


Table A.12 Monthly averages of forecasted gridded temperature $\left({ }^{\circ} \mathrm{C}\right)$ for the Wakatomika Creek watershed (USGS Gage Station 03144000) calculated over the period of 2046-2065.

\begin{tabular}{|c|c|c|c|c|c|c|c|c|c|c|}
\hline \multicolumn{2}{|c|}{ GCM: } & 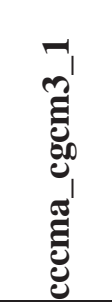 & 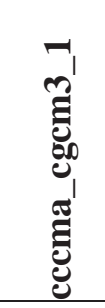 & 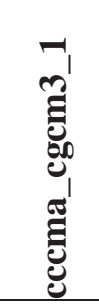 & 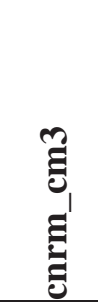 & 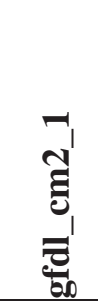 & 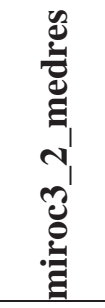 & 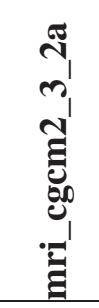 & 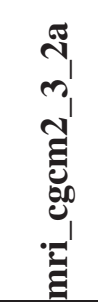 & 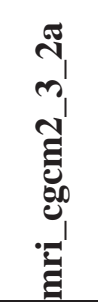 \\
\hline \multicolumn{2}{|c|}{$\begin{array}{l}\text { Emissions } \\
\text { Scenario: }\end{array}$} & a1b & b1 & b1 & a1b & a1b & a1b & a2 & b1 & b1 \\
\hline \multicolumn{2}{|c|}{ Run: } & 1 & 1 & 2 & 1 & 1 & 2 & 2 & 3 & 4 \\
\hline \multirow{12}{*}{ 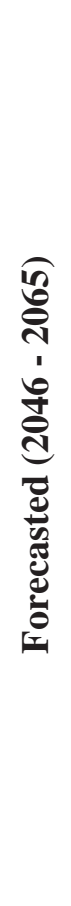 } & $\mathbf{J}$ & -0.58 & -1.79 & -2.55 & -0.40 & -0.98 & -0.28 & -1.57 & -3.26 & -1.53 \\
\hline & F & 2.16 & 0.57 & 0.22 & -0.76 & 0.77 & 2.17 & 1.02 & -0.53 & -1.04 \\
\hline & $\mathbf{M}$ & 7.52 & 6.57 & 6.39 & 5.30 & 4.80 & 9.16 & 5.89 & 5.16 & 4.29 \\
\hline & $\mathbf{A}$ & 12.95 & 11.61 & 12.16 & 11.43 & 12.10 & 13.28 & 12.05 & 10.66 & 10.90 \\
\hline & $\mathbf{M}$ & 18.06 & 17.39 & 17.67 & 17.50 & 18.23 & 18.99 & 17.92 & 16.78 & 16.68 \\
\hline & $\mathbf{J}$ & 23.20 & 21.92 & 22.22 & 23.04 & 23.27 & 23.14 & 22.03 & 21.83 & 21.97 \\
\hline & $\mathbf{J}$ & 25.32 & 24.12 & 24.17 & 24.88 & 26.80 & 26.06 & 24.11 & 23.82 & 24.04 \\
\hline & A & 23.85 & 23.67 & 23.43 & 24.18 & 26.57 & 25.45 & 23.68 & 23.31 & 22.13 \\
\hline & $\mathbf{S}$ & 19.78 & 18.64 & 19.89 & 21.30 & 21.45 & 21.61 & 19.93 & 18.87 & 19.32 \\
\hline & O & 14.16 & 12.66 & 13.82 & 13.52 & 13.43 & 14.87 & 13.95 & 12.65 & 13.20 \\
\hline & $\mathbf{N}$ & 7.67 & 7.22 & 7.26 & 7.39 & 6.66 & 8.97 & 7.58 & 6.29 & 7.55 \\
\hline & D & 1.89 & 1.16 & 0.29 & 1.47 & 2.17 & 3.26 & 1.21 & 0.39 & 1.68 \\
\hline
\end{tabular}


Table A.13 Monthly averages of hindcasted gridded precipitation ( $\mathrm{mm} /$ day) for the Pond Creek watershed (USGS Gage Station 03302000) calculated over the periods of 1961-1999 and 1980-1999.

\begin{tabular}{|c|c|c|c|c|c|c|c|c|c|c|}
\hline \multicolumn{2}{|c|}{ GCM: } & 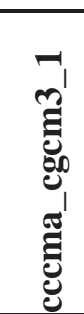 & 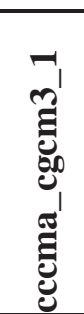 & 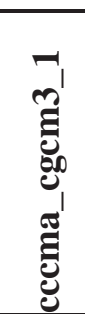 & 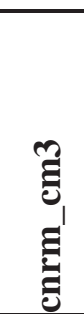 & 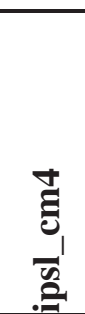 & 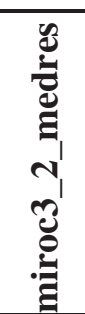 & 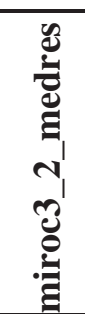 & 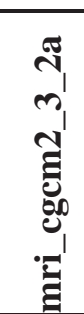 & 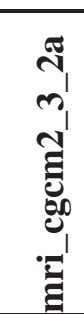 \\
\hline \multicolumn{2}{|c|}{$\begin{array}{l}\text { Emissions } \\
\text { Scenario: }\end{array}$} & $\mathbf{a} 2$ & b1 & b1 & $\mathbf{a} 1 \mathbf{b}$ & $\mathbf{a} 1 \mathbf{b}$ & a1b & b1 & $\mathbf{a} 2$ & b1 \\
\hline \multicolumn{2}{|c|}{ Run: } & 3 & 2 & 3 & 1 & 1 & 1 & 2 & 1 & 4 \\
\hline \multirow{12}{*}{ 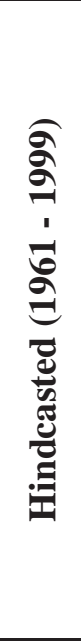 } & $\mathbf{J}$ & 2.17 & 2.24 & 2.17 & 2.28 & 2.15 & 2.16 & 2.19 & 1.93 & 1.93 \\
\hline & $\mathbf{F}$ & 2.28 & 2.11 & 2.28 & 2.20 & 2.33 & 2.42 & 2.42 & 2.27 & 2.56 \\
\hline & $\mathbf{M}$ & 2.81 & 2.84 & 2.81 & 2.75 & 2.69 & 2.80 & 2.71 & 2.72 & 2.78 \\
\hline & $\mathbf{A}$ & 2.72 & 2.84 & 2.72 & 2.87 & 2.82 & 2.81 & 2.82 & 2.92 & 2.95 \\
\hline & $\mathbf{M}$ & 2.90 & 2.68 & 2.90 & 2.76 & 2.79 & 2.78 & 2.72 & 2.76 & 2.76 \\
\hline & $\mathbf{J}$ & 2.33 & 2.54 & 2.33 & 2.23 & 2.21 & 2.20 & 2.17 & 2.51 & 2.38 \\
\hline & $\mathbf{J}$ & 2.02 & 2.05 & 2.02 & 2.10 & 2.24 & 2.19 & 2.26 & 2.03 & 2.32 \\
\hline & A & 1.73 & 1.74 & 1.73 & 1.40 & 1.67 & 1.57 & 1.60 & 1.83 & 1.80 \\
\hline & $\mathbf{S}$ & 1.71 & 1.64 & 1.71 & 1.60 & 1.71 & 1.73 & 1.59 & 1.84 & 1.95 \\
\hline & O & 1.84 & 1.85 & 1.84 & 1.88 & 1.80 & 1.92 & 1.95 & 1.94 & 1.67 \\
\hline & $\mathbf{N}$ & 2.58 & 2.58 & 2.58 & 2.43 & 2.61 & 2.58 & 2.69 & 2.55 & 2.70 \\
\hline & D & 2.50 & 2.57 & 2.50 & 2.39 & 2.57 & 2.57 & 2.60 & 2.54 & 2.60 \\
\hline \multirow{12}{*}{ 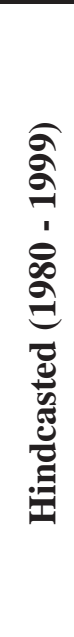 } & $\mathbf{J}$ & 1.99 & 2.23 & 1.99 & 2.35 & 2.45 & 2.10 & 2.24 & 1.75 & 2.17 \\
\hline & $\mathbf{F}$ & 2.48 & 1.92 & 2.48 & 2.15 & 2.31 & 2.25 & 2.74 & 2.33 & 2.93 \\
\hline & $\mathbf{M}$ & 3.02 & 2.88 & 3.02 & 2.66 & 2.77 & 2.81 & 2.93 & 2.60 & 2.92 \\
\hline & $\mathbf{A}$ & 2.77 & 2.83 & 2.77 & 2.95 & 3.16 & 2.77 & 2.73 & 3.06 & 3.04 \\
\hline & $\mathbf{M}$ & 2.93 & 2.48 & 2.93 & 2.75 & 2.78 & 3.24 & 2.77 & 3.01 & 2.65 \\
\hline & $\mathbf{J}$ & 2.14 & 2.39 & 2.14 & 2.19 & 2.30 & 2.38 & 2.08 & 2.52 & 2.37 \\
\hline & $\mathbf{J}$ & 2.27 & 2.18 & 2.27 & 2.11 & 2.34 & 2.22 & 2.19 & 1.93 & 2.01 \\
\hline & $\mathbf{A}$ & 1.88 & 1.86 & 1.88 & 1.40 & 1.65 & 1.55 & 1.47 & 1.99 & 1.61 \\
\hline & $\mathbf{S}$ & 1.54 & 1.92 & 1.54 & 1.74 & 1.83 & 1.63 & 1.62 & 1.68 & 1.72 \\
\hline & $\mathbf{O}$ & 1.84 & 1.82 & 1.84 & 1.79 & 2.01 & 2.10 & 2.30 & 1.88 & 1.69 \\
\hline & $\mathbf{N}$ & 2.86 & 2.85 & 2.86 & 2.45 & 2.21 & 2.47 & 2.55 & 2.90 & 2.73 \\
\hline & D & 2.82 & 2.65 & 2.82 & 2.36 & 2.67 & 2.60 & 3.05 & 2.45 & 2.69 \\
\hline
\end{tabular}


Table A.14 Monthly averages of hindcasted gridded temperature $\left({ }^{\circ} \mathrm{C}\right)$ for the Pond Creek watershed (USGS Gage Station 03302000) calculated over the periods of 1961-1999 and 1980-1999.

\begin{tabular}{|c|c|c|c|c|c|c|c|c|c|c|}
\hline \multicolumn{2}{|c|}{ GCM: } & 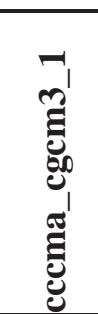 & 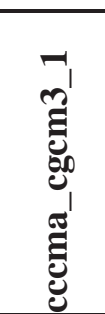 & 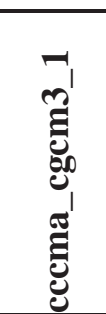 & 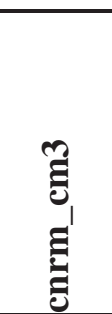 & 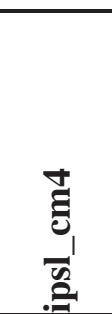 & 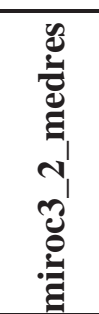 & 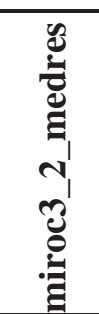 & 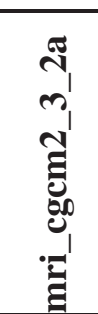 & 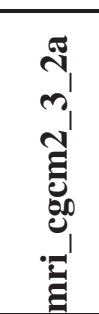 \\
\hline \multicolumn{2}{|c|}{$\begin{array}{l}\text { Emissions } \\
\text { Scenario: }\end{array}$} & a2 & b1 & b1 & a1b & a1b & a1b & b1 & a2 & b1 \\
\hline \multicolumn{2}{|c|}{ Run: } & 3 & 2 & 3 & 1 & 1 & 1 & 2 & 1 & 4 \\
\hline \multirow{12}{*}{ 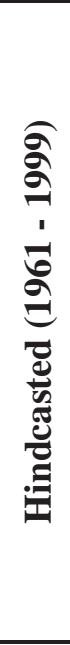 } & $\mathbf{J}$ & 0.41 & 0.34 & 0.41 & 0.40 & 0.32 & 0.31 & 0.18 & 0.29 & 0.29 \\
\hline & $\mathbf{F}$ & 2.71 & 2.48 & 2.71 & 2.58 & 2.57 & 2.66 & 2.67 & 2.67 & 2.75 \\
\hline & $\mathbf{M}$ & 7.89 & 7.95 & 7.89 & 8.00 & 7.91 & 8.03 & 8.07 & 7.99 & 8.03 \\
\hline & $\mathbf{A}$ & 13.70 & 13.55 & 13.70 & 13.57 & 13.52 & 13.75 & 13.68 & 13.63 & 13.69 \\
\hline & $\mathbf{M}$ & 18.74 & 18.71 & 18.74 & 18.79 & 18.66 & 18.76 & 18.73 & 18.82 & 18.82 \\
\hline & $\mathbf{J}$ & 23.19 & 23.25 & 23.19 & 23.27 & 23.20 & 23.26 & 23.24 & 23.19 & 23.24 \\
\hline & $\mathbf{J}$ & 25.37 & 25.35 & 25.37 & 25.36 & 25.35 & 25.37 & 25.33 & 25.37 & 25.36 \\
\hline & A & 24.56 & 24.53 & 24.56 & 24.57 & 24.50 & 24.53 & 24.51 & 24.49 & 24.47 \\
\hline & $\mathbf{S}$ & 20.88 & 20.85 & 20.88 & 20.80 & 20.80 & 20.71 & 20.83 & 20.76 & 20.72 \\
\hline & O & 14.55 & 14.41 & 14.55 & 14.51 & 14.48 & 14.49 & 14.50 & 14.47 & 14.51 \\
\hline & $\mathbf{N}$ & 8.35 & 8.42 & 8.35 & 8.34 & 8.52 & 8.43 & 8.48 & 8.46 & 8.49 \\
\hline & D & 2.83 & 2.87 & 2.83 & 2.82 & 2.83 & 2.72 & 2.93 & 2.94 & 3.00 \\
\hline \multirow{12}{*}{ 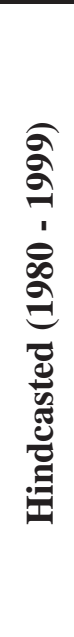 } & $\mathbf{J}$ & 0.41 & 0.92 & 0.41 & 0.95 & 0.21 & 0.41 & 0.06 & 0.10 & 0.77 \\
\hline & $\mathbf{F}$ & 2.78 & 2.35 & 2.78 & 2.79 & 2.85 & 2.76 & 2.60 & 3.22 & 3.21 \\
\hline & $\mathbf{M}$ & 7.78 & 8.03 & 7.78 & 8.76 & 8.90 & 8.99 & 7.77 & 7.70 & 8.43 \\
\hline & A & 14.00 & 14.11 & 14.00 & 14.23 & 14.45 & 13.94 & 14.29 & 13.39 & 14.18 \\
\hline & $\mathbf{M}$ & 19.03 & 18.90 & 19.03 & 19.06 & 18.76 & 18.68 & 18.86 & 18.84 & 19.02 \\
\hline & $\mathbf{J}$ & 23.53 & 23.88 & 23.53 & 23.50 & 23.30 & 23.29 & 23.28 & 23.58 & 23.57 \\
\hline & $\mathbf{J}$ & 25.61 & 25.65 & 25.61 & 25.79 & 25.60 & 25.50 & 25.40 & 25.53 & 25.80 \\
\hline & A & 24.87 & 24.90 & 24.87 & 24.89 & 25.01 & 24.65 & 24.83 & 24.92 & 24.76 \\
\hline & $\mathbf{S}$ & 21.13 & 21.55 & 21.13 & 21.06 & 20.84 & 20.90 & 21.06 & 21.39 & 20.90 \\
\hline & $\mathbf{O}$ & 15.34 & 14.42 & 15.34 & 14.61 & 14.50 & 14.88 & 14.94 & 15.22 & 14.71 \\
\hline & $\mathbf{N}$ & 8.30 & 8.91 & 8.30 & 8.40 & 8.67 & 8.81 & 8.47 & 9.22 & 8.48 \\
\hline & D & 2.78 & 3.16 & 2.78 & 3.86 & 3.39 & 2.88 & 2.84 & 2.86 & 2.48 \\
\hline
\end{tabular}


Table A.15 Monthly averages of forecasted gridded precipitation ( $\mathrm{mm} /$ day) for the Pond Creek watershed (USGS Gage Station 03302000) calculated over the period of 2046-2065

\begin{tabular}{|c|c|c|c|c|c|c|c|c|c|c|}
\hline \multicolumn{2}{|c|}{ GCM: } & 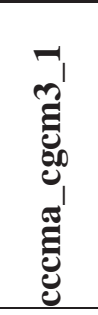 & 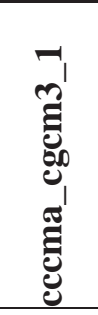 & 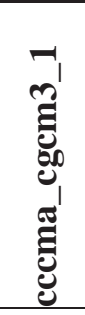 & 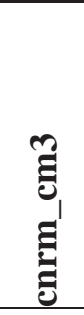 & 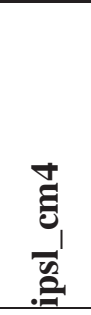 & 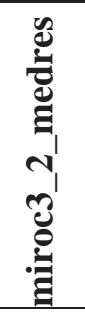 & 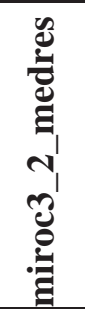 & 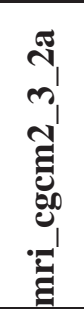 & 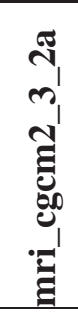 \\
\hline \multicolumn{2}{|c|}{$\begin{array}{c}\text { Emissions } \\
\text { Scenario: }\end{array}$} & a2 & b1 & b1 & a1b & a1b & a1b & b1 & $\mathbf{a} 2$ & b1 \\
\hline \multicolumn{2}{|c|}{ Run: } & 3 & 2 & 3 & 1 & 1 & 1 & 2 & 1 & 4 \\
\hline \multirow{12}{*}{ 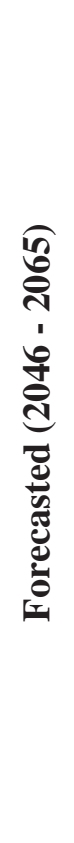 } & $\mathbf{J}$ & 2.23 & 2.03 & 2.62 & 2.26 & 2.07 & 1.67 & 2.34 & 2.37 & 2.26 \\
\hline & $\mathbf{F}$ & 2.02 & 2.34 & 2.77 & 2.69 & 2.35 & 2.76 & 2.63 & 2.72 & 2.44 \\
\hline & $\mathbf{M}$ & 3.32 & 3.18 & 3.10 & 3.30 & 2.99 & 3.05 & 2.84 & 2.90 & 2.54 \\
\hline & A & 2.70 & 3.31 & 3.11 & 3.26 & 2.73 & 2.94 & 2.74 & 3.32 & 3.00 \\
\hline & $\mathbf{M}$ & 2.92 & 2.16 & 3.04 & 3.24 & 2.56 & 2.22 & 3.00 & 2.65 & 2.73 \\
\hline & $\mathbf{J}$ & 2.85 & 2.04 & 2.68 & 2.43 & 2.11 & 1.66 & 2.40 & 2.54 & 2.67 \\
\hline & $\mathbf{J}$ & 1.79 & 1.91 & 1.68 & 1.62 & 2.89 & 1.38 & 1.99 & 2.09 & 2.27 \\
\hline & A & 1.78 & 1.63 & 1.56 & 1.45 & 1.98 & 1.11 & 1.49 & 2.16 & 2.03 \\
\hline & $\mathbf{S}$ & 1.63 & 1.68 & 1.86 & 1.69 & 1.29 & 1.11 & 1.64 & 2.70 & 2.22 \\
\hline & O & 2.34 & 1.85 & 2.31 & 1.90 & 2.03 & 1.72 & 1.91 & 2.33 & 1.91 \\
\hline & $\mathbf{N}$ & 3.44 & 3.39 & 2.66 & 2.37 & 3.04 & 2.35 & 2.10 & 2.87 & 2.02 \\
\hline & D & 3.16 & 2.68 & 3.05 & 2.49 & 3.00 & 2.79 & 2.86 & 2.79 & 2.41 \\
\hline
\end{tabular}


Table A.16 Monthly averages of forecasted gridded precipitation ( $\mathrm{mm} /$ day) for the Pond Creek watershed (USGS Gage Station 03302000) calculated over the period of 2046-2065.

\begin{tabular}{|c|c|c|c|c|c|c|c|c|c|c|}
\hline \multicolumn{2}{|c|}{ GCM: } & 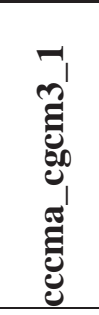 & 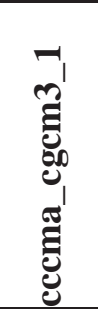 & 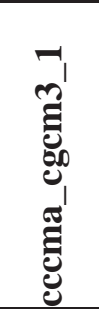 & 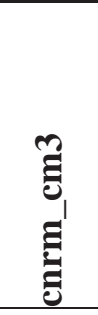 & 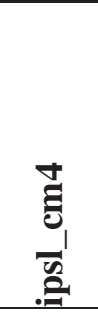 & 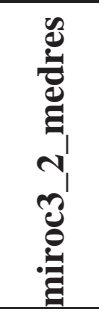 & 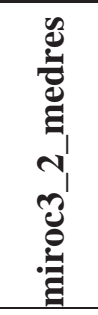 & 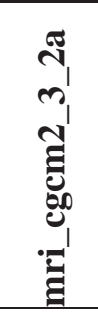 & 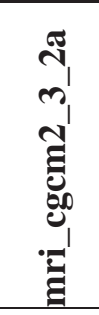 \\
\hline \multicolumn{2}{|c|}{$\begin{array}{l}\text { Emissions } \\
\text { Scenario: }\end{array}$} & a2 & b1 & b1 & a1b & a1b & a1b & b1 & a2 & b1 \\
\hline \multicolumn{2}{|c|}{ Run: } & 3 & 2 & 3 & 1 & 1 & 1 & 2 & 1 & 4 \\
\hline \multirow{12}{*}{ 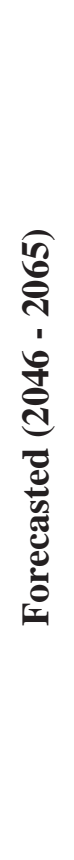 } & $\mathbf{J}$ & 2.02 & 1.07 & 1.71 & 3.31 & 4.52 & 3.10 & 3.38 & 2.41 & 2.28 \\
\hline & $\mathbf{F}$ & 5.99 & 4.36 & 4.55 & 3.76 & 8.24 & 6.45 & 5.97 & 4.43 & 3.53 \\
\hline & $\mathbf{M}$ & 11.29 & 10.45 & 9.42 & 10.22 & 12.36 & 11.53 & 11.94 & 9.75 & 8.44 \\
\hline & $\mathbf{A}$ & 16.27 & 16.12 & 15.73 & 15.82 & 17.62 & 17.27 & 15.71 & 15.47 & 15.05 \\
\hline & $\mathbf{M}$ & 21.31 & 21.13 & 21.08 & 21.01 & 22.30 & 21.97 & 20.75 & 20.47 & 20.17 \\
\hline & $\mathbf{J}$ & 26.12 & 25.56 & 25.70 & 26.18 & 26.29 & 26.63 & 24.94 & 25.25 & 25.06 \\
\hline & $\mathbf{J}$ & 28.27 & 27.58 & 27.42 & 27.98 & 28.11 & 29.62 & 28.10 & 27.11 & 27.22 \\
\hline & $\mathbf{A}$ & 27.25 & 26.90 & 27.65 & 27.32 & 28.03 & 29.19 & 27.66 & 26.40 & 25.53 \\
\hline & $\mathbf{S}$ & 23.60 & 23.21 & 23.32 & 24.65 & 24.51 & 25.77 & 23.83 & 22.97 & 22.91 \\
\hline & $\mathbf{O}$ & 18.11 & 17.30 & 16.72 & 17.03 & 18.46 & 17.81 & 17.69 & 16.95 & 16.73 \\
\hline & $\mathbf{N}$ & 10.72 & 10.29 & 9.67 & 10.81 & 11.79 & 12.34 & 11.14 & 10.13 & 10.77 \\
\hline & D & 5.09 & 3.41 & 3.69 & 4.81 & 7.65 & 5.76 & 5.65 & 4.68 & 5.07 \\
\hline
\end{tabular}




\section{Appendix B. Spatial Data: DEMs and Soil Layers}

This appendix contains maps of digital elevation models (DEMs) and soil layers input into the SWAT models for each case study watershed. A table is also included which provides identification information for relevant soil types included with each map, relating the Map Unit Keys in the legend to the soil series names. 

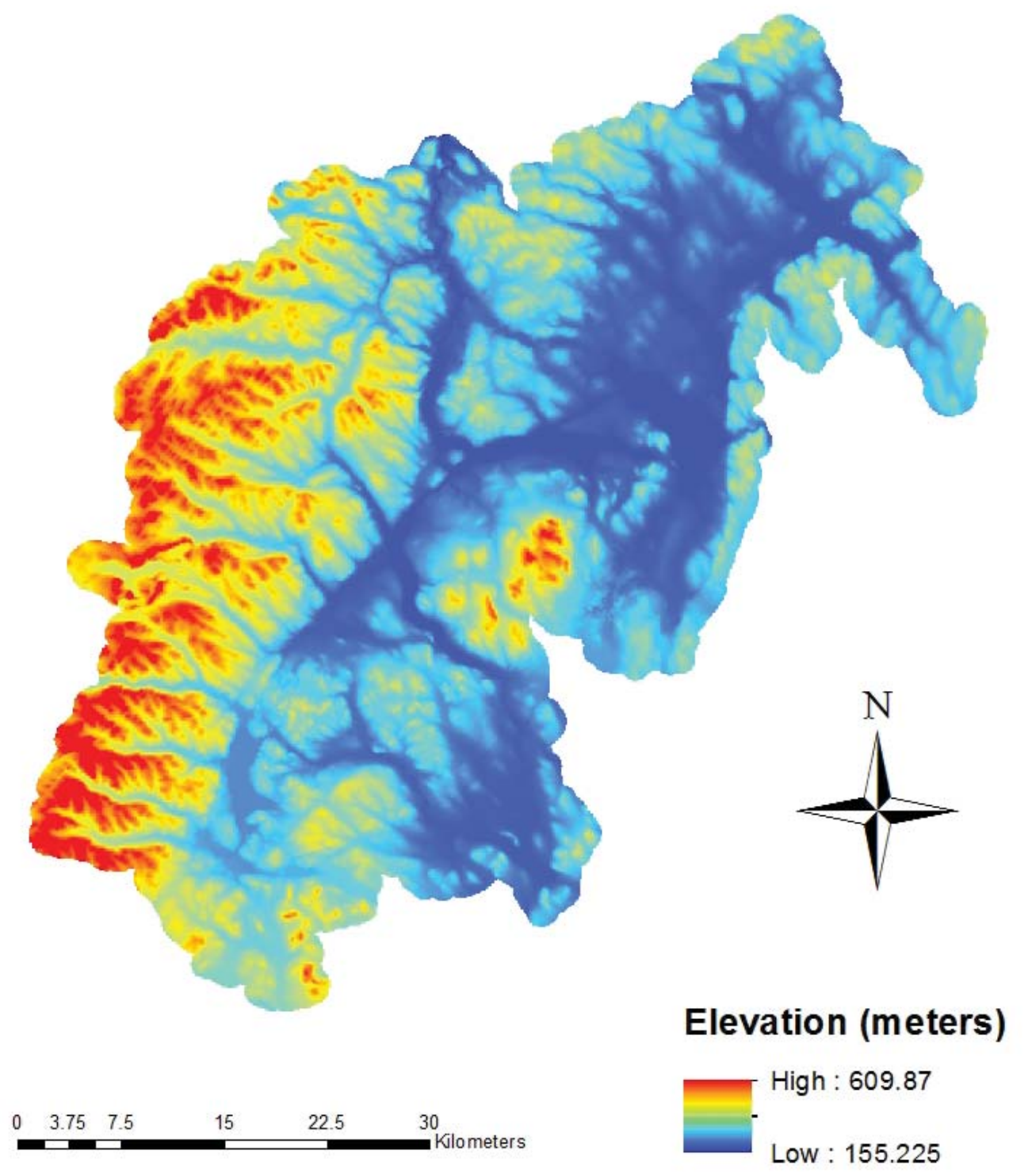

Figure B.1 DEM of Fish River watershed (USGS Gage Station 01013500). 


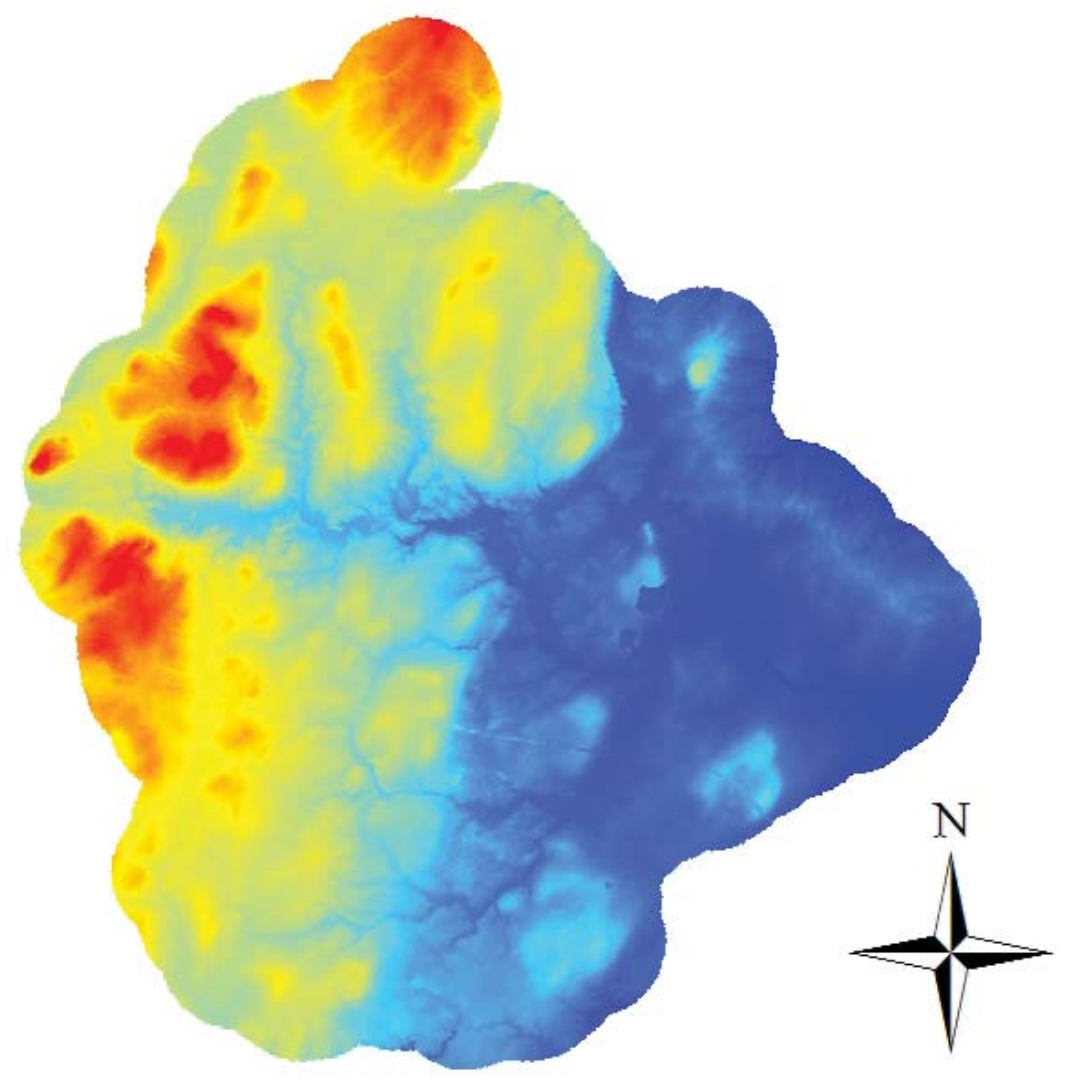

Elevation (meters)

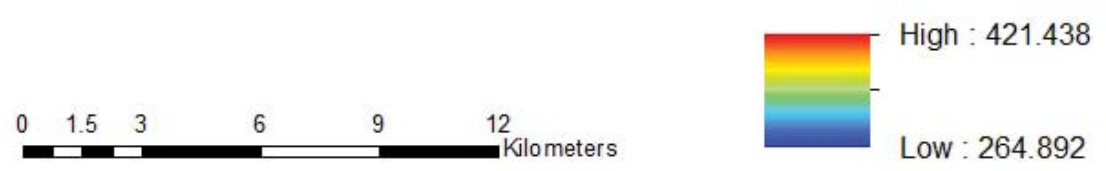

Figure B.2 DEM of Eagle Creek watershed (USGS Gage Station 03093000). 


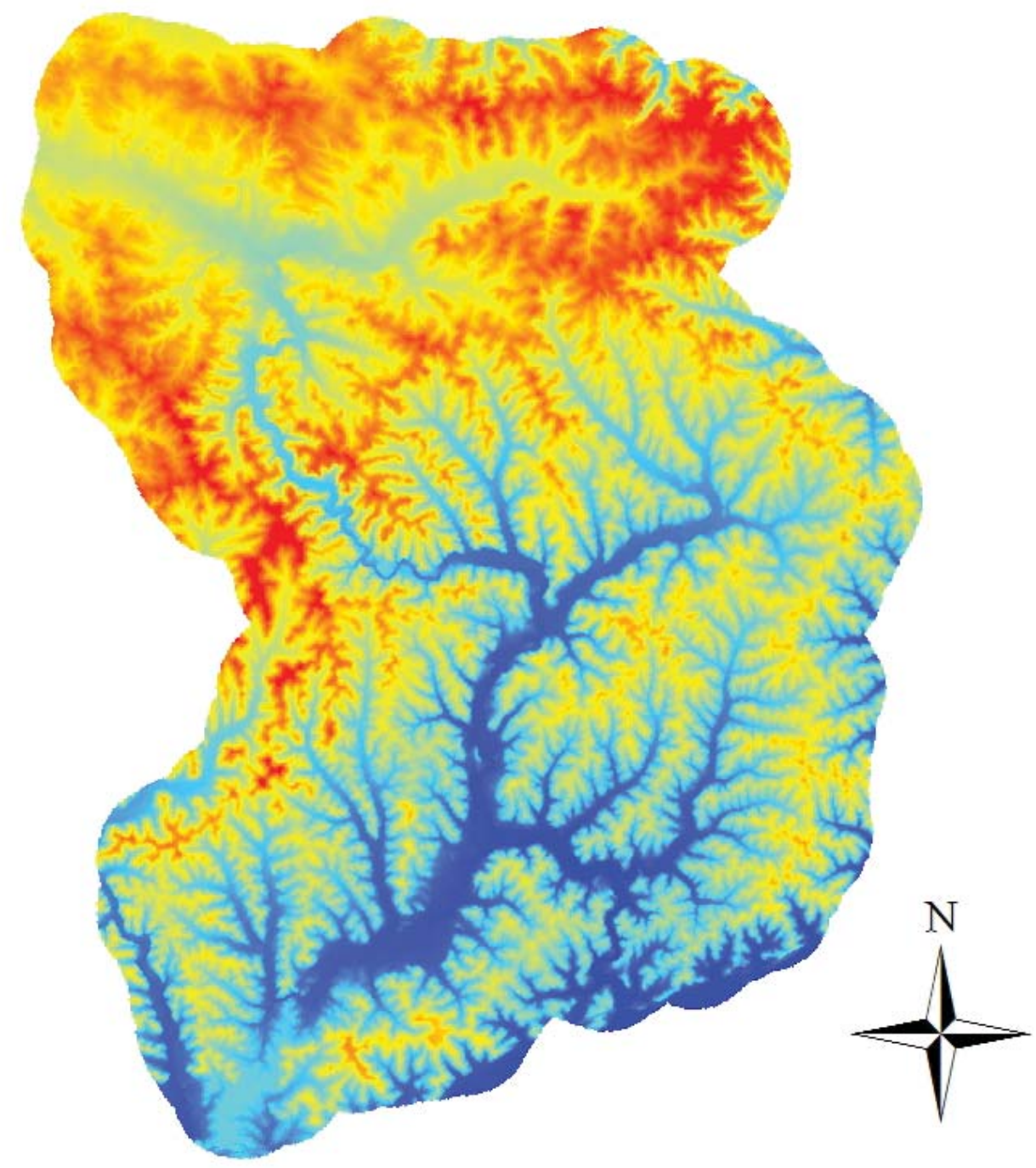

\section{Elevation (meters)}

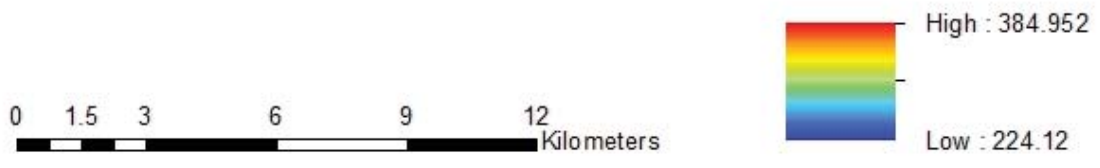

Figure B.3 DEM of Wakatomika Creek watershed (USGS Gage Station 03144000). 


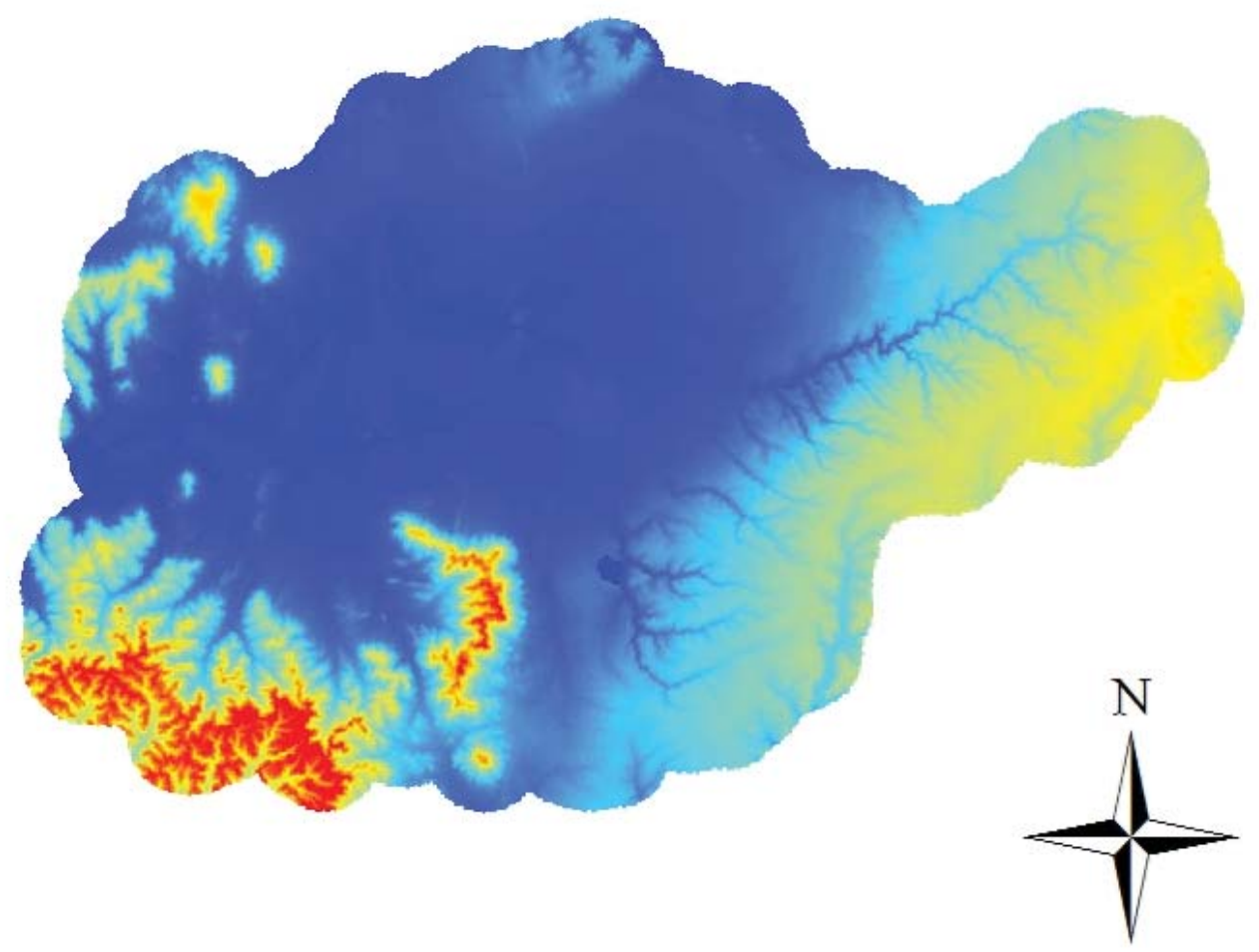

\section{Elevation (meters)}

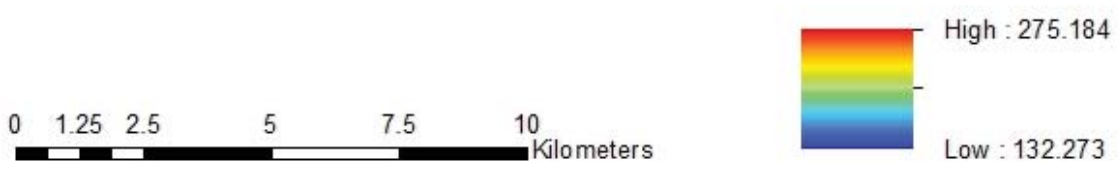

Figure B.4 DEM of Pond Creek watershed (USGS Gage Station 03302000). 

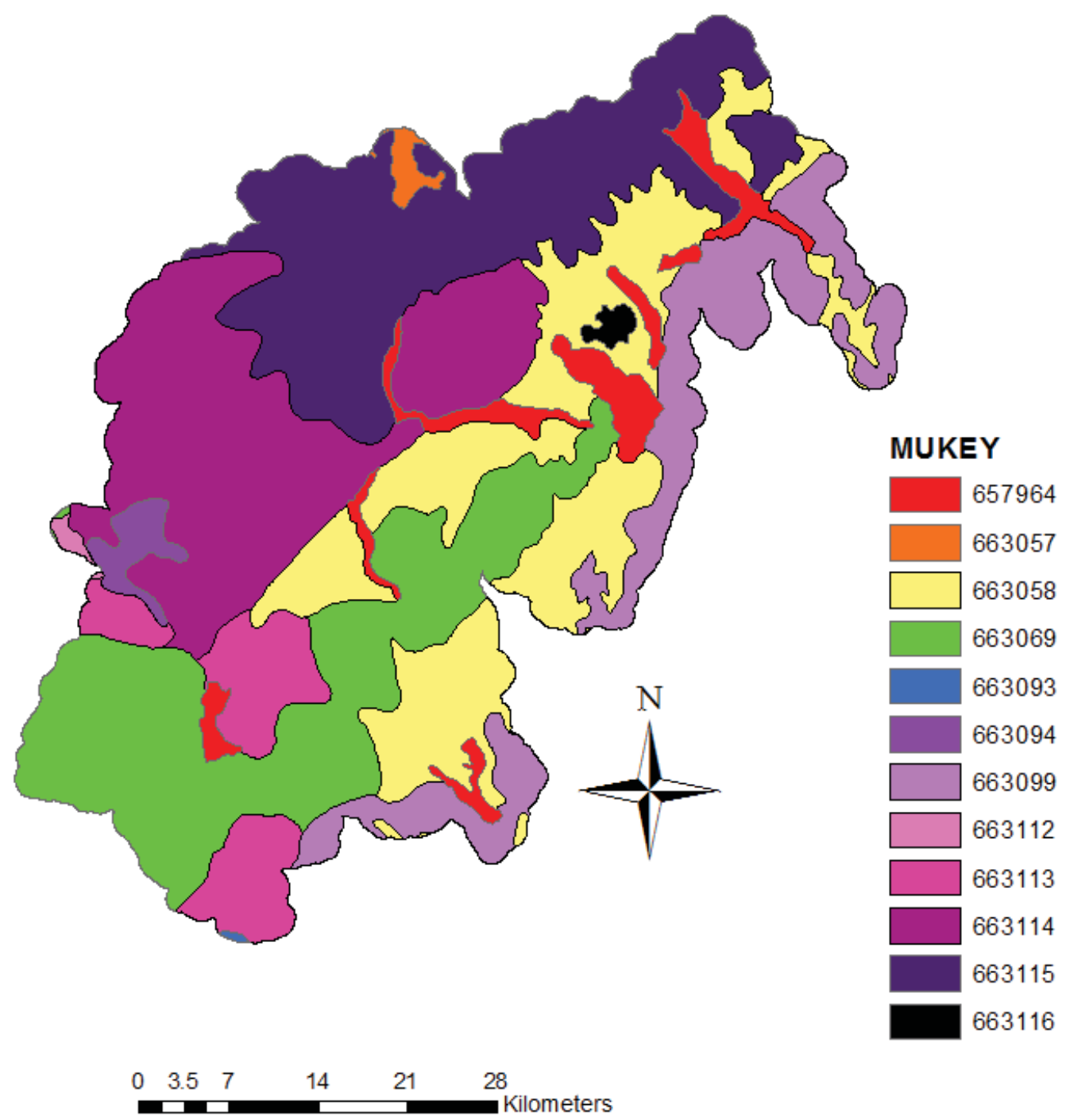

Figure B.5 SSURGO soils layer of Fish River watershed (USGS Gage Station 01013500). 


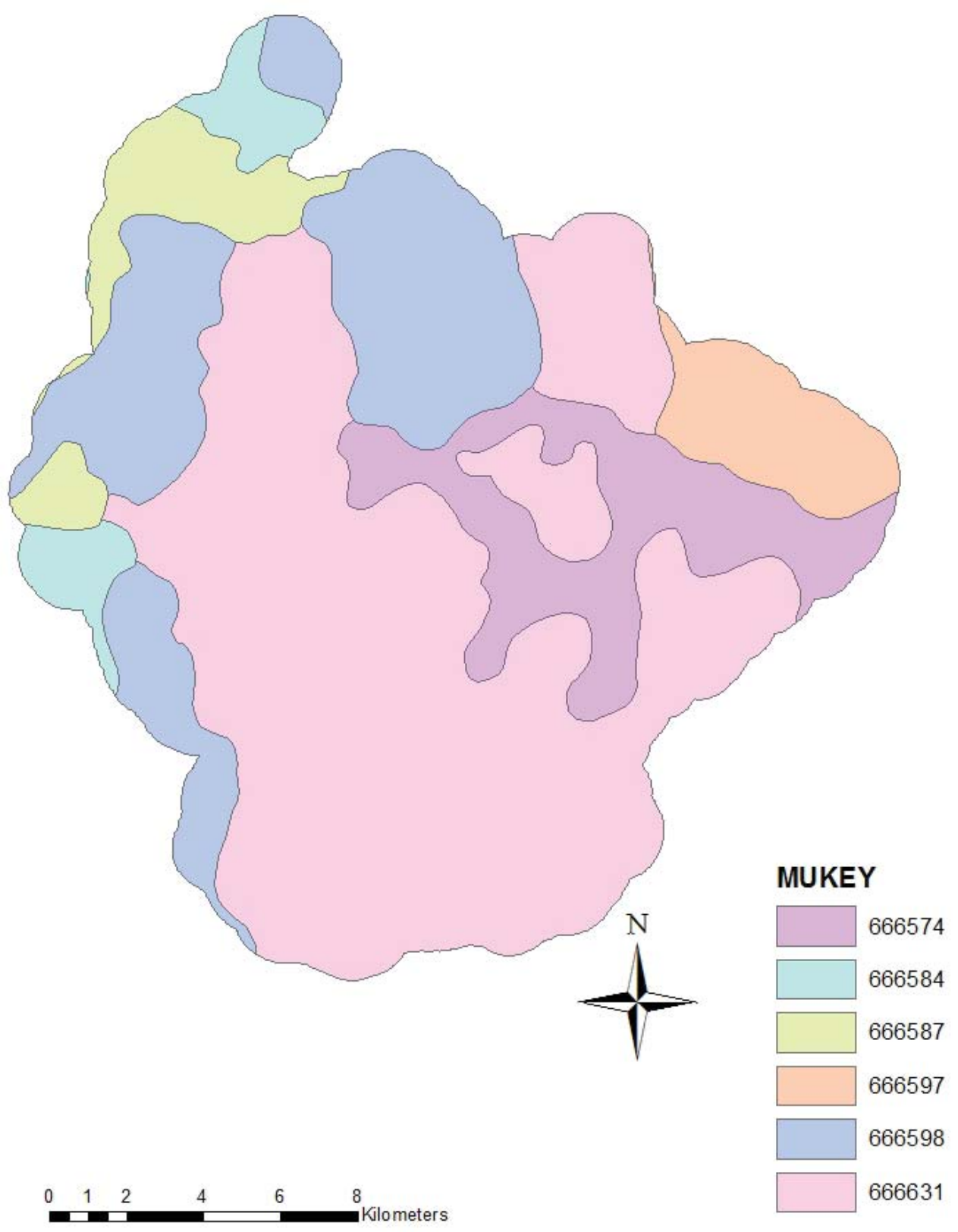

Figure B.6 SSURGO soils layer of Eagle Creek watershed (USGS Gage Station 03093000). 


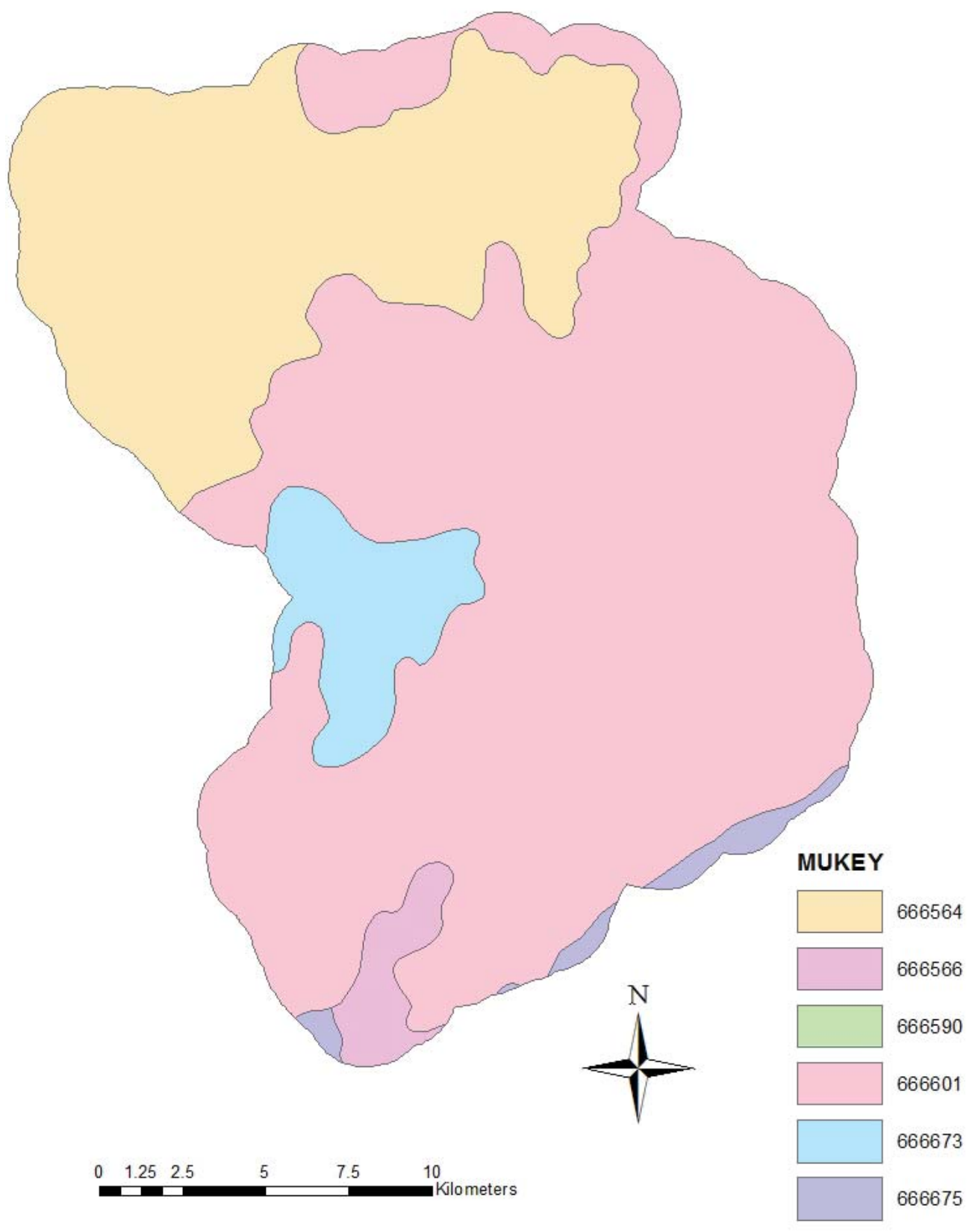

Figure B.7 SSURGO soils layer of Wakatomika Creek watershed (USGS Gage Station 03144000). 


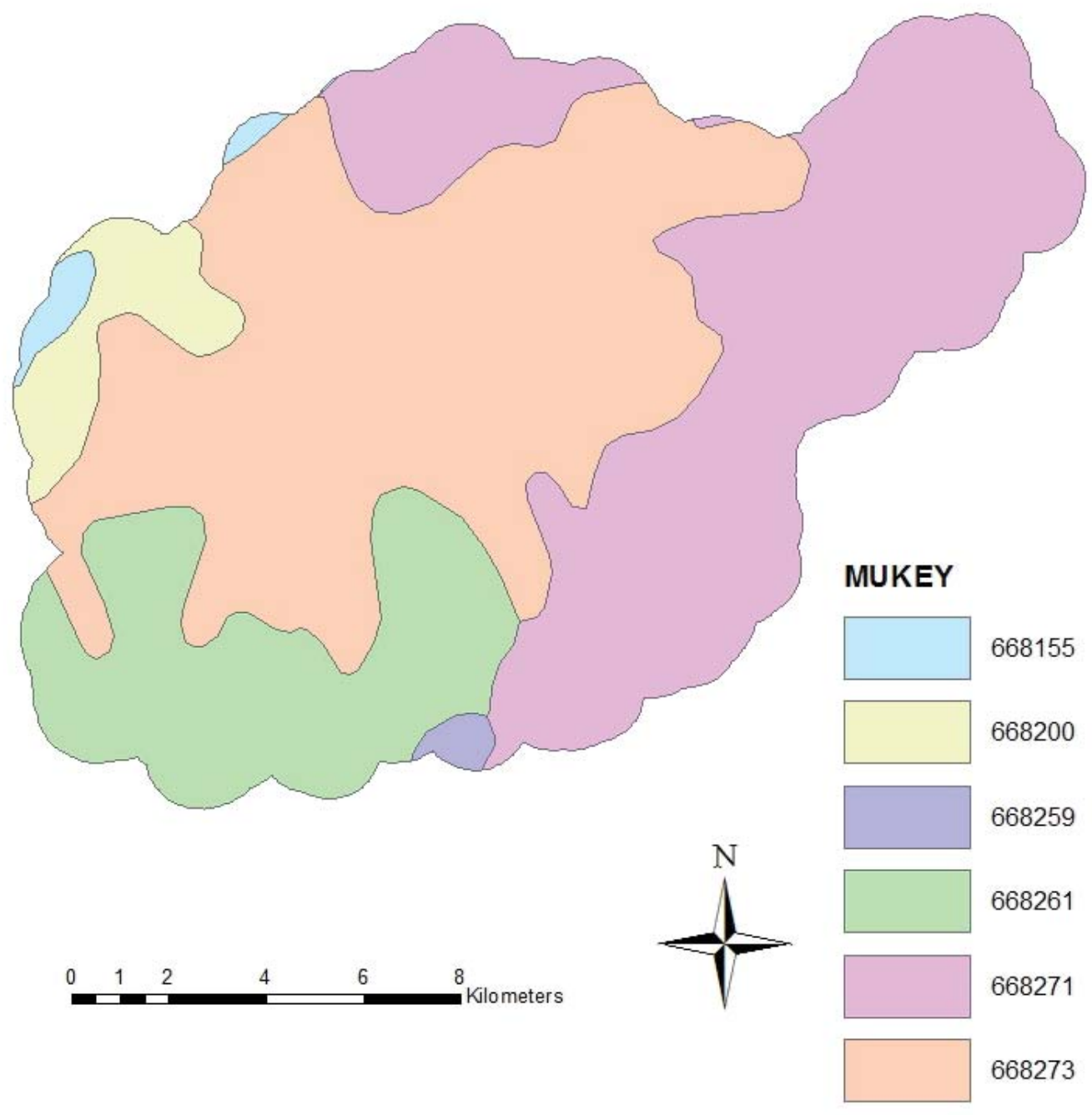

Figure B.8 SSURGO soils layer of Pond Creek watershed (USGS Gage Station 03302000). 
Table B.1 Component soil series for all watersheds and SSURGO map units.

\begin{tabular}{|c|c|c|c|}
\hline Watershed & $\begin{array}{c}\text { Map Unit } \\
\text { Key }\end{array}$ & $\begin{array}{c}\text { Map } \\
\text { Unit } \\
\text { Symbol }\end{array}$ & Component Series Names \\
\hline \multirow{13}{*}{$\begin{array}{c}\text { Fish River } \\
\text { Watershed } \\
\text { (USGS Gage } \\
\text { 01013500) }\end{array}$} & 657964 & s8369 & Water \\
\hline & 663057 & s3194 & Stetson-Masardis-Allagash \\
\hline & 663058 & s3195 & Daigle-Burnham-Aurelie \\
\hline & 663069 & s3206 & Monson-Elliotsville-Daigle-Aurelie \\
\hline & & & Wonsqueak-Vassalboro-Stetson-Medomak- \\
\hline & 663093 & s3230 & Masardis \\
\hline & 663094 & s3231 & Ricker-Monson-Elliotsville \\
\hline & 663099 & s3236 & Perham-Monarda-Daigle-Chesuncook \\
\hline & 663112 & s3249 & Telos-Monarda-Burnham \\
\hline & 663113 & s3250 & Telos-Monson-Monarda-Elliotsville \\
\hline & 663114 & s3251 & Thorndike-Telos-Chesuncook \\
\hline & 663115 & s3252 & Winnecook-Thorndike-Plaisted-Howland \\
\hline & 663116 & s3253 & Vassalboro-Sebago-Cathro \\
\hline \multirow{7}{*}{$\begin{array}{c}\text { Eagle Creek } \\
\text { Watershed } \\
\text { (USGS Gage } \\
\text { 03093000) }\end{array}$} & 666574 & s6073 & Haskins-Fitchville \\
\hline & & & Wooster-Ravenna-Frenchtown-Chili- \\
\hline & 666584 & s6083 & Canfield \\
\hline & 666587 & s6086 & Chili \\
\hline & 666597 & s6096 & Remsen-Geeburg \\
\hline & 666598 & s6097 & Wadsworth-Rittman \\
\hline & 666631 & s6130 & Mahoning-Ellsworth \\
\hline \multirow{6}{*}{$\begin{array}{c}\text { Wakatomika } \\
\text { Creek } \\
\text { Watershed } \\
\text { (USGS Gage } \\
\text { 03144000) }\end{array}$} & 666564 & s6063 & Titusville-Mechanicsburg-Homewood \\
\hline & 666566 & s6065 & Rainsboro-Negley-Cana \\
\hline & 666590 & s6089 & Melvin-Fitchville-Euclid \\
\hline & 666601 & s6100 & Coshocton-Brownsville \\
\hline & 666673 & s6172 & Rigley-Coshocton \\
\hline & 666675 & s6174 & Sebring-Mentor-Lorain-Glenford-Fitchville \\
\hline \multirow{6}{*}{$\begin{array}{c}\text { Pond Creek } \\
\text { Watershed } \\
\text { (USGS Gage } \\
03302000 \text { ) }\end{array}$} & 668155 & s2630 & Otwell-Newark-Lawrence-Huntington-Elk \\
\hline & 668200 & s2675 & Zanesville-Rockcastle-Memphis-Loring \\
\hline & 668259 & s2734 & Trappist-Lenberg-Colyer-Caneyville \\
\hline & 668261 & s2736 & Garmon-Crider \\
\hline & 668271 & s2746 & Nicholson-Crider-Caneyville \\
\hline & 668273 & s2748 & Nicholson-Faywood-Fairmount-Beasley \\
\hline
\end{tabular}
145 


\section{Appendix C. Calibrated Parameters}

This appendix includes tables for each watershed which provide descriptions, ranges, and values of calibrated parameters used in modeling using ArcSWAT. The absolute min and max listed in the table refer to the realistic physical bounds on the parameters, while the calibrated min and max refer to the uncertainty bounds SWAT-CUP produced. The official calibrated value used was generally the mean of the uncertainty bounds. 


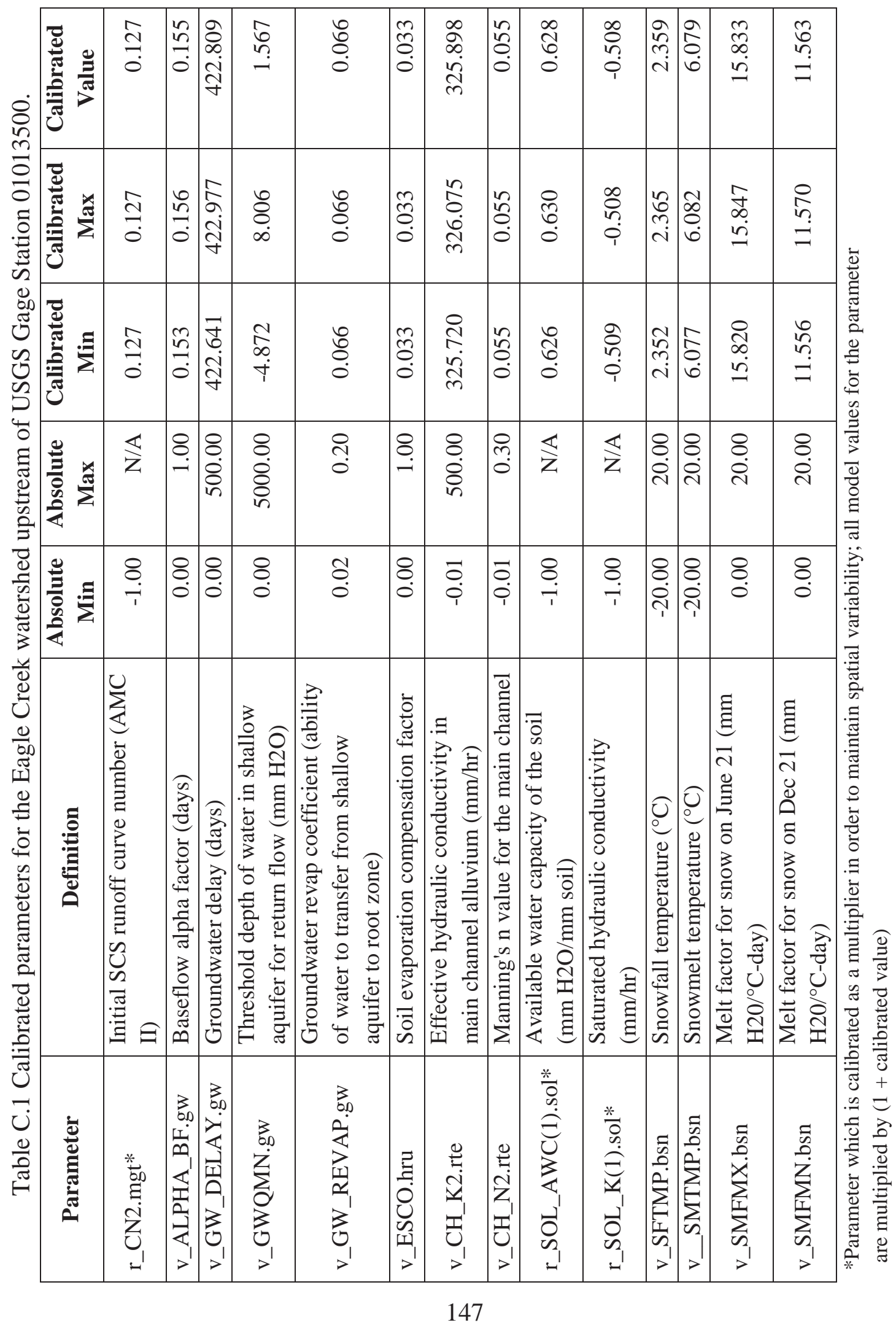




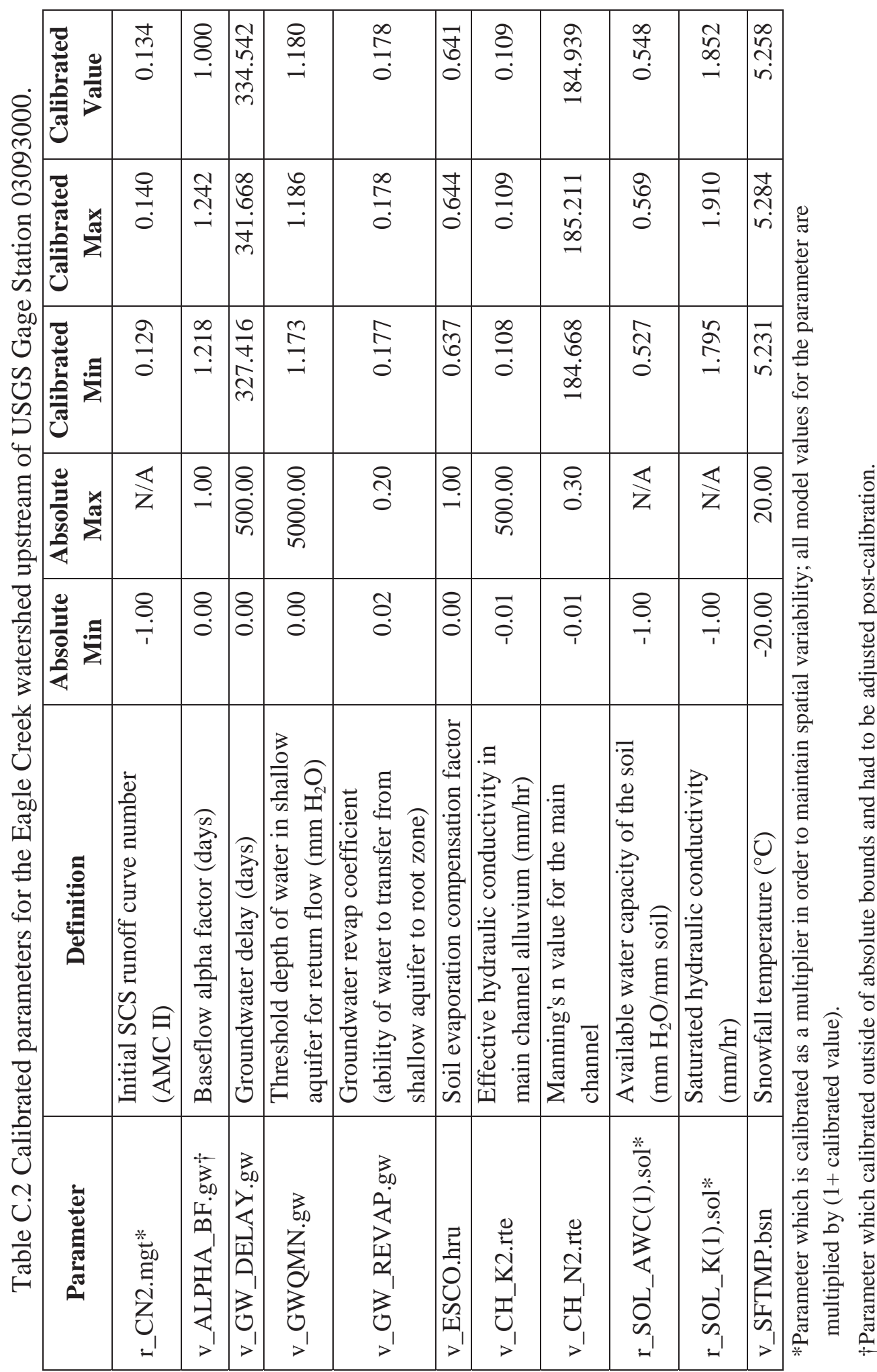




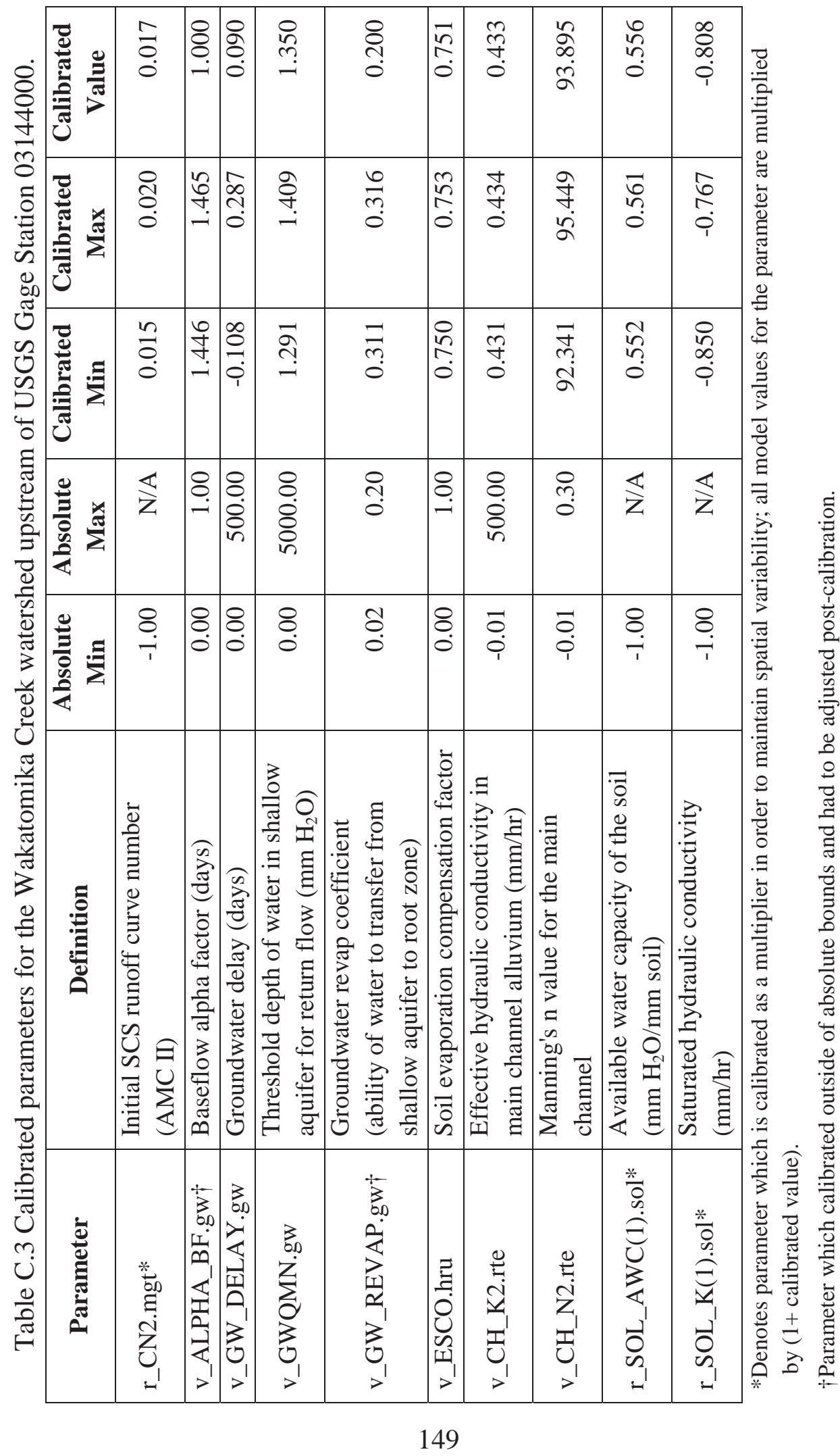




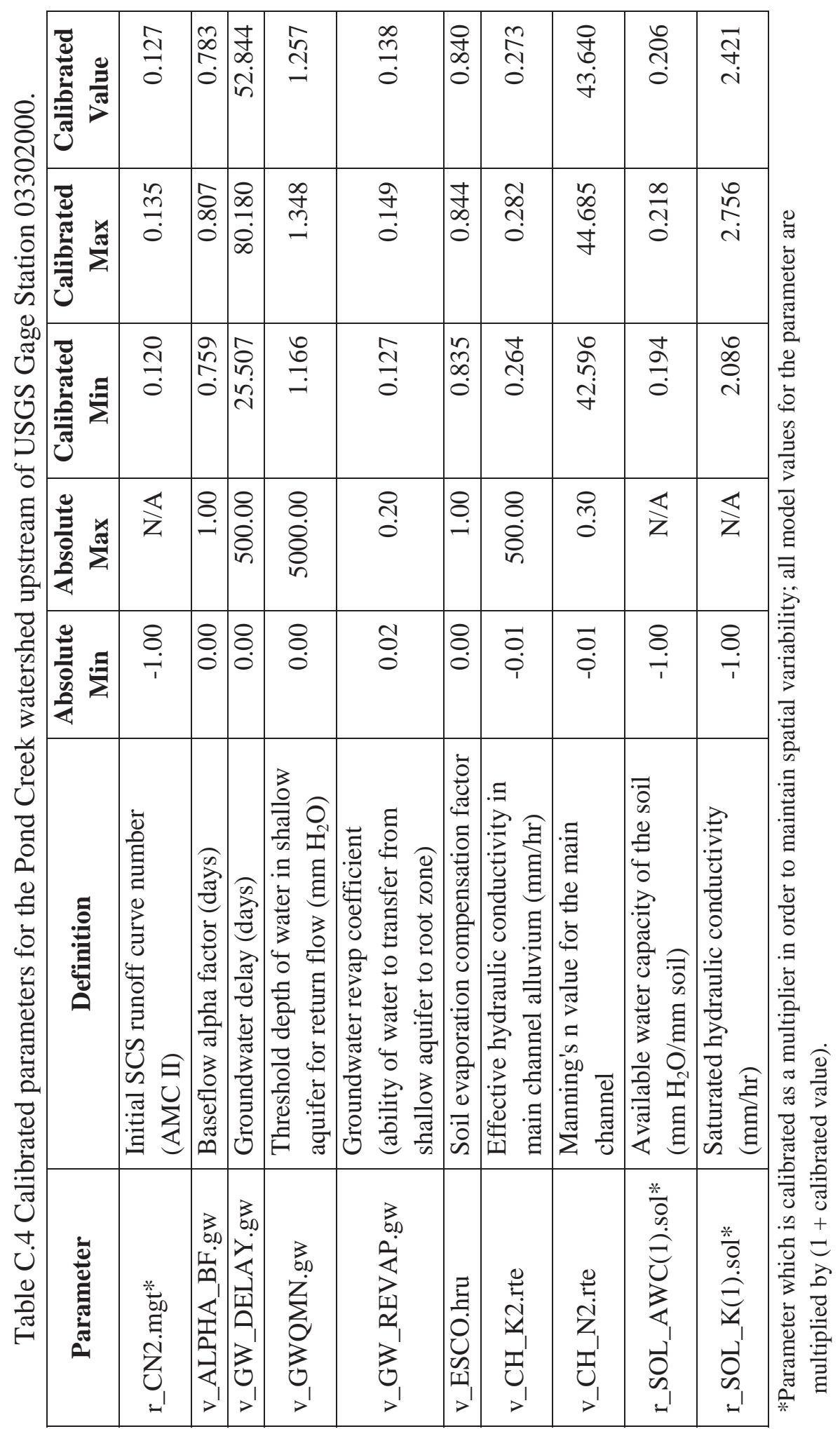

